\title{
Guidelines
}

\section{Responsible, Safe, and Effective Use of Biologics in the Management of Low Back Pain: American Society of Interventional Pain Physicians (ASIPP) Guidelines}

\begin{abstract}
Annu Navani, MD1, Laxmaiah Manchikanti, MD², Sheri L. Albers, DO³,
Richard E. Latchaw, MD, Jaya Sanapati, MD ${ }^{5}$, Alan D. Kaye, MD, $\mathrm{PhD}^{6}$,

Sairam Atluri, $\mathrm{MD}^{7}$, Sheldon Jordan, $\mathrm{MD}^{8}$, Ashim Gupta, PhD, MBA ${ }^{9}$, David Cedeno, $\mathrm{PhD}^{10}$,

Alejandro Vallejo, BS ${ }^{11}$, Bert Fellows, MA ${ }^{12}$, Nebojsa Nick Knezevic, MD, PhD ${ }^{13}$,

Miguel Pappolla, MD ${ }^{14}$, Sudhir Diwan, MD ${ }^{15}$, Andrea M. Trescot, MD ${ }^{16}$, Amol Soin, MD ${ }^{17}$,

Adam M. Kaye, PharmD, FASCP, FCPhA ${ }^{18}$, Steve M. Aydin, DO ${ }^{19}$, Aaron K. Calodney, MD ${ }^{20}$,

Kenneth D. Candido, MD21, Sanjay Bakshi, MD ${ }^{22}$, Ramsin M. Benyamin, MD'23,

Ricardo Vallejo, MD, PhD ${ }^{24}$, Art Watanabe, MD ${ }^{25}$, Douglas Beall, MD ${ }^{26}$, Todd P. Stitik, MD27,

Patrick M. Foye, MD ${ }^{28}$, Erik M. Helander, $\mathrm{MBBS}^{29}$, and Joshua A. Hirsch, MD ${ }^{30}$
\end{abstract}

From: American Society of Interventional Pain Physicians

Author Affiliations and Disclosures on pp. S61-S62

Address Correspondence: Laxmaiah Manchikanti, MD

2831 Lone Oak Road

Paducah, Kentucky 42003

E-mail:drlm@thepainmd.com

Manuscript received: 09-15-2018 Revised manuscript received: 10-15-2018

Accepted for publication: 11-19-2018

Free full manuscript: www.painphysicianjournal.com
Background: Regenerative medicine is a medical subspecialty that seeks to recruit and enhance the body's own inherent healing armamentarium in the treatment of patient pathology. This therapy's intention is to assist in the repair, and to potentially replace or restore damaged tissue through the use of autologous or allogenic biologics. This field is rising like a Phoenix from the ashes of underperforming conventional therapy midst the hopes and high expectations of patients and medical personnel alike. But, because this is a relatively new area of medicine that has yet to substantiate its outcomes, care must be taken in its public presentation and promises as well as in its use.

Objective: To provide guidance for the responsible, safe, and effective use of biologic therapy in the lumbar spine. To present a template on which to build standardized therapies using biologics. To ground potential administrators of biologics in the knowledge of the current outcome statistics and to stimulate those interested in providing biologic therapy to participate in high quality research that will ultimately promote and further advance this area of medicine.

Methods: The methodology used has included the development of objectives and key questions. A panel of experts from various medical specialties and subspecialties as well as differing regions collaborated in the formation of these guidelines and submitted (if any) their appropriate disclosures of conflicts of interest. Trustworthy standards were employed in the creation of these guidelines. The literature pertaining to regenerative medicine, its effectiveness, and adverse consequences was thoroughly reviewed using a best evidence synthesis of the available literature. The grading for recommendation was provided as described by the Agency for Healthcare Research and Quality (AHRQ).

\section{Summary of Evidence:}

Lumbar Disc Injections:

Based on the available evidence regarding the use of platelet-rich plasma (PRP), including one high-quality randomized controlled trial (RCT), multiple moderate-quality observational studies, a single-arm meta-analysis and evidence from a systematic review, the qualitative evidence has been assessed as Level III (on a scale of Level I through V) using a qualitative modified approach to the grading of evidence based on best-evidence synthesis.

Based on the available evidence regarding the use of medicinal signaling/ mesenchymal stem cell (MSCs) with a high-quality RCT, multiple moderate-quality observational studies, a single-arm meta-analysis, and 2 systematic reviews, the qualitative evidence has been assessed as Level III (on a scale of Level I through $\mathrm{V}$ ) using a qualitative modified approach to the grading of evidence based 
on best evidence synthesis.

Lumbar Epidural Injections

Based on one high-quality RCT, multiple relevant moderate-quality observational studies and a single-arm meta-analysis, the qualitative evidence has been assessed as Level IV (on a scale of Level I through V) using a qualitative modified approach to the grading of evidence based on best evidence synthesis.

\section{Lumbar Facet Joint Injections}

Based on one high-quality RCT and 2 moderate-quality observational studies, the qualitative evidence for facet joint injections with PRP has been assessed as Level IV (on a scale of Level I through V) using a qualitative modified approach to the grading of evidence based on best evidence synthesis.

\section{Sacroiliac Joint Injection}

Based on one high-quality RCT, one moderate-quality observational study, and one low-quality case report, the qualitative evidence has been assessed as Level IV (on a scale of Level I through V) using a qualitative modified approach to the grading of evidence based on best evidence synthesis.

Conclusion: Based on the evidence synthesis summarized above, there is Level III evidence for intradiscal injections of PRP and MSCs, whereas the evidence is considered Level IV for lumbar facet joint, lumbar epidural, and sacroiliac joint injections of PRP, (on a scale of Level I through $\mathrm{V}$ ) using a qualitative modified approach to the grading of evidence based on best evidence synthesis.

Regenerative therapy should be provided to patients following diagnostic evidence of a need for biologic therapy, following a thorough discussion of the patient's needs and expectations, after properly educating the patient on the use and administration of biologics and in full light of the patient's medical history. Regenerative therapy may be provided independently or in conjunction with other modalities of treatment including a structured exercise program, physical therapy, behavioral therapy, and along with the appropriate conventional medical therapy as necessary. Appropriate precautions should be taken into consideration and followed prior to performing biologic therapy. Multiple guidelines from the Food and Drug Administration (FDA), potential limitations in the use of biologic therapy and the appropriate requirements for compliance with the FDA have been detailed in these guidelines.

Key words: Regenerative medicine, platelet-rich plasma, medicinal signaling cells, mesenchymal stem cells, stromal vascular fraction, bone marrow concentrate, chronic low back pain, discogenic pain, facet joint pain, Food and Drug Administration, minimal manipulation, evidence synthesis

Disclaimer: These guidelines are based on the best available evidence and do not constitute inflexible treatment recommendations. Due to the changing body of evidence, this document is not intended to be a "standard of care." These guidelines are meant to provide a basis for the understanding behind the role of biologics in healing, to provide a source of appropriate indications for the use of biologics, to facilitate and help standardize biologic therapy, and to encourage the performance of high-quality studies in effort to document outcomes and advance this field.

\subsection{InTRODUCTION}

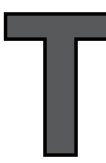

he field of Regenerative Medicine is expanding exponentially, creating new frontiers for the treatment of musculoskeletal and spinal pathology. Musculoskeletal and spinal complaints are 2 of the major reasons for seeking medical advice. Dieleman et al $(1,2)$ and Conway (3) in an analysis of United States (U.S.) spending on personal health care, public health, and increases of health care costs from 1996 to 2013 showed an estimated spending of $\$ 87.6$ billion in managing low back and neck pain, and $\$ 95.9$ billion for managing musculoskeletal pain, accounting for the third and fourth highest health care costs among disease categories. Numerous therapeutic techniques have been developed for the management of chronic spinal pain, including over-the-counter medications, complex surgical fusions, and a variety of image-guided interventional techniques (4-9). Despite these advances, treatment complications, poor outcomes, and persisting disabilities are contributing to the rise in health care costs and human suffering $(1-3,10,11)$.

Among the 30 leading diseases and injuries contributing to years lived with disability in 1990, 2010, and 2016 in the U.S., low back pain and major depression ranked numbers 1 and 2 respectively, with other musculoskeletal disorders ranking number 4 and neck pain ranking number 6 .

The management of spinal pain and other musculoskeletal disorders requires the appropriate diagnoses and the use of effective therapeutic modalities, under the auspices of evidence-based medicine, in a cost effective manner. Given the continued zeal for health care reform, including decreased health care costs (1-4, $8,9,12-16)$, government officials have produced legislation including the Affordable Care Act (ACA), along with a massive number of regulations, with mixed and often devastating results. Consequently, health care providers 
have turned to natural and holistic therapies. The success of such therapies in professional athletes has thrust regenerative medicine into the forefront (17).

Regenerative medicine is based on the process of replacing, engineering or regenerating human cells, tissues or organs to restore or establish normal function (17-30). Stimulating the body's inherent repair mechanism and supplementing this process with homologous or autologous biologics when the body cannot heal itself is the foundation of regenerative medicine. Regenerative medicine incorporates biomedical, biochemical, and biomechanical technologies to improve cellular migration, replication, and modelling. Biomedical approaches include the injection of mesenchymal stromal/ stem cells (medicinal signaling cells) or progenitor cells called cell therapy, the induction of regeneration by biologically active molecules administered alone or as a complex of infused cells referred to as immunomodulation therapy, and transplantation of in vitro grown organs and tissues that fall under the umbrella of tissue engineering (17,30-32).

Despite its appeal, there are just concerns regarding the ethical use of regenerative medicine. Both the medical literature and the general media have presented regenerative medicine as a "cure-all" for many disease processes, praying upon the hopes of desperate patients, without appropriate evidence reflecting both safety and reliable, consistent efficacy over the long term $(17,21,30,32-43)$. Guidelines are pathways to gain evidence needed to justify the use of regenerative medicine, thereby negating these controversies. Although there are a large number of guidelines used in the management of spinal pain, including those of interventional pain management and surgical intervention, there are no guidelines addressing the use of regenerative medicine for the musculoskeletal system, and specifically for the spine.

The American Society of Interventional Pain Physicians (ASIPP) has been at the forefront of guideline development for the use of both interventional techniques and opioids $(8,9)$. Consequently, these guidelines have been developed to foster the responsible, safe, and effective use of biologics in the musculoskeletal system. These guidelines include an overview of current literature applicable to the use of platelet-rich plasma (PRP) and medicinal signaling/ mesenchymal stem cell (MSC) injections as applied to the lumbar spine, including discs, facet joints, sacroiliac joints, as well as paraspinal muscles, ligaments, and tendons. These guidelines also incorporate various aspects of the current national and international regulatory and bioethical recommendations. Finally, these guidelines provide an overview of clinical policies and procedures necessary to offer this therapy in a safe and professional environment.

\subsection{Methods}

\subsection{Rationale}

The National Uniform Claims Committee (NUCC) defines interventional pain management as the discipline of medicine devoted to the diagnosis and treatment of pain related disorders principally with the application of interventional techniques in managing subacute, chronic, persistent, and intractable pain, independently or in conjunction with other modalities of treatment (44). In addition, the Medicare Payment Advisory Commission (MedPAC) defines interventional pain management techniques as minimally invasive procedures including percutaneous precision needle placement of drugs in targeted areas or ablation of targeted nerves; surgical techniques such as laser and endoscopic discectomy; and the placement of intrathecal infusion pumps and spinal cord stimulators for the diagnosis and management of chronic, persistent, or intractable pain (45).

Chronic spinal pain is a complex and multifactorial disease process, of which low back pain is the most common. The high prevalence of chronic spinal pain, the numerous treatment modalities applied in the management of the problem, and the growing social and economic costs continue to influence medical decision-making. Lumbar intervertebral discs, facet joints, sacroiliac joints, ligaments, fascia, muscles, and nerve root dura are all pain generators of low back and lower extremity pain (8). Interventional pain physicians are familiar with various image-guided interventional techniques for the management of low back and extremity pain, and regenerative medicine techniques are well-suited additions to their armamentarium following appropriate training under the enclosed guidelines.

\subsection{Objectives}

The objectives of these guidelines are to provide a rational and systematic approach to the application of regenerative medicine techniques based upon the available evidence concerning comparative effectiveness, safety, and avoidance of adverse effects in the treatment of low back and extremity pain 


\subsubsection{Key Questions}

These guidelines focus on the following key questions regarding low back and extremity pain:

1. What is the impact of chronic low back and extremity pain on health care resources?

2. What are the statistics regarding the trends in utilization of treatment modalities?

3. What is the pathophysiologic and structural basis of low back pain?

4. What are the available regenerative medicine therapies?

5. How do regenerative medicine therapies work in the treatment of low back and extremity pain?

6. Are regenerative medicine therapies effective in managing chronic low back pain?

7. What are current guidelines for biologics?

8. What are the adverse consequences/harms of regenerative therapies?

9. What are the best preventive and therapeutic strategies to improve outcomes when performing regenerative therapies?

10. What comprises responsible performance of regenerative injection therapy?

\subsection{Adherence to Trustworthy Standards}

In preparation of these guidelines for regenerative medicine therapies, the standards from the Institute of Medicine (IOM) and the National Guideline Clearinghouse Extent Adherence to Trustworthy Standards (NEATS) were followed (46-48). The NEATS instrument was developed and tested as a tool to be used by the trained staff at the Agency for Healthcare Research and Quality (AHRQ) National Guideline Clearinghouse to provide assessment focused on adherence.

\subsubsection{Disclosure of Guideline Funding Source}

Responsible, safe, and effective guidelines for regenerative medicine therapies in managing low back pain were commissioned, prepared, edited, and endorsed by ASIPP without external funding sought or obtained.

\subsubsection{Disclosure and Management of Financial Conflicts of Interests}

Potential conflicts of interest for all panel members within the last 5 years were evaluated prior to the finalizing of these guidelines. Conflicts of interests extended beyond financial relationships, including personal experience, practice patterns, academic interests, and promotions. Participants with previously established conflicts are considered those with opinions not being in line with previously developed ASIPP guidelines or the overall philosophical approach of ASIPP. The panel members with potential conflicts were recused from discussion or preparation of the guidelines in which they had conflicts of interest, and these members agreed not to discuss any aspect of a given guideline with the related industry before data publication.

\subsubsection{Composition of Guideline Development Group}

A panel of experts in regenerative medicine from various medical fields, convened by ASIPP, reviewed the evidence and formulated recommendations for regenerative medicine therapies as applied to low back pain. The panel was instructed to assess the evidence pertaining to important aspects of regenerative therapies. However, due to the emerging nature of regenerative medicine techniques in managing low back pain, the number of available participants for guideline preparation was limited compared to other guideline panels $(8,9)$. Even with this limitation, the panel provided a broad representation of academic and non-academic clinical practitioners with interest and expertise in regenerative injection therapies and in the management of patients with chronic low back pain.

\subsection{Evidence Review}

These guidelines were developed utilizing consensus among the panel members after they had reviewed all published literature concerning the use and safety of regenerative injection therapy in patients with chronic non-cancer low back and lower extremity pain. The recommendations have been developed using principles of best evidence synthesis developed by the Cochrane Review, incorporating multiple guidelines modified by ASIPP (49).

\subsubsection{Grading or Rating the Quality or Strength of Evidence}

The grading of evidence is based on randomized controlled trials (RCTs), observational studies, and other clinical reports. In addition, systematic reviews and meta-analyses were utilized. The grading of evidence based on ASIPP guidelines is shown in Table 1.

This grading system specifies levels of scientific evidence and offers an approach to grading the quality of evidence and secondarily the strength of recommendations. AHRQ has recommended a similar approach to the strength of a recommendation $(47,48)$. 
Table 1. Qualitative modified approach to grading of evidence.

\begin{tabular}{|l|l|l||}
\hline Level I & Strong & $\begin{array}{l}\text { Evidence obtained from multiple relevant high quality randomized controlled trials for } \\
\text { effectiveness }\end{array}$ \\
\hline Level II & Moderate & $\begin{array}{l}\text { Evidence obtained from at least one relevant high quality randomized controlled trial or } \\
\text { multiple relevant moderate or low quality randomized controlled trials }\end{array}$ \\
\hline Level III & Fair & $\begin{array}{l}\text { Evidence obtained from at least one relevant high quality nonrandomized trial or observational } \\
\text { study with multiple moderate or low quality observational studies }\end{array}$ \\
\hline Level IV & Limited & Evidence obtained from multiple moderate or low quality relevant observational studies \\
\hline Level V & Consensus based & $\begin{array}{l}\text { Opinion or consensus of large group of clinicians and/or scientists for effectiveness as well as to } \\
\text { assess preventive measures, adverse consequences, effectiveness of other measures. }\end{array}$ \\
\hline
\end{tabular}

Modified from: Manchikanti et al. A modified approach to grading of evidence. Pain Physician 2014; 17:E319-E325 (49).

Table 2. Guide for strength of recommendations.

\begin{tabular}{||l|l||}
\hline Rating for Strength of Recommendation \\
\hline Strong & $\begin{array}{l}\text { There is high confidence that the recommendation reflects best practice. This is based on: a) strong evidence for a true } \\
\text { net effect (e.g., benefits exceed harms); b) consistent results, with no or minor exceptions; c) minor or no concerns } \\
\text { about study quality; and/or d) the extent the panelists' agreement. Other compelling considerations (discussed in the } \\
\text { guideline's literature review and analyses) may also warrant a strong recommendation. }\end{array}$ \\
\hline Moderate & $\begin{array}{l}\text { There is moderate confidence that the recommendation reflects best practice. This is based on: a) good evidence for a } \\
\text { true net effect (e.g. benefits exceed harms); b) consistent results, with minor and/or few exceptions; c) minor and/or few } \\
\text { concerns about study quality; and/or d) the extent of panelists' agreement. Other compelling considerations (discussed } \\
\text { in the guideline's literature review and analyses) may also warrant a moderate recommendation. }\end{array}$ \\
\hline Weak & $\begin{array}{l}\text { There is some confidence that the recommendation offers the best current guidance for practice. This is based on: a) } \\
\text { limited evidence for a true net effect (e.g., benefits exceed harms); b) consistent results, but with important exceptions; } \\
\text { c) concerns about study quality; and/or d) the extent of panelists' agreement. Other considerations (discussed in the } \\
\text { guideline's literature review and analyses) may also warrant a weak recommendation. }\end{array}$ \\
\hline
\end{tabular}

Source: National Guideline Clearinghouse Extent Adherence to Trustworthy Standards (NEATS) instrument (47).

\subsubsection{Assessment and Recommendations of Benefits and Harms}

These guidelines clearly describe the potential benefits and harms for the interventions and explicitly link the information to specific recommendations.

\subsubsection{Evidence Summary of Recommendations}

Guideline-supporting documents summarize the relevant supporting evidence and link this information to the recommendations.

\subsubsection{Rating or Grading the Strength of Recommendations}

IOM standards demand that for each recommendation, a rating of the strength of the recommendation related to benefits and harms, available evidence, and the confidence in the underlying evidence should be provided. To meet appropriate standards, the rating schemes recommended by NEATS were utilized as shown in Table 2 (47).

\subsubsection{Specificity of Recommendations}

Guideline recommendations are specific and un- ambiguous, providing guidance on what regenerative therapies should be utilized on a given disease process, and under what, if any, restrictions.

\subsection{External Review}

Guidelines have been subjected to external peer review as per the policies of the publishing journal, Pain Physician.

\subsection{Updating Guidelines}

The regenerative injection therapy guidelines will be updated within 5 years or less, based on significant changes in the scientific evidence, public policy, or adverse events occurring before January 2024.

\subsection{Impact of Low Back Pain on Health Care}

Key Question 1. What is the impact of chronic low back and extremity pain on health care resources?

As illustrated in multiple worldwide reports, the impact of chronic pain is enormous (1-3,8-11,50-64). The annual U.S. expenditures alone (including direct medical costs and lost wages) may be higher than those 
for cancer, heart disease, and diabetes combined. Even with these high expenditures, the treatments are marginally effective. The IOM report of 2011 concludes that the epidemic of chronic pain demands public health approaches with public education to counter myths, stereotypes, and stigma that hinder better care (50).

Figure 1 shows back pain to be more common than neck pain or osteoarthritis of the knee relative to years lived with disability. Figures 2 and 3 show expenditures related to back and neck pain relative to other conditions. (10)

Chronic pain is defined by the International Association for the Study of Pain (IASP) as "pain that exists beyond an expected time frame for healing" (65).
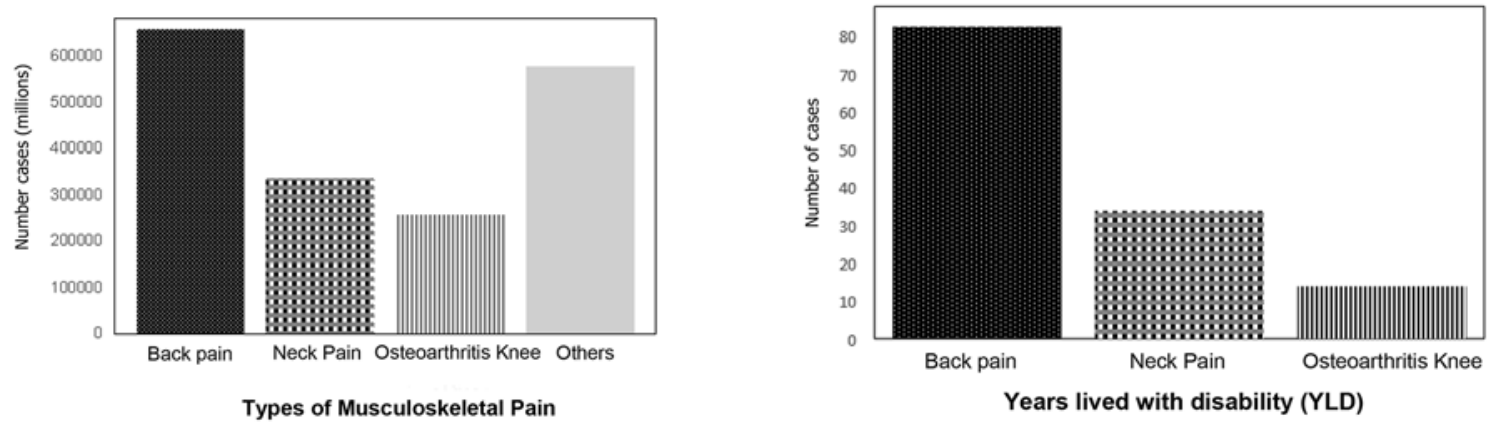

A: Number of persons affected by musculoskeletal pain (millions); B: Global number of years lived with disability (YLD; millions); Data are as of 2010, updated from the Source Global Burden of Disease 2010 Study

Fig. 1. Prevalence of musculoskeletal pain and years lived with disability (YLD).

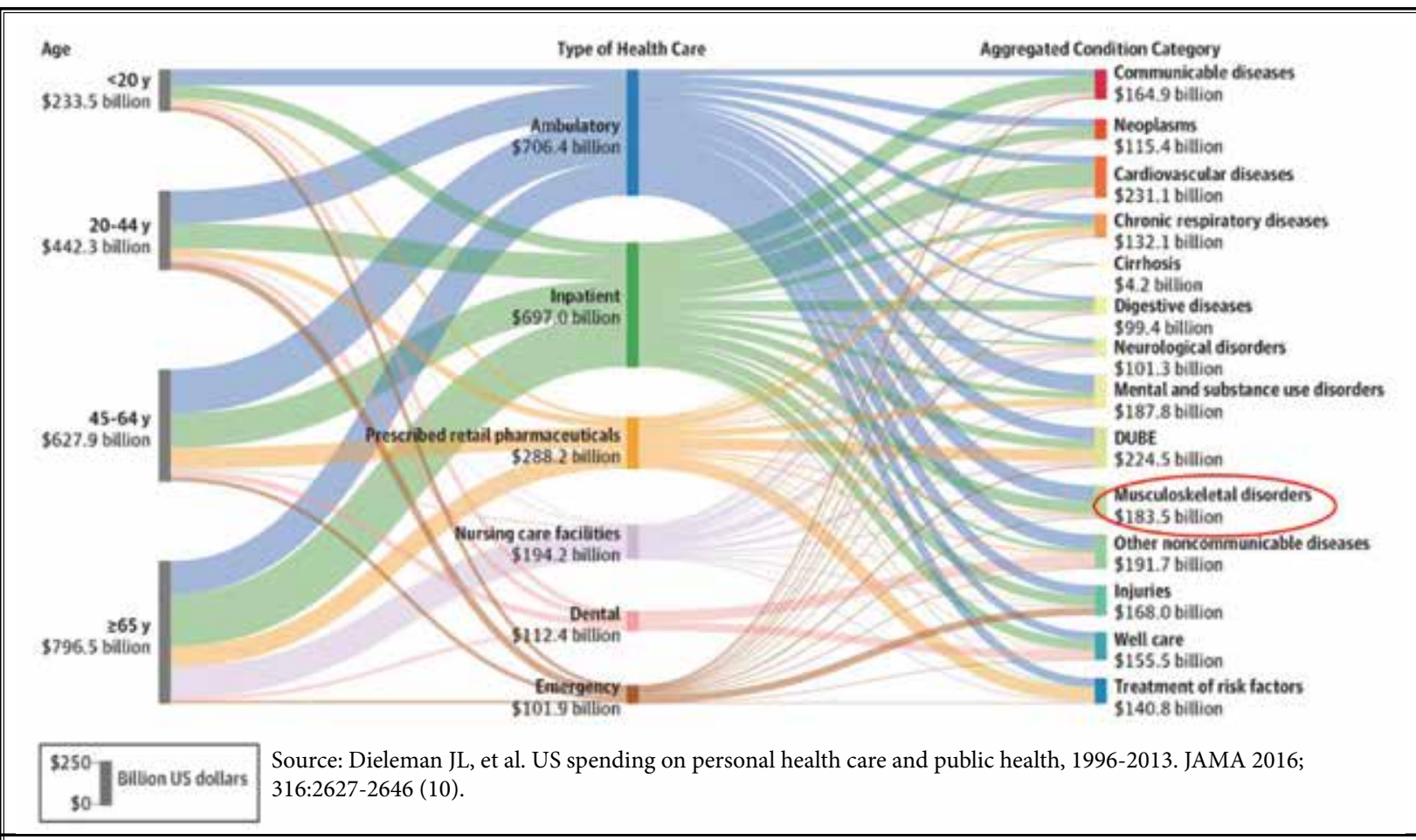

Fig. 2. U.S. Spending on health care. 


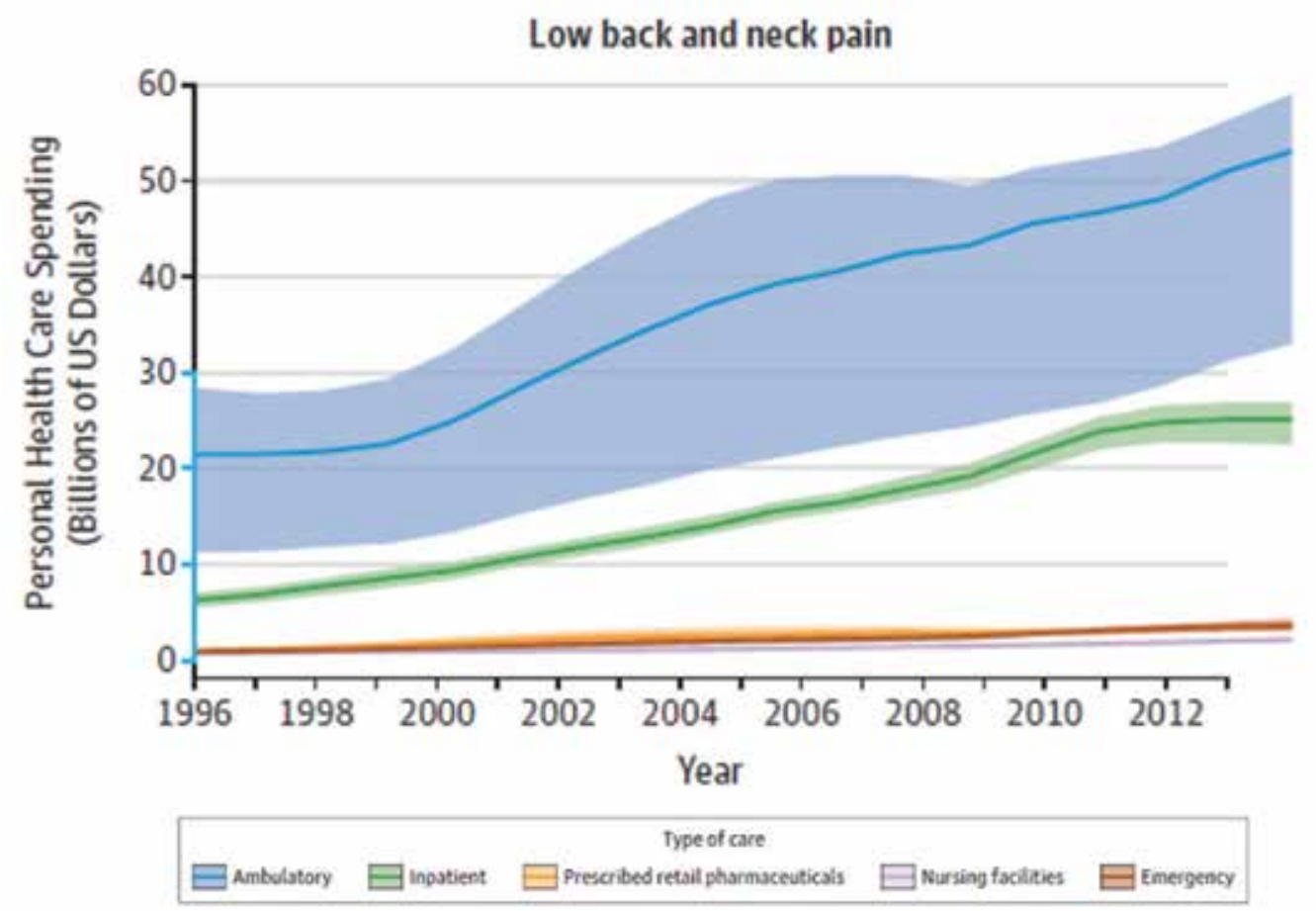

Source: Dieleman JL, et al. US spending on personal health care and public health, 1996-2013. JAMA 2016; 316:2627-2646 (1).

Fig. 3. U.S. Spending on low back and neck pain.

However, others have defined chronic pain in more descriptive and functional terms. ASIPP has defined chronic pain as "pain that persists 6 months after an injury and beyond the usual course of an acute disease or a reasonable time for a comparable injury to heal, that is associated with chronic pathologic processes that cause continuous or intermittent pain for months or years, that may continue in the presence or absence of demonstrable pathologies; may not be amenable to routine pain control methods; and healing may never occur" (8).

A recent study of the state of the U.S. health between 1990 and 2010 describing the burden of diseases, injuries, and risk factors (10) showed that, with increasing life expectancy, morbidity, and chronic disability now account for nearly half of the U.S. health burden, despite substantial progress and improvement in health. The estimates of regional spine pain vary, with the highest prevalence in the low back of $43 \%$, followed by the neck at $32 \%$, with the lowest in the thoracic spine (63). Among the 30 leading diseases and injuries contributing to years lived with disability in the
U.S. between 1990 and 2010, low back pain, other musculoskeletal disorders, and neck pain ranked numbers 1,3 , and 4 respectively, while major depression and anxiety disorders ranked numbers 2 and 5 respectively (10). More recent analysis of the state of U.S. health from 1990 to 2016 (11) showed similar results with low back pain, other musculoskeletal disorders, and neck pain ranked numbers 1, 4, and 6, respectively. Major depressive disorders, migraine, and anxiety disorders ranked numbers 2, 5, and 7, respectively. In addition, this analysis also showed opioid disorders changed from number 7 between 1990 and 2010 to number 8 between 1990 and 2016. These results were echoed in multiple other manuscripts $(56,57)$. Consequently, the top 5 conditions are consistently primary sources of or significantly related to chronic pain. Studies on the global burden of disability have determined the point prevalence of low back pain as $9.4 \%$, with $17 \%$ of these individuals suffering from severe chronic low back pain while $25 \%$ of them suffer from severe chronic low back pain accompanied with leg pain (57). Chronic persistent spinal pain is reported to last at least one year in $25 \%$ 
to $60 \%$ of patients, and even longer than one year in many patients. These findings contradict the usual belief that pain is always of limited duration $(8,55,66)$. In fact, a recent study of long-term outcomes in a large, prospective observational cohort of older adults with back pain showed that over $80 \%$ of the individuals reported back pain or back pain-related disability at 2 years following their initial visits (66). This study also showed that these patients experienced $30 \%$ to $50 \%$ improvement in back pain and disability, respectively, 2 years after their initial visits. However, only $16 \%$ had complete resolution of their back pain and disability at 2 years despite multiple spinal interventions.

\subsection{Prevalence of Usage of Health Care Modalities in Managing Low Back Pain}

Key Question 2. What are the statistics regarding the trends in utilization of treatment modalities?

Exploding health care costs are major U.S. and world issues which have led to the implementation of various health care reform measures, regulations, and to the imposition of guidelines which have often been based on public policy priorities to reduce health care costs. These governmental actions have often resulted from feigned evidence-based medicine and comparative effectiveness research muddled with conflicts and controversies (1-15). Dieleman et al (1) showed an estimated spending of $\$ 87.6$ billion in managing low back and neck pain, accounting for the third highest amount in their study. Martin et al (53) also demonstrated expenditures of $\$ 86$ billion in costs for managing back and neck problems. There has been escalating growth of various modalities for the treatment of musculoskeletal/spinal pain, including physical therapy, drug therapy, interventional techniques, and surgical interventions (1-12,55,66-94).

While the utilization of interventional techniques and surgical interventions are the focus of current debate, other conservative modalities have also been utilized extensively. Unfortunately, despite diagnostic and therapeutic advances, the prevalence of low back pain, secondary disability, and their adverse economic impact, continue to escalate.

\subsection{Surgery}

National trends in surgical interventions have been well described $(5-7,67,69-72,83-85)$. Best et al (67) assessed the national surgical trends for intervertebral disc disorders and spinal stenosis between 1994 and 2006.
The number of procedures increased from 6.1 to 34.2 for intervertebral disc disorders, and from 0.38 to 3.46 for spinal stenosis per 100,000 population. Yoshihara et al (85) in an assessment of national surgical trends for lumbar degenerative disc disease in the U.S. from 2000 to 2009 showed a 2.4-fold population-adjusted increase. Bae et al (6) showed that from 2004 to 2009 there was an increase of spinal fusions for lumbar spinal stenosis from $21.5 \%$ to $31.2 \%$, even though the rate of decompressions decreased from $58.5 \%$ to $49.2 \%$.

Reoperation rates for disc herniation and spinal stenosis have been shown to vary from 10 to $23 \%$ (70). Overall, $40 \%$ of postoperative develop post-surgery syndrome or failed back surgery syndrome, requiring further treatment. Unfortunately, the numbers of preand post-operative patients with disabilities requiring surgical interventions including complex fusions, those patients being treated for failed back surgery syndrome, and patients with refractory chronic low back pain continue to increase $(8,9,76,86-93,95-99)$.

\subsection{Interventional Techniques}

The use of interventional techniques for the treatment of spinal pain and musculoskeletal disorders continued to increase with recent declines (4,8,19,87-89). There was a minimal increase in transforaminal epidural injections and a significant increase in radiofrequency neurotomy as shown in Figs. 4 to 6 frin 2009 to $2016(4,89,90)$. Despite these increases, there has been a significant reduction in epidural injections and lumbar facet joint nerve blocks. In addition to the modest declines in epidural and lumbar facet joint injections, there have been extensive declines in adhesiolysis, as shown in Fig. 7 from 2009 to 2016 (86).

A recent analysis of the utilization of interventional techniques for managing chronic pain in the Medicare population after the institution of the ACA showed a decrease (4,90-93). The analysis of the fee-for-service (FFS) Medicare data from 2000 to 2009 demonstrated an increase of $11.8 \%$ per year per 100,000 population, whereas the data between 2009 and 2016 showed an overall decrease in utilization of interventional techniques by $0.6 \%$ per year.

The utilization of interventional techniques have been criticized for their lack of evidence-based medicine (95-100). However, there have been a multitude of studies based upon randomized controlled trials (RCTs) and evidence synthesis demonstrating significant effectiveness of interventional techniques when appropriately performed $(8,97,101-121)$. Further, apart from 


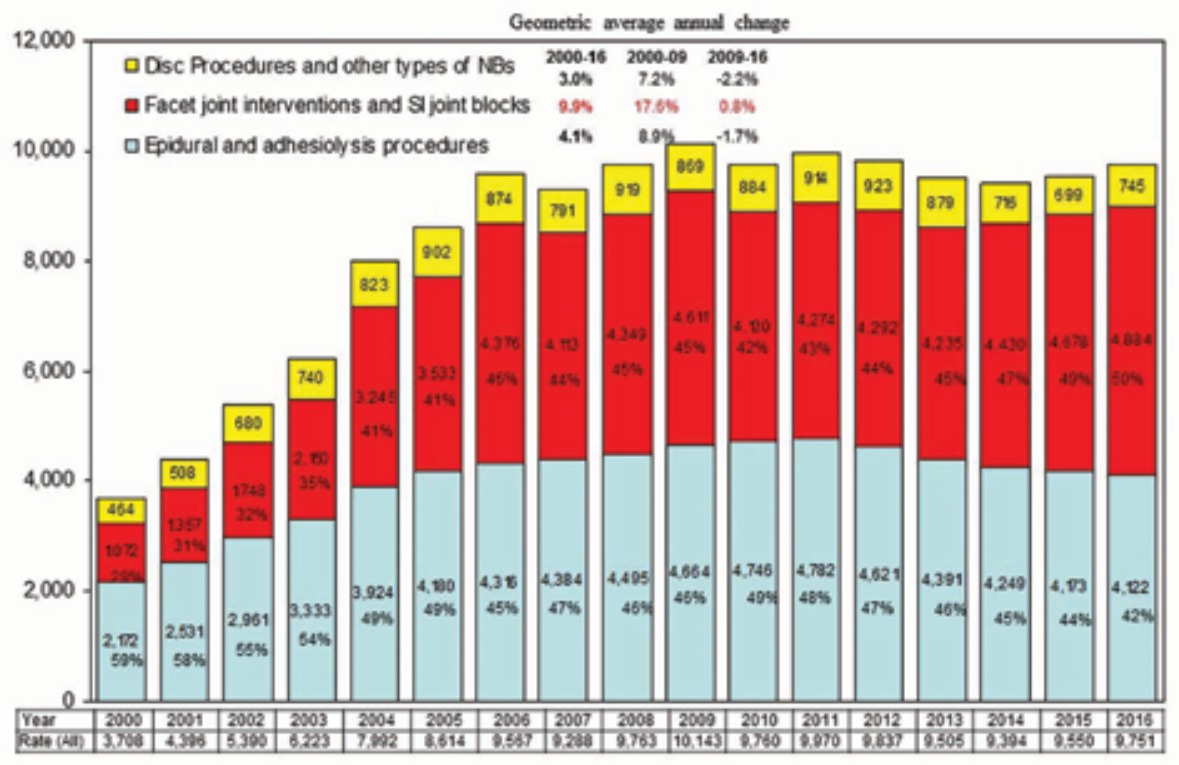

Fig. 4. Distribution of procedural characteristics (rates) by type of procedures from 2000 to 2016 (4).

their clinical effectiveness, the cost effectiveness of multiple interventional techniques has been demonstrated (122-127).

\subsection{Opioid Usage}

Opioids have been used extensively for the treatment of chronic pain, in addition to numerous other drugs, including nonsteroidal anti-inflammatory agents (NSAIDs) and anti-epileptic drugs $(9,128)$. Opioid misuse increased approximately 4,700\% from 1996 to 2011 (128). In a prospective evaluation of psychotherapeutic and illicit drugs used by patients presenting with chronic pain at the time of their initial evaluation, Manchikanti et al (129) showed that $94 \%$ of the patients were on long-term opioids, with $30 \%$ of these patients taking a combination of opioids and benzodiazepines. A significant proportion of these patients were on high dose opioids. Manchikanti et al (9) calculated

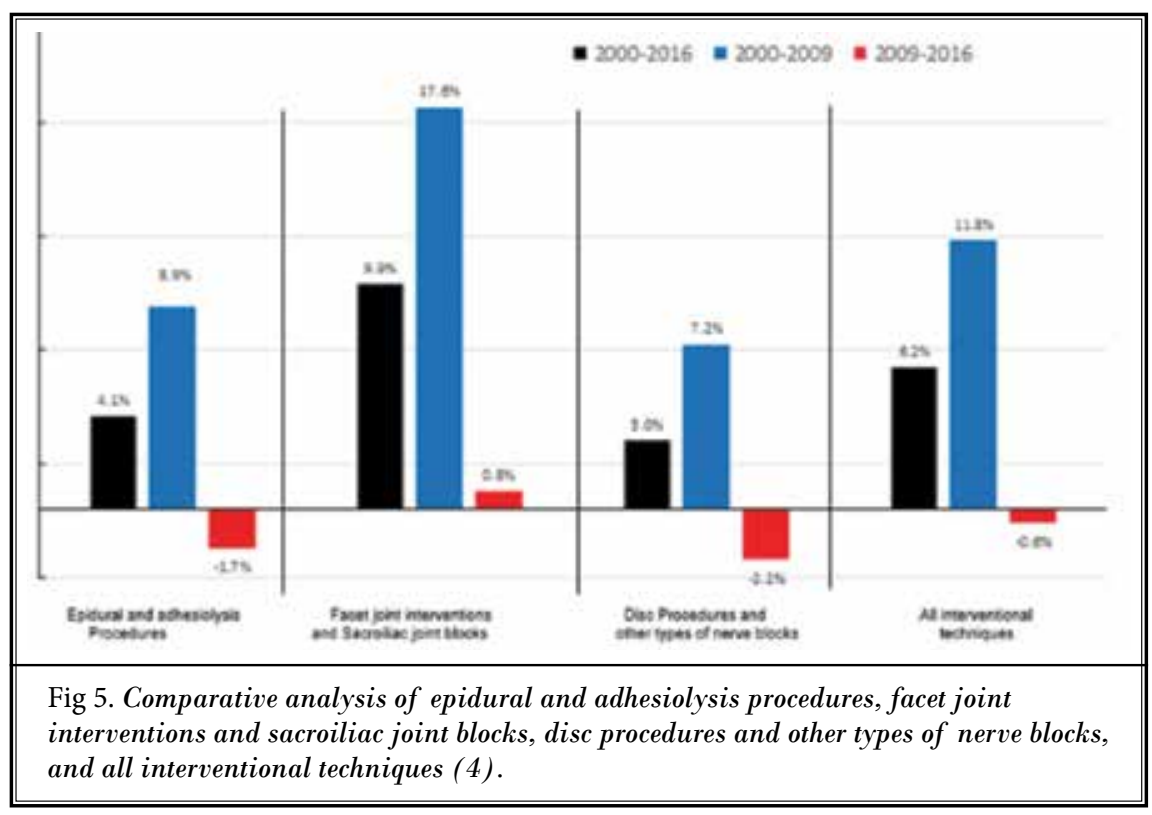

global opioid consumption in $\mathrm{kg}$ from 2000 to 2014, showing a total increase of $210 \%$ from $69,092 \mathrm{~kg}$ in 2000 to $214,490 \mathrm{~kg}$ in 2014 . They also showed that opioid consumption in the U.S. increased from 46,946 kg in 2000 to 148,316 kg in 2014, representing an increase of $178.4 \%$. Proportionate use of opioids in the U.S. compared to global consumption ranged from $67.9 \%$ to $75 \%$, with the U.S. population under $4.8 \%$ of the world's population. The data also showed that the majority of the opioid prescriptions were coming from non-pain management professionals (9). There is extensive literature available on the growing epidemic of the medical 

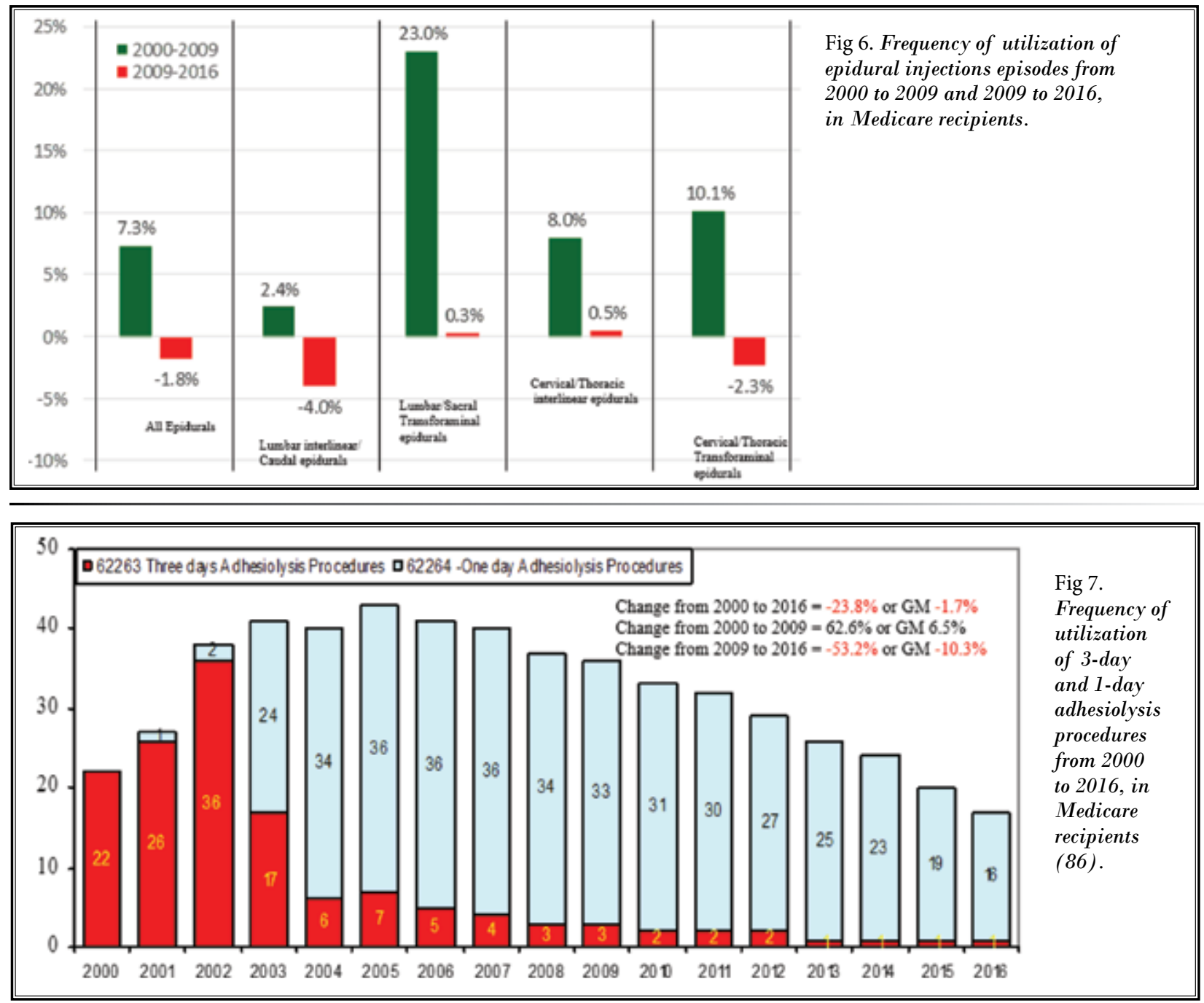

Fig. 8 Number of opioid overdose deaths by category, 1999 to 2017.

Source: National Institute on Drug Abuse. Overdose death rates.

August 2018 https://www. drugabuse.gov/ related-topics/ trends-statistics/ overdose-deathrates (135).
30,000

25,000

20,000

15,000

10,000

5,000

0 
use and abuse of opioid analgesics and other controlled substances, which is closely associated with an economic burden and increased fatalities in the U.S. and many developed countries (9). Data shows that in 2016, more than 11 million Americans misused prescription opioids. Overdose deaths continue to be a major concern for the U.S., accounting for over 64,000 deaths in $2016(9,130,131)$, increasing to 72,000 deaths in 2017 , of which 49,068 were due to licit and illicit opioids (130-135).

Synthetic opioids other than methadone were responsible for 29,406 deaths, heroin for 15,958 deaths, natural and semi-synthetic opioids or prescription opioids for 14,958 deaths, cocaine for 14,556 deaths, methamphetamine for 10,721 deaths, and methadone for 3,295 deaths as shown in Fig. 8 (130-135). However, the evidence demonstrates that illicit fentanyl contributed to almost $60 \%$ of the deaths, whereas overall prescription opioid deaths without fentanyl or heroin, but including other illicit drugs, may have contributed to less than 8,000 deaths in 2017.
The Drug Enforcement Administration's (DEA) mandated reduction in the production of opioids of $25 \%$ in 2017 and $20 \%$ in 2018 and other measures showed a decline in total prescriptions and overall dosages, from a high of 252 million opioid prescriptions in 2013 to 196 million in 2017, as shown in Fig. 9 (133-140). In fact, a decreasing rate of prescriptions of over $9 \%$ annually from 2013 to 2017 was evident. In addition, data from 2017 showed that 23.3 billion fewer morphine milligram equivalents (MME) were dispensed to patients on a volume basis, with dispensed prescriptions decreasing $12.2 \%$, while patients receiving high doses (greater than 90 MMEs per day) declined by $16.1 \%$ (140). Despite the decrease in opioid prescriptions, the opioid abuse and death rates are not decreasing (Fig. 10) (140) because of the availability of illicit narcotics.

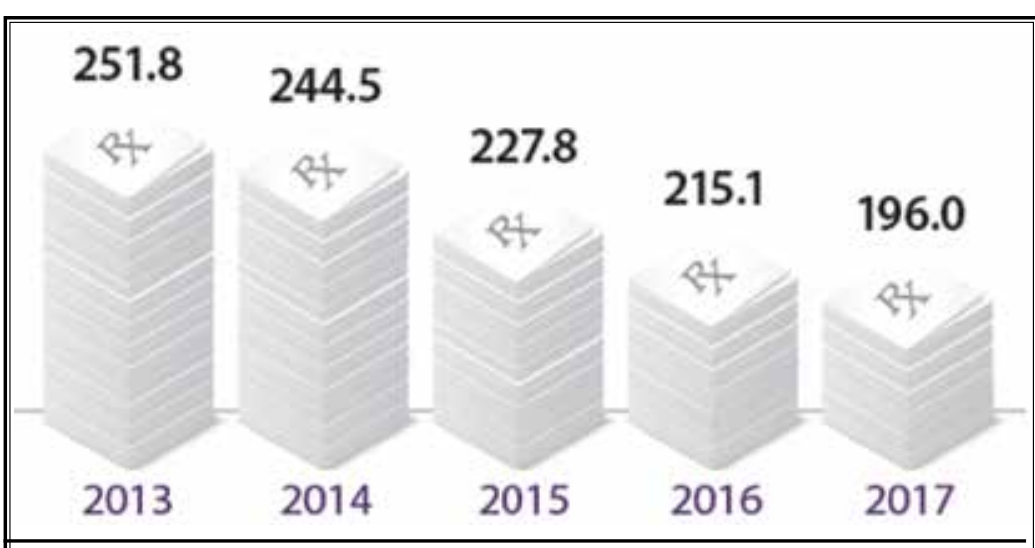

Fig. 9. Total opioid prescriptions (in millions), 2013-2017. Source: Xponent, IQVIA (140)

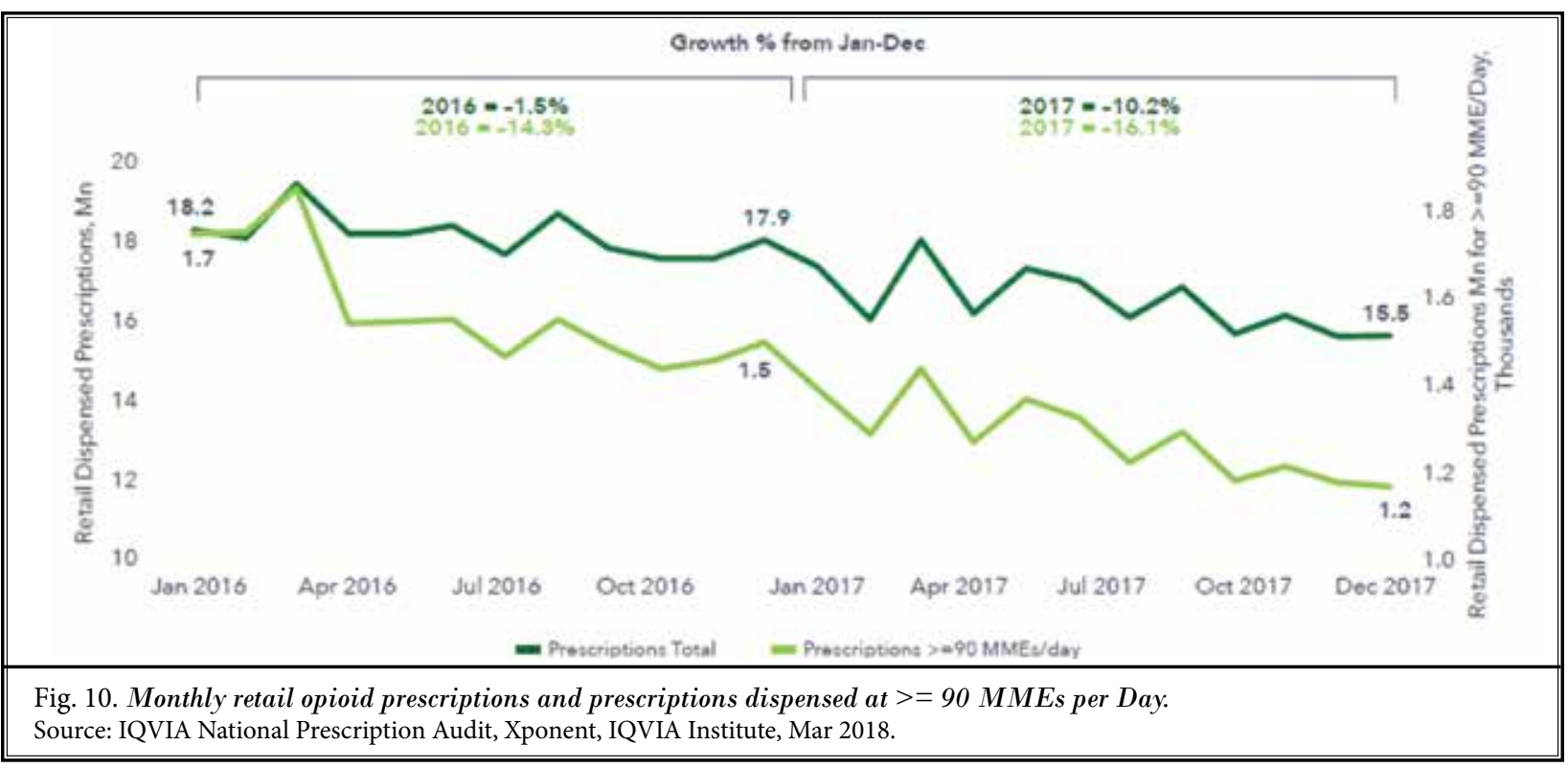




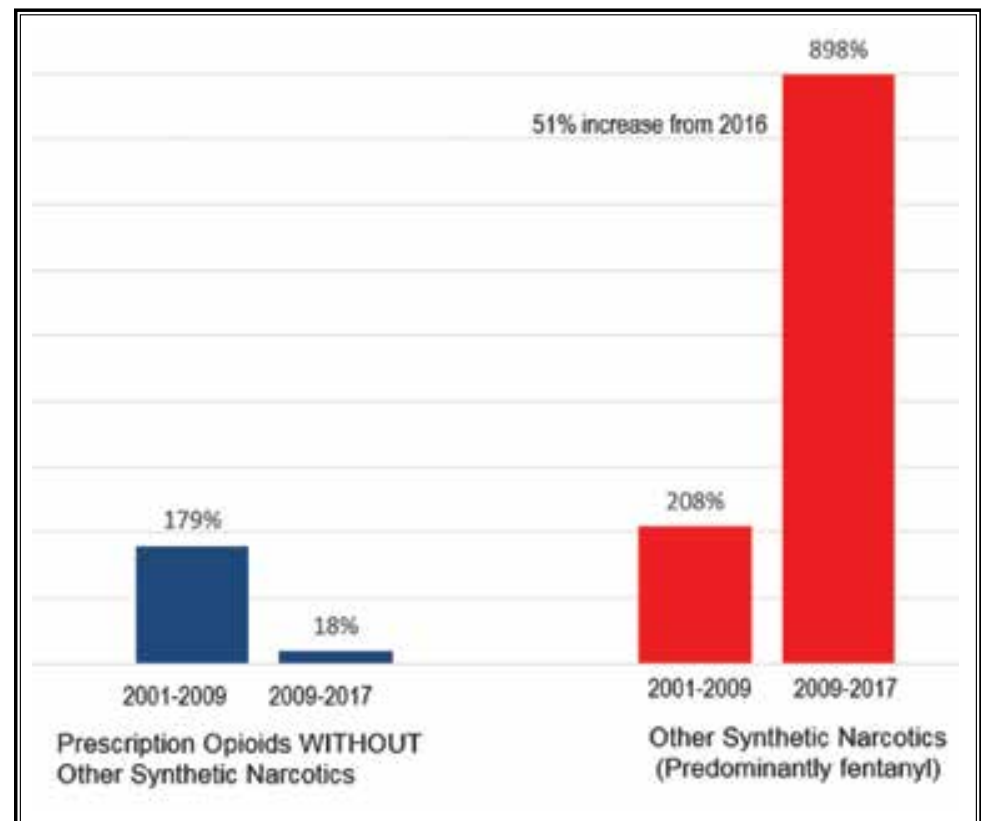

Fig. 11. Quantification of opioid deaths.

Source: https://www.drugabuse.gov/related-topics/trends-statistics/overdose-deathrates. Accessed on 9/20/2018

The opioid epidemic is taking a great toll on the health and economy of the U.S. and the rest of the world. In an analysis of deaths and years of life lost with percentage change of the 25 leading causes of death in the U.S., from 1990 to 2016, opioid use disorders ranked number 52 in 1990, moving up to number 15 in 2010, and remaining at 15th in $2016(10,11)$. In contrast, years lived with disability for the 25 leading causes of disability and injury, opioid use disorders ranked number 7 in 1990 and 2010, but moved to 8 th in 2016, showing very little improvement over the years $(10,11)$.

Deaths caused by illicit/synthetic fentanyl and heroin have been counted as prescription opioid deaths due to the inability to separate fentanyl formulations and the metabolites of heroin, as shown in Fig. $11(135,139)$. Overall, deaths from synthetic narcotics, primarily fentanyl, increased 898\% from 2009 to 2017 $(130-135,139)$. Deaths attributed to illicitly manufactured fentanyl doubled from 10,000 to over 20,000 between 2015 and 2016 (132). The quantification of prescription and synthetic opioid deaths yields startling results as demonstrated in Fig. 11. Prescription opioid deaths increased 18\% between 2009 and 2016, compared to the marked increase of 179\% from 2001 to 2009 (139). Thus, beginning in 2009, the public-at-large and both governmental and medical authorities appropriately focused on the obvious opioid epidemic. Despite the reduction in prescription opioid deaths as of 2016, the problem persists. Consequently, the appropriate management of painful conditions using long-term treatment alternatives to narcotics is essential for their management to increase the quality of life. Governmental and medical authorities continue to work on the enormous problem of illicit narcotics.

\subsection{Cost Utility}

Health care costs and utilization continue to escalate, despite minor reductions since 2009 following the enactment of the ACA (12-16). Clinical and cost effectiveness have become cornerstones in health care policies dealing with all forms of medical interventions (122-127,141-150). Two wellpublicized studies of the cost effectiveness of surgical as opposed to nonoperative treatment for lumbar disc herniation and spinal stenosis with and without degenerative spondylolisthesis showed $\$ 69,403$ gained per quality-adjusted life year (QALY) in the surgical management of lumbar disc herniation, $\$ 77,600$ for spinal stenosis without degenerative spondylolisthesis, and $\$ 115,600$ for spinal stenosis with degenerative spondylolisthesis $(143,144)$. Taylor et al (123) showed the cost effectiveness of spinal cord stimulation versus surgery and other interventions at $£ 5,624$ ( $\$ 7,058$ USD) per QALY. Cost utility analysis was performed for interventional techniques compared to alternative treatments utilizing RCTs by Manchikanti et al (124-127), showing the cost utility of caudal epidural injections at $\$ 3,628$, percutaneous adhesiolysis at $\$ 4,426$, lumbar interlaminar epidural injections at $\$ 3,301(126,127)$, therapeutic lumbar facet joint nerve blocks at $\$ 4,432$ (124), and therapeutic cervical facet joint nerve blocks at $\$ 4,261$ (125). Multiple therapies including an exercise program, education using cognitive and behavioral therapy (CBT), and physical therapy were shown to be associated with significantly higher costs than interventional techniques (146-150). A combination of an exercise program and CBT education were found to be superior to education alone in patients with low back pain for more than 3 months, resulting in a QALY of $\$ 8,650$ (148). Fritz et al (149) performed a cost effectiveness study of primary care management for 
Responsible, Safe, and Effective Use of Biologics in the Management of Low Back Pain

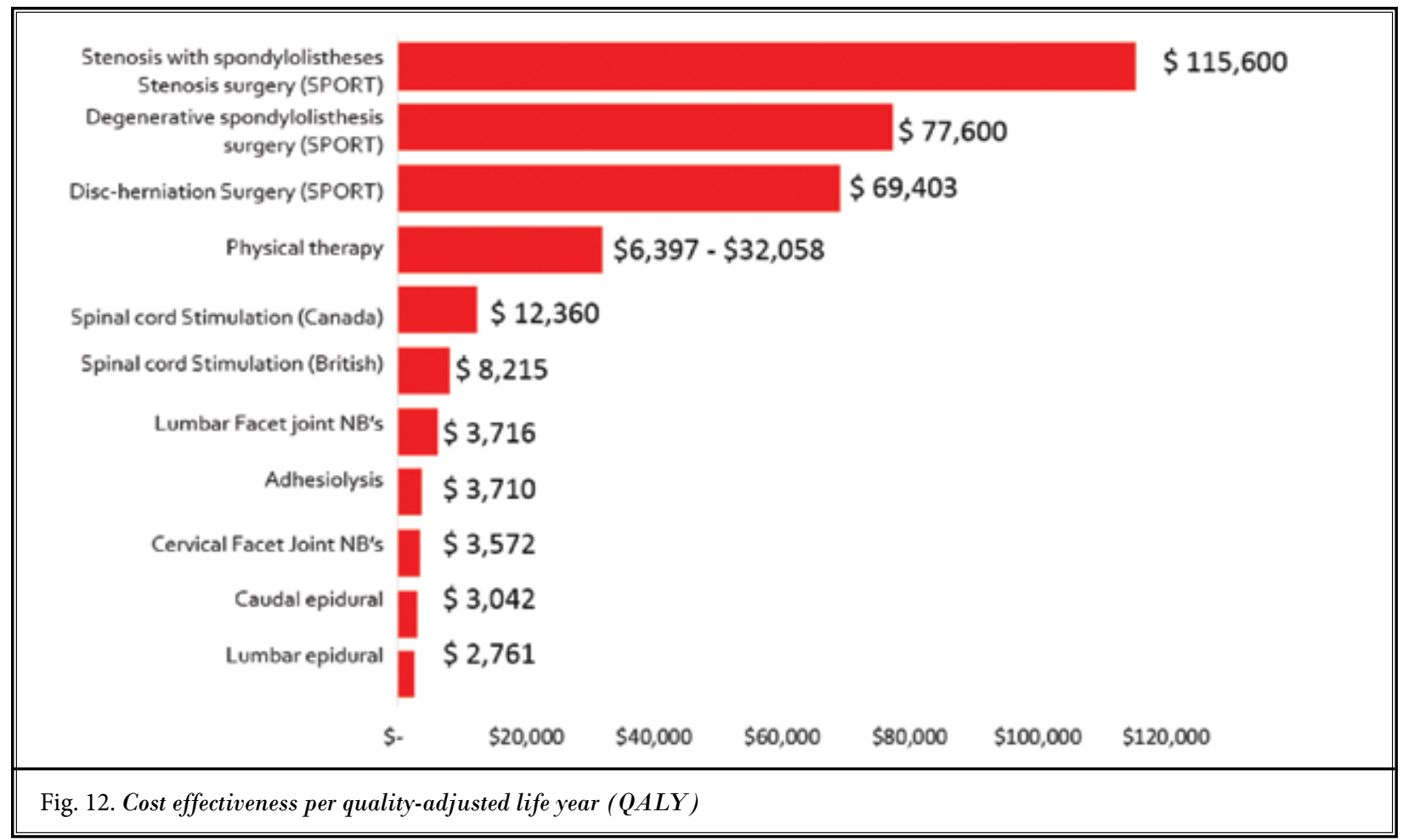

acute low back pain, showing that early physical therapy resulted in a better quality of life with an incremental cost effectiveness ratio of \$32,058 per QALY. Kepler et al (146) performed a systematic review of various interventional modalities used in spine treatment showing that only $45 \%$ of the 33 analyzed studies had a cost less than $\$ 100,000$ per QALY, whereas around $23 \%$ had costs greater than $\$ 100,000$ per QALY. Indrakanti et al (147) showed that nonoperative treatments demonstrated greater value than surgery. Figure 12 shows comparative cost utility analysis of various modalities of treatments in managing chronic pain.

\subsection{Pathophysiologic and Structural Basis of Low Back Pain}

Key Question 3: What is the pathophysiologic and structural basis of low back pain?

Low back pain is the most common of all spinal and even chronic pain problems. Based on the available evidence, lumbar intervertebral discs, facet joints, sacroiliac joints, ligaments, fascia, muscles, the nerve root and its dorsal ganglion, and the dural sleeve have been shown to be capable of transmitting pain in the lumbar spine with resulting symptoms of low back pain and lower extremity pain $(101,103-105,112,151-154)$.

\subsection{Disc Related Pathology}

Chronic persistent low back and radicular pain may be secondary to disc degeneration, disc herniation, spinal stenosis, or the post lumbar surgery syndrome resulting in disc-related pain with or without radiculopathy $(8,18,112)$. Discogenic pain with or without disc herniation has been described since 1934 (112,151-157). Lumbar disc disorders may present as internal disc disruption (degeneration with an intact annulus fibrosis), nuclear herniation (protrusion, extrusion, or free fragment) via an annular fissure, or simply discogenic pain (leakage of disc fluid through an annular fissure). The prevalence of symptomatic herniated lumbar disc is about $1 \%$ to $5 \%$, and the prevalence of lumbar radiculopathy or sciatica is 9.8 per 1,000 cases $(1 \%)(112,156,158)$. While lumbar radiculopathy secondary to disc herniation resolves spontaneously in $23 \%$ to $48 \%$ of the patients, $30 \%$ to $70 \%$ will still have pronounced symptoms after one year, with $5 \%$ to $15 \%$ of patients undergoing surgery $(145,159)$. The intervertebral disc has been described as a source of low back and lower extremity pain based on decades of pre-clinical, clinical, and epidemiological research, though the precise mechanisms still continue to be debated $(8,18,112,151,154,160-164)$. Controlled evaluations of patients with proven lumbar disc disease 


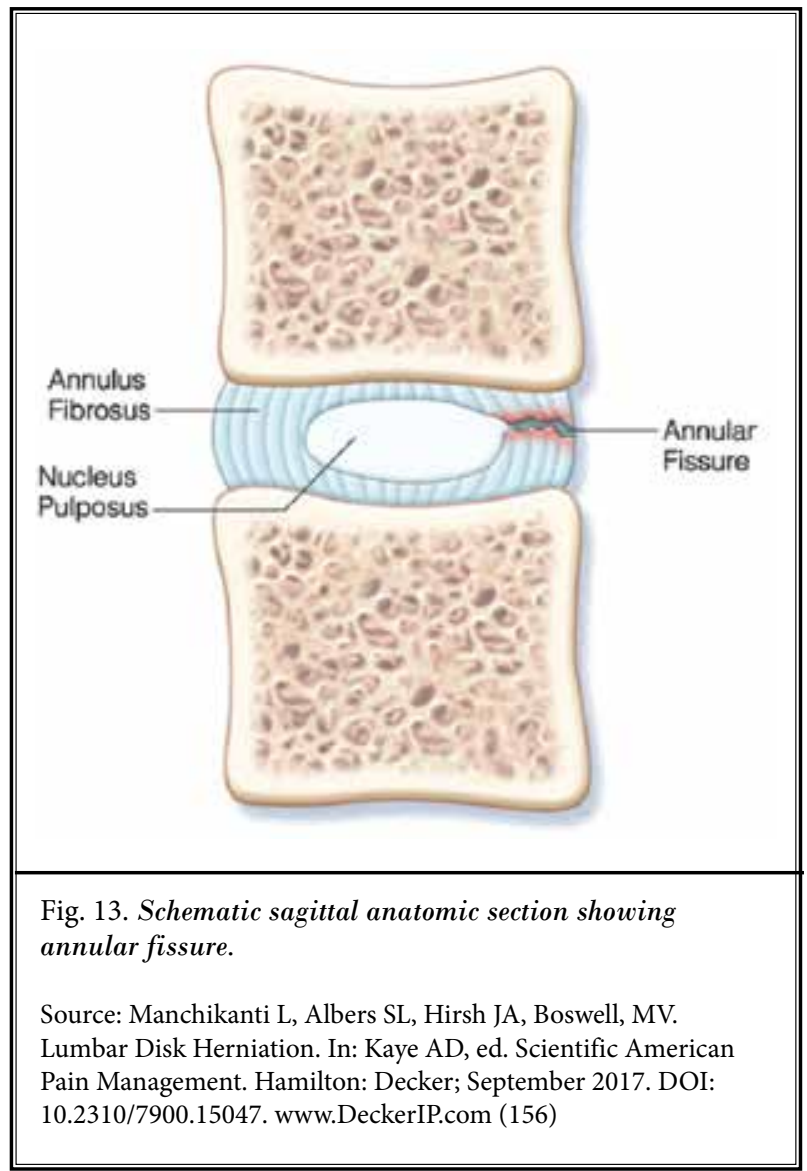

showed a prevalence of internal disc disruption in 39\% of a cohort of young patients following injury (164), and $42 \%$ in a heterogenous population comprised of all age groups and types of low back pain (165).

Disc pathology begins with nuclear and/or inner annular degeneration, potentially followed by annular disruption, which may permit nuclear herniation. Ongoing degeneration can lead not only to disc herniation, but can also contribute to central canal and foraminal stenoses, segmental instability, and degenerative scoliosis. The initial pathology in disc degeneration is the decrease in water content of the nucleus, followed by fissuring of the inner annulus, which allows the disc to bulge. The resulting changes in disc morphology lead to altered spinal biomechanics and also irritation of nerve roots by chemical irritation via an outer annular fissure near a nerve root, displacement or direct compression by disc material, or vascular compromise with canal or vascular stenoses. Discogenic pain may occur without internal disc disruption, such as by chemical leakage through an outer annular fissure, irritating the annulus, epidural soft tissues, and dura $(8,18,151,154,160-165)$. Disc degeneration and herniation alter the disc integrity and predisposes the disc to additional pathology over time (156). Figures 13-15 show the pathophysiology of discogenic pain with disc herniation. Figure 16 shows a normal lumbar disc, whereas Fig. 17 shows disc bulging

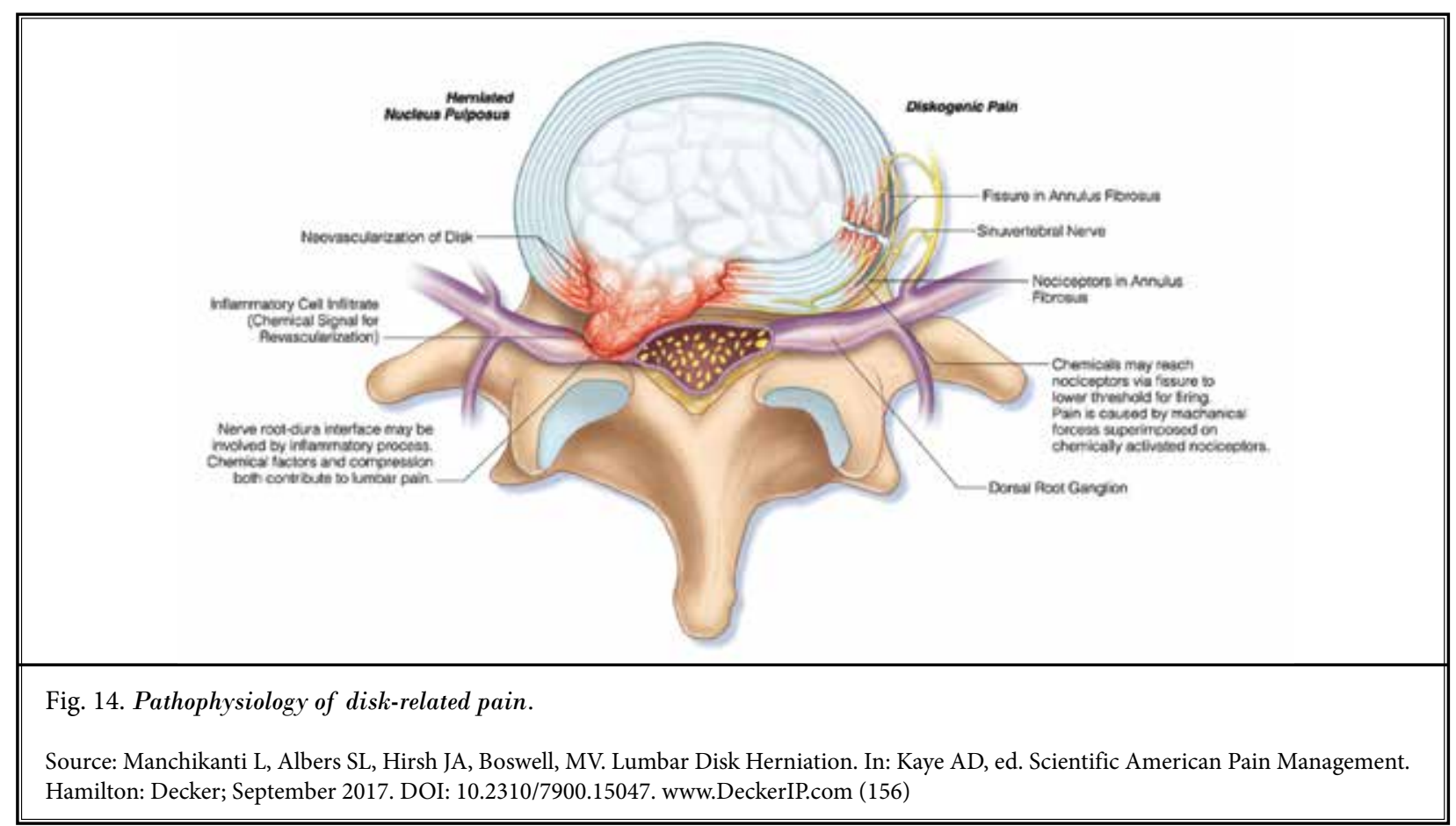




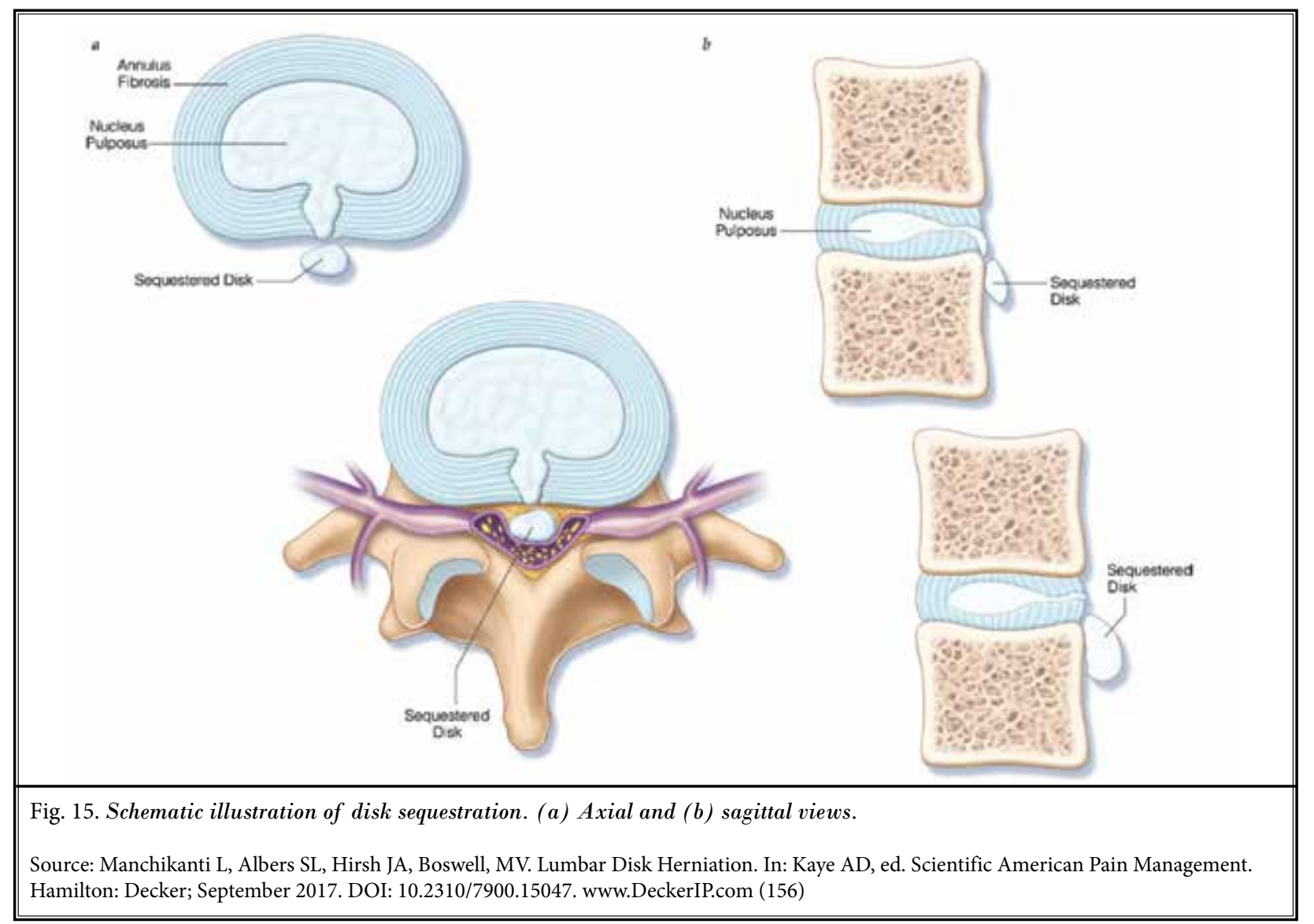

and mild protrusion. Figure 18 shows a disc extrusion. Figure 19 shows chronic endplate changes (Modic Type I) and moderate central spinal canal stenosis.

\subsection{Spinal Stenosis}

Spinal stenosis is defined as narrowing of the spinal canal, resulting in symptoms and signs caused by entrapment and compression of the intraspinal neural and vascular structures. Varying degrees of stenosis have been shown to be present in $27.2 \%$ of the elderly population (166-168).

Congenital or acquired spinal stenosis may be central, foraminal, or a combination of both. Disc bulging, protrusion, and extrusion combined with osteophytes and arthritic changes of the facet joints and hypertrophy of the ligamenta flava can cause narrowing of the spinal canal and encroachment and/or compression on the contents of the dural sac. Foraminal stenosis is largely secondary to degenerative facet disease, with the possible addition of a significant disc component, producing compression or distortion of the exiting nerve root. Symptoms of central spinal stenosis is secondary to direct compression of the cauda equina, altered arterial flow to the cauda equina, venous congestion producing increased epidural pressure, and nerve root excitation by local inflammation $(8,166-168)$. Because spinal stenosis is a multifactorial disorder, the clinical presentation can be variable, ranging from focal radiculopathy to neurogenic claudication manifested by pain in the buttocks or legs when walking which disappears with sitting or lumbar flexion. Foraminal stenosis presents with radicular pain. A combination of central and foraminal stenoses generally presents with neurogenic claudication as well as radicular pain. In addition to congenital and acquired stenoses, acute trauma may also produce central and/or foraminal stenoses secondary to retropulsion of the vertebral body middle column into the spinal canal, with or without a significant epidural hematoma, along with distortion of the neural foramina.

Anterolisthesis of one vertebral body on another can be secondary to degenerative facet disease or, less 


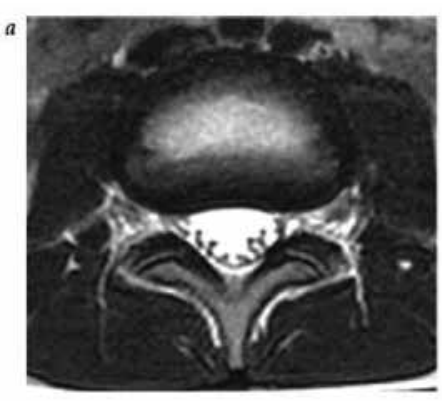

(a) Axial T2-weighted image of a normal lumbar disk. Central area of increased signal represents the nucleus pulposus. Darker signal on the periphery represents the annulus fibrosus. Spinal canal width and facets are normal. (b) Normal thoracolumbar spine from T11 through S5. Sagittal T2-weighted image demonstrates normal signal within the intervertebral disks and vertebral bodies. Central area of increased signal represents the hydrated nucleus pulposus. Darker signal at the disk periphery represents the annulus fibrosus. Disks and vertebral bodies are also normal in height. Spinal canal is normal in width. Conus (green arrow) is seen at T12.

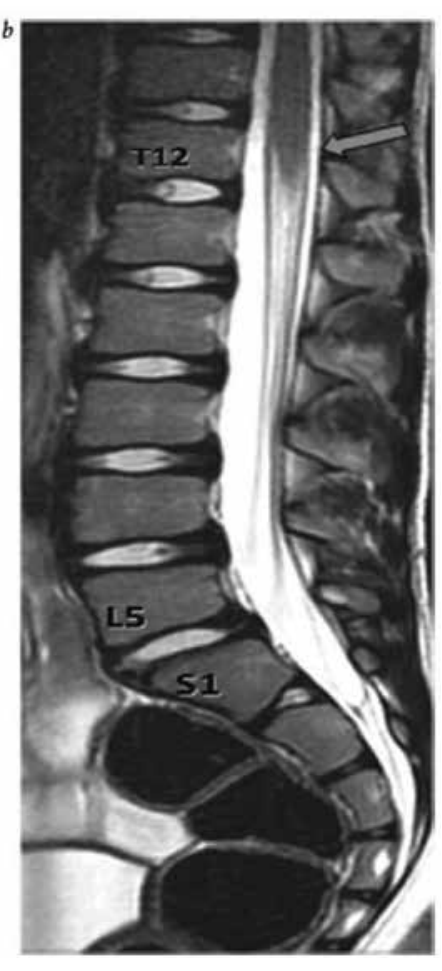

Fig. 16. Normal lumbar disk.

Source: Manchikanti L, Albers SL, Hirsh JA, Boswell, MV. Lumbar Disk Herniation. In: Kaye AD, ed. Scientific American Pain Management. Hamilton: Decker; September 2017. DOI: 10.2310/7900.15047. www. DeckerIP.com (156)

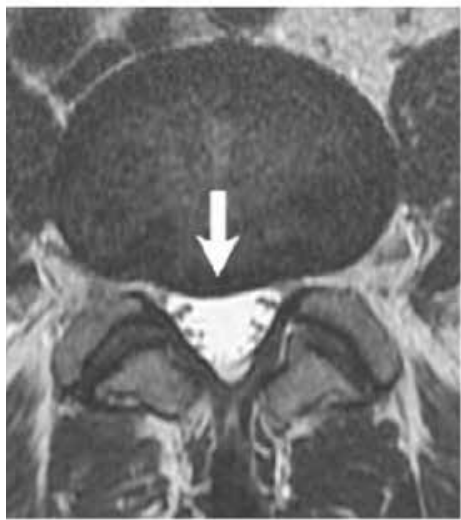

Source: Manchikanti L, Albers SL, Hirsh JA, Boswell, MV. Lumbar Disk Herniation. In: Kaye AD, ed. Scientific American Pain Management. Hamilton: Decker; September 2017. DOI: 10.2310/7900.15047. www.DeckerIP. com (156)

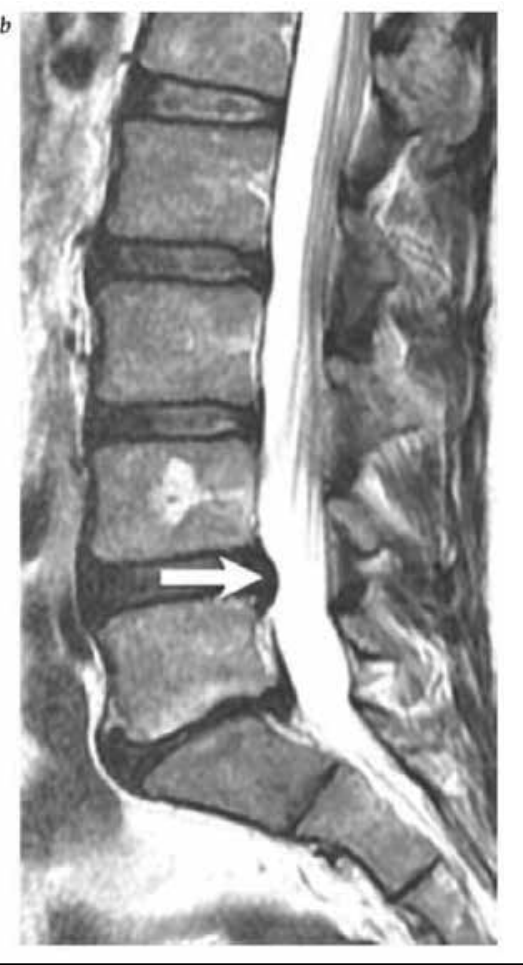

Fig. 17. Mild L4-L5 disk protrusion. (a) Axial and (b) sagittal T2-weighted images. The disk projects posteriorly in the midline (arrows). commonly, a defect in the pars interarticularis (spondylolysis), and can be an important component of both central and foraminal stenoses. It is vital to recognize increased slippage (instability when moving from a supine to a standing position or occurring with flexion), since this will influence treatment options.

Figure 20 shows a schematic illustration of spinal stenosis, whereas Figs. 21 to 23 show a radiographic presentation of lumbar spinal stenosis.

\subsection{Post Surgery Syndrome}

Low back and lower extremity pain occurs following lumbar spine surgery in a large proportion of cases, estimated to be as high as $40 \%(8,76)$. The incidence of the failed back surgery syndrome may be as high as 80,000 cases per year (76). Based on increasing surgical interventions, this number may be much higher. Even though post lumbar laminectomy syndrome 
Fig. 18. Disk extrusion with recent inferior migration and right $L 4$ root posterior displacement.

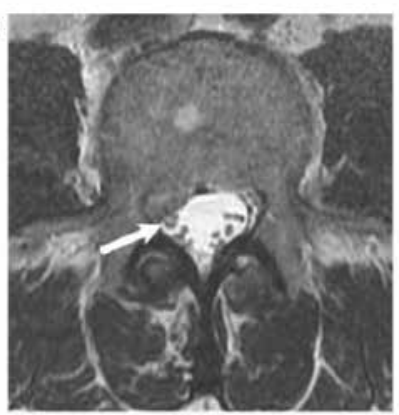

(a) The axial view demonstrates a component extending into the right lateral recess at the disk space level, posteriorly displacing the right $\mathrm{L} 4$ nerve root (white arrow). (b) Sagittal view. Part of this extrusion has an increased signal most consistent with a higher water content (black arrow), indicating its recent herniation.

Source: Manchikanti L, Albers SL, Hirsh JA, Boswell, MV. Lumbar Disk Herniation. In: Kaye AD, ed. Scientific American Pain Management. Hamilton: Decker; September 2017. DOI: 10.2310/7900.15047. www.DeckerIP.com (156)

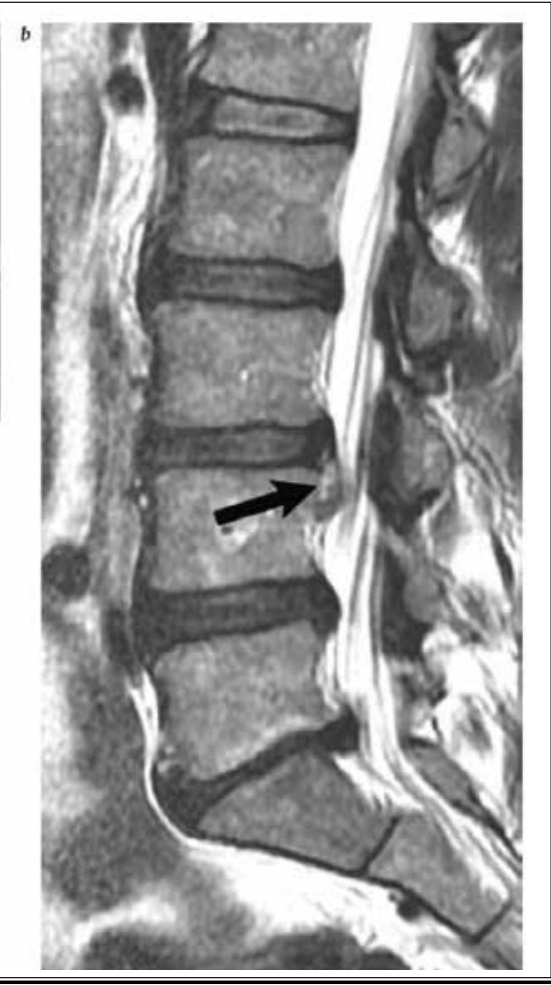

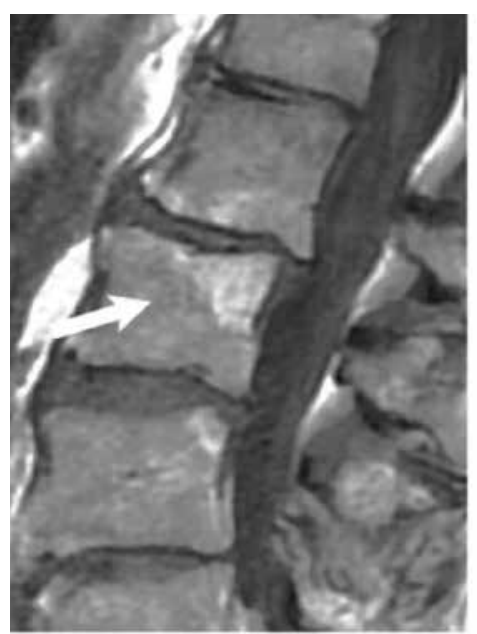

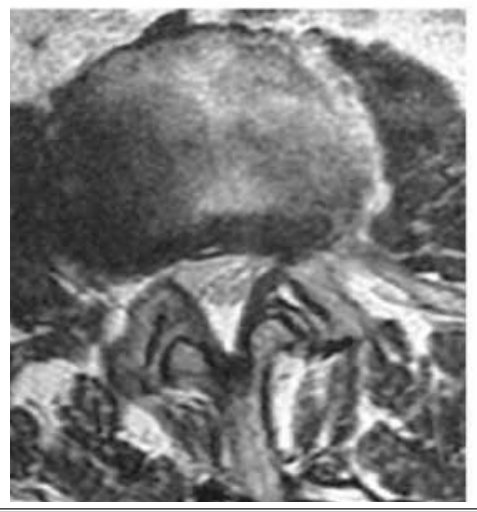

www.painphysicianjournal.com

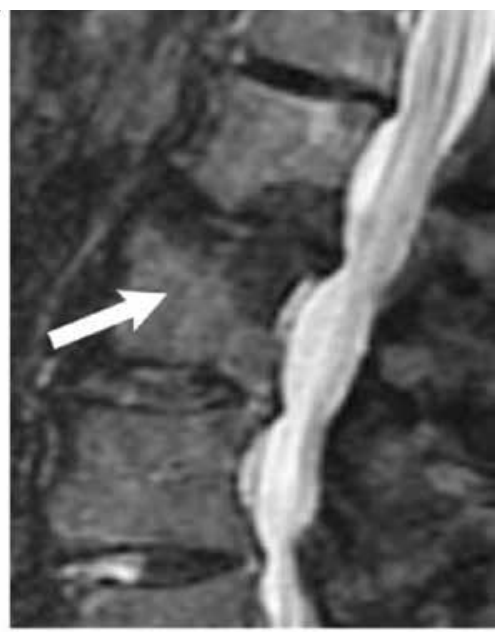

Fig. 19. Chronic end-plate changes (Modic type I) and moderate central spinal canal stenosis.

Source: Manchikanti L, Albers SL, Hirsh JA, Boswell, MV. Lumbar Disk Herniation. In: Kaye AD, ed. Scientific American Pain Management. Hamilton: Decker; September 2017. DOI: $10.2310 / 7900.15047$. www.DeckerIP.com (156)

(a) A sagittal T1-weighted magnetic resonance image shows hyperintense changes (arrow) within both the L2 and L3 vertebral bodies on either side of a narrowed, bulging, degenerated disk. (b) A short tau inversion recovery image nulls the fat signal and excludes the presence of edema, which would be typical of acute Modic type I changes (arrow). (c) An axial T2-weighted image shows a bulging disk with an annular fissure and moderate facet hypertrophy, producing a mild degree of central canal spinal stenosis. 


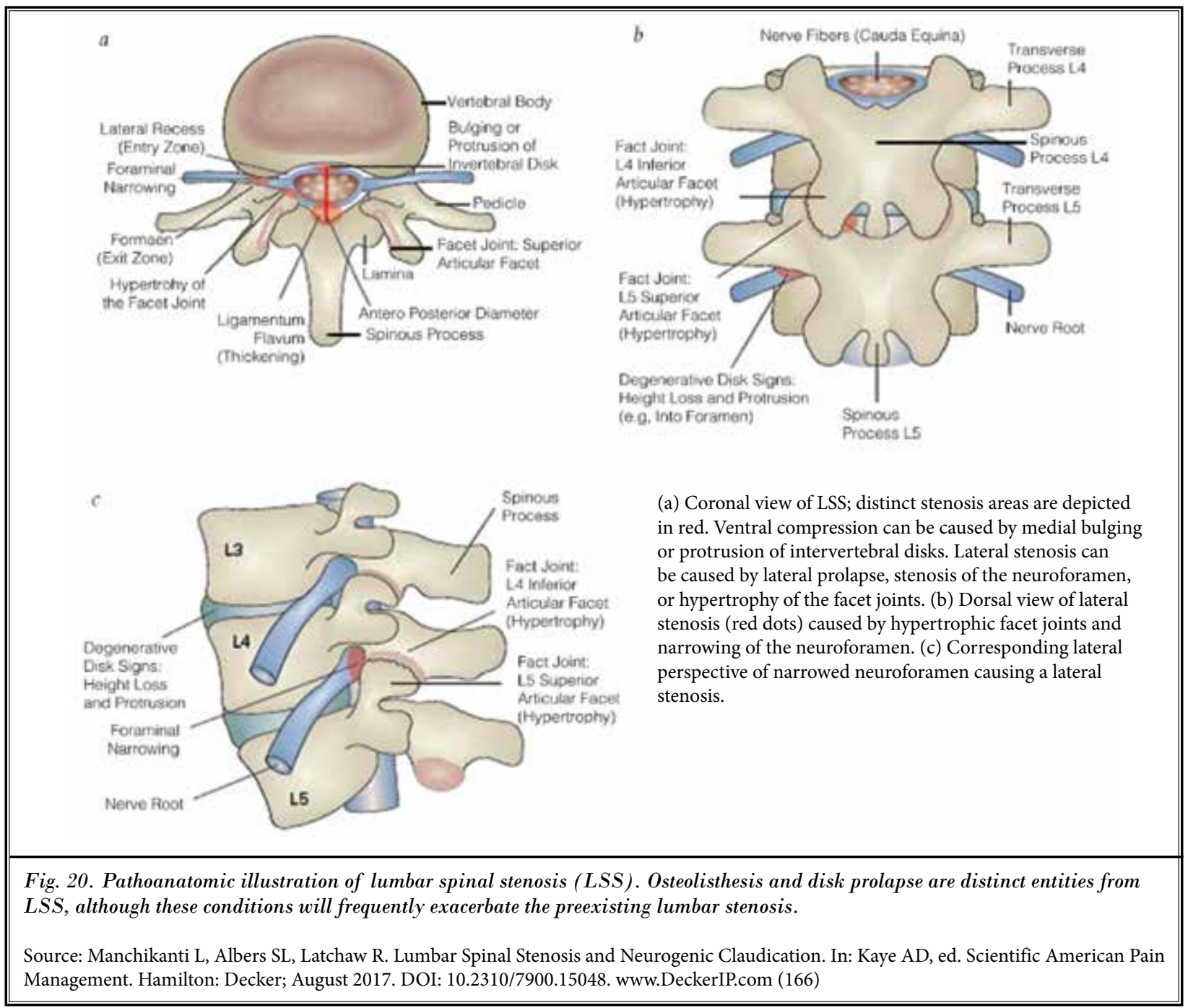

or failed back surgery syndrome denotes a failure of treatment, the nomenclature itself is inaccurate since it can be seen following any type of surgical intervention. Consequently, a more appropriate term would be the postsurgery syndrome. Furthermore, this term does not necessarily indicate a failed surgical procedure. Rather this may indicate a technically successful operation that has not been able to produce a satisfactory long-term clinical outcome. Pain and disability in the low back and lower extremity following lumbar spine surgery may be secondary to epidural fibrosis, sacroiliac joint pain, disc herniation, discogenic pain, spinal stenosis, arachnoiditis, facet joint pain, acquired spondylolisthesis, and/ or myofascial pain, along with inappropriate surgery. A relatively common medium to long-term sequela is adjacent level degeneration. In addition, changes in posture and body dynamics may challenge muscle and ligamentous structures with the eventuation of secondary pain generators such as the piriformis muscle.

\subsection{Facet-related Pathology}

Facet joints are pairs of joints that stabilize and guide motion in the spine (8). Lumbar facet joints are a well-recognized source of low back and referred pain into the lower extremities in patients with chronic low back pain, and controlled studies have established them as potential sources of chronic pain $(8,101,102,104,154)$. In addition, the degenerated facets contribute to the cycle of discogenic pain because of their altered morphology and angulation, allowing for spondylolisthesis. Ultimately, they are major factors in the development of spinal stenosis. Facet joints are well 


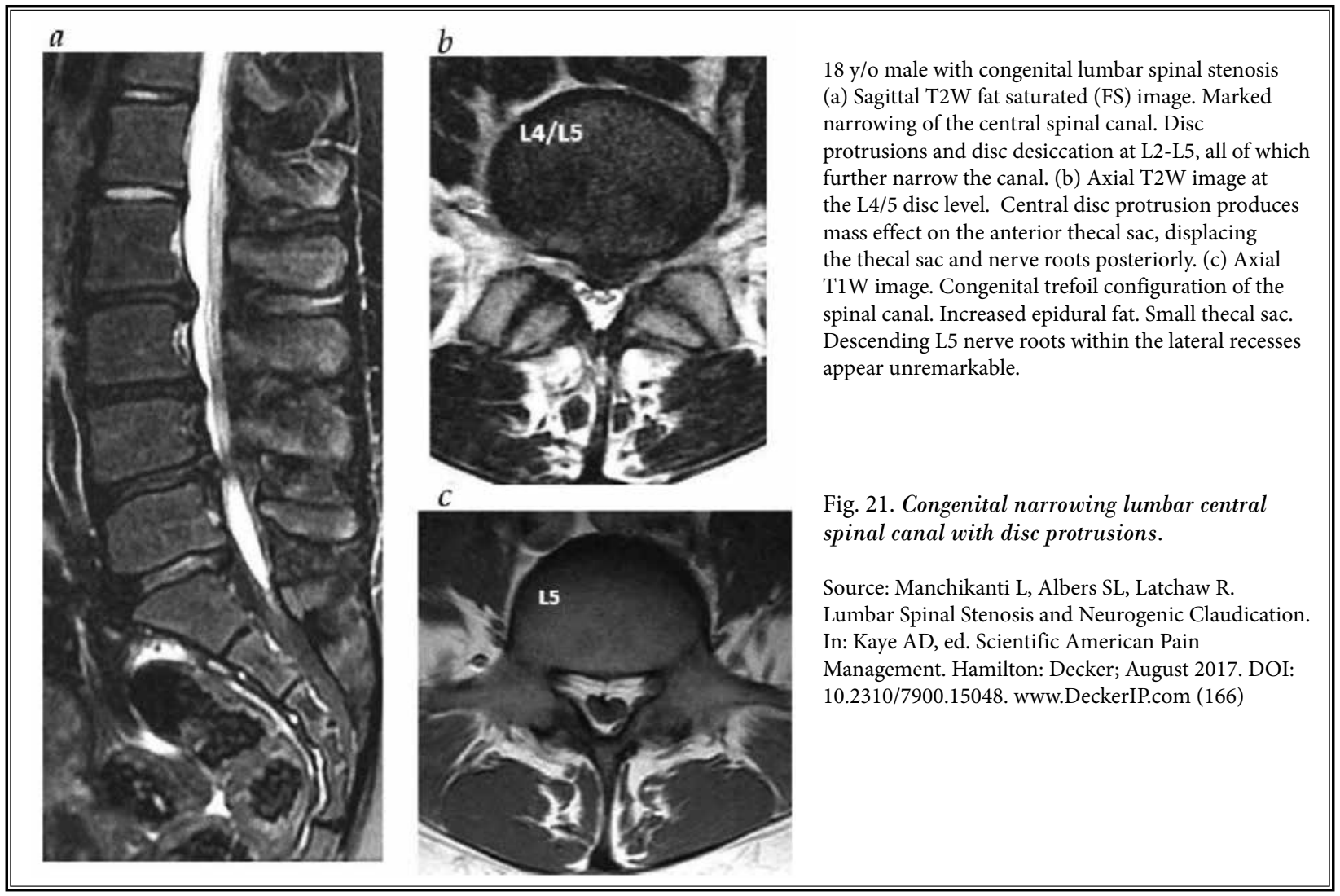

44 y/o male with chronic low back pain, NIC and bilateral L4 radiculopathy. (a) Sagittal T2W image demonstrating congenital lumbar stenosis along with multilevel DDD to include diffuse disc bulging from L2L5, endplate osteophytes and endplate reactive marrow changes. Ligamenta flava hypertrophy is severe at $\mathrm{L} 3 / 4$. (b) Axial T2W image at the pedicular level of $\mathrm{L} 3$ showing the congenital trefoil appearance of the spinal canal with superimposed degenerative facet disease and severe ligamenta flava hypertrophy. The degenerative changes further decrease the already narrowed AP dimension of the spinal canal (grade $\mathrm{C} / \mathrm{D}$ central spinal stenosis as there is questionable epidural fat posteriorly). (c) Axial T2W image through the $\mathrm{L} 3 / 4$ disc demonstrating severe spinal canal stenosis to include severe central canal (grade D) and bilateral lateral recess stenoses. Moderately severe facet hypertrophy and moderate ligamenta flava hypertrophy contribute and worsen the underlying congenital stenosis.

Fig. 22. Degenerative disc disease superimposed on congenital lumbar stenosis.

Source: Manchikanti L, Albers SL, Latchaw R. Lumbar Spinal Stenosis and Neurogenic Claudication. In: Kaye AD, ed. Scientific American Pain Management. Hamilton: Decker; August 2017. DOI: 10.2310/7900.15048. www.DeckerIP.com (166)
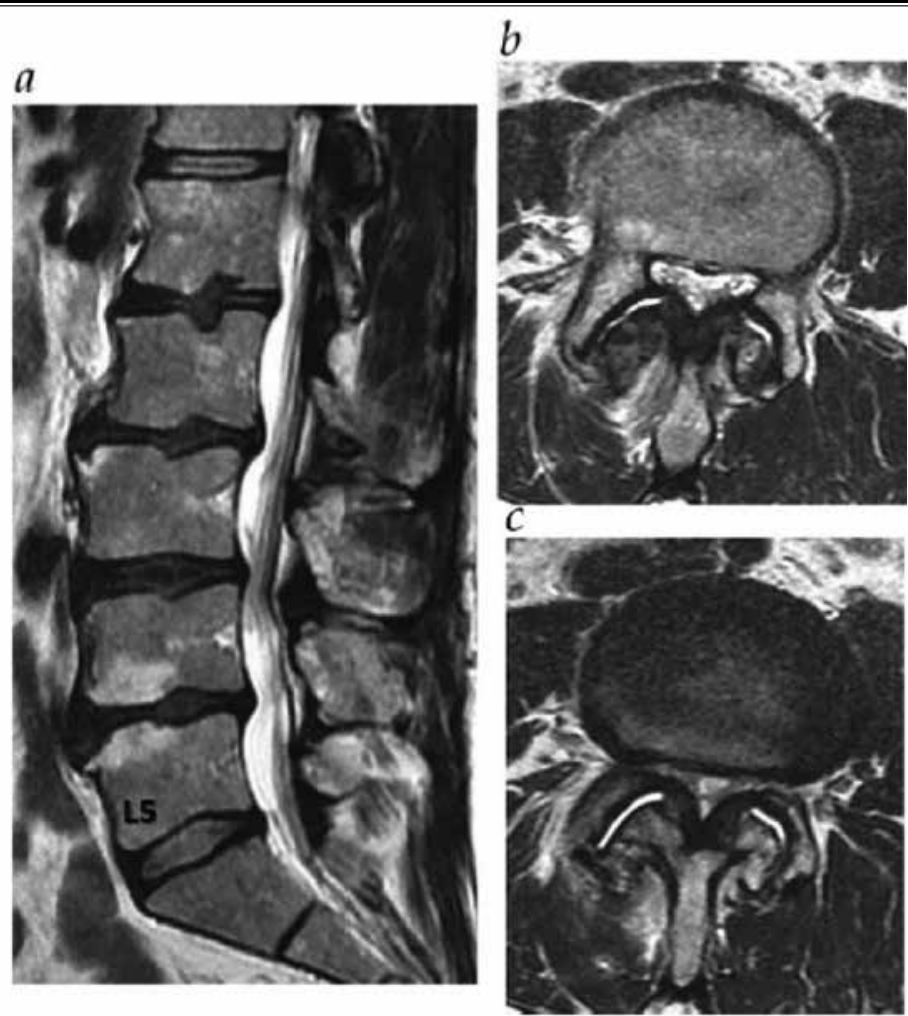

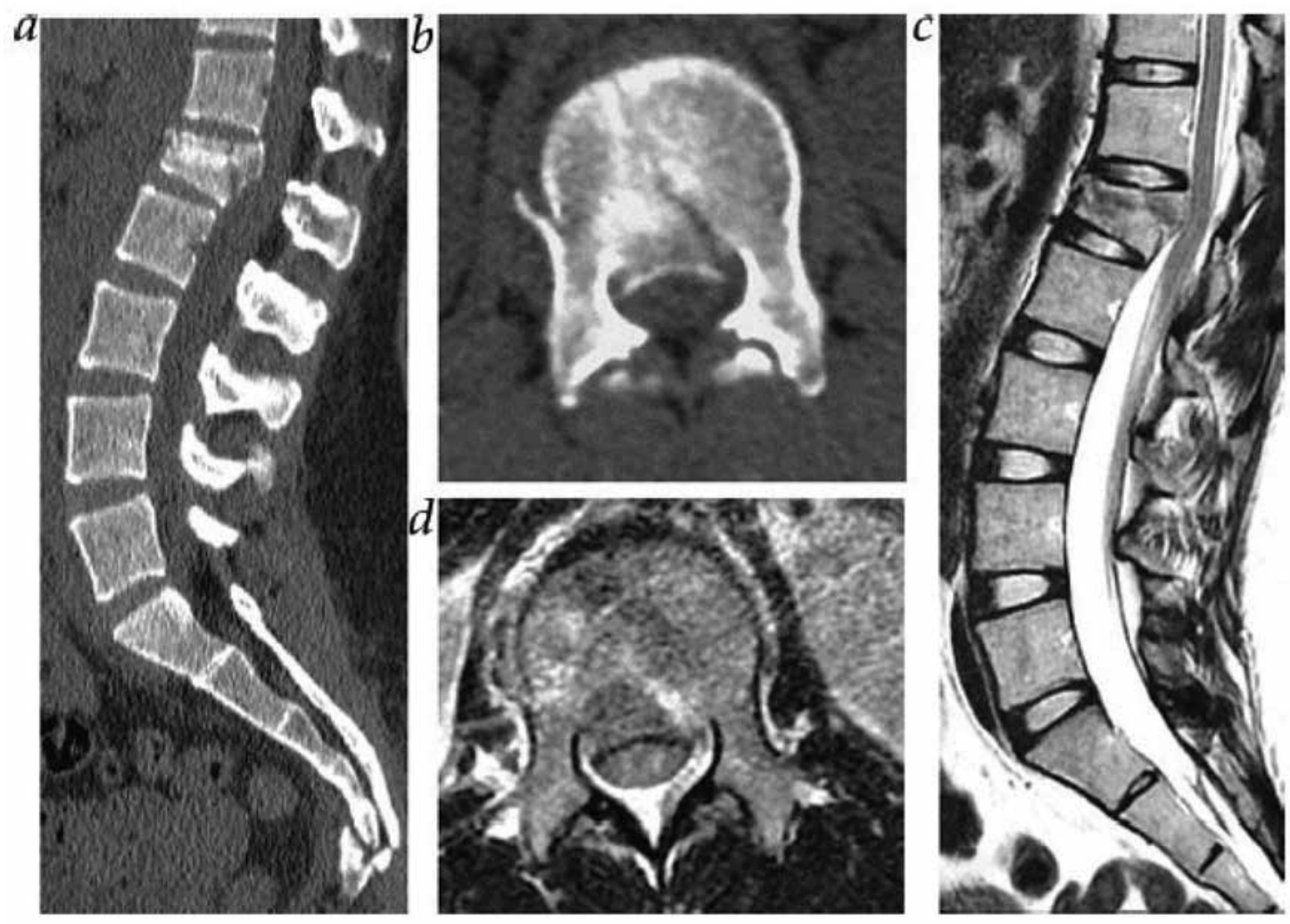

$28 \mathrm{y} / \mathrm{o}$ female status post 15 foot fall. (a) Sagittal CT. Comminuted burst fracture of L1 with retropulsion of the superiorposterior fracture fragments. Additional shear type comminuted distal sacral fracture at sacro-coccygeal junction. (b) Axial CT. Retropulsed L1 fragments abut the thecal sac and displace sac and cord posteriorly. (c) Sagittal T2W image. Comminuted L1 fracture with retropulsion of the superior fragments compressing and displacing the thecal sac and cord posteriorly. Increased signal within cord and conus consistent with edema. (d) Axial T2W image. Mottled increased signal within the spinal cord consistent with edema from L1 burst fracture and reptropulsed fragments. Cord is compressed and displaced posteriorly. Small left sided hematoma.

Fig. 23. Trauma and acute central spinal canal stenosis.

Source: Manchikanti L, Albers SL, Latchaw R. Lumbar Spinal Stenosis and Neurogenic Claudication. In: Kaye AD, ed. Scientific American Pain Management. Hamilton: Decker; August 2017. DOI: 10.2310/7900.15048. www.DeckerIP.com (166)

innervated by the medial branches of the dorsal rami. Neuroanatomic, neurophysiologic, and biomechanical studies have demonstrated free and encapsulated nerve endings in lumbar facet joints, as well as nerves containing substance $P$ and calcitonin gene-related peptide $(8,101,102,104,154)$. Multiple factors including mechanical injury, inflammation, and degeneration of the facet joints have been shown to produce persistent pain in animal models, as well as in humans (169-172). Prostaglandin E2 (PGE2) has been identified as a key mediator of inflammation-induced behavioral sensitivity and increased neuronal excitability $(152,173)$. Overall, the diagnosis established by controlled diagnostic blocks in chronic low back pain patients has shown a prevalence of facet joint pain ranging from $16 \%$ to $41 \%(8,101,102,104)$.

\subsection{Sacroiliac Joint Pain}

The sacroiliac joint is accepted as a potential source of low back and/or buttock pain with or without lower extremity pain $(8,103)$. The sacroiliac joint receives innervation from the lumbosacral nerve roots. Neurophysiological studies have demonstrated both nociceptive and proprioceptive afferent units in the sacroiliac joint. Pain referral patterns based on sacroiliac joint provocation and analgesic response to local anesthetic in asymptomatic volunteers and patients with pain have been studied. The relatively accurate diagnosis of 
sacroiliac joint pain is made by controlled local anesthetic blocks. These studies have shown the prevalence of sacroiliac joint pain in chronic low back and lower extremity pain to be between $10 \%$ to $25 \%$. The literature suffers with a paucity of studies assessing the role of multiple available treatments.

\subsection{Ligaments, Fascia, and Muscles}

A significant prevalence of chronic low back pain may be related to muscles and ligaments in the low back, pelvis, and lower extremities (8). However, the available controlled diagnostic techniques are not amenable for an accurate diagnosis of these conditions or their prevalence.

\subsection{Regenerative Medicine}

Key Question 4. What are the available regenerative medicine therapies?

Biological therapies assist the healing of tissues damaged acutely or chronically, including ligaments, menisci, articular cartilage, tendons, discs, and joints. While there are a variety of biologicals utilized in regenerative therapy of the spine and other musculoskeletal disorders, PRP and MSCs are the current mainstays of regenerative medicine treatment.

\subsection{Platelet-Rich Plasma (PRP)}

PRP is a concentrate of whole blood that is cen- trifuged to obtain plasma rich in platelets and hence growth factors. In the U.S., PRP is approved by the FDA for use with ligament grafting and the approximation of bony matrices during reconstructive procedures. Benefits occur by the increased concentration of growth factors that are secreted by platelets in an inflammatory environment, i.e., platelet-derived growth factors. These growth factors are essential to the healing process, as they increase fibroblast and/ or osteoblast metabolic activity while reducing cell apoptosis; promoting angiogenesis, thereby increasing blood flow and circulation to the new-forming tissues; and increasing the expression of the pro-collagen gene and collagen-derived growth factors, which increase the tensile strength of the new tissue (17-19,23,174180). Components of PRP include platelets, leukocytes, and red blood cells. However, platelets are central to mediating the anabolic effects of PRP by virtue of releasing growth factors stored in their alpha granules (178). Notable growth factors released from platelets that are involved in the healing process are shown in Table 3 (181-184).

Proteins present in PRP that stimulate proliferation include endothelial growth factor, platelet-derived growth factor, vascular endothelial growth factor, and basic fibroblast growth factor (b-FGF). Inhibitory proteins such as b-FGF2 are equally important in mediating overproliferation (180), although the exact balance between

Table 3. Function of growth factors stored in platelet-rich plasma.

\begin{tabular}{|l|l||}
\hline Growth Factor & Function \\
\hline PDGF & $\begin{array}{l}\text { Stimulates cell proliferation, chemotaxis, and differentiation } \\
\text { Stimulates angiogenesis }\end{array}$ \\
\hline TGF- $\beta$ & $\begin{array}{l}\text { Stimulates production of collagen type I and type III, angiogenesis, re-epithelialization, and synthesis of } \\
\text { protease inhibitors to inhibit collagen breakdown }\end{array}$ \\
\hline VEGF & Stimulates angiogenesis by regulating endothelial cell proliferation and migration \\
\hline EGF & $\begin{array}{l}\text { Influences cell proliferation and cytoprotection } \\
\text { Accelerates re-epithelialization } \\
\text { Increases tensile strength in wounds } \\
\text { Facilitates organization of granulation tissue }\end{array}$ \\
\hline bFGF & $\begin{array}{l}\text { Stimulates angiogenesis } \\
\text { Promotes stem cell differentiation and cell proliferation } \\
\text { Promotes collagen production and tissue repair }\end{array}$ \\
\hline IGF-1 & $\begin{array}{l}\text { Regulates cell proliferation and differentiation } \\
\text { Influences matrix secretion from osteoblasts and production of proteoglycan, collagen, and other noncollagen } \\
\text { proteins }\end{array}$ \\
\hline
\end{tabular}

Abbreviations: PDGF = platelet-derived growth factor; TGF- $b=$ transforming growth factor-b; VEGF = vascular endothelial growth factor; EGF $=$ epidermal growth factor; bFGF = basic fibroblast growth factor; IGF-1 = insulin-like growth factor.

Adapted and Modified from: Refs. (181-184) 
Table 4. Consensus statements on platelet-rich plasma.

\begin{tabular}{||l|l||}
\hline 1 & $\begin{array}{l}\text { Nomenclature and classification system that encompasses autologous blood/plasma products and categorizes preparations in } \\
\text { sufficient detail to facilitate comparison across studies is not available. } \\
\text { - A widespread system must be developed with involvement of academics, clinicians, and industry representatives }\end{array}$ \\
\hline 2 & $\begin{array}{l}\text { Quality assessment with influence of donor variance and processing and delivery factors on the composition of PRP must be } \\
\text { established. }\end{array}$ \\
\hline 3 & $\begin{array}{l}\text { A validated assay of the efficacy of PRP should be established for each clinical application. } \\
\text { - Specific formulations of PRP should be matched with specific pathologic indications. } \\
\text { - Methods for establishing proof of safety and efficacy of PRP should be determined. This process may require evidence of } \\
\text { phenotype stability or viability for each indication. }\end{array}$ \\
\hline 4 & $\begin{array}{l}\text { The relationship between PRP composition and efficacy must be established. } \\
\text { - Minimum standards of reporting for all studies (preclinical and clinical) evaluating PRP must be established to facilitate } \\
\text { communication and the interpretation and synthesis of scientific investigations. These standards must include measured } \\
\text { characteristics of the PRP, factors relating to the donor, processing, and delivery of the PRP and outcome parameters. }\end{array}$ \\
\hline
\end{tabular}

$\mathrm{PRP}=$ platelet-rich plasma

Adapted from: LaPrade RF, Dragoo JL, Koh JL, et al. AAOS Research Symposium Updates and Consensus: Biologic Treatment of Orthopaedic Injuries. J Am Acad Orthop Surg 2016; 24:e62-e78 (188).

these proteins is not known. Because each person expresses unique proportional quantities of these proteins, it is uncertain if concentrating an individual's autologous proteins is ideal for their body's healing needs. Since the therapy is dependent on the function of the host's platelets, the therapeutic concentration of PRP injectate is recommended to be at least 2.5 times greater than the peripheral plasma concentration. Lesser concentrations are probably sub-therapeutic, and greater concentrations reduce osteoclastic activity (174).

PRP has been developed with a multitude of formulations (179). A meta-analysis reported 14 different indications for treatment and 9 different preparation systems used in clinical studies (185). Consequently, multiple authors have proposed classification systems for the various types of PRP based on its content including platelets, white blood cells, fibrin network, and exogenous activators. Dohan Ehrenfest et al (186) described a classification system based on cell content, primarily the amount of white blood cells, and the fibrin architecture. Based on these parameters, they grouped PRP into 4 different types.

- $\quad$ Pure PRP (PPRP), which does not contain leukocytes and has a low-density fibrin network.

- Leukocyte-rich PRP (L-PRP) has an increased concentration of white blood cells in addition to a high concentration of platelets, but also has a lowdensity fibrin network.

- Pure platelet-rich fibrin (P-PRF) is free of leukocytes, but has a high-density fibrin network.

- Leukocyte- and platelet-rich fibrin (L-PRF) has an increased concentration of leukocytes and a highdensity fibrin network.
The preparations with a low-density fibrin network allow for injectable applications, which are more commonly used for musculoskeletal conditions. Consequently, the first 2 preparations are commonly utilized. The third and fourth preparations with high-density fibrin networks allow for a clot with growth factor present in the matrix architecture (186).

DeLong et al (187) proposed a classification known as the PAW (Platelets, Activation, White Blood Cells) classification of PRP based on platelet concentration, activators, and the presence of white blood cells, placing them into multiple categories based on their contents. Even though PRP nomenclature remains variable and no single classification system is consistently used, it is critical for clinicians to know what is in the milieu of PRP that is being injected (52). The American Academy of Orthopaedic Surgeons (AAOS) (188) identified several obstacles to the advancement of PRP therapies and made recommendations on how future research efforts should be directed to overcome the challenges. The consensus statement of PRP preparation and use from the AAOS is shown in Table 4 (188). The multiple variables that may influence the growth factor profile of PRP related to donor, processing, and delivery are shown in Table 5.

DEPA (Dose of injected platelets, Efficiency of production, Purity of the PRP, Activation of the PRP) classification has been proposed to extend the characterization of the injected PRP preparation. A classification system based on the platelet concentration and the presence or absence of white blood cells in the PRP. Lana et al (30) described a new classification called MARSPILL: M: Method; A: activation, R: red blood cells, 
S: spin, P: platelets, I: image guidance, L: leukocytes, L: light activation.

The platelet poor fraction of blood is also known to have substances that may be of use for regenerative approaches including fibrinogen, alpha 2 macroglobulin and exosomes. A discussion about these factors is beyond the purview of the present review.

\subsection{Medicinal Signaling Cells or Mesenchymal Stem Cells (MSCs)}

Stem cells are essentially the base-model versions of each kind of cell, and have the potential to become one or more specific kind of cell. Fetal stem cells have the potential to not only differentiate into any kind of cell, but also to self-renew. Adult stem cells are located throughout adult tissue and are primed to become the cells in and for that particular tissue, as stimulated by the surrounding environment $(17,189-195)$. The adult stem cells described by Caplan (189) have become well recognized but are now called "medicinal signaling cells (MSCs)" (189-195). These adult MSCs have a narrower range of potentials, but are sufficient for use in many current and emerging musculoskeletal and spine therapies.

A major benefit from of MSCs is their inherent lack of significant histocompatibility complex (MHC) class II surface proteins. This not only allows them to conform to a variety of different cell types, but also decreases the risk of rejection when transferred between hosts (allogeneic transfer) $(187,196)$. MSCs that have clasped on to the vascular tree as pericytes are also able to migrate to a site of injury and then differentiate into the cell required for healing, such as osteoclasts, to directly contribute to the remodeling process $(187,196)$.

An important area of research regarding the potential mechanism of action of MSCs is that of a paracrine influence" affecting the efficacy in differentiation of the cells. The concentration of the surrounding catabolic cytokines from acute inflammation favors osteoclastic activity, and the balance must shift away from inflammation in order for the anabolic effects of MSCs to take place. Two examples supporting this premise are the following: 1) there is evidence that concentrating MSCs in an area to artificially favor the balance towards osteoblastic activity is feasible, and has been a successful technique in preventing graft vs. host disease; 2). MSCs are most effective in degenerative diseases where there is little active inflammation (197).

Over the years, multiple researchers have attempted to standardize the nomenclature used in MSC re-
Table 5. Variables that may influence the growth factor profile of platelet-rich plasma.

\begin{tabular}{|cl|}
\hline \hline Donor & \\
- & Age \\
- & Gender \\
- & Comorbidities \\
- & Nutritional status \\
\hline - Processing \\
- & Blood collection and storage conditions \\
- & Spin protocol (speed, time) \\
- & Storation protocol (agent, concentration, timing) \\
\hline Delivery & \\
- & Form of delivery (gel, solution) \\
- Timing of delivery in relation to isolation \\
- & Timing of delivery in relation to activation \\
- & Injury chronicity \\
\hline
\end{tabular}

Adapted from: LaPrade RF, Dragoo JL, Koh JL, et al. AAOS Research Symposium Updates and Consensus: Biologic Treatment of Orthopaedic Injuries. J Am Acad Orthop Surg 2016; 24:e62-e78 (188).

search (17). However, such standardization efforts have been unsuccessful because of variations and methods of isolation, culture, and assay resulting in complicated and, at times, misleading nomenclature. In 2006, the International Society for Cellular Therapy (ISCT) produced a position statement suggesting the minimum criteria required to define MSCs (198).

The first report of stem cells described those unique cells derived from bone marrow. They remain the most commonly utilized type of adult stem cells, and have the approval and recommendations of the FDA (17). Since that time, MSCs have been isolated from multiple organs and tissues with variable advantages and disadvantages depending upon the source. Apart from the intersource variation, MSCs originating in different anatomic locations having the same tissue may vary in yield and characteristics (188). Consequently, the equivalency of MSC populations derived from distinct anatomic origins continues to be debated and remains contentious. MSC populations from multiple sources have shown differences with respect to the immunophenotype, secreted cytokine profile, and results of proteome analysis (199-201). Further, it also has been shown that cloned human MSCs isolated from fat default to adipogenic potential, whereas those isolated from bone marrow default to osteogenic potential, indicating the importance of origin which ultimately influences the characteristics of MSCs and potentially the eventual outcomes (199). Thus, 4 key pathways that 
Table 6. Consensus statements on stem cell therapy.

\begin{tabular}{|c|c|}
\hline 1 & $\begin{array}{l}\text { It is essential to identify the factors contributing to tissue development, regeneration, and healing in each specific tissue. } \\
\text { - } \quad \text { The mechanisms regulating these contributions must be characterized. }\end{array}$ \\
\hline 2 & $\begin{array}{l}\text { The optimum preparation of stem cells for each indication must be established in a systematic fashion. } \\
\text { - } \\
\text { - } \quad \text { Mensiderations should include cell number, concomitant use of growth factors, predifferentization, and vehicle. } \\
\text { each specific indication. }\end{array}$ \\
\hline 3 & $\begin{array}{l}\text { The mechanism responsible for therapeutic effects observed in applications and appropriate outcome parameters must be } \\
\text { established. } \\
\text { A standardized assay of stem cell efficacy is needed. } \\
\text { - } \\
\text { regulatory agencies. This process may require evidence of phenotype stability or viability. } \\
\text { - The most appropriate control for clinical studies evaluating stem cell therapy in each indication must be identified. } \\
\text { - The most appropriate, replicable outcomes must be established. }\end{array}$ \\
\hline
\end{tabular}

Adapted from: LaPrade RF, Dragoo JL, Koh JL, et al. AAOS Research Symposium Updates and Consensus: Biologic Treatment of Orthopaedic Injuries. J Am Acad Orthop Surg 2016; 24:e62-e78 (188).

have been identified in tissue regeneration, namely osteogenesis, adipogenesis, chondrogenesis (200-203), and fibrinogenesis $(204,205)$ are derived with differing potential from MSCs that come from bone marrow compared to adipose tissue.

Adipose MSCs also have the noted characteristic of pro-angiogenic properties, which makes them a very promising therapy for both ischemic/vascular therapies and for commonly injured hypo- to avascular regions such as the avascular zone of the knee meniscus. Bone marrow-derived MSCs have the same progenitor potential as the adipose derived MSCs, but also home to the site of injury through a series of chemoattractants, integrating into the host marrow, bone, and cartilage (197).

True adult stem cells, in general, are relatively scarce; they can be difficult to isolate; they grow slowly; and they do not differentiate well without the appropriate peripheral cytokines. It can be difficult to isolate sufficient therapeutic quantities of these cells. These disadvantages may be partially overcome by selection of stem cells from an appropriate source such as bone marrow from a source containing red marrow such as the iliac crest where extraction yields $95-100 \%$ viable cells (187).

Due to the scarcity of stem cells, laboratory culture has been used to enrich and expand MSC populations (206), taking advantage of the rapid expansion of MSCs in laboratory conditions. However, laboratory cultures are not approved by the FDA $(17,38-40)$. Consequently, within the confines of the FDA regulations requiring minimal manipulation, the stromal vascular fraction (SVF) which is derived from chemically manipulated adipose tissue is not recommended, and laboratory cultures are not approved by the FDA. The AAOS (188) has provided a consensus statement on stem cell therapy, as shown in Table 6.

Although the absolute number of stem cells found in bone marrow concentrate may be relatively low, those growth factors that are derived in the bone aspirate process may confer additional therapeutic value to this process.

It is also important to consider that adult stem cells may contain the mutations of the host cell obtained at meiosis, and these mutations may be expressed regardless of the cell type into which they differentiate (187). Gene therapy is being actively studied to ensure the safety and efficacy of this biologic therapy.

\subsection{Other Commercially Available Biologic Preparations}

A simple web-based search can yield a multitude of kits and biologic products for office use. The Center for Biologic Evaluation and Research provides an 8 page listing of all commercially available biologic products byproduct name, date of licensure, and the date (if applicable) that it was withdrawn from the market (207).

A biologic of significant interest in regenerative medicine is the exosome or microvesicle (208). Similar to MSCs, exosomes are secretory products that home and travel via local diffusion, delivering proteins, micro RNA, and messenger RNA. However, unlike MSCs, extracellular vesicles or exosomes demonstrate a number of advantages distinct from their parent cells. They can travel systemically without the risk of clumping and they do not demonstrate a first pass effect into the lungs when administered intravascularly. They can also easily cross the blood-brain barrier without the utilization of mannitol. Exosomes are important in autocrine signaling (locally between the same cells), paracrine 
signaling (locally between cells of different types) and endocrine signaling (between distant cells). Key immune and growth factors present in exosomes are similar to those found in MSCs. Exosomes have been utilized in a multitude of disorders similar to the use of MSCs (208).

Alpha 2 Macroglobulin (A2M) has known to be associated with degeneration of the discs serving as a dual regulator for both anabolism and catabolism in the cartilaginous endplate of intervertebral disc. It's expression has been shown to be more in nucleus pulposus compared to annulus fibrosus and recently, been shown to protect against the progression of IVD degeneration by inhibiting effects of pro-inflammatory cytokines. Similarly, intradiscal tocilizumab therapy has been studied in patients with discogenic low back pain.

\subsection{Pathophysiologic Basis of Biologic Therapies}

Key Question 5. How do regenerative medicine therapies work in the treatment of low back and extremity pain?

The components of a 3-joint theory of spinal degeneration include intervertebral disc degeneration, facet loading, and degeneration, which can lead to spinal deformity, nerve root compression and possibly central canal and/or foraminal stenoses $(17,18,112,209,210)$. Regenerative treatments for low back pain conditions have emerged over the years because of the suboptimal outcomes from conventional treatments and the population's demand for more natural and holistic medical approaches $(17,18,25,209-222)$. Both PRP and stem cells represent 2 promising regenerative therapies that are currently being used in managing low back pain and radiculopathy.

\subsection{Intervertebral Disc}

The disc is composed of the nucleus pulposus, the annulus fibrosis, and the fibrous attachments to the vertebral endplates (Sharpey's fibers). The intervertebral disc is a dynamic structure, with the disc microenvironment relying on a harmonious balance between anabolic and catabolic factors important for normal disc cell turnover (169). Growth factors including transforming growth factor- $\alpha$ (TGF- $\alpha$ ), bone morphologic proteins (BMP), growth and differentiation factor 5 (GDF5), and insulin-like growth factor (IL-GF) are examples of important anabolic factors. Conversely, catabolic metabolism is achieved by catabolic enzymes, inflammatory cytokines, proteinases, and aggrecanases, which include interleukin-1 (IL-1), tumor necrosis factor- $\alpha$ (TNF- $\alpha$ ), a disintegrin and metalloproteinase with thrombospondin motifs (ADAMTS), and matrix metalloproteinase (MMPs). Degenerated discs contain cell clusters producing matrix-degrading enzymes, including MMPs (220). Unfortunately, the disc is relatively avascular, creating a difficult microenvironment with low oxygen tension, and a paucity of nutrients for intervertebral disc cells. Thus, analogous to other cartilaginous structures, limited vascular support is a significant contributor to the poor natural regenerative capacity of intervertebral discs when metabolic homeostasis is disrupted $(18,213,223-233)$

Degenerative disc disease is defined as a diffuse, progressive, and age-related phenomenon characterized by nuclear dehydration and fibrosis with resultant disc space narrowing of approximately 3-4\% height loss per year (223). The pathophysiological mechanisms of degeneration include mechanical, biochemical, nutritional, and genetic factors contributing to a shift towards catabolic metabolism within the disc microenvironment. Hallmarks of degenerative disc disease include increased MMP activation, decreased intervertebral disc cell viability, and decreased proteoglycan production (219). The degeneration of the disc includes the development of focal fissures extending outward from the nucleus into the annulus (radial fissures) or along annular lamellae described as circumferential fissures $(18,156,223,225)$. Further disc space narrowing leads to a redistribution of axial mechanical forces on the disc and on nearby structures including the vertebral body endplates and facet joints. With progressive degeneration, the disc loses its ability to act as a shock absorber and begins to bulge, pulling on Sharpey's fibers, which leads to the development of endplate osteophytes, $(156,223,224)$. Further degenerative disc disease may or may not result in discogenic low back pain $(156,219,224)$.

Annular fissures have been described as providing a conduit for inflammatory chemical mediators to trigger nociceptive nerve endings in the outer annulus fibrosis $(156,223,225)$. In addition, nerve ingrowth proliferates along fissure sites with increasing exposure to nociceptive and mechanical stimuli. Discogenic pain develops with internal disc disruption when annular pain fibers are directly stimulated by inflammatory mediators; these fibers may also be indirectly stimulated by increased mechanical loading pressure $(18,156,223,225)$. Internal disc disruption has been shown to be present in approximately $36 \%$ to $39 \%$ of the patients $(164,165)$, whereas, discogenic pain secondary to degenerative 


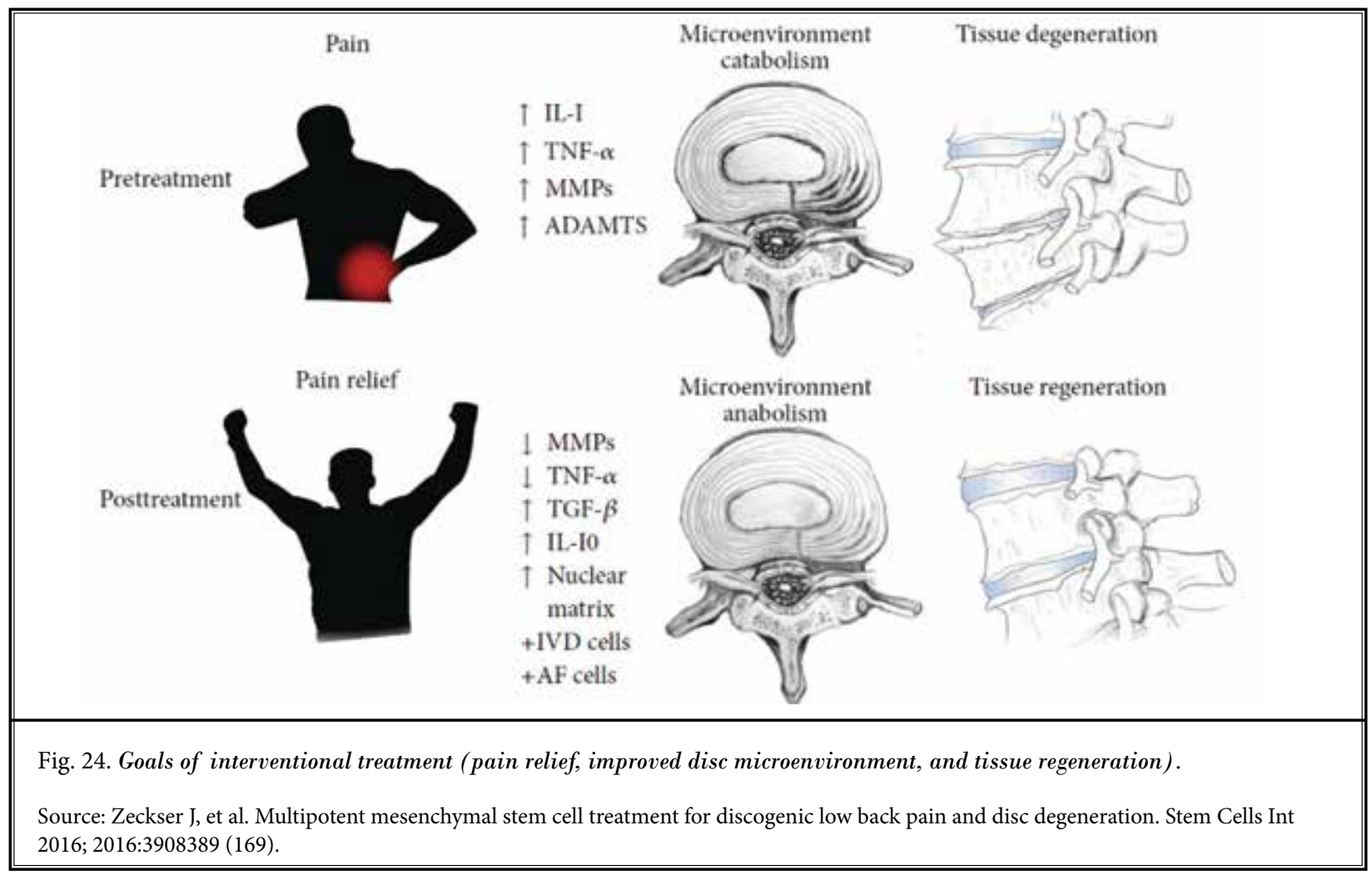

disc disease has been shown to be present in $26 \%$ of the patients (162).

Disc herniation is displacement of nuclear disc material beyond the normal confines of the nucleus, extending into and beyond the annulus to a variable degree $(156,223)$. As described earlier and as shown in Figs. 13-15, multiple stages include disc protrusion, extrusion, and sequestration. Disc herniation has been described to be the most common etiology of radicular leg pain through either mechanical compression of nerve roots or chemical radiculitis (156). In addition, disc herniation may contribute to focal low back pain as a result of the inflammation of the dural sleeve of the nerve root described as somatic referred pain, or from activation of outer annular pain fibers within the disc $(156,223)$. An alteration of the annulus may contribute to decreased disc integrity and acceleration of the degenerative disc disease (169).

Despite obvious tissue deterioration, viable cells isolated from degenerated discs have shown an ability to proliferate and differentiate in vitro, even though regeneration potential is limited (226). In fact, progenitor cells have been isolated from human degenerated discs (227), potentially derived from specific niche re- gions located near the cartilaginous endplates (228) that migrate into the disc (229). While degenerated discs exhibit necrosis, cell senescence, and apoptosis, viable cells have been identified (220). Zeckser et al (169) have stated that all interventional therapies should optimally strive to fulfill a trio of treatment objectives including the decline and/or resolution of primary nociceptive disc pain with functional improvement, slowing and/or reversal of the catabolic metabolism and associated degradation within the disc environment, and partial or complete restoration of disc tissue, as shown in Fig. 24 (169). Even though the majority of therapies in managing disc related pain have shown variable degrees of patient improvement, they still produce suboptimal outcomes because they do not fulfill the 3 criteria of Zeckser et al (169). It is hoped that regenerative techniques will lead to better outcomes by fulfilling these criteria than epidural injections with or without steroids $(8,97,106,107,111-118)$, intradiscal therapies $(18,111,230)$, surgical interventions with or without fusion $(213,232)$.

Percutaneously delivered multipotential MSCs have recently gained attention for their potential to revolutionize the treatment of discogenic low back pain. MSC 
therapy may provide the necessary cellular support for regeneration. Current research suggests that these treatments may have the ability to uniquely accomplish the 3 stated objectives for treating disc pathology as shown in Fig. 25. However, the intervertebral disc is avascular, presenting a potential impediment to the viability of intradiscal cell implantation $(26,233,234)$. Fortunately, several authors have demonstrated that regenerative techniques can lead to positive effects on intervertebral disc cell proliferation (26,235-282).

Stem cell therapy may address the underlying sources of disc degeneration by mitigating inflammation within the nucleus pulposus, rehydrating the nucleus, by remodeling the tissues or recruiting peripheral cells and nutrients, and/or by restoring the disc height to remove pressure on the adjacent nerves $(206,213,221,222)$. These effects are achieved by decelerating or reversing the degenerative process by promoting synthesis of proteoglycans and Type II collagen (213). Stem cell therapy in animal models has consistently led to increased disc height, improved magnetic resonance imaging (MRI) T2 signal intensity, decreased grade of histologic disc degeneration, and increased expression of Type II collage $(212,221)$. Ghosh et al (237) reported that the injection of mesenchymal precursor cells (MPCs) in a bovine model produced increased disc height, higher T2 MRI signal, improved histological grading scores, and restoration of the extracellular matrix or ECM. An in vitro pilot study (238) assessing autogenous MSCs from the vertebral body showed enhancement of intervertebral disc generation via paracrine interaction. Some authors have speculated that implanting MSCs into a degenerated intervertebral disc may both stimulate MSC differentiation into a nucleus pulposus or annulus fibrosus-like phenotype and stimulate the biological activation of residual viable cells within the degenerated disc for self-repair (238). Others have investigated the effect of the proinflammatorydegenerative intervertebral disc microenvironment on the regenerative and immunomodulatory behavior of mesenchymal stem-stomal cells in vivo and in vitro (239-242) and have shown viability of MSCs, active cell migration, and an increase of multiple growth factors.

A systematic review of 53 manuscripts (25) of MSC use in the treatment of spinal cord injury, intervertebral disc repair, and spinal fusion demonstrated regeneration in both mice and rats following the injections of MSCs. A significant deceleration in disc degeneration was reported beginning 2 weeks following MSC injection (243). Although equally effective, MSCs derived from bone marrow or adipose tissue survived only for 2 weeks. Another study demonstrated regeneration following bone marrow MSCs implanted into the tail discs of rodents (244), which resulted in proliferation of nucleus pulposus cells, an increase in disc height, and a decreased concentration of MSCs 4 weeks post injection. It was also shown that MSCs derived from umbilical cords were safely transplanted into patients, resulting in decreased pain and improved lumbar function (245). The comparative effects of MSCs and nucleus pulposus cells were also assessed (246). This study did not find conclusive evidence indicating MSCs were better than nucleus pulposus cells for transplantation. In contrast, multiple other studies have suggested that MSCs might work better when co-cultured (247). Further, co-transplantation of bone marrow-MSCs (BM-MSCs) and annulus fibrosus cells significantly increased Type II collagen and glycosaminoglycan expression (248). In addition, a telocollagen gel as a carrier in various studies has allowed BM-MSCs to survive up to 48 weeks while restoring disc height and water content (249). However, another carrier, hyaluronan gel, was found to have possible cytotoxic effect on MSCs and resulted in a decrease in injected cell numbers during the first 7 days, indicating hyaluronan failed to retain MSCs at the site of injection.

Regarding MSCs, Wang et al (250) demonstrated that MSCs derived from 4 origins (nucleus pulposus, annulus fibrosus, cartilage end plate, and bone marrow) showed similar capabilities to differentiate into the appropriate cell required for intervertebral disc regeneration. They suggested that any of these cell lines can be used for therapy, with convenience and quantity of extraction guiding the selection. Long-term studies of MSC intradiscal therapy are being conducted, but at this time the greatest duration of study length is 24 months.

Review of MSC use for intradiscal pathology by Valadà et al (251) describes the efficacy of intervertebral disc regeneration using stems cells from all origins (bone marrow, adipose, synovial fluid, muscle-derived stem cells, olfactory neural stem cells, induced pluripotent stem cells, hematopoietic stem cells, disc stem cells, embryonic stem cells) and tissue engineering approaches (hydrogel, viscoelastic scaffolds, and hyaluronic-based scaffolds). They conclude that patients could expect benefit from stem cell mediated therapy for mild-moderate grade intervertebral disc disease, as long as the structural integrity of the disc is preserved. There was no commentary on chronicity (251). Noriega 
et al (283) demonstrated that the injection of $25 \mathrm{x}$ $10^{10}$ allogeneic cells per disc segment achieved faster and more significant improvement than controls, and that allogeneic MSCs should be considered for patient comfort, procedural convenience, and in cases of stem cell deficiency. Pettine et al (253) showed that of 26 surgical candidates for spinal fusion or disc replacement surgery, $24(92 \%)$ were able to avoid surgery for 12 months, and 21 patients $(81 \%)$ were able to avoid surgery by 2 years following intradiscal bone marrow mesenchymal cell implantation. While no patient worsened, some improved on the MRI-based Pfirrmann grading system.

PRP may also be used for intervertebral disc degeneration, facet joint arthritis, and sacroiliac joint arthritis. While MSCs are used more commonly for intervertebral disc degeneration than PRP, inhibition of matrix degrading enzymes may occur with PRP (1719,23,174-180,211). PRP contains amplified levels of growth factors and cytokines, which stimulate tissue healing. Over the years, clinicians have hypothesized that placing a high concentration of growth factors directly at the site of collagen injury promotes their function as humeral mediators to induce the natural healing cascade $(211,254)$. An in vitro study of PRPinfused human intervertebral disc cultures supported this hypothesis and exhibited nucleus pulposus proliferation and differentiation, as well as the up regulation of proteoglycan synthesis (255). In animal models of experimentally injured intervertebral discs, treatments with intradiscal PRP have produced restoration of normal cellular architecture and disc height $(256,257)$. PRP has been postulated to have an anti-inflammatory effect. In fact, an in vitro study found that the cytokines TNF- $\alpha$ and IL-1), induced proinflammatory degrading enzymes and their mediators were suppressed with the addition of PRP into the collagen matrix of human nucleus pulposus cells (258). PRP-impregnated gelatin hydrogel injected into the degenerated intervertebral discs of a rabbit model resulted in significantly higher water content as demonstrated by MRI, which corresponded with increased intradiscal proteoglycan content, up regulated micro RNA precursors for Type II collagen, and the significant reduction in apoptotic nucleus pulposus cells (259). Additionally, in a percutaneous annulus puncture induced degenerated disc rat model, discs treated with PRP had fewer inflammatory cells, higher preservation of normal morphology, and higher fluid content on T2 MRI compared with a sham injection after 4 weeks (256).

\subsection{Facet Joints}

PRP is the biologic most commonly used in the treatment of lumbar facet joints. The platelet-derived growth factors concentrated within PRP are essential to the healing process. These growth factors increase fibroblast and/or osteoblast metabolic activity while reducing cell apoptosis; promote angiogenesis, thereby increasing blood flow and circulation to the newforming tissue; and increase the expression of the pro-collagen gene and collagen-derived growth factor, which increases the tensile strength of the new tissue $(175,176)$. Proliferative proteins present in PRP include the endothelial growth factor, platelet-derived growth factor, vascular endothelial growth factor, and B-FGF (152).

Kristjánsson and colleagues (260) showed that the MSCs harvested from facet joints and interspinous ligaments had the trilineage potential to differentiate into osteogenic, adipogenic, and chondrogenic cells under the appropriate conditions. They concluded that facet joints and interspinous ligaments could provide an alternative source of MSCs for tissue engineering applications.

At present there is very little literature regarding the application of stem cells in the treatment of facet joint and sacroiliac joint pain. There is extensive literature discussing the application of MSCs for articular cartilage regeneration. The intra-articular use of autologous MSCs represents the current state-of-the-art treatment for cartilage regeneration (261).

\subsection{Sacroiliac Joint}

There is extensive literature discussing the use and effectiveness of biologicals in the management of peripheral joint pain. These same principles may be applied to sacroiliac joint injections and sacroiliac joint ligamentous infiltration $(21,174)$.

\subsection{Effectiveness of Biologic Therapy in Chronic Low Back Pain}

Key Question 6. Are regenerative medicine therapies effective in managing chronic low back pain?

The methodology incorporated into the preparation of these guidelines includes the utilization of IOM standards for systematic review of comparative effectiveness research (262) as well as the use of additional publications relevant to systematic reviews and guideline preparation $(8,9,46,47,49,262-265)$. These guidelines focus on the effectiveness of regenerative treatment modalities in managing low back and lower 
extremity pain having a variety of etiologies. Appendix Table 1 shows the Preferred Reporting Items for Systematic Reviews and Meta-Analyses (PRISMA) criteria and Appendix Table 2 shows A Measurement Tool to Assess Systematic Reviews (AMSTAR) criteria.

\subsection{Data Sources}

The literature search was strategized based on multiple available sources including PubMed, the Cochrane library, Google searches, the FDA, the CDC, and controlled clinical trials. The search was conducted over a time frame spanning from January 2000 to June 2018.

\subsection{Search Criteria}

Search criteria extensively covered chronic low back pain of various origins and injectable biologicals including PRP and MSCs.

The search criteria was as follows:

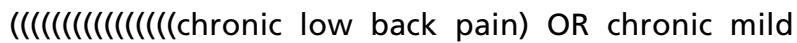
back OR upper back pain) OR disc herniation) OR discogenic pain) OR herniated lumbar discs) OR nerve root compression) OR lumbosciatic pain) OR postlaminectomy) OR lumbar surgery syndrome) OR radicular pain) $O R$ radiculitis) $O R$ sciatica) $O R$ spinal fibrosis) OR spinal stenosis) AND $((()((()($ epidural injection) OR platelet rich plasma injection or stem cell injection) OR epidural perineural injection) $O R$ interlaminar epidural) OR intraarticular platelet rich plasma OR stem cells) OR nerve root blocks) OR periradicular infiltration) OR transforaminal injection) OR platelet rich plasma OR stem cells) OR intradiscal injections or PRP or stem cells or sacroiliac joint or ligament injections or PRP or stem cells))) AND ((meta-analysis [pt] OR randomized controlled trial [pt] OR controlled clinical trial [pt] OR randomized controlled trials [mh] OR random allocation [mh] OR double-blind method [mh] OR singleblind method [mh] OR clinical trial [pt] OR clinical trials [mh] OR ("clinical trial" [tw]) OR ((singl* [tw] OR doubl* [tw] OR trebl* [tw] OR tripl* [tw]) AND (mask* [tw] OR blind* [tw])) OR (placebos [mh] OR placebo* [tw] OR random* [tw] OR research design [mh:noexp]) NOT (animals [mh] NOT human [mh])))

\subsection{Study Selection}

Study selection was based on predefined inclusion criteria where studies reported at least 3 months of outcomes assessment and included all types of studies having an appropriate description. We included intradiscal injections, all types of epidural injections, intraarticular injections of facet joints, nerve blocks, sacroiliac joint injections, and sacroiliac joint ligamentous injections.

\subsection{Data Extraction and Methodological Quality Assessment}

Data extraction and methodologic quality assessment was performed by at least 2 of the review authors independently, in an unblinded standardized manner. The quality assessment of each individual article used in this analysis was performed utilizing the Cochrane review criteria (Appendix Table 3) (266), Interventional Pain Management techniques Quality Appraisal of Reliability and Risk of Bias Assessment (IPM-QRB) criteria (Appendix Table 4) (267) for randomized controlled trials (RCTs) was used, as was the Interventional Pain Management Techniques - Quality Appraisal of Reliability and Risk of Bias Assessment for Nonrandomized Studies (IPM-QRBNR) (Appendix Table 5) (268). Utilizing the Cochrane review criteria (266) or the IPM-QRB criteria (267), or the IPM-QRBNR (268), studies that met the inclusion criteria with a score of at least 9 to 13 for the Cochrane review criteria or 32 to 48 for the IPM-QRB and the IPM-QRBNR criteria were considered high quality and scores of 5 to 8 or 16 to 31 (respectively) were considered moderate quality, whereas those sources with scores of less than 5 or 16 (respectively) were considered low quality. Due to the scarcity of the literature, all studies were included in data synthesis or analysis.

All systematic reviews and studies were reviewed by 2 authors. Any disagreements between the reviewers were resolved by a third author and consensus. If there were any conflicts of interest with a manuscript (i.e. authorship), the review authors were recused from assessment and analysis.

\subsection{Outcome of the Studies}

For the present analysis, either $50 \%$ relief from the baseline pain score or a change of at least 3 points on an 11-point pain scale of 0 to 10 or 3-point or 30-point change on Visual Analog Scale (VAS) of $10 \mathrm{~cm}$ or 100 $\mathrm{mm}$ was considered clinically significant. For functional status improvement, a change of $30 \%$ or more on disability scores or $50 \%$ improvement from baseline was considered clinically significant.

A study was judged to be positive if the relevance and effectiveness of the regenerative injection therapy of interest was demonstrated with either a control group or upon comparison from baseline to follow-up. A negative study was defined as one where no differ- 
ence was seen between the treatments or where no improvement from baseline could be measured. Reference point measurements were considered at 3 months, 6 months, and 1 year.

\subsection{Analysis of Evidence}

The analysis of the evidence was performed based on best-evidence synthesis and was modified and collated using multiple available criteria, including the Cochrane Review criteria and the United States Preventive Task Force (USPSTF) criteria as illustrated in Table 1 (49). The analysis was conducted using 5 levels of evidence ranging from strong to opinion- or consensus-based. The results of best evidence as per grading were utilized. At least 2 of the review authors independently, in an unblinded, standardized manner, analyzed the evidence. Any disagreements between reviewers were resolved by a third author and consensus was attained. If there were any conflicts of interest (e.g., authorship), these reviewers were recused from assessment and analysis.

\subsection{Meta-analysis}

The meta-analysis was performed using the Comprehensive Meta-analysis version 3.0 (Biostat Inc., Englewood, NJ). For pain and functional status improvement data, the studies were reported as standardized mean differences (SMD) with 95\% confidence intervals $(\mathrm{Cl})$. Data were plotted with forest plots to evaluate treatment effects. Heterogeneity was interpreted through $\mathrm{I}^{2}$ statistic.

Random-effects model (single-arm) meta-analysis was planned to assess net changes in the same outcome variable $(28,29)$. Heterogeneity among the effect sizes of individual studies was assessed using the $\mathrm{I}^{2}$ index and Q statistic. Heterogeneity analyzed with the $I^{2}$ statistic was defined as low (25\%-50\%), moderate (50\%-75\%), or high (>75\%) (269). Subgroup analyses were conducted based on follow-up periods (6 vs. 12 months or more) and the injected biologic solution type (MCSs vs. PRP). We conducted meta-regression analysis to identify factors related to a decrease in the pain score following therapy.

All analyses were based on each modality of treatment and the solution injected. Short-term improvement was defined as any improvement lasting for at least 3 months, and long-term improvement was described as that lasting for 6 months or longer. Metaanalysis was performed only when at least 3 studies were available and included an appropriate sample size of at least 10 for nonrandomized studies.

\subsection{Results}

Our search strategy utilizing the PRISMA flow diagram as shown in Appendix Fig. 1, illustrated published literature evaluating regenerative medicine therapies identifying 5 systematic reviews (25-29) and 26 individual manuscripts which met the criteria for inclusion (247,253,270-293). All of the individual studies were included in the recent systematic review by Sanapati et al (29) since the appropriate methodologic quality, bias assessment and utilization in qualitative and quantitative evidence synthesis of those manuscripts met the inclusion criteria.

\subsection{Systematic Reviews}

The search criteria identified 5 systematic reviews (25-29). Of these, only 1 systematic review studied MSCs in spinal cord injury, intervertebral disc repair, and spinal fusion (25). This review identified almost 2,600 manuscripts; however, only 53 met eligibility criteria. Of these, there were 28 studies on intervertebral disc repair, 6 were on spinal cord injury, and 9 were on spinal fusion. This systematic review found that MSCs were a very good source for treatment of spinal conditions. They also concluded that, despite the source of cells which has varied within the publications, the overall majority of studies used BM-MSCs. Bone marrow has been described as the gold standard of MSC origin.

The systematic review by Wang et al (27) assessed the efficacy of intervertebral disc regeneration with stem cells using a meta-analysis of animal control studies. Consequently, this study was not included in the evidence synthesis.

The 3 remaining systematic reviews $(26,27,29)$ were assessed for methodologic quality assessment by PRISMA and AMSTAR. They showed variable quality. Two systematic reviews included a single arm meta-analysis $(28,29)$ and both were of high quality by AMSTAR and PRISMA criteria. The results of the assessment are shown in Appendix Tables 6 and 7.

\subsubsection{Analysis of Systematic Reviews}

Wu et al (28) included 6 studies which were eligible for the review. From baseline to follow-up, they reported a 44.2-point decrease in the pooled mean difference in pain scores, and a 32.2 point pooled mean difference in the Oswestry Disability Index (ODI) with no adverse effects. In view of the improved pain relief and disability scores, they concluded that cell-based therapy is an option for patients who have discogenic low back pain. 
However, they recommended that stringently designed, randomized, double blind clinical trials with appropriately determined sample sizes will be needed to confirm the clinical efficacy and safety of cell-based therapy.

In their analysis, Wu et al (28) reported that 3 studies $(253,270,271)$ used stem cells, 3 studies used chondrocytes $(247,272,273), 5$ studies used expanded cells $(247,270-273)$ and 1 study used unexpanded cells (253) that were injected into the lumbar disc with a cell dose range from 1 to $23 \pm 5$ million cells. The mean follow-up time among the 6 trials $(247,253,270-273)$ was 22 months. In 5 of these studies, the post-treatment clinical outcomes were assessed with the Numeric Rating Scale (NRS) and the Visual Analog Scale (VAS) $(253,270,271,273)$.

Wu et al (28) also conducted a subgroup analysis to explore the source of heterogeneity in pain scores with respect to the follow-up periods (6 months vs. $\geq 12$ months), the injected cell type (stem cell vs. chondrocyte), and the cell preprocessing conditions (expanded vs. non-expanded). Their analysis demonstrated no difference in the decreased pain score among these variables (28). Subsequent metaregression analysis to determine factors that were related to the decrease in pain scores following stem cell therapy showed that the pain score decrease was related to cell type (stem cells vs. chondrocytes), with stem cells being more effective than chondrocytes in reducing pain.

In this same systematic review, Wu et al (28) also reviewed the MRI examinations. Four trials had reviewed the post-treatment MRIs for identification of any interval changes $(247,271-273)$. One study found improvements in the post-treatment disc contour or height (272). Another study assessed the ratio of fluid content in affected discs compared to healthy discs and found that this ratio was low at the beginning of the treatment, was unchanged at 6 months, but showed an increase by 12 months (271). One study found a substantially higher normalization of disc fluid content $(41 \%)$ in the autologous cultured disc derived chondrocyte treated group when compared with the control group (25\%) (273). Another study (247) identified stability in the post-treatment MRI findings that extended over 3 years.

In a systematic review of regenerative therapies for intervertebral disc degeneration by Basso et al (26), identified 3 manuscripts that involved the use of PRP, and 4 manuscripts that involved the use of stem cells. Of the 7 manuscripts, $3(247,271,281)$ manuscripts were included in the systematic review by Wu et al (28). The number of patients included in these studies varied from 8 to 86 . Five of the studies had very small sample sizes. Only 2 studies had larger sample sizes, 47 and 86. Timing of the follow-up examination was variable, extending from 8 weeks to 2 years. All of the studies reported that the intradiscal injection of PRP was safe and effective in relieving pain and increasing function. It should be kept in mind that the majority of these studies were small, observational reports or case series and, therefore, provide limited evidence for PRP injection therapy in the management of discogenic pain. The results of the various studies by Basso et al (26), are included in our tables which summarize the literature for PRP use in the treatment of intervertebral disc degeneration.

Sanapati et al (29) identified 26 manuscripts, of which 23 met the criteria for inclusion $(247,253,270$ 293) $(253,271-281,283-293)$ following the removal of duplicate publications $(253,281)$. Three studies using stem cell therapy were excluded due to a sample size of fewer than 10 participants $(247,270,282)$. Of the remaining 20 studies, 1 utilized 3 modalities of treatment (278). Results indicated Level III evidence for disc injections of PRP and MSCs, and Level IV evidence for epidural injections, lumbar facet joint injections, and sacroiliac joint injections. However, single arm metaanalysis was performed only for disc injections and epidural injections.

\subsection{Analysis of Individual Studies}

All the initial 26 manuscripts available for inclusion $(247,253,270-293)$ were considered by Sanapati et al (29) with rigorous assessment for the inclusion criteria, methodologic quality, and risk of bias assessment and for inclusion in qualitative and quantitative analyses incorporating best evidence synthesis using a single arm meta-analysis. Consequently, no additional analysis was performed.

Based on the recent systematic review by Sanapati et al (29), including all the available manuscripts, and due to lack of any other manuscripts, no analysis of individual studies was conducted and the data from Sanapati et al was adapted.

\subsection{Evidence Analysis and Synthesis}

Evidence analysis and synthesis was performed for lumbar discogenic pain, lumbar facet joint pain, and sacroiliac joint pain. This evidence was adapted from the systematic reviews of Sanapati et al (29), Wu et al (28), and Basso et al (26). There was no additional evidence for inclusion. Summary characteristics of the 
Table 7. Characteristics and outcomes of studies of PRP in intervertebral disc degeneration.

\begin{tabular}{|c|c|c|c|}
\hline Study Details & $\begin{array}{l}\text { Chronicity of Injury } \\
\text { and Biologic Used }\end{array}$ & $\begin{array}{l}\text { Follow-up } \\
\text { Period }\end{array}$ & Conclusions \\
\hline $\begin{array}{l}\text { Tuakli-Wosornu et al, } 2016 \text { (277) } \\
\text { Lumbar discogenic pain } \\
\text { Prospective, double-blind, } \\
\text { randomized controlled study, } \mathrm{n}=47\end{array}$ & $\begin{array}{l}\text { Chronic } \\
\text { PRP injections }\end{array}$ & One year & $\begin{array}{l}\text { Intradiscal injections of PRP } \mathrm{x} 1 \text { showed significant } \\
\text { improvement at } 8 \text {-week follow-up, with maintained } \\
\text { improvement compared to controls at 1-year } \\
\text { follow-up. }\end{array}$ \\
\hline $\begin{array}{l}\text { Monfett et al, } 2016 \text { ( } 276 \text { ) } \\
\text { Lumbar discogenic pain, lumbar } \\
\text { disc degeneration } \\
\text { Prospective trial, } n=29\end{array}$ & $\begin{array}{l}\text { Chronic } \\
\text { PRP injections }\end{array}$ & 2 years & $\begin{array}{l}\text { Intradiscal PRP injections show continued safety } \\
\text { and improvements in pain and function at } 2 \text { years } \\
\text { post-procedure }\end{array}$ \\
\hline $\begin{array}{l}\text { Navani et al, } 2018 \text { (274) } \\
\text { Lumbar discogenic pain } \\
\text { Prospective case series } n=20\end{array}$ & $\begin{array}{l}\text { Chronic } \\
\text { PRP, single injection, } 2 \mathrm{~mL} \\
\text { injected up to } 3 \text { disc levels }\end{array}$ & 18 months & $\begin{array}{l}\text { At } 18 \text { months, } 15 \text { patients remained for survey } \\
\text { compared to } 18 \text { patients surveyed at } 6 \text { months: } \\
>50 \% \text { relief in VAS in } 93 \% \text { of patients at } 18 \text { months } \\
(\mathrm{n}=14 / 15) \text { and in } 94 \% \text { of patients }(\mathrm{n}=17 / 18) \text { at } 6 \\
\text { months }(2) \text {. Improvement in SF- } 36 \text { scores in } 93 \% \text { of } \\
\text { patients at } 18 \text { months }(\mathrm{n}=14 / 15) \text { compared to } 100 \% \\
(\mathrm{n}=18 / 18) \text { at } 6 \text { months. }\end{array}$ \\
\hline $\begin{array}{l}\text { Akeda et al, } 2017 \text { (279) } \\
\text { Lumbar discogenic pain } \\
\text { Preliminary clinical trial, } \mathrm{n}=14\end{array}$ & $\begin{array}{l}\text { Chronic } \\
\text { PRP injections }\end{array}$ & 12 months & $\begin{array}{l}\text { Intradiscal injection of autologous PRP releasate in } \\
\text { patients with low back pain was safe with no adverse } \\
\text { events observed during follow-up } \\
\text { The results showed reduction in mean pain scores } \\
\text { at one month, sustained throughout the observation } \\
\text { periods of } 6 \text { months and } 12 \text { months. }\end{array}$ \\
\hline $\begin{array}{l}\text { Levi et al, } 2016 \text { (275) } \\
\text { Lumbar discogenic pain } \\
\text { Prospective trial, } \mathrm{n}=8\end{array}$ & $\begin{array}{l}\text { Chronic } \\
\text { PRP, single injection }\end{array}$ & 6 months & $\begin{array}{l}\text { Single or multiple levels (up to } 5 \text { ) of discogenic pain } \\
\text { injected with PRP showed encouraging improvement, } \\
\text { with more patients developing improvement over time. } \\
\text { Cohort up to } 6 \text { months. }\end{array}$ \\
\hline $\begin{array}{l}\text { Kirchner and Anitua, } 2016 \text { (278) } \\
\text { Lumbar disc degeneration } \\
\text { Observational retrospective pilot } \\
\text { study, } \mathrm{n}=86\end{array}$ & $\begin{array}{l}\text { Chronic } \\
\text { PRGF-Endoret }\end{array}$ & 6 months & $\begin{array}{l}\text { Fluoroscopy-guided infiltrations of intervertebral discs } \\
\text { and facet joints with PRGF in patients with chronic } \\
\text { low back pain resulted in significant pain reduction } \\
\text { assessed by VAS. } \\
\text { The results showed reduction of the VAS over time. } \\
\text { The study ended at } 6 \text { months with } 91 \% \text { of the patients } \\
\text { showing an excellent score, } 8.1 \% \text { showing moderate } \\
\text { improvement, and } 1.2 \% \text { showing lack of response. }\end{array}$ \\
\hline
\end{tabular}

PRP=platelet-rich plasma; PRGF = plasma rich in growth factors; VAS = Visual Analog Scale; SF-36= 36-item Short Form Survey

Adapted from: Sanapati J, et al. Do regenerative medicine therapies provide long-term relief in chronic low back pain: A systematic review and metaanalysis. Pain Physician 2018; in press (29).

included studies are described in Tables 7-11. Methodologic quality assessment of all the manuscripts are shown in Tables 12-14.

\subsubsection{Lumbar Disc Injections}

\subsubsection{Platelet-Rich Plasma}

Both the methodologic quality assessment and the risk of bias assessment have shown that the RCT (277) was of high quality based on the Cochrane review criteria and the IPM-QRB criteria as demonstrated in Tables 12 and 13 (29). All of the observational studies were of moderate quality $(274-276,278,279)$ as assessed by the IPM-QRBNR criteria and as depicted in Table 14 (29).

Study characteristics are described in Table 7. Since there was only 1 RCT meeting the criteria (277), a 2-arm 


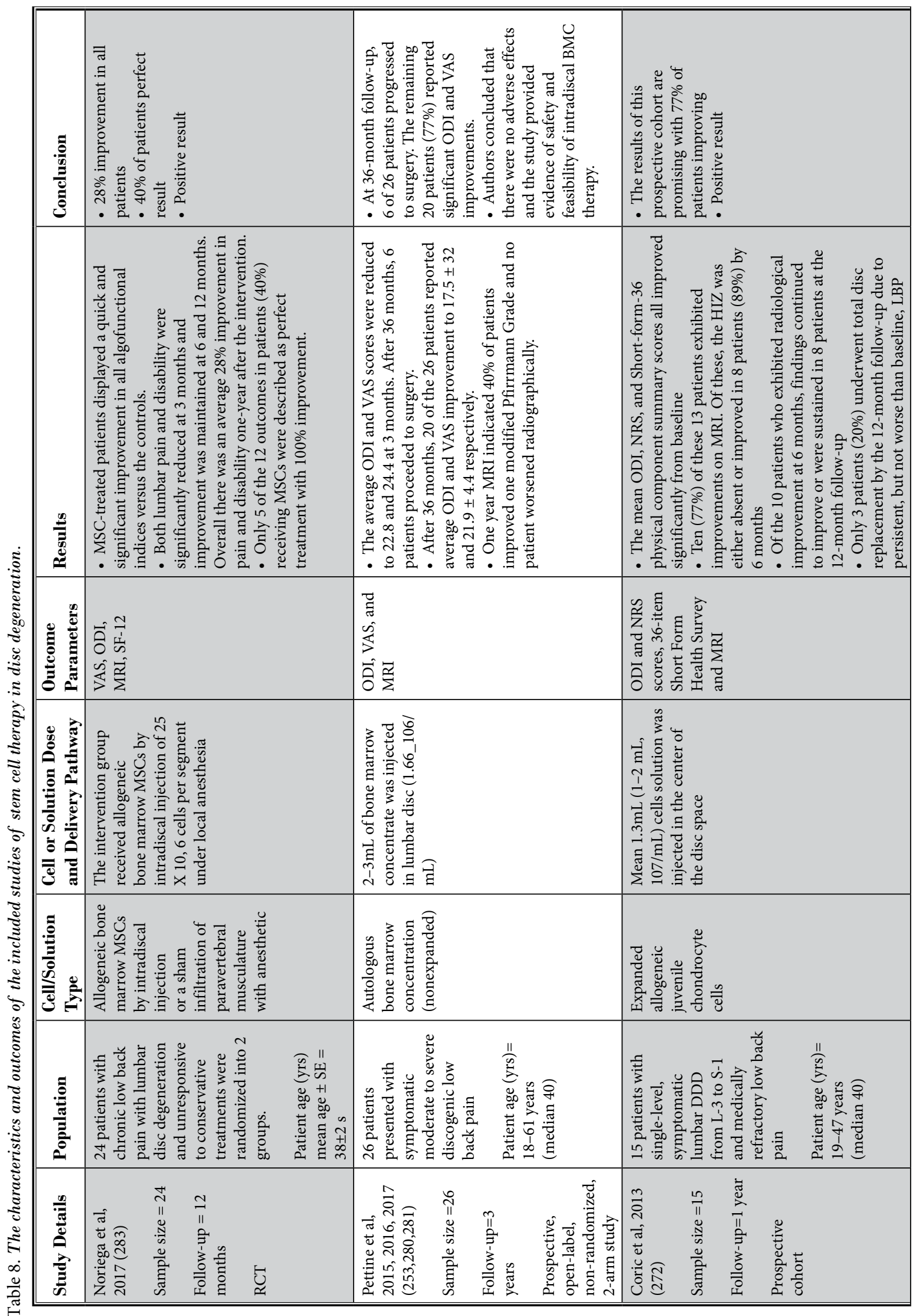

www.painphysicianjournal.com 


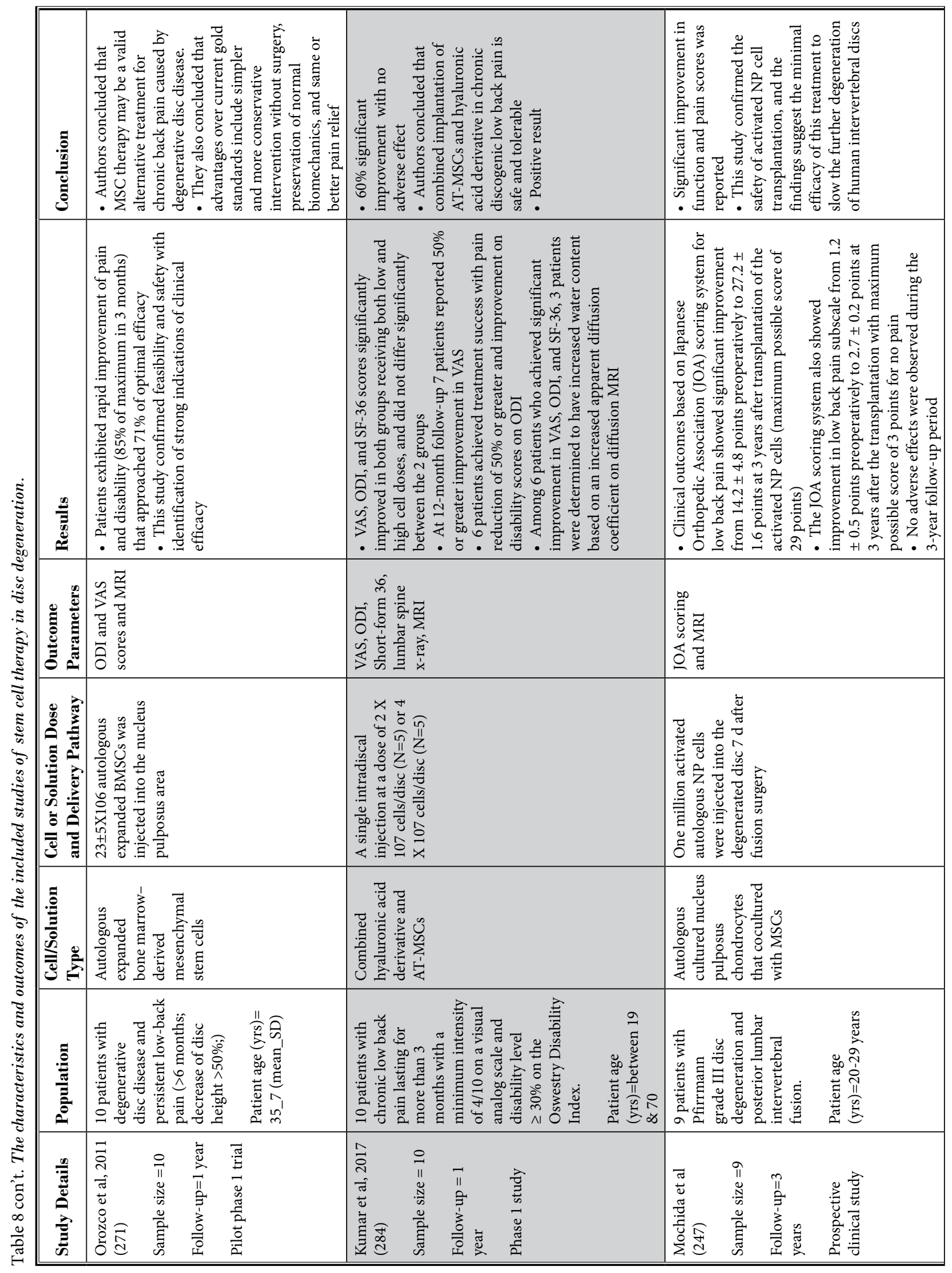




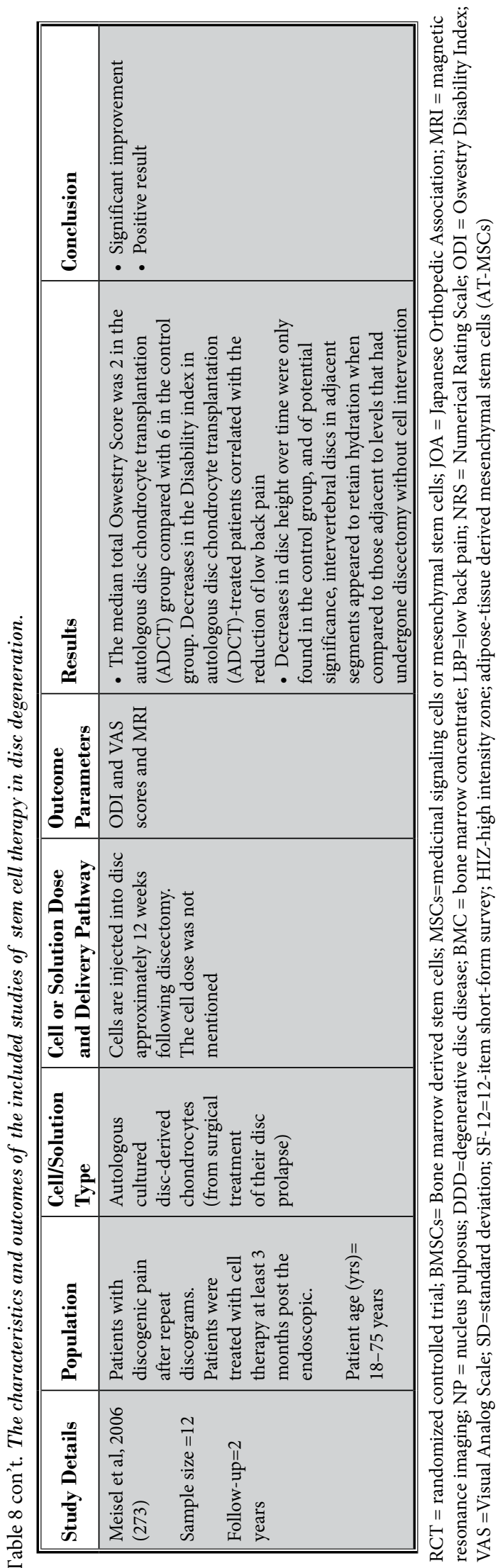

meta-analysis was not feasible (29). Thus, a single-arm meta-analysis was performed which included all of the studies. Since the study details of the RCT were only available through 8 weeks, the data from the RCT was not included in the long-term assessment. Figure 26 shows the single-arm meta-analysis from the decreased pain score data obtained after the 6-month follow-up evaluation. With a pooled sample size of 171, 5 of the studies demonstrated a decrease in the pain scores following treatment $(274-276,278,279)$. The pooled mean difference in pain scores from baseline to 6-month follow-up was $40.29 \pm 13.76$ points $(95 \% \mathrm{Cl}$ : -67.25 to $\left.-13.33, P<0.001, I^{2} 93.3 \%\right)$. Heterogeneity across the studies was high $\left(1^{2}=98 \%\right)$.

Figure 26 shows the pain relief data obtained from the 12-month follow-up evaluation. Three studies with a pooled sample size of 63 , were included and demonstrated a decrease in post-treatment pain scores $(274,276,279)$. The pooled mean difference in pain scores from baseline to 12-month follow-up was $34.405 \pm 6.879$ points (95\% Cl: -47.88 to $-20.92, P<0.013, \mathrm{I}^{2} 77.2 \%$ ). Heterogeneity across the studies was high $\left(1^{2}=77 \%\right)$. The authors of the 3 studies utilized different tools for functional improvement, and detailed data from their findings was not available. As a result, a meta-analysis of functional improvement data was not feasible.

\subsubsection{Medicinal Signaling Cells or Mesenchymal Stem Cells}

A total of 9 manuscripts studying MSCs as cellbased therapies for lumbar discogenic low back pain $(247,253,270-273,280-284)$ were identified (29). Of these, there was one RCT (283). Three manuscripts reported data from only a single study $(253,280,281), 2$ studies had a small sample size of only 2 patients each $(270,282)$, and 1 study had a sample size of 9 patients (247). Consequently, only 6 studies met the inclusion criteria $(271-273,280,283,284)$. The methodologic quality and risk of bias assessment of these studies showed high quality evidence for the RCT (283) based on both the Cochrane review and the IPM-QRB criteria as shown in Tables 12 and 13 (29). Five of the observational studies that met inclusion criteria showed moderate quality (271-273,280,284) utilizing the IPM-QRBNR criteria as shown in Table 14 (29).

Table 8 breaks down the characteristics and outcomes of these MCS therapy for lumbar discogenic pain studies (29).

Because Sanapati's et al's (29) systematic review contained data from only a single RCT (283), a 2-arm 


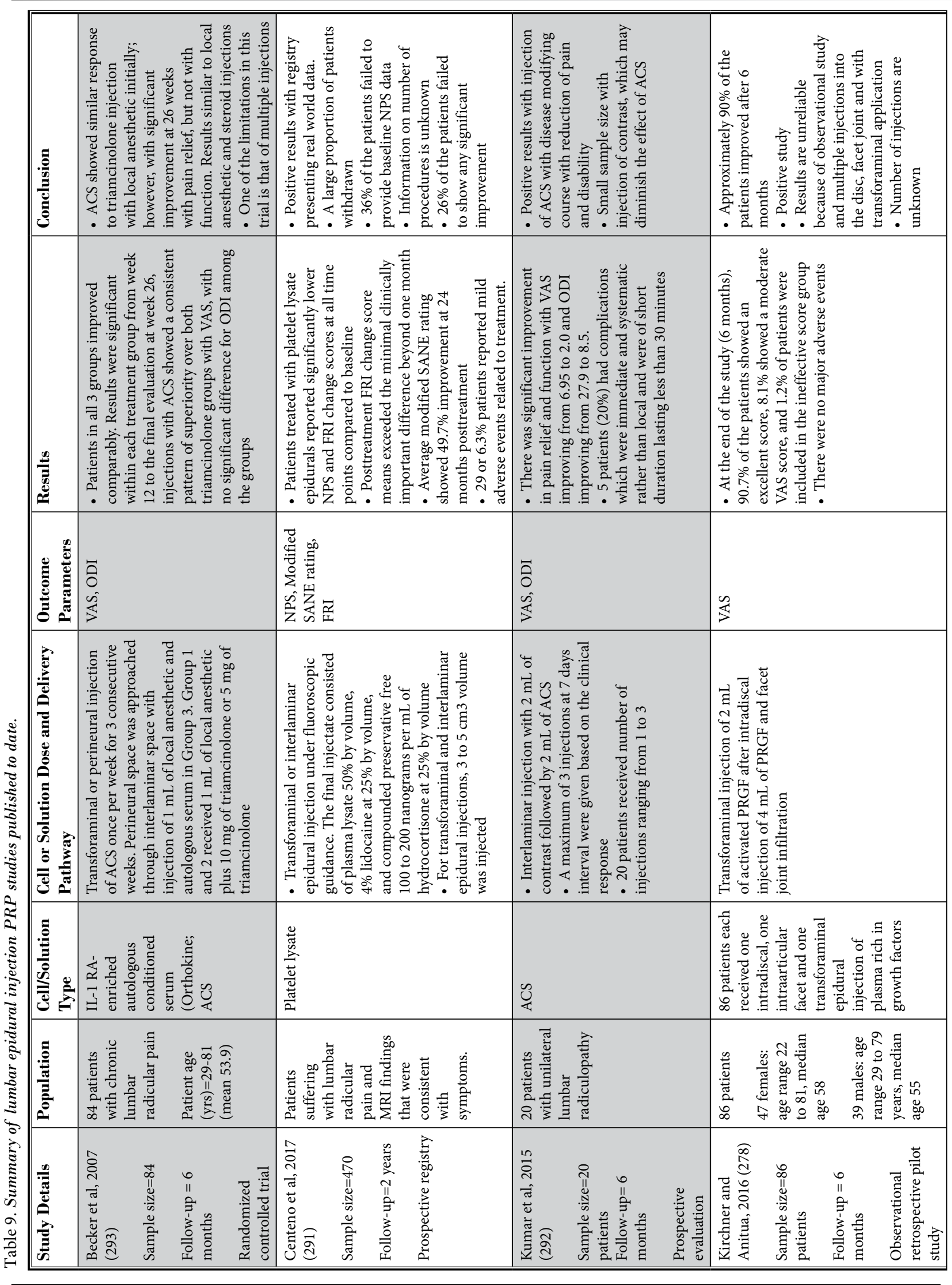




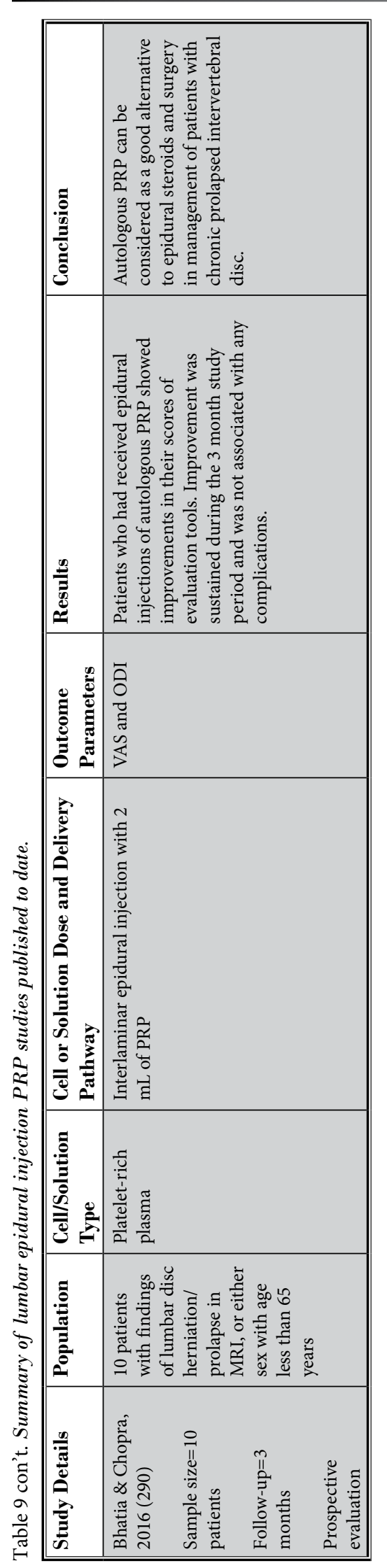

meta-analysis was not feasible. They performed a single-arm meta-analysis utilizing the 6 available studies in addition to the single RCT $(271-273,280,283,284)$. Inclusion of these 6 studies revealed a pooled sample size of $71(271-273,281,283,284)$.

Based on a single arm meta-analysis, Fig. 27 plots the changes in the pain scores $(271-273,281,283,284)$. The pooled mean difference in the decreased pain scores from baseline to the 12 month follow-up was 36.943 points $(95 \% \mathrm{Cl}$ : -49.855 to $-24.030, P<0.001$. Heterogeneity across the studies was high $\left(I^{2}=86 \%\right)$.

Figure 28 shows the functional scores. Six studies reported an ODI assessment $(271-273,281,283,292)$. This data was available over 12 months. The pooled mean difference in the decreased disability scores from baseline to the 12-month follow-up was 26.342 points (95\% $\mathrm{Cl}$ : -32.359 to $-20.325, P<0.001)$. Heterogeneity across the studies was moderate $\left(I^{2}=55 \%\right)$.

\subsubsection{Epidural Injections}

Multiple biologics have been administered epidurally in the management of radicular pain $(278,290-293)$. However, only preliminary data is available for these studies. There has been only 1 randomized, double blind, reference-controlled study that has evaluated epidurally administered biologics for the treatment of radicular pain (293). The others have been prospective or retrospective observational studies (278,290-292). The only systematic review assessing epidural biologic injections was performed by Sanapati et al (29). Methodologic quality and risk of bias assessment of their included studies (29) showed that one RCT was of high quality (293) based on the Cochrane review and the IPM-QRB criteria as shown in Tables 12 and 13. The assessment of observational studies by the IPM-QRBNR demonstrated moderate quality for each of these studies as shown in Table 14 (278,290-292).

Since there was only 1 randomized, double-blind, controlled trial (293), a 2-arm systematic review was not feasible (29). Consequently, a single-arm systematic review and meta-analysis was performed (Fig. 29) (29).

Table 9 shows summary characteristics of lumbar epidural injections of PRP studies.

\subsubsection{Lumbar Facet Intraarticular Injections}

The literature search by Sanapati et al (29) regarding the use of regenerative therapies for lumbar facet joint pain yielded 3 studies that assessed the role of PRP in lumbar facet joint injections $(278,285,286)$. Of these 3 studies, only 1 study was randomized in its comparison of 
Table 10. Summary of lumbar facet joint PRP studies published to date.

\begin{tabular}{|c|c|c|c|}
\hline Study Details & Methods & Results & Conclusion \\
\hline $\begin{array}{l}\text { Wu et al, } 2017 \text { (286) } \\
\text { Sample size }=46 \\
\text { Follow-up=6 months } \\
\text { Prospective randomized trial } \\
\text { Chronic facet joint pain }\end{array}$ & $\begin{array}{l}46 \text { patients with lumbar facet } \\
\text { syndrome were randomized } \\
\text { to intra-articular injections } \\
\text { of PRP versus local } \\
\text { anesthetic/corticosteroid } \\
\text { Outcomes were assessed } \\
\text { with VAS, ODI, and RMDQ }\end{array}$ & $\begin{array}{l}\text { - Back pain improved in both groups } \\
\text { immediately and at one month follow-up } \\
\text { - At } 3 \text { months, back pain relief was superior } \\
\text { in PRP injection group compared to steroid } \\
\text { group } \\
\text { - Functional status improvement was } \\
\text { observed in both groups; however, at } 3 \\
\text { months, there was significant improvement } \\
\text { in PRP group compared to steroid group } \\
\text { - Highest objective success rate with over } \\
50 \% \text { pain relief in } 81 \% \text { was found at } 3 \text { and } \\
6 \text { months after treatment, whereas highest } \\
\text { success rate in } 85 \% \text { of the patients in the } \\
\text { steroid group dissipated after one month } \\
\end{array}$ & $\begin{array}{l}\text { - There was significant } \\
\text { improvement in both } \\
\text { groups in short-term. } \\
\text { However, improvement was } \\
\text { long lasting for } 6 \text { months in } \\
\text { PRP group } \\
\text { - Positive study } \\
\text { - Limited with a small } \\
\text { number of patients }\end{array}$ \\
\hline $\begin{array}{l}\text { Wu et al, } 2016 \text { (285) } \\
\text { Sample size }=19 \\
\text { Follow-up=3 months } \\
\text { Prospective clinical evaluation } \\
\text { Chronic facet joint pain }\end{array}$ & $\begin{array}{l}19 \text { patients with lumbar } \\
\text { facet syndrome given intra- } \\
\text { articular injections of PRP } \\
\text { Outcomes were assessed } \\
\text { with VAS, ODI, and RMDQ }\end{array}$ & $\begin{array}{l}\text { - } 79 \% \text { of the patients reported satisfactory } \\
\text { improvement with good or excellent at } 3 \\
\text { month follow-up after injection of PRP } \\
\text { - ODI and RMDQ were also significantly } \\
\text { improved. There were no adverse events. } \\
\text { A positive small study of intraarticular } \\
\text { injection of autologous PRP }\end{array}$ & $\begin{array}{l}\text { Positive results in a study } \\
\text { with a small number of } \\
\text { patients and relatively short } \\
\text { follow-up of } 3 \text { months }\end{array}$ \\
\hline $\begin{array}{l}\text { Kirchner and Anitua, } 2016 \text { (278) } \\
\text { Sample size }=86 \\
\text { Follow-up = } 6 \text { months } \\
\text { Observational retrospective pilot } \\
\text { study, } n=86 \text { humans } \\
\text { Facet Joint Syndrome }\end{array}$ & $\begin{array}{l}\text { One intradiscal, one intra- } \\
\text { articular facet, and one } \\
\text { transforaminal epidural } \\
\text { injection of PRGF under } \\
\text { fluoroscopic guidance- } \\
\text { control were carried out in } \\
86 \text { patients with chronic LBP. }\end{array}$ & $\begin{array}{l}\text { VAS showed a statistically significant drop } \\
\text { at } 1,3 \text {, and } 6 \text { months after the treatment } \\
(P<0.0001) \text { except for the pain reduction } \\
\text { between the 3rd and } 6 \text { th month whose } \\
\text { signification was lower }(P<0.05) \text {. }\end{array}$ & $\begin{array}{l}\text { - Positive study with } \\
\text { multiple drawbacks with } \\
\text { multiple injections in } \\
\text { each setting with injection } \\
\text { into disc, facet joint, and } \\
\text { epidural space } \\
\text { - Extremely high positive } \\
\text { results in a low quality } \\
\text { observational study }\end{array}$ \\
\hline
\end{tabular}

VAS=visual analog scale; ODI=Oswestry Disability Index; RMDQ=Roland Morris Disability Questionnaire; PRP=platelet-rich plasma;

$\mathrm{PRGF}=$ platelet-rich growth factor; $\mathrm{LBP}=$ low back pain

Adapted from: Sanapati J, et al. Do regenerative medicine therapies provide long-term relief in chronic low back pain: A systematic review and metaanalysis. Pain Physician 2018; in press (29).

PRP to a local anesthetic combined with a corticosteroid (286). The methodologic quality assessment of lumbar facet intraarticular injections demonstrated that the single RCT (286) was of high quality by the Cochrane review quality and the IPM-QRB criteria as shown in Tables 12 and 13 . The remaining 2 studies $(278,285)$ demonstrated moderate quality based on the IPM-QRBNR criteria as shown in Table 14. Of the 3 studies, 2 were performed by the same group of authors and had sample sizes of 19 (285) and 46 (286). The third study performed by Kirchner and Anitua (278) was a complicated study using multiple injections (intradiscal, facet joint, as well as transforaminal) and reported excellent results. Because of the limitations of these 3 studies, a meta-analysis could not be performed. The summary characteristics of these studies are listed in Table 10.

\subsubsection{Sacroiliac Joint Injection}

The effectiveness of biologicals, specifically PRP, has been evaluated by 1 RCT (287) and 2 observational studies $(288,289)$. The methodologic quality and risk of bias assessment of sacroiliac joint injections showed that the RCT (287) was of high quality based on the Cochrane review criteria and was of moderate quality based on the IPM-QRB criteria as shown in Tables 12 and 13 . Of the 2 observational studies $(288,289), 1$ study was of moderate quality (288) while the second study one was of low quality (289) as shown in Table 14.

Because of the minimal number of studies with only 1 study performed as an RCT (287-289), a metaanalysis could not be performed. Table 11 describes a summary of the studies of sacroiliac joint PRP injections. 
Table 11. Summary of sacroiliac joint injection PRP studies published to date.

\begin{tabular}{|c|c|c|c|}
\hline Study Details & Methods & Results & Conclusion \\
\hline $\begin{array}{l}\text { Singla et al, } 2017 \text { (287) } \\
\text { Sample size }=40 \\
\text { Follow-up=3 months } \\
\text { Prospective, randomized open } \\
\text { blinded endpoint study } \\
\text { Chronic low back pain with } \\
\text { sacroiliac joint pathology }\end{array}$ & $\begin{array}{l}\text { Patients were randomized into } 2 \text { groups } \\
\text { with one group receiving } 1.5 \mathrm{~mL} \text { of } \\
\text { methylprednisolone } 40 \mathrm{mg} / \mathrm{mL} \text { and } \\
1.5 \mathrm{~mL} \text { of } 2 \% \text { lidocaine with } 0.5 \mathrm{~mL} \text { of } \\
\text { saline, whereas, PRP group receiving } 3 \\
\text { mL of leukocyte free PRP with } 0.5 \mathrm{~mL} \\
\text { of calcium chloride with ultrasound } \\
\text { guided sacroiliac joint injection } \\
\text { Outcomes were assessed with VAS } \\
\text { scores, ODI, and SF-12 }\end{array}$ & $\begin{array}{l}\text { - At 3-month follow-up, } 90 \% \text { of the } \\
\text { patients reported satisfactory relief } \\
\text { with PRP; whereas, satisfactory relief } \\
\text { was observed in } 25 \% \text { of the patients } \\
\text { receiving steroids. } \\
\text { - A strong association was observed } \\
\text { in patients receiving PRP and showing } \\
\text { a reduction of VAS of greater than } 50 \% \\
\text { from baseline }\end{array}$ & $\begin{array}{l}\text { - Positive first } \\
\text { prospective, randomized } \\
\text { study } \\
\text { - Small number of } \\
\text { patients }\end{array}$ \\
\hline $\begin{array}{l}\text { Navani \& Gupta, } 2015 \text { (288) } \\
\text { Sample size }=10 \text { ( } 4 \text { males, } 6 \\
\text { females) with sacroiliac joint pain } \\
\text { of greater than } 6 \text { months duration } \\
\text { Age Distribution }=5 \text { patients } \\
\text { below } 40 \text { and } 5 \text { patients over } 40 \\
\text { Sacroiliac joint pain }\end{array}$ & $\begin{array}{l}\text { Sacroiliac joint injection under } \\
\text { fluoroscopic guidance with PRP }\end{array}$ & $\begin{array}{l}\text { - All patients improved } 3 \text { months post } \\
\text { injection and maintained low pain levels } \\
\text { not requiring any additional treatment } \\
\text { up to } 6 \text { months post injection } \\
\text { - SF- } 36 \text { demonstrated improvement } \\
\text { in both physical component summary } \\
\text { scores and mental component summary } \\
\text { scores in all patients } \\
\text { - No adverse events }\end{array}$ & $\begin{array}{l}\text { A positive case series of } \\
10 \text { patients }\end{array}$ \\
\hline $\begin{array}{l}\text { Ko et al, } 2017 \text { (289) } \\
\text { Sample size }=4 \\
\text { Follow-up }=2 \text { yrs. } \\
\text { Case series }\end{array}$ & $\begin{array}{l}\text { Sacroiliac joint injection with PRP } \\
\text { under ultrasound } \\
\text { Outcomes were assessed with Short } \\
\text { form, McGill Pain Questionnaire, } \\
\text { NRS, and ODI }\end{array}$ & $\begin{array}{l}\text { - At } 12 \text {-month follow-up there was } \\
\text { marked improvement in joint stability, a } \\
\text { statistically significant reduction in pain, } \\
\text { and improvement in quality of life } \\
\text { - The clinical benefits of PRP were still } \\
\text { significant at } 4 \text { years post treatment }\end{array}$ & $\begin{array}{l}\text { PRP showed long lasting } \\
\text { positive results in this } \\
\text { short case series of } 4\end{array}$ \\
\hline
\end{tabular}

$\mathrm{PRP}=$ platelet-rich plasma; SF-36=36-item short form health survey; VAS=Visual Analog Scale; ODI=Oswestry Disability Index; SF-12=12-item short form health survey; NRS=Numeric Rating Scale

Adapted from: Sanapati J, et al. Do regenerative medicine therapies provide long-term relief in chronic low back pain: A systematic review and metaanalysis. Pain Physician 2018; in press (29).

Table 12. Methodological quality assessment of randomized trials utilizing Cochrane review criteria.

\begin{tabular}{|l|c|c|c|c|c||}
\hline & $\begin{array}{c}\text { Tuakli-Wosornu } \\
\text { et al (277) }\end{array}$ & $\begin{array}{c}\text { Becker et } \\
\text { al (293) }\end{array}$ & $\begin{array}{c}\text { Wu et al } \\
(\mathbf{2 8 6})\end{array}$ & $\begin{array}{c}\text { Singla et } \\
\text { al (287) }\end{array}$ & $\begin{array}{c}\text { Noriega et } \\
\text { al (283) }\end{array}$ \\
\hline Randomization adequate & $\mathrm{Y}$ & $\mathrm{Y}$ & $\mathrm{Y}$ & $\mathrm{Y}$ & $\mathrm{Y}$ \\
\hline Concealed treatment allocation & $\mathrm{Y}$ & $\mathrm{Y}$ & $\mathrm{Y}$ & $\mathrm{Y}$ & $\mathrm{Y}$ \\
\hline Patient blinded & $\mathrm{Y}$ & $\mathrm{Y}$ & $\mathrm{Y}$ & $\mathrm{Y}$ & $\mathrm{Y}$ \\
\hline Care provider blinded & $\mathrm{Y}$ & $\mathrm{N}$ & $\mathrm{Y}$ & $\mathrm{N}$ & $\mathrm{N}$ \\
\hline Outcome assessor blinded & $\mathrm{Y}$ & $\mathrm{Y}$ & $\mathrm{Y}$ & $\mathrm{Y}$ & $\mathrm{Y}$ \\
\hline Drop-out rate described & $\mathrm{Y}$ & $\mathrm{Y}$ & $\mathrm{Y}$ & $\mathrm{Y}$ & $\mathrm{Y}$ \\
\hline All randomized participants analyzed in the group & $\mathrm{Y}$ & $\mathrm{Y}$ & $\mathrm{Y}$ & $\mathrm{Y}$ \\
\hline Reports of the study free of suggestion of selective outcome reporting & $\mathrm{Y}$ & $\mathrm{Y}$ & $\mathrm{Y}$ & $\mathrm{Y}$ & $\mathrm{Y}$ \\
\hline $\begin{array}{l}\text { Groups similar at baseline regarding most important prognostic } \\
\text { indicators }\end{array}$ & $\mathrm{Y}$ & $\mathrm{Y}$ & $\mathrm{Y}$ & $\mathrm{Y}$ & $\mathrm{Y}$ \\
\hline Co-interventions avoided or similar & $\mathrm{Y}$ & $\mathrm{Y}$ & $\mathrm{Y}$ & $\mathrm{Y}$ & $\mathrm{Y}$ \\
\hline Compliance acceptable in all group & $\mathrm{Y}$ & $\mathrm{Y}$ & $\mathrm{Y}$ & $\mathrm{Y}$ & $\mathrm{Y}$ \\
\hline Time of outcome assessment in all groups similar & $\mathrm{Y}$ & $\mathrm{Y}$ & $\mathrm{Y}$ & $\mathrm{Y}$ \\
\hline Are other sources of potential bias likely & $\mathrm{Y}$ & $\mathrm{Y}$ & $\mathrm{Y}$ & $\mathrm{Y}$ & $\mathrm{Y}$ \\
\hline Score & $13 / 13$ & $12 / 13$ & $13 / 13$ & $12 / 13$ & $12 / 13$ \\
\hline
\end{tabular}

$\mathrm{Y}=$ Yes; $\mathrm{N}=$ No; $\mathrm{U}=$ Unclear

Adapted from: Sanapati J, et al. Do regenerative medicine therapies provide long-term relief in chronic low back pain: A systematic review and metaanalysis. Pain Physician 2018; in press (29). 
Pain Physician: Guidelines Issue 2019; 22:S1-S74

Table 13. Methodologic quality assessment of randomized trials utilizing IPM-QRB.

\begin{tabular}{|c|c|c|c|c|c|c|}
\hline & & $\begin{array}{l}\text { Tuakli- } \\
\text { Wosornu } \\
\text { et al (277) }\end{array}$ & $\begin{array}{l}\text { Becker et } \\
\text { al (293) }\end{array}$ & $\begin{array}{l}\text { Wu et al } \\
(286)\end{array}$ & $\begin{array}{l}\text { Singla et } \\
\text { al (287) }\end{array}$ & \begin{tabular}{|l} 
Noriega \\
et al \\
$(\mathbf{2 8 3})$ \\
\end{tabular} \\
\hline I. & TRIAL DESIGN AND GUIDANCE REPORTING & & & & & \\
\hline 1. & CONSORT or SPIRIT & 0 & 0 & 0 & 0 & 0 \\
\hline II. & DESIGN FACTORS & & & & & \\
\hline 2. & Type and Design of Trial & 3 & 2 & 2 & 2 & 3 \\
\hline 3. & Setting/Physician & 3 & 2 & 3 & 3 & 1 \\
\hline 4. & Imaging & 3 & 3 & 3 & 1 & 3 \\
\hline 5. & Sample Size & 2 & 2 & 2 & 1 & 0 \\
\hline 6. & Statistical Methodology & 1 & 2 & 1 & 1 & 1 \\
\hline III. & PATIENT FACTORS & & & & & \\
\hline 7. & Inclusiveness of Population & 2 & 2 & 2 & 2 & 2 \\
\hline 8. & Duration of Pain & 2 & 2 & 2 & 2 & 2 \\
\hline 9. & Previous Treatments & 2 & 2 & 2 & 2 & 2 \\
\hline 10. & Duration of Follow-up with Appropriate Interventions & 2 & 2 & 1 & 0 & 2 \\
\hline IV. & OUTCOMES & & & & & \\
\hline 11. & Outcomes Assessment Criteria for Significant Improvement & 2 & 2 & 4 & 1 & 4 \\
\hline 12. & Analysis of all Randomized Participants in the Groups & 2 & 2 & 2 & 2 & 2 \\
\hline 13. & Description of Drop Out Rate & 1 & 1 & 1 & 1 & 1 \\
\hline 14. & Similarity of Groups at Baseline for Important Prognostic Indicators & 2 & 2 & 2 & 2 & 2 \\
\hline 15. & Role of Co-Interventions & 1 & 1 & 1 & 1 & 1 \\
\hline V. & RANDOMIZATION & & & & & \\
\hline 16. & Method of Randomization & 2 & 2 & 2 & 2 & 2 \\
\hline VI. & ALLOCATION CONCEALMENT & & & & & \\
\hline 17. & Concealed Treatment Allocation & 2 & 2 & 2 & 2 & 2 \\
\hline VII. & BLINDING & & & & & \\
\hline 18. & Patient Blinding & 1 & 2 & 1 & 1 & 1 \\
\hline 19. & Care Provider Blinding & 1 & 0 & 0 & 0 & 0 \\
\hline 20. & Outcome Assessor Blinding & 1 & 2 & 1 & 1 & 0 \\
\hline VIII. & CONFLICTS OF INTEREST & & & & & \\
\hline 21. & Funding and Sponsorship & 0 & 2 & 0 & 0 & 3 \\
\hline 22. & Conflicts of Interest & 2 & 2 & 2 & 2 & 0 \\
\hline \multicolumn{2}{|c|}{ TOTAL } & 37 & 39 & 36 & 29 & 34 \\
\hline
\end{tabular}

Adapted from: Sanapati J, et al. Do regenerative medicine therapies provide long-term relief in chronic low back pain: A systematic review and metaanalysis. Pain Physician 2018; in press (29).

\subsection{Assessment of Evidence}

Evidence was assessed for intradiscal, epidural, lumbar facet, and sacroiliac joint injections.

\subsubsection{Intradiscal Injections}

Evidence for intradiscal injections was based on the use of 2 injected biologicals, either PRP or MSCs.

\subsubsection{Platelet-Rich Plasma}

Based on the available evidence, including 1 high-quality RCT (90), multiple moderate-quality observational studies $(274-276,278,279)$, a single-arm meta-analysis, and evidence from a systematic review (26), the qualitative evidence has been assessed as Level III (on a scale of Level I through V) using a qualitative 


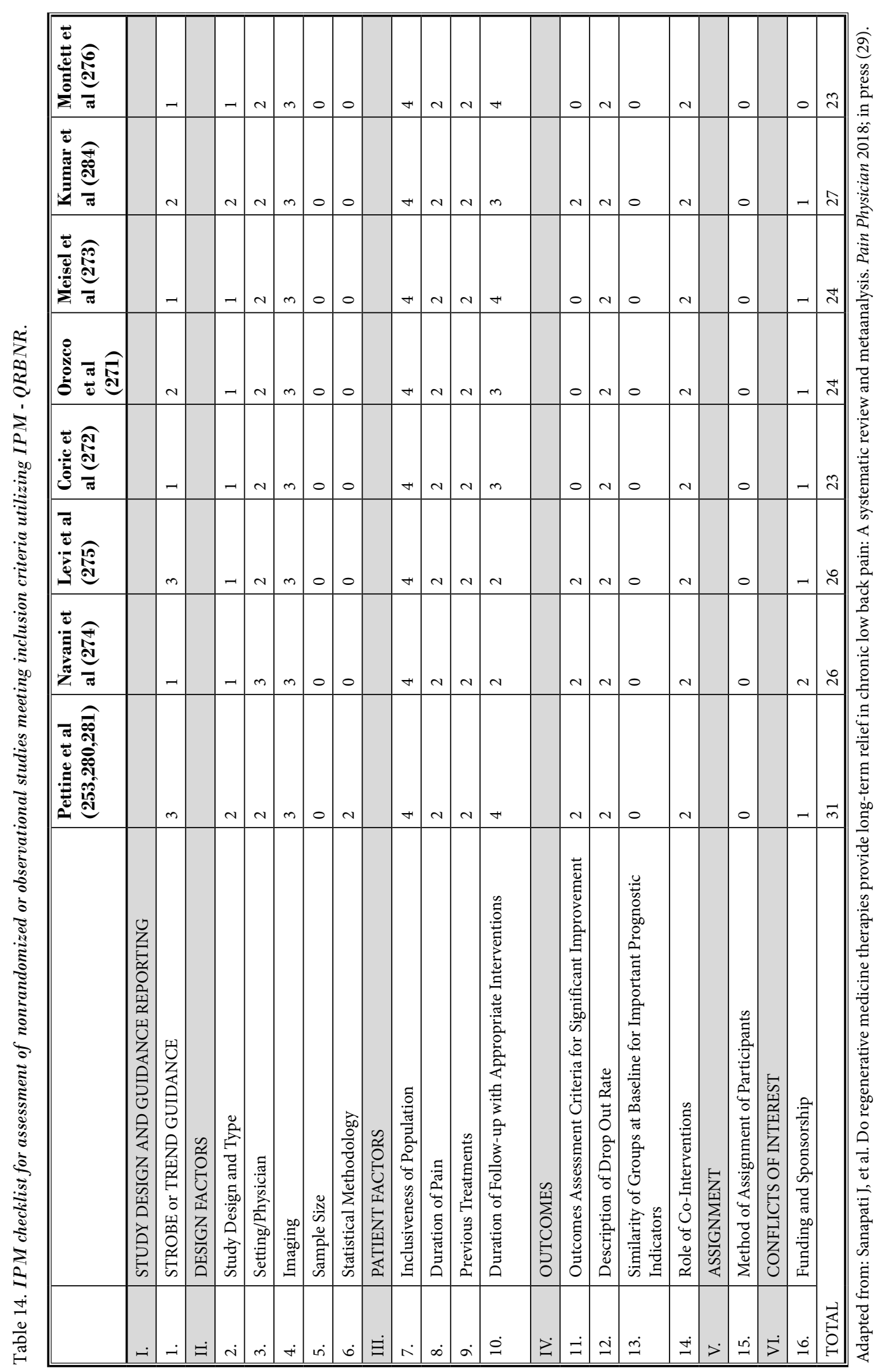




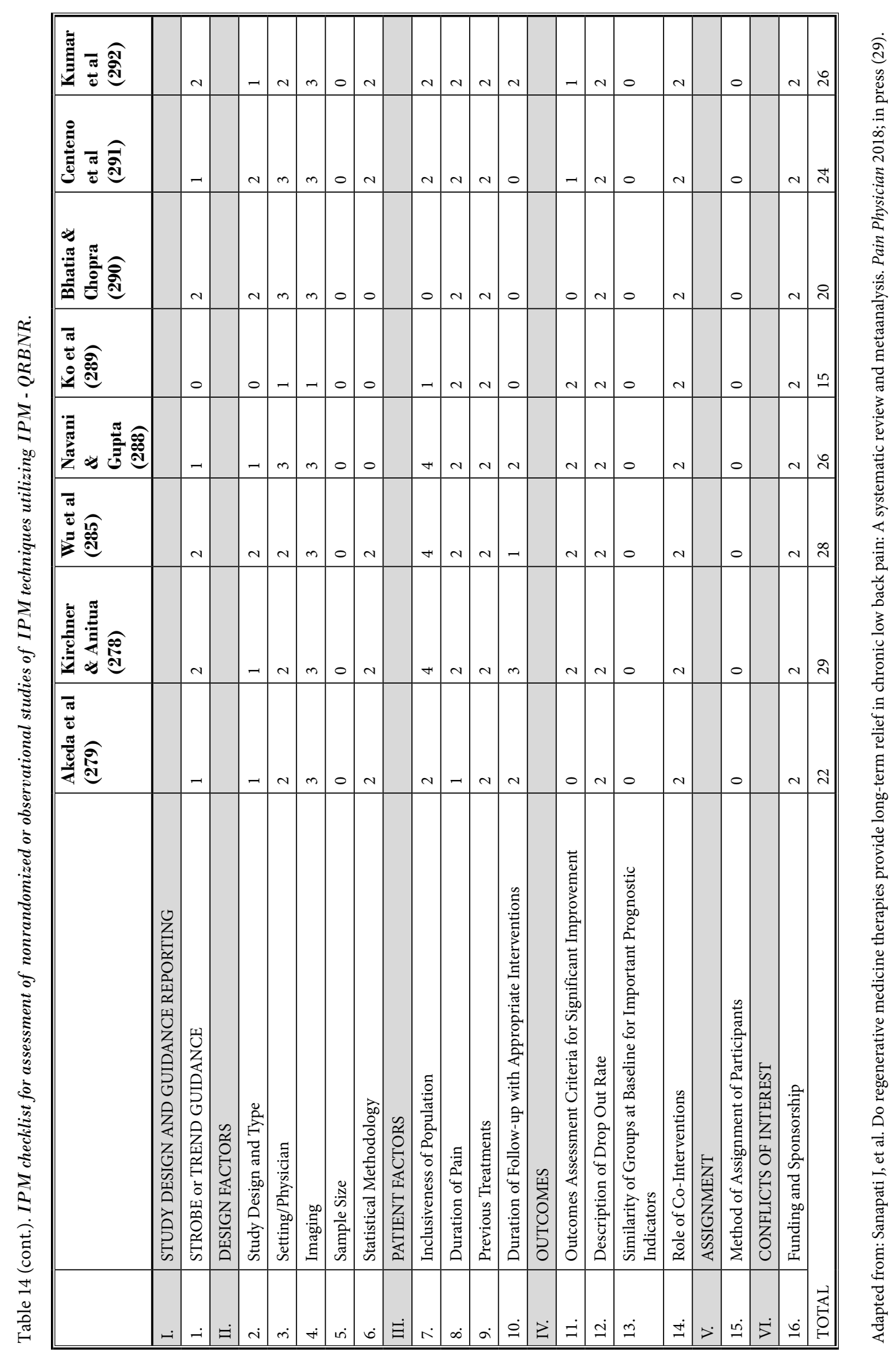


Responsible, Safe, and Effective Use of Biologics in the Management of Low Back Pain

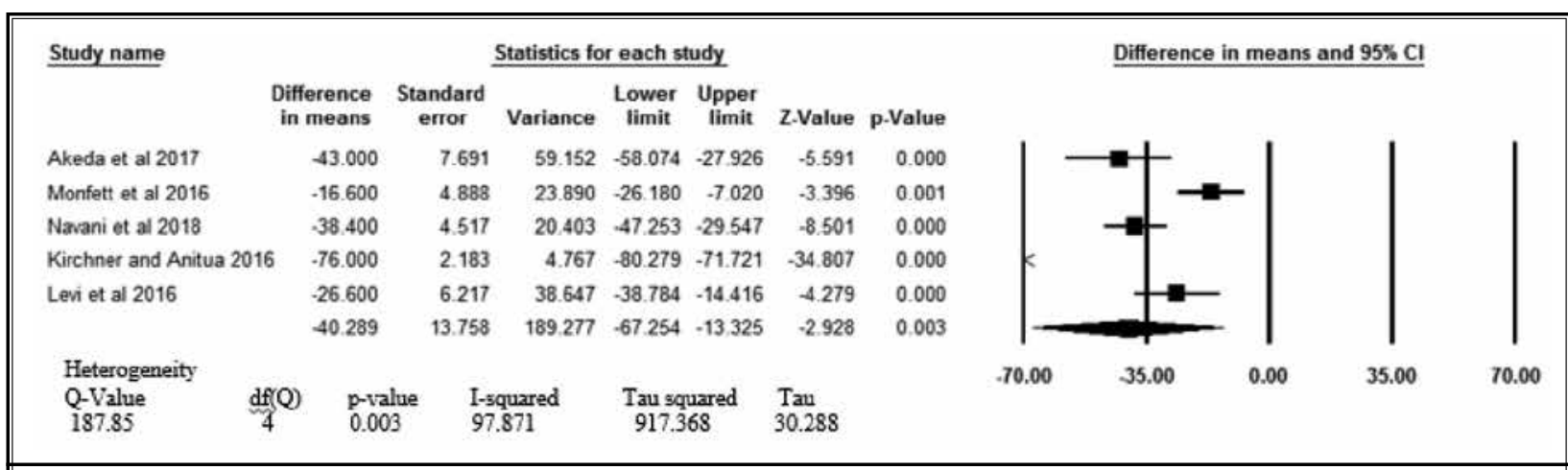

Fig. 25. Decreased pain score (numerical rating scale or visual analog scale, 0-100) after treatment (6-month follow-up data) of lumbar disc injections of PRP.

Adapted from: Sanapati J, et al. Do regenerative medicine therapies provide long-term relief in chronic low back pain: A systematic review and metaanalysis. Pain Physician 2018; 21:515-540 (29).

\begin{tabular}{|c|c|c|c|c|c|c|c|c|c|c|c|c|}
\hline \multirow[t]{2}{*}{ Study name } & \multicolumn{7}{|c|}{ Statistics for each study } & \multicolumn{5}{|c|}{ Difference in means and $95 \% \mathrm{Cl}$} \\
\hline & $\begin{array}{l}\text { Difference } \\
\text { in means }\end{array}$ & $\begin{array}{l}\text { Standard } \\
\text { error }\end{array}$ & Variance & $\begin{array}{c}\text { Lower } \\
\text { limit }\end{array}$ & $\begin{array}{c}\text { Upper } \\
\text { limit }\end{array}$ & Z-value & p-Value & & & & & \\
\hline Akeda et al 2017 & -46.000 & 8.580 & 73.616 & -62.816 & -29.184 & -5.361 & 0.000 & & & ! & | & | \\
\hline Monfett et al 2016 & -21.900 & 4.963 & 24.629 & -31.627 & -12.173 & -4.413 & 0.000 & & & & & \\
\hline \multirow[t]{2}{*}{ Navani et al 2018} & -38.300 & 4.385 & 19.233 & -46.895 & -29.705 & -8.733 & 0.000 & & & & & \\
\hline & -34.405 & 6.879 & 47.326 & -47.888 & -20.921 & -5.001 & 0.000 & & & & 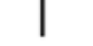 & \\
\hline $\begin{array}{l}\text { Heterogeneity } \\
\text { Q-Value } \\
10.139\end{array}$ & $\frac{d f^{\prime}}{2}$ & $\begin{array}{c}\text { p-value } \\
0.013\end{array}$ & $\begin{array}{l}\text { I-squared } \\
\text { 77.166 }\end{array}$ & $\begin{array}{l}\text { Tau sq } \\
106.51\end{array}$ & $\begin{array}{l}\text { uared } \\
11\end{array}$ & $\begin{array}{l}\text { Tau } \\
10.320\end{array}$ & & -70.00 & -35.00 & 0.00 & 36.00 & 70.00 \\
\hline
\end{tabular}

Fig 26. Pain scores (numerical rating scale or visual analog scale, 0-100) after treatment (12-month follow-up data) with lumbar disc PRP injections.

Adapted from: Sanapati J, et al. Do regenerative medicine therapies provide long-term relief in chronic low back pain: A systematic review and metaanalysis. Pain Physician 2018; 21:515-540 (29).

\begin{tabular}{|c|c|c|c|c|c|c|c|c|c|c|c|}
\hline \multirow[t]{2}{*}{$\underline{\text { Study name }}$} & \multicolumn{7}{|c|}{ Statistics for each study } & \multicolumn{4}{|c|}{ Difference in means and $95 \% \mathrm{Cl}$} \\
\hline & $\begin{array}{l}\text { Difference } \\
\text { in means }\end{array}$ & $\begin{array}{l}\text { Standard } \\
\text { error }\end{array}$ & Variance & $\begin{array}{c}\text { Lower } \\
\text { limit }\end{array}$ & $\begin{array}{l}\text { Upper } \\
\text { limit }\end{array}$ & z-Value & p-Value & & & & \\
\hline Coroc D 2013 & -22.330 & 1.030 & 1.061 & -24.349 & -20.311 & -21.680 & 0.000 & & $\mathbf{\square}$ & | & $\mid$ \\
\hline Kumar H 2017 & -36.000 & 6.609 & 43.679 & -48.953 & -23.047 & -5.447 & 0.000 & & & & \\
\hline Meisel HJ 2006 & -41.450 & 8.509 & 72.403 & -58.127 & -24.773 & -4.871 & 0.000 & & & & \\
\hline Noriega DC 2017 & -20.000 & 11.768 & 138.486 & -43.065 & 3.065 & -1.700 & 0.089 & & & & \\
\hline Orozco L 2011 & -48.900 & 7.288 & 53.115 & -63.184 & -34.616 & -6.710 & 0.000 & & & & \\
\hline \multirow[t]{2}{*}{ Pettine K, 2015} & -53.400 & 7.920 & 62.726 & -68.923 & -37.877 & -6.742 & 0.000 & & & & \\
\hline & -36.943 & 6.588 & 43.401 & -49.855 & -24.030 & -5.608 & 0.000 & & & & \\
\hline $\begin{array}{l}\text { Heterogeneity } \\
\text { Q-Value } \\
35.678\end{array}$ & $\frac{\mathrm{df}(\mathrm{Q})}{5}$ & $\begin{array}{l}\text { p-value } \\
0.000\end{array}$ & $\begin{array}{l}\text { I-squared } \\
85.989\end{array}$ & $\begin{array}{l}\text { Tau sq } \\
204.54\end{array}$ & & $\begin{array}{c}\text { Tau } \\
14.302\end{array}$ & & -90.00 & -45.00 & 45.00 & 90.00 \\
\hline \multicolumn{12}{|c|}{$\begin{array}{l}\text { Fig 27. Changes in pain score (numerical rating scale or visual analog scale, } 0-100) \text { after treatment (12 months follow data) of } \\
\text { cell therapy of lumbar disc. } \\
\text { Adapted from: Sanapati J, et al. Do regenerative medicine therapies provide long-term relief in chronic low back pain: A systematic review and } \\
\text { metaanalysis. Pain Physician 2018; 21:515-540 (29). }\end{array}$} \\
\hline
\end{tabular}




\begin{tabular}{|c|c|c|c|c|c|c|c|c|c|c|c|c|c|}
\hline \multirow[t]{2}{*}{ Study name } & \multicolumn{8}{|c|}{ Statistics for each study } & \multicolumn{5}{|c|}{ Difference in means and $95 \% \mathrm{Cl}$} \\
\hline & \multicolumn{2}{|c|}{$\begin{array}{l}\text { Difference } \\
\text { in means }\end{array}$} & $\begin{array}{l}\text { tandard } \\
\text { error }\end{array}$ & Variance & $\begin{array}{c}\text { Lower } \\
\text { limit }\end{array}$ & $\begin{array}{l}\text { Upper } \\
\text { limit }\end{array}$ & Z-Value & p-Value & & & & & \\
\hline Coric D 2013 & \multicolumn{2}{|c|}{-27.649} & 0.555 & 0.308 & -28.737 & -26.561 & -49.818 & 0.000 & & ב & | & I & 1 \\
\hline Kumar H 2017 & \multicolumn{2}{|c|}{-26.000} & 5.672 & 32.172 & -37.117 & -14.883 & -4.584 & 0.000 & & & & & \\
\hline Meisel HJ 2006 & \multicolumn{2}{|c|}{-41.190} & 7.438 & 55.324 & -55.768 & -26.612 & -5.538 & 0.000 & & - & & & \\
\hline Noriega DC 2017 & \multicolumn{2}{|c|}{-12.000} & 9.523 & 90.688 & -30.665 & 6.665 & -1.260 & 0.208 & & & 一 & & \\
\hline Orozco L 2011 & \multicolumn{2}{|c|}{-17.600} & 4.699 & 22.081 & -26.810 & -8.390 & -3.745 & 0.000 & & $\longrightarrow$ & & & \\
\hline Pettine KA 2015 & \multicolumn{2}{|c|}{-33.900} & 8.393 & 70.442 & -50.350 & -17.450 & -4.039 & 0.000 & & & & & \\
\hline & \multicolumn{2}{|c|}{-26.342} & 3.070 & 9.425 & -32.359 & -20.325 & -8.580 & 0.000 & & & & & \\
\hline $\begin{array}{l}\text { Heterogeneity } \\
\text { Q-Value }\end{array}$ & \multirow{2}{*}{\multicolumn{2}{|c|}{$\begin{array}{cr}\mathrm{df}(\mathrm{Q}) & \mathrm{p} \text {-value } \\
5 & 0.048\end{array}$}} & \multirow{2}{*}{\multicolumn{2}{|c|}{$\begin{array}{l}\text { I-squared } \\
55.324\end{array}$}} & Tau squared & Tau & & & -60.00 & -30.00 & 0.00 & 30.00 & 60.00 \\
\hline 11.1922 & & & & & 26.461 & 5.144 & & & & & & & \\
\hline
\end{tabular}

Fig 28. Changes in Oswestry Disability Index (ODI) after treatment (12 months follow data) of cell therapy of lumbar disc.

Adapted from: Sanapati J, et al. Do regenerative medicine therapies provide long-term relief in chronic low back pain: A systematic review and metaanalysis. Pain Physician 2018; 21:515-540 (29).

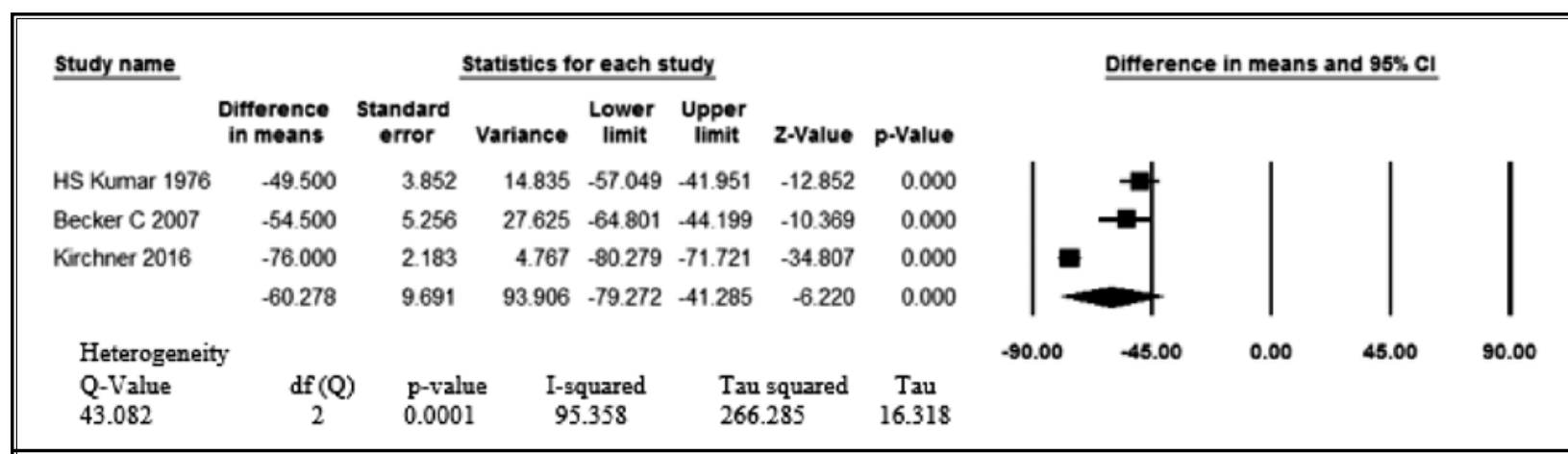

Fig 29. Changes in pain scores (0-100) after treatment (6 months follow data) of epidural PRP injections.

Adapted from: Sanapati J, et al. Do regenerative medicine therapies provide long-term relief in chronic low back pain: A systematic review and metaanalysis. Pain Physician 2018; 21:515-540 (29).

modified approach to the grading of evidence based on best-evidence synthesis.

\subsubsection{Medicinal Signaling Cells or Mesenchymal Stem Cells}

Based on the available evidence with a high-quality RCT (283), multiple moderate-quality observational studies (271-273,280,284), a single-arm meta-analysis, and 2 systematic reviews $(26,28)$, the qualitative evidence has been assessed as Level III (on a scale of Level I through V) using a qualitative modified approach to the grading of evidence based on best evidence synthesis.

\subsubsection{Epidural Injections}

Based on 1 high-quality RCT (293), multiple rele- vant moderate-quality observational studies $(278,290-$ 293) and a single-arm meta-analysis, the qualitative evidence has been assessed as Level IV (on a scale of Level I through $\mathrm{V}$ ) using a qualitative modified approach to the grading of evidence based on best evidence synthesis.

\subsubsection{Lumbar Facet Joint Injections}

Based on 1 high-quality RCT (286) and 2 moderate-quality observational studies $(278,285)$, the qualitative evidence for facet joint injections with PRP has been assessed as Level IV (on a scale of Level I through V) using a qualitative modified approach to the grading of evidence based on best evidence synthesis. 


\subsubsection{Sacroiliac Joint Injection}

Based on 1 high-quality RCT (287), 1 moderatequality observational study (288), and 1 low-quality case report (289), the qualitative evidence has been assessed as Level IV (on a scale of Level I through V) using a qualitative modified approach to the grading of evidence based on best evidence synthesis.

\subsection{Summary of Evidence}

Based on systematic reviews and individual studies, the summary of evidence is as follows:

1. Utilizing best evidence synthesis principles based on 3 systematic reviews $(26,28,29)$ and 6 individual studies of PRP $(274-276,278,279)$ and MSCs (271$273,280,284)$, the evidence for biologic management of lumbar discogenic pain has been assessed as Level III of V for PRP and MSC therapy.

2. Utilizing best evidence synthesis principles based on a single systematic review (29) and 3 individual studies $(278,285,286)$, the evidence for management of lumbar facet joint disorders has been assessed as Level IV of V for PRP.

3. Utilizing best evidence synthesis principles based on a single systematic review (29), and 5 individual studies (278,290-293), the evidence for management of low back and lower extremity pain with epidural biologic injections has been assessed as Level IV of $\mathrm{V}$ for PRP.

4. Utilizing best evidence synthesis principles based on one systematic review (29), and 3 individual studies (287-289), the evidence for biologic management of sacroiliac joint pain has been assessed as Level IV of $\mathrm{V}$ for PRP.

\subsection{Current Guidelines for Biologics in Industry and Regulatory Agencies}

Key Question 7. What are the current guidelines for the use of biologics?

\subsection{FDA/WHO as Regulatory Agency for Biologic Therapies}

A multitude of regulatory and ethical challenges exist in the application of regenerative medicine therapies for the treatment of various chronic pain conditions $(33,34,35,37,38,294-316)$. Of the 3 commonly used biologics, PRP and MCSs from bone marrow aspirate appear to be the least controversial, whereas adiposederived MCSs appear to be the most controversial.

The World Health Organization (WHO) serves as the directing and coordinating authority for health within the United Nations system. The World Health Assembly initiated the preparation of the first WHO Guiding Principles on Transplantation, which were endorsed by the Assembly in 1991, and which were most recently updated in 2010. These guidelines target appropriateness for use, human ethics, trafficking, availability of organs/obtainment, and discrepancy in costs among countries (294). They also encourage the registry of all providers and users of biologic products to collect global information regarding safety and adverse reactions (295).

Taylor-Weiner and Graff Zivin (299) described the unlicensed stem cell clinics in the United States as medicine's "Wild West". They reported that regardless of whether or not stem-cell therapy holds great potential, the field is less advanced than the public has been led to believe. They also point out that the majority of therapies offered by these stem cell clinics use adipose-derived stem cells packaged as a product called stromal vascular fraction (SVF) and that procedures using SVF have become increasingly popular because of the relative ease of acquiring the cells. They reveal that in the production of SVF, clinics collect liposuction aspirate from a patient, chemically separate the stem cells from the surrounding fat tissue, and administer the isolated cells back to the patient intravenously or by injection into the tissue to be treated. They also state that although it is easy to obtain SVF, the treatments are unproven and these stem cell clinics have been operating without regulation because of ambiguous FDA guidelines. In multiple manuscripts, the FDA $(33,38,297)$ has warned that the current excitement over the potential for stem cell therapy to improve patient outcomes or even cure diseases must be accompanied by the understanding of its risks and benefits with the development of therapeutic approaches being based strictly on sound scientific evidence. The FDA continues to express concerns regarding stem cell therapy due to the lack of scientific evidence. Turner also described multiple issues related to the use of adipose-derived autologous stem cell interventions (37).

At the center of these contentious arguments is the fact that the FDA has not approved any adipose-derived stem cell medical products for the U.S. marketplace to date. Providers performing adipose-derived stem cell interventions claim that they are engaged in the practice of medicine, and that the FDA does not directly regulate the practice of medicine $(33,35,37,38,297,303$ $305,309,310)$. Turner (37) believes that these procedures do not fall under the same surgical procedure exception 
Pain Physician: Guidelines Issue 2019; 22:S1-S74

Table 15. Categories of human cells, tissues, or cellular and tissue-based products (HCT/Ps).

\begin{tabular}{|l||}
\hline HCT/P \\
\hline Cardiovascular tissue \\
\hline Cell-derived therapeutic products (e.g., pancreatic islets, mesenchymal stem or stromal cells, fibroblasts \\
\hline Dura mater \\
\hline Hematopoietic progenitor cells derived from peripheral or cord blood (including hematopoietic stem cells) \\
\hline Musculoskeletal tissue (include adipose-derived stem cells) \\
\hline Ocular tissue \\
\hline Placenta or amnion \\
\hline Reproductive cells and tissues \\
\hline Skin \\
\hline Not HCT/P \\
\hline Blood vessels that are a part of an organ intended for transplantation \\
\hline Human collagen \\
\hline Human milk \\
\hline In vitro diagnostic products \\
\hline $\begin{array}{l}\text { Minimally manipulated bone marrow for homologous use and not combined with another article (with a few exceptions described in the tissue } \\
\text { regulations) }\end{array}$ \\
\hline Nonhuman cells, tissues, or organs \\
\hline Vascular composite allografts \\
\hline Vascularized human organs for transplantation \\
\hline Whole blood or blood components, including platelet-rich plasma \\
\hline
\end{tabular}

Source: Marks P, Gottlieb S. Balancing safety and innovation for cell-based regenerative medicine. N Engl J Med 2018 378:954-959 (297).

identified in 21 CFR 1271; however, many practitioners disagree with Turner (310). Guidance for the industry, issued by the FDA, currently addresses what actions clinicians and manufacturers can perform while remaining within the scope of the exception $(297,303,304)$.

\subsection{Human Cells, Tissues, and Cellular and Tissue-Based Products (HCT/Ps)}

Marks and Gottlieb (297) described the regulatory context for regenerative medicine. To implement comprehensive policy framework, the FDA's statutory authority in this area is based in part on the Public Health Service (PHS) Act. Section 351 of this Act provides the FDA with authority surrounding the licensure of biologic products, and Section 361 mandates that the agency will issue and enforce regulations necessary to prevent the introduction, transmission, or spread of infectious disease. That regulatory framework is riskbased and is divided into human cells, tissues, cellular, and tissue-based products (HCT/Ps) (297).

The products that are regulated under both Sections 351 and 361 of the Act are biologic products and must be studied under the provisions set forth for in- vestigational new drugs (303). Furthermore, the manufacturers of such products are required to submit a biologics license application to the FDA for approval of their products before marketing. This creates a discrepancy since the products that are regulated solely under Section 361 and under the implementing regulations do not need premarket approval. Instead of premarket approval, these products require registration and listing with the FDA prior to marketing. However, these products still must be produced in compliance with the appropriate provisions in order to prevent the transmission of infectious diseases (297).

The decision pertaining to the regulatory pathway to be followed for a given product rests in part on whether the product meets or does not meet the criteria of the regulations promulgated under the Code of Federal Regulations part 1271 of Title 21 of 2005. Under this section, products that are regulated solely under Section 361 generally are those that do not undergo substantial processing (requiring only minimal manipulation), are used in a manner for the recipient that is similar to that of the donor (homologous use), are not combined with another drug or biologic prod- 
ucts, and do not have a systematic effect unless they are designed for autologous transplantation, first- or second-degree-related allogeneic transplantation, or have been designed for reproductive use as shown in Table 15 (297). Thus, any HCT/P products other than tissue such as corneas and heart valves, are regulated as drugs, biologics, or devices and require the appropriate regulatory submissions for the conduct of clinical trials and marketing (297). Figure 30 illustrates in a flow chart how manufacturers and health care providers should apply the criteria outlined in 21 CFR 1271 to determine if a product meets the definition of an HCT/P (303).

In summary, an HCT/P product is regulated solely under Section 361 of the PHS Act and 21 CFR Part 1271 if it meets all of the following criteria $(297,303,304)$ :

1) The HCT/P is minimally manipulated;

2) The HCT/P is intended for homologous use only, as reflected by the labeling, advertising, or other indications of the manufacturer's objective intent;

3) The manufacture of the HCT/P does not involve the combination of the cells or tissues with another article, except for water, crystalloids, or a sterilizing, preserving, or storage agent, provided that the addition of water, crystalloids, or the sterilizing, preserving, or storage agent does not raise new clinical safety concerns with respect to the HCT/P; and

4) Either:

i) The HCT/P does not have a systemic effect and is not dependent upon the metabolic activity of living cells for its primary function; or

ii) The HCT/P has a systemic effect or is dependent upon the metabolic activity of living cells for its primary function, and:

a) Is for autologous use;

b) Is for allogeneic use in a first-degree or second-degree blood relative; or

c) Is for reproductive use.

If an HCT/P does not meet the criteria set out in 21 CFR1271.10(a), and if the establishment that manufactures the HCT/P does not qualify for any of the exceptions in 21 CFR 1271.15, the HCT/P will be regulated as a drug, device, and/or biological product under the FD\&C Act, and/or section 351 of the PHS Act (42 U.S.C. 262), and applicable regulations, including 21 CFR Part 1271 , and premarket review of the product will be required.

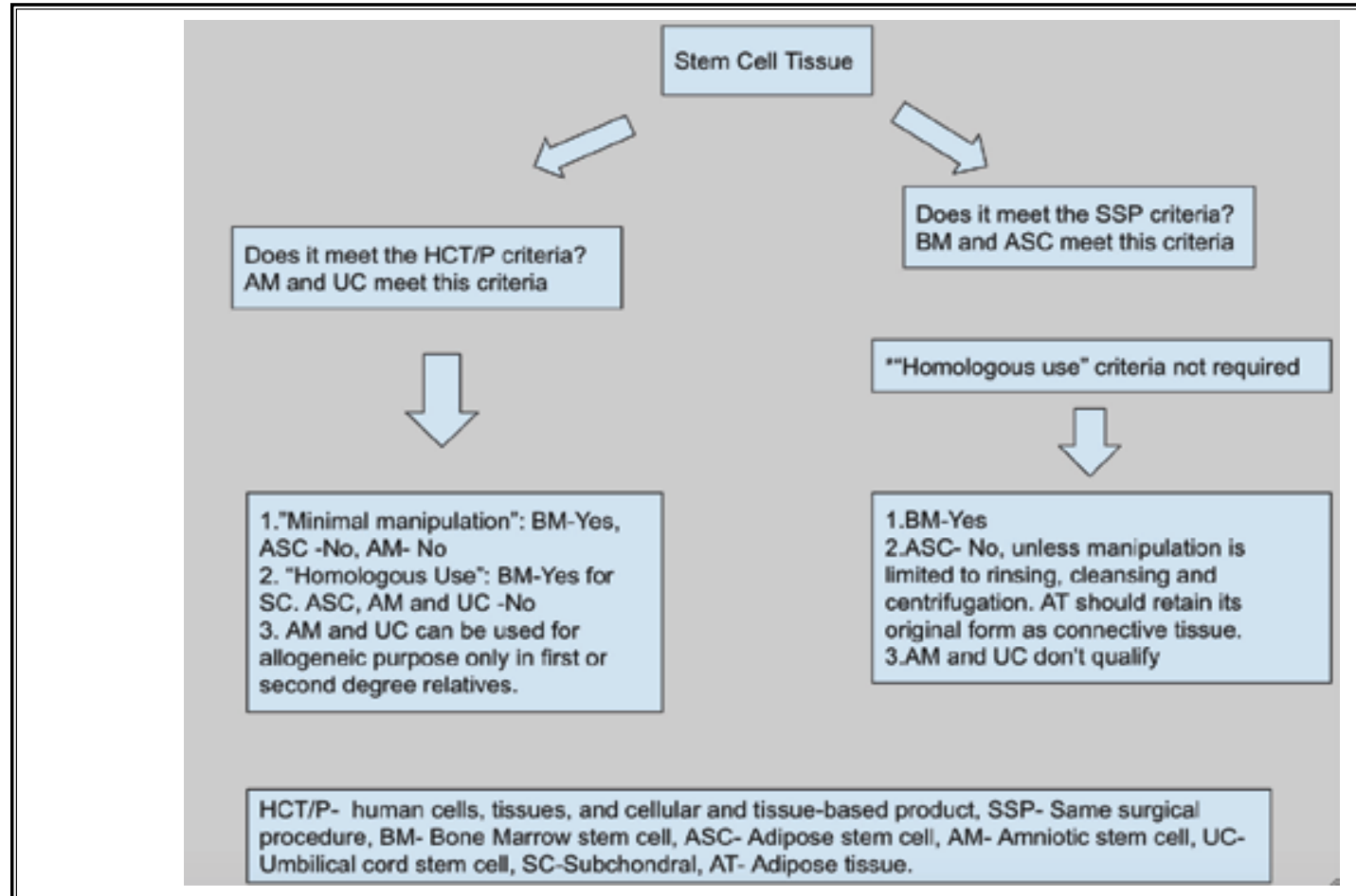

Fig. 30. Flowchart to illustrate the definition of an HCT/P criteria in 21 CFR 1271.15(b) and 1271.10(a). 


\subsection{Minimal Manipulation}

Section 1271.10(a)(1) (21 CFR 1271.10(a)(1)) provides that one of the criteria for an HCT/P to be regulated solely under section 361 of the PHS Act and the regulations in Part 1271 is that the HCT/P is minimally manipulated $(297,303,304)$. As defined in 21 CFR 1271.3(f), minimal manipulation means:

1) For structural tissue, processing that does not alter the original relevant characteristics of the tissue relating to the tissue's utility for reconstruction, repair, or replacement;

2) For cells or nonstructural tissues, processing that does not alter the relevant biological characteristics of cells or tissues.

The FDA noted that if information does not exist to show that the processing meets the definition of minimal manipulation, the FDA considers the processing of an HCT/P to be "more than minimal manipulation" and cannot qualify for regulation solely under section 361 of the PHS Act and 21 CFR Part 1271 (297,303,304).

Section 1271.3(f) provides two definitions of minimal manipulation, one that applies to structural tissue and one that applies to cells or nonstructural tissues. For structural tissue, minimal manipulation means that the processing of the HCT/P does not alter the original relevant characteristics of the tissue relating to the tissue's utility for reconstruction, repair, or replacement (21 CFR 1271.3(f)(1)). For cells or nonstructural tissues, minimal manipulation means that the processing of the HCT/P does not alter the relevant biological characteristics of cells or tissues (21 CFR 1271.3(f)(2)).

Original relevant characteristics of structural tissues generally include the properties of that tissue while in the donor that contribute to the tissue's function or functions. Similarly, relevant biological characteristics of cells or nonstructural tissues generally include the properties of the cells or nonstructural tissues within the donor that contribute to the cell's or tissue's function(s). Processing that alters the original characteristics of the HCT/P, raises increased safety and effectiveness concerns for the HCT/P because there would be less basis on which to predict the product's function after transplantation (303). Thus, the determination of whether an HCT/P is minimally manipulated is based on the effect that manufacturing has on the original relevant characteristics of the HCT/P as the HCT/P exists within the donor, and is not based on the intended use of the HCT/P in the recipient.
Processing is defined as any activity performed on an HCT/P, other than recovery, donor screening, donor testing, storage, labeling, packaging, or distribution, such as testing for microorganisms, preparation, sterilization, steps to inactivate or remove adventitious agents, preservation for storage, and removal from storage (21 CFR 1271.3(ff)). Processing also includes cutting, grinding, shaping, culturing, enzymatic digestion, and decellularization (303).

Tissues that physically support or serve as a barrier or conduit, or connect, cover, or cushion in the donor are generally considered structural tissues for the purposes of determining the applicable regulatory definition (i.e., bone, skin).

Adipose tissue is considered a structural tissue for the purpose of applying the HCT/P regulatory framework. Adipose tissue is typically defined as a connective tissue composed of clusters of cells (adipocytes) surrounded by a reticular fiber network and interspersed small blood vessels, divided into lobes and lobules by connective tissue septa (313). Additionally, adipose tissue contains other cells, including preadipocytes, fibroblasts, vascular endothelial cells, and macrophages $(317,318)$. Adipose tissue provides cushioning and support for other tissues, including the skin and internal organs, stores energy in the form of lipids, and insulates the body, among other functions. While adipose tissue has multiple functions, because it is predominantly composed of adipocytes and surrounding connective tissues that provide cushioning and support to the body, the FDA considers adipose tissue to be a structural tissue for the purpose of applying the HCT/P regulatory framework.

To evaluate whether processing of adipose tissue would meet the regulatory definition of minimal manipulation, one should consider whether the processing alters the original relevant characteristics of the adipose tissue relating to its utility to provide cushioning and support (Fig. 31). An opposition view may consider the presence of stem cells within adipose tissue as an indication that this tissue also functions as a repository for regenerative factors.

\subsection{Homologous Use}

Section 1271.10(a)(2) (21 CFR 1271.10(a)(2)) provides that one of the criteria for an HCT/P to be regulated solely under section 361 of the PHS Act and the regulations in Part 1271 is that the "HCT/P is intended for homologous use only, as reflected by the labeling, advertising, or other indications of the manufacturer's objective intent." 
As defined in 21 CFR 1271.3(c), homologous use means the repair, reconstruction, replacement, or supplementation of a recipient's cells or tissues with an HCT/P that performs the same basic function or functions in the recipient as in the donor. This criterion reflects the FDA's conclusion that there would be increased safety and effectiveness concerns for $\mathrm{HCT} / \mathrm{Ps}$ that are intended for a non-homologous use, because there is less basis on which to predict the product's behavior, whereas HCT/Ps for homologous use can reasonably be expected to function appropriately (assuming all of the other criteria are also met) $(303,304)$.

In applying the homologous use criterion, the FDA will determine what the intended use of the HCT/P is, as reflected by the labeling, advertising, and other indications of a manufacturer's objective intent, and will then apply the homologous use definition.

Homologous use means the repair, reconstruction, replacement, or supplementation of a recipient's cells or tissues with an HCT/P that performs the same basic function or functions in the recipient as in the donor (21 CFR 1271.3(c)), including when such cells or tissues are for autologous use:

- Recipient cells or tissues that are identical (e.g., skin for skin) to the donor cells or tissues, and perform one or more of the same basic functions in the recipient as the cells or tissues performed in the donor; or,

- Recipient cells or tissues that may not be identical to the donor's cells or tissues, but that perform one or more of the same basic functions in the recipient as the cells or tissues performed in the donor (319-321).

For the purpose of applying the HCT/P regulatory framework, the same basic function or functions of $\mathrm{HCT} / \mathrm{Ps}$ are considered to be those basic functions that the HCT/P performs in the body of the donor, which, when transplanted, implanted, infused, or transferred, the HCT/P would then be expected to perform in the recipient. It is not necessary for the $\mathrm{HCT} / \mathrm{P}$ in the recipient to perform all of the basic functions it performed in the donor in order to meet the definition of homologous use. However, to meet the definition of homologous use, any of the basic functions that the HCT/P is expected to perform in the recipient must be a basic function that the HCT/P performed in the donor.
The use of an HCT/P from adipose tissue for the repair, reconstruction, replacement, or supplementation of adipose tissue would be considered a homologous use. In these situations, the FDA would consider the HCT/P from adipose tissue to be performing the same basic function in the recipient as in the donor. In contrast, the use of an HCT/P from adipose tissue for the treatment of a degenerative, inflammatory, or demyelinating disorder would generally be considered a non-homologous use. Figure 31 illustrates how manufacturers and healthcare providers should apply the criteria outlined in 21 CFR 1271.15(b) and 1271.10(a) for HCT/Ps (303).

\subsection{Regulatory Scope and Compliance Policy}

This guidance only applies to products and establishments that are subject to FDA's regulations in 21 CFR Part 1271. Establishments that meet the same surgical procedure exception in 21 CFR 1271.15(b) are not subject to FDA's regulations in 21 CFR Part 1271.

This guidance also does not apply to products that fall outside the definition of HCT/P in 21 CFR 1271.3(d). For example, PRP (blood taken from an individual and given back to the same individual as PRP) is not an HCT/P under Part 1271 because it is a blood product. Accordingly, FDA does not apply the criteria in 21 CFR 1271.10(a) to PRP, and PRP is outside the scope of this guidance.

\subsection{FDA's Comprehensive Framework for Regenerative Medicine}

As per Marks and Gottlieb (297), the FDA recognizes the time and effort that go into the creation of regulatory submission and the effect that working through the regulatory process can have on timelines for the development of innovative products. Consequently, in November 2017, building on this policy and scientific opportunities, the FDA released a comprehensive framework for the oversight of regenerative medicine to help the field continue to advance. This regulatory framework is articulated in 2 final and 2 draft guidance documents as shown in Table 16 (297). The FDA's new policy framework is more clearly described for the developers of regenerative medicine to provide a distinction between therapies that require premarket authorization and those that do not. Consequently, the FDA provided appropriate criteria for minimal manipulation and homologous use. As part of the regulatory framework, the FDA also articulated a risk-based compliance and enforcement policy. 
Pain Physician: Guidelines Issue 2019; 22:S1-S74

Table 16. Four guidance documents describing the regenerative medicine framework. *

\begin{tabular}{|c|c|c|}
\hline Document & Summary & Example \\
\hline $\begin{array}{l}\text { Same Surgical Procedure } \\
\text { Exception under } 21 \text { CFR } \\
\text { 12.71.15(b): Questions and } \\
\text { Answers Regarding the Scope } \\
\text { of the Exception -- Final }\end{array}$ & $\begin{array}{l}\text { Addresses the criteria required for the exception, the types } \\
\text { of procedures generally considered to be the same surgical } \\
\text { procedure, and what processing steps can be undertaken to } \\
\text { still meet the exception. In essence, this guidance clarifies } \\
\text { how the regulations apply in order to facilitate the optimal } \\
\text { care of patients undergoing surgical procedures. }\end{array}$ & $\begin{array}{l}\text { A situation in which this guidance would } \\
\text { apply is when a piece of the skull is removed } \\
\text { for decompression after traumatic head injury. } \\
\text { The bone may be minimally processed, stored, } \\
\text { and then returned to the patient a few weeks } \\
\text { later when the acute event is over, without the } \\
\text { need for regulatory interaction with FDA. }\end{array}$ \\
\hline $\begin{array}{l}\text { Regulatory Considerations } \\
\text { for Human Cells, Tissues, } \\
\text { and Cellular and Tissue- } \\
\text { Based Products: Minimal } \\
\text { Manipulation and } \\
\text { Homologous Use - Final }\end{array}$ & $\begin{array}{l}\text { Provides FDA's interpretation of the existing regulatory } \\
\text { definitions of minimal manipulation and homologous } \\
\text { use. The guidance clarifies that these are distinct concepts } \\
\text { and notes how to determine whether an HCT/P has been } \\
\text { minimally manipulated or is intended for homologous use. } \\
\text { The guidance also describes the compliance and enforcement } \\
\text { policy that the FDA will use for HCT/Ps. For the first } 36 \\
\text { months after issuance of the final guidance in November } \\
\text { 2017, the FDA intends to exercise enforcement discretion for } \\
\text { certain products that pose a low risk to public health so that } \\
\text { sponsors will be able to have a dialogue with the agency and } \\
\text { file the appropriate regulatory documentation. }\end{array}$ & $\begin{array}{l}\text { Adipose tissue is considered to be a structural } \\
\text { tissue for the purpose of the regulatory } \\
\text { framework. This is relevant to determining } \\
\text { the appropriate regulatory pathway for stem } \\
\text { cells derived from adipose tissue, which in } \\
\text { many applications will be regulated under } \\
\text { both Sections } 351 \text { and } 361 \text { of the Public Health } \\
\text { Service Act. }\end{array}$ \\
\hline $\begin{array}{l}\text { Evaluation of Devices Used } \\
\text { with Regenerative Medicine } \\
\text { Advanced Therapies - Draft }\end{array}$ & $\begin{array}{l}\text { Provides a comprehensive resource to developers of devices } \\
\text { used with RMATs. Topics covered include how the FDA } \\
\text { will simplify and streamline its application of regulatory } \\
\text { requirements for devices and cell-tissue combination } \\
\text { products. }\end{array}$ & $\begin{array}{l}\text { Under certain circumstances, a device that } \\
\text { is used with an RMAT might be classified as } \\
\text { a class III device or be limited to a specific } \\
\text { intended use with only one type of cell. }\end{array}$ \\
\hline $\begin{array}{l}\text { Expedited Programs for } \\
\text { Regenerative Medicine } \\
\text { Therapies for Serious } \\
\text { Conditions -- Draft }\end{array}$ & $\begin{array}{l}\text { Provides information about the expedited programs available } \\
\text { to RMATs, including fast-track and breakthrough-therapy } \\
\text { designations, and describes the FDA's considerations in } \\
\text { implementing the new expedited program for RMATs. } \\
\text { The guidance also describes an innovative program using } \\
\text { cooperative development open to regenerative medicine } \\
\text { products. }\end{array}$ & $\begin{array}{l}\text { Multiple sites that manufacture a product using } \\
\text { a common process may collaborate on clinical } \\
\text { trials as part of a development program, which } \\
\text { ultimately results in biologics licenses for each } \\
\text { of the individual sites. }\end{array}$ \\
\hline
\end{tabular}

${ }^{*}$ The listed guidance documents can be accessed at www.fda/gov/BiologicsBloodVaccines/CellularGeneTherapyProducts/ucm58218.thm' RMAT denotes regenerative medicine advanced therapy.

Source: Marks P, Gottlieb S. Balancing safety and innovation for cell-based regenerative medicine. N Engl J Med 2018 378:954-959 (297).

\subsubsection{Expediting the Development of New Therapies}

The FDA has developed a process of expediting the development of new therapies. The FDA traditionally has focused on insuring the quality, safety, and efficacy of medical products. However, its mandate has expanded to encompass a role in expediting the developments of new therapies, particularly those aimed at serious or life-threatening conditions. Consequently, the expedited programs including:

- Fast track designation

- Priority review

- Accelerated approval

- Designation as a breakthrough therapy
The FDA reports that these programs have been successful in accomplishing the goal of expediting the development of new therapies (322). Furthermore, the FDA also described its role in facilitating innovation while upholding the agency's approval standards, especially when it comes to areas of unmet medical need and new technologies as expressed in the legislative initiative contained in the 21st Century Cures Act, which was enacted on December 13, 2016 (323). To facilitate therapeutic advances from stem cell therapies, along with other HCT/Ps, the 21st Century Cures Act introduced an additional expedited program in which a product is designated as a regenerative advanced therapy, or regenerative medicine advanced therapy (RMAT). This designation provides sponsors of a quali- 
fied regenerative medicine product that is intended for the treatment of serious or life-threatening conditions with advantages similar to those of breakthrough therapy designation; provided that preliminary clinical evidence indicates that the therapy addresses unmet medical needs. The requirement for preliminary clinical evidence of efficacy distinguishes RMAT from the breakthrough designation, which requires preliminary clinical evidence of a substantial improvement over existing therapies. Further, RMAT-designated products that receive accelerated approval may be eligible to use an expanded range of options to fulfill their postapproval commitments. Such options include the use of traditional studies, as well as the submission of patient registries or other sources of real world evidence $(324,325)$. Multiple requests have been submitted for RMAT designation with the FDA approving at least onethird of them.

\subsubsection{Implementation of Comprehensive Framework}

The FDA described that it strove to take a modern approach to the existing regulations and statutes, balancing the objective of fostering expedient development of innovation products for patients who have medical needs with the need to ensure that such therapies are both safe and effective. In addition, as part of the regulatory framework, the FDA also articulated a risk-based compliance and enforcement policy. This policy essentially allows developers of lower risk products up to 36 months from November 16, 2017, to determine whether they need to submit an application for an investigational new drug or a marketing application in light of the recently published guidance documents and, if such an application is needed, to prepare the new drug or marketing application. However, the FDA intends to take additional enforcement actions in cases in which it believes unproven products may put patients at risk.

Finally, working within the existing regulatory framework, the FDA will make use of all available regulatory pathways and will adopt the use of some new principles that will make the appropriate premarket evaluation of stem cell-based therapies more efficient. On a large scale, the FDA will be incorporating some new concepts for how small investigators and firms can see and meet approval standard for products through efficient and expedited pathways. To achieve this goal, the FDA will provide tools to encourage individual or small groups of physicians to collaborate in support of the development of a stem cell or other regenerative medicine product, which will ultimately lead to the receipt of a biologics license by each of the physicians or groups (Fig. 31).

\subsection{State Medical Board Regulations/ Guidelines}

On April 21, 2017, Senator Lamar Alexander requested the Federation of State Medical Boards (FSMB) (326) to respond to multiple questions including:

1. How do state medical boards investigate complaints against stem cell clinics?

2. How are the existing false claims best practices enforced or used by state medical boards?

3. Are there standards or best practices regarding the use and communication of novel technology, such as adult stem cells?

4. Are there standards for education that are necessary before implementing novel technology, such as adult stem cell procedures?

Consequently, the FSMB formed a working group to develop a report on stem cells and regenerative medicine including the problem of direct-to-consumer clinics (41). The working group expressed concern over the landscape of stem cell clinics in the United States. They expressed that stem cell clinics market the presence of multiple elements including affiliations with a professional society or network, partnerships with academic institutions, FDA approval or explicit mention of exemption from FDA oversight, mention of official endorsement from a local or other authority or professional accreditation, listing of patents granted, and the statement that clinical trials of investigational stem cells based on interventions are being conducted (327). Table 17 shows co-opted tokens of scientific legitimacy as described by Sipp et al (328).

The working group expressed concern that the lack of a formal mechanism for reporting outcomes of unproven stem cells interventions, both positive and negative, adds to the difficulty involved in generating data on the effectiveness of such interventions, as does the fact that there is neither a requirement, nor a mechanism, for reporting adverse events related to interventions administered outside of the clinical trials and investigations. The working group emphasized existing regulations and made 10 recommendations in their draft report as shown in Table 18.

These recommendations as shown in Table 18 are as follows (41): 
A Traditional Development of a Biologic Product
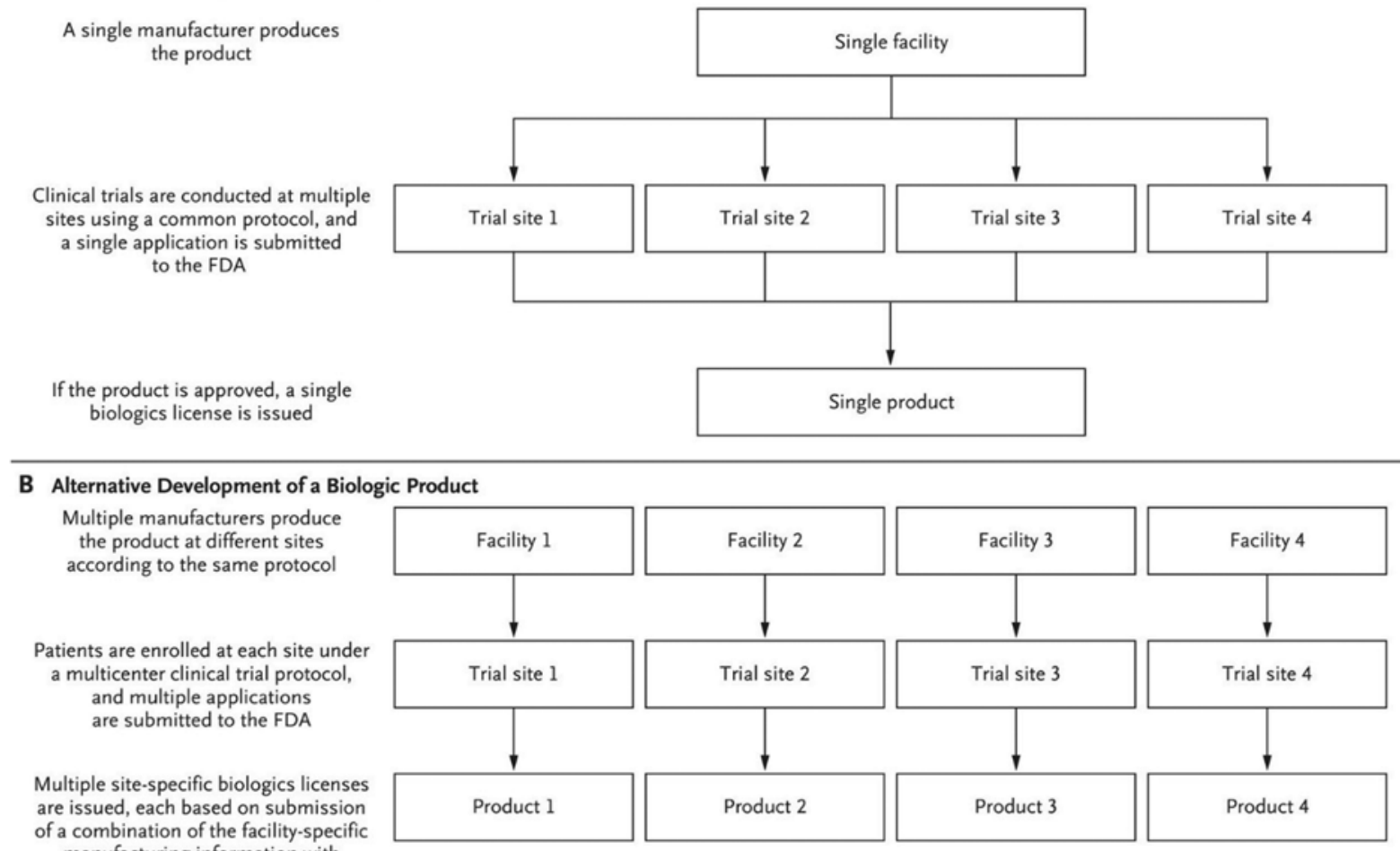

manufacturing information with

the common clinical trial data

from all sites

In the traditional development pipeline (Panel A), a single manufacturer produces the product at a single manufacturing facility and sponsors the clinical trials, which are conducted at multiple clinical sites. The manufacturer ensures that the product is manufactured consistently with appropriate quality control for use at each site and that it is administered pursuant to the protocol. The manufacturer then collects and analyzes the data from the clinical trials and submits a biologics licensing application to the Food and Drug Administration (FDA). If the product is approved, the manufacturer then receives a biologics license to produce and distribute the product. As an alternative to this process (Panel B), multiple manufacturers, which may be individual physicians or groups of physicians, enter into a cooperative development agreement. These manufacturers then produce the product at different sites according the same protocol, which includes appropriate quality-control procedures to help ensure consistency between different lots produced at different sites. Patients are enrolled at each of the sites that are manufacturing the product in a multicenter clinical trial protocol. Once the data from the multicenter trial are analyzed to evaluate the safety and efficacy of the product, the individual physicians or groups of physicians submit a biologics licensing application that includes the manufacturing protocol used, the clinical data obtained at the individual site, and the results of the multicenter clinical trial showing safety and efficacy. This ultimately results in the issuance of a site-specific biologics license for the product made by each physician or group of physicians.

Fig. 31. Traditional versus alternative development of a biologic product.

Source: Marks P, Gottlieb S. Balancing safety and innovation for cell-based regenerative medicine. N Engl J Med 2018 378:954-959 (297).

1. State Medical Boards raise awareness among licensee of applicable federal and state legislation and guidelines regarding regenerative and stem cell therapies, including "right to try" legislation existing or pending at the state and federal levels. State medical boards should also keep their licensees and the public apprised of new developments and regulations in the field of regenerative and stem cell therapies including educational sources, guidance documents, and appropriate industry and stakeholder information on a state medical board's website. State medical boards should further provide information as to reporting procedures of adverse actions related to stem cell interventions.

2. State medical boards should examine their policies and rules addressing informed consent and con- 
Table 17. Co-opted tokens of scientific legitimacy.

\begin{tabular}{|l|l||}
\hline Accreditations and awards & $\begin{array}{l}\text { Asserting certification of products or practices by international standards organizations or claiming training } \\
\text { certification }\end{array}$ \\
\hline Boards and advisers & $\begin{array}{l}\text { Convening scientific or medical advisory boards featuring prominent business leaders and academic faculty } \\
\text { members }\end{array}$ \\
\hline Clinical study registration & Registering trials whose apparent purpose is solely to attract patients willing to pay to participate in them \\
\hline Ethics review & Using the imprimatur of "ethics review" to convey a sense of legitimacy to their products or procedures \\
\hline Location & Renting of laboratory or business space within a legitimate scientific or government institution \\
\hline Membership & Joining established academic or professional societies to suggest legitimacy by association \\
\hline Outcome registries & Publication of open ended voluntary monitoring data sets rather than undertaking controlled clinical trials \\
\hline Patenting & $\begin{array}{l}\text { Suggesting that patent applications or grants indicate clinical utility rather than initiation of an application } \\
\text { process or recognition of novelty and inventiveness }\end{array}$ \\
\hline Publication & Publishing research and commentary in journals with limited anonymous peer review \\
\hline Rationales & $\begin{array}{l}\text { Citing preclinical and other research findings to justify clinical application without sufficient efficacy testing } \\
\text { in humans }\end{array}$ \\
\hline Self regulation & Forming organizations to self regulate in ways that support premature commercialization \\
\hline Technical language & $\begin{array}{l}\text { Using scientific sounding words that imply academic rigor } \\
\text { Testimonials and endorsements }\end{array}$ \\
\hline Testimonials and endorsements & Providing expert opinions or celebrity comments on unsupported clinical uses or standing of the provider \\
\hline
\end{tabular}

Source: Sipp D, Caulfield T, Kaye J, et al. Marketing of unproven stem cell based interventions: A call to action. Sci Transl Med 2017; 9(397) (328).

sider expanding these to include a shared decision making framework that includes the following general elements at a minimum:

- An explanation, discussion, and comparison of treatment options with the patient

- An assessment of the patient's values and preferences

- Arrival at a decision in partnership with the patient

- An evaluation of the patient's decision in partnership with the patient

3. State medical boards should review professional marketing materials and claims, including any office/clinic and/or doctor websites, and information publicly available about an office/clinic or licensee on online blogs or social media, as information sources in the investigation of complaints made against physicians.

4. State medical boards should proactively monitor warning letters sent to licensees that are made publicly available on the FDA website in order to ascertain information, and consider opening an investigation, about licensees who may be engaged in other unscrupulous or unprofessional practices related to the provision of regenerative and stem cell therapy. State medical boards should investigate such practices, when appropriate, in conjunction with applicable state laws, policies, and procedures (329).
Table 18. Draft FSMB stem cell recommendations.

\begin{tabular}{|l||}
\hline 1. Med Boards should raise awareness amongst licensees \& \\
\hline 2. Examine rules on consent, potentially update \& \\
\hline 3. Review clinic claims and marketing materials \& \\
\hline 4. Follow-up on FDA warnings \\
\hline 5. Physicians should know patients well, stay in area of training \& \\
\hline 6. Use caution in areas w/o evidence, exhaust standards of care 1st \& \\
\hline 7. Avoid deceptive claims, raising expectations \& \\
\hline 8. Don't use gag orders, disclaimers to avoid liability \& \\
\hline 9. Support claims w/evidence including peer reviewed papers \& \\
\hline 10. Avoid excessive fees \\
\hline
\end{tabular}

Source: Draft report of the FSMB Workgroup to study regenerative and stem cell therapy practices, December 2017 (41).

5. Physicians must only offer treatments to patients for which they have a bona fide physician patient relationship. Physicians must have received adequate and appropriate training, and be able to perform any proposed interventions safely and competently (330).

6. Where evidence is unavailable for a particular treatment in the form of clinical trials or case studies, physicians must only proceed with an appropriate rationale for the proposed treatment, and justification of its use, in relation to the patient's symptoms or condition. Novel, experimental, and 
Pain Physician: Guidelines Issue 2019; 22:S1-S74

Table 19. Regulations applicable to stem cell based products adapted from regulatory focus.org Nov 2012 (351).

\begin{tabular}{|l|l|l|}
\hline Treatment product & Guidance and Legislation & Regulatory Law \\
\hline $\begin{array}{l}\text { Human stem cell, tissue, or cellular-based } \\
\text { products (HCT/P) }\end{array}$ & Section 361, Public Health Service Act, Infectious disease & 21 CFR 12711.3(d) \\
\hline Biologics & $\begin{array}{l}\text { Section 361, Public Health Service Act, Premarket approval, safety and } \\
\text { effectiveness }\end{array}$ & 21 CFR 600 \\
\hline Drugs & Food, Drug, and Cosmetic Act & 21 CFR 200 \\
\hline $\begin{array}{l}\text { Cell therapy and gene therapy when genetic } \\
\text { material is transferred to cells ex vivo }\end{array}$ & $\begin{array}{l}\text { Application of Current Statutory Authorities to Human Somatic Cell } \\
\text { Therapy Product and Gene Therapy Products, 14 Oct 1993 }\end{array}$ & $\begin{array}{l}\text { US Public Health Service. Guideline on Infectious Disease Issues in } \\
\text { Xenotransplantation, FDA 28 January 1997 }\end{array}$ \\
\hline Xenotransplantation & & 21 CFR 800 \\
\hline Medical devices & &
\end{tabular}

unproven interventions should only be proposed when traditional or accepted proven treatment modalities have been exhausted. In such instances, there must still be a basis in theory or peer reviewed acknowledged practice (331).

7. Physicians should employ a "shared decision-making" process when discussing treatment options with patients. Physicians must avoid any claims that may be deceptive or are intentionally or knowingly false or misleading, especially in terms of making promises about uncertain or unrealistic outcomes.

8. Physicians should not use gag orders (rulings that a case must not be discussed publicly) or disclaimers as a way to circumvent liability.

9. Physicians should be prepared to support any claims made about benefits of treatments or devices with documented evidence, for example with studies published in peer reviewed publications.

10. Physicians should refrain from charging excessive fees for treatments provided. Further, physicians should not recommend, provide, or charge for unnecessary medical services, nor should they make intentional misrepresentations to increase the level of payment they receive.

\subsection{Clinical Guidelines}

Key questions 8, 9, and 10

8. What are the adverse consequences/harms of regenerative injection therapy?

9. What are the best preventive and therapeutic strategies to improve outcomes when performing regenerative injection therapy?

10. What comprises responsible performance of regenerative injection therapy?

Beyond the general indications discussed above, the guidelines presented below for the most appropriate treatment will offer recommendation based on the area of treatment, chronicity, and the type of injection. These recommendations will also consider the use of biologic therapy in an algorithm of treatment (first-line or other); obtaining a diagnosis necessary to initiate therapy; having knowledge of the number of treatments suggested to improve subjective pain and objective functional improvement scores; as well as employing evidence-based research in the use of regenerative therapies for a given condition.

\subsection{Safety, Efficacy, and Informed Decision}

To enhance safety, the patient should be considered a partner and should consider this therapy as an investment as a consumer. Consumers are encouraged to become empowered with as much reliable and independently verified information as possible. Individuals should ask whether the treatment is routine, if there is any scientific data to predict an expected response, and should ask about any benefits or adverse effects of the treatment. Consumers also should be instructed to learn about how the therapy works and understand how the treatment will be performed. They should also be committed to any follow-up visits and treatments that are necessary.

It cannot be emphasized enough, that before all interventional procedures, a consent form should be discussed with the patient and signed by both the provider and the patient. Risks and benefits of the procedure must be discussed, as well as giving a verbal review of the inclusion and exclusion criteria; this will prevent any future incidental errors or miscommunication in patient assumptions that the provider is fully aware of every medical problem they may have.

Factors a patient may want to consider before undergoing a cell therapy procedure include the following:

1. Physician Selection: Consumers must ensure that the physician who performs the treatment holds a 
medical license and is board certified in the specific field of medicine or treating specialty for the condition being addressed. Consumers also must ensure that the physician performing the treatments is appropriately trained and, if necessary, holds at least a competency certification in regenerative medicine, if available, from an organization widely accepted, with rigorous testing of their fund of knowledge, and clinical and technical competency, such as the American Board of Interventional Pain Physicians (ABIPP) (www.abipp.org).

2. Location Selection: The consumer also should assess the facility where the treatment will be given and determine whether the personnel at that facility are knowledgeable, trained in the particular area, and know what to do in an emergency situation. Informed decision making also includes understanding the regulatory oversight, certification. and accreditation process.

3. Medical Claims: Claims such as "miracle cure" or claims to cure serious conditions often are not credible and may pose a significant risk to public health and safety. All claims made by clinics and/ or physicians should be based on accepted and acknowledged scientific evidence and medical experience. Claims of safety should be based upon the collection of data through an established and accepted grading scale, such as the Adverse Event Reporting system used by the U.S. Department of Health and Human Services Office of Human Research Protections.

4. Travel for Therapies: Consumers considering stem cell transplantation in the U.S. should ask their physicians if the necessary Food and Drug Administration, or FDA, approval has been obtained, or if the procedure will be part of an FDA-regulated clinical study.

5. Shared Decision-Making: Shared decision-making has been described as one of the fundamental approaches to improving the quality of US health care (332). The Institute of Medicine (IOM), now the National Academy of Sciences, defined patient-centered care as "care that is respectful of and responsive to individual patient preferences, needs, and values," and that ensures "that patient values guide all clinical decisions (333)." As the definition implies, the most important attribute of patient-centered care is the active engagement of patients when fateful health care decisions must be made - when an individual patient arrives at a crossroads of medical options, where the diverging paths have different and important consequences with lasting implications (332). Usual examples described are major surgeries, medications that must be taken for the rest of one's life, and screening and diagnostic tests that can trigger cascades of serious and stressful interventions. To add to these complex medical issues is decision-making related to regenerative therapies, which also incorporates financial implications as most insurers do not cover these procedures, multiple ethical issues including false advertising, and lackluster evidence - though evidence is evolving rapidly in favor of regenerative therapy. Through shared decision-making, apart from avoiding over diagnosis and over treatment, clinicians can help patients understand the importance of their values and preferences in making the decisions that are best for them (334). The present evidence shows that when patients know they have options for the best treatment, most of them will want to participate with their clinicians in making the choice. Consequently, clinicians need to relinquish their role as the single paternalistic authority and train to become more effective coaches or partners focusing on what matters to the patients and considering their wishes. Thus, shared decisionmaking is crucial in regenerative therapy.

6. Informed Consent: Informed consent to medical treatment is fundamental to both ethics and law. Patients have the right to receive information and ask questions about recommended treatments so that they can make well-considered decisions about care. Successful communication in the patient-physician relationship fosters trust and supports shared decision-making as described above.

In obtaining informed consent, physicians should assess the patients ability to understand the relevant medical information and the implications of the treatment alternatives and to make an independent, voluntary decision. The physician should include information about the diagnosis, the nature and purpose of recommended interventions, the burdens, risks, and expected benefits of all options, including foregoing treatment.

It is crucial to obtain informed consent in regenerative therapy considering the various issues described throughout this manuscript specifically due to the lack of an appropriate wealth of evidence, widespread guidelines except the present ones, highly prevalent fraud and abuse, and the expenses of the treatment. 
There must be personal reflection, research, and due diligence practiced in all areas of the procedure in order to deliver safe and effective therapy. It is encouraged that providers not only personally research available publications, but also personally cooperate with the manufacturers of their chose extraction kits; attend continuing medical education sessions regarding injection techniques including those with ultrasound guidance; and personally, review his or her equipment to ensure high-quality industry standards.

\subsection{Office Set-Up}

The environment in which a stem cell injection occurs must be a highly aseptic environment with comprehensive controls of both raw materials and handlers. To reach affordability and mass scale, the production process should be highly reproducible and validated both on a small scale for a single patient and on a large scale of a multitude of patients. The physicians performing the procedures need to be properly trained and comfortable in performing the interventional techniques. They must be ready and available to handle any resulting complications at all times, and be available on-call for emergencies that may ensue from the procedure.

\subsection{Contraindications}

Multiple contraindications described in the literature include:

- Hematologic blood dyscrasias

- Platelet dysfunction

- Septicemia or fever

- Cutaneous infections in the area to be injected

- Anemia (hemoglobin less than $10 \mathrm{~g} / \mathrm{dl}$ )

- Malignancy, particularly with hematologic or bony involvement

- Allergy to bovine products if bovine thrombus is to be used

- Severe psychiatric impairment or unrealistic expectation

For an autologous therapy procedure, cell harvesting from the patient will be aimed at collecting healthy cells whenever this is possible. This is an especially important consideration for patients with inherited diseases. A disease with $100 \%$ mosaicism would be a contraindication for autologous biologic therapy, as every cell would carry the undesirable mutation. However, lesser degrees of mosaicism become a relative contraindication. For example, mosaicism in hemophilia is found in only $30 \%$ of cases, thus leaving $70 \%$ of such patients with the potential to benefit from MSC or PRP therapy. Thus, consultation with a genetic specialist should be considered. There should be some awareness that abnormal proteins including those related to Parkinson's and Alzheimer's disease may be found in tissues throughout the body and may constitute a source of inadvertent spread of a prion-like effect.

\subsection{Pre, Intra, and Post Procedural Considerations}

The following recommendations are generally acceptable guidelines followed by practitioners for preinjection management of the patient:

1. The patient candidacy requirements, as emphasized above, are met. Imaging modalities must also demonstrate the pathology, and can include MRI, computed tomography (CT) scan, ultrasound, or $\mathrm{x}$ ray as appropriate for viewing a specific pathology.

2. The patient should avoid the use of any corticosteroids two or three weeks before the procedure. Also, NSAIDs are avoided within one week of the procedure; any necessary anticoagulation precautions should be taken before the procedure as recommended by consensus guidelines from ASIPP and American Society of Regional Anesthesia and Pain Medicine (335,336).

3. Before and during the procedure, anti-anxiety medications and mild sedation may be required for certain patients. However, deep sedation should be avoided ensuring that the patients are arousable and alert at all times.

Considerations for pre-injection management of biologic materials include:

1. To be clinically effective, it is agreed that platelet concentration in an injectate should be at least 2.5 times greater than the baseline plasma concentration (174).

2. The biologics follow the FDA recommended "minimal manipulation" and "homologous use" draft guidelines in clinical practice.

3. Cell viability is comparable between fresh extraction, 24 hours, and 72 hours, though proliferation may be enhanced at 24 hours. It is recommended to use the cells within 24 hours of thawing from a frozen medium (337) if so used.

4. The tri-lineage capabilities, differentiation, and 
viability of MSCs are not affected by the gauge (G) of the needle used to extract them (when 19G, $21 \mathrm{G}$, and $23 \mathrm{G}$ needles were compared), although it has been found that a $19 \mathrm{G}$ needle reduced the incidence of apoptosis (337).

5. A $2 \mathrm{~mL}$ syringe is recommended to avoid overinflation. The majority of available studies are also performed with this value (337).

We recommend the following considerations for intra-injection management (337):

1. Cell material, patient, joint location and effected side should be verified before injection.

2. Materials should be injected under direct visualization with image guidance such as with ultrasound, fluoroscopic, CT, MRI or arthroscopidendoscopic guidance.

The following recommendations are crucial for post-injection management:

1. Patients should be instructed to rest and partially immobilize the injected body part for a few days to 2 weeks.

2. The patient should avoid anti-inflammatory medications for at least a few weeks postoperatively, as the therapy is grounded in the benefit of the patient's inflammatory cascade. The risks and benefits for Aspirin should be reviewed in conjunction with the patient and the clinician prescribing it.

3. Post-operative instructions should be verbally discussed with the patient and the person driving the patient home. Red flags and appropriate pain control measures should also be reviewed. A written copy of the instructions should be given to the patient or the patient's driver prior to discharge.

4. Close follow-up should be scheduled every 2-4 weeks post-procedure. Follow-ups can extend to 1 or 2 times per year once there has been a demonstration of significant subjective and objective report of improvement in pain and function and is based on the discretion of the clinic thereafter.

The following course of action is recommended for continued therapy:

1. Repeat injections may be required, depending on the patient's response. This in turn may depend on several factors including the nature and extent of the pathology, the type and quality of the biologic used, the baseline health status of an individual, and the injection technique. These factors are important and should be taken into account when considering regenerative medicine treatments for patients. Pain and functional improvements are the most likely effected outcomes as opposed to any structural improvement given the limitations of the currently available biologics.

2. Frequent repeat imaging is not recommended unless there has been a change in patient symptoms or pathology. However, obtaining an x-ray to determine improvement in a joint space or as an indirect assessment of cartilage interval while treating osteoarthritis or obtaining an MRI scan to identify changes in soft tissue structures including articular cartilage, may be considered necessary.

\subsection{Antithrombotic Implications}

\subsubsection{Risks in Regenerative Medicine}

Bone marrow aspiration and intra-articular/soft tissue injections have low risks of bleeding, while central nervous system/meningeal related injections have a higher risk of bleeding. A comprehensive review with literary search was conducted by ASIPP (336) analyzing various guidelines which produced recommendations specific to interventional techniques and the associated risk of bleeding. These recommendations are dependent on multiple factors including the patient's risk factors and the managing physician's opinion (8,335-342). While bleeding risk is present with any interventional procedure, thromboembolic events must be considered equally and must be clinically correlated in relation to a patient's past medical history, social history, and risk of each relative to these factors.

With respect to NSAIDS and aspirin when used in interventional techniques, there is little to no risk of bleeding at low doses. High doses of these medications should be evaluated and altered if the clinician correlates their medication status with previous episodes of heavy bleeding $(8,335,336,341)$. Many patients may be taking additional medications that increase their risk of bleeding or supplements such as selective serotonin reuptake inhibitors (SSRIs), fish oil, garlic, and many others. Phosphodiesterase inhibitors also do not significantly increase the risk of bleeding in interventional techniques; however, they may or may not be discontinued in accordance with patient history $(8,335,336,341)$. It has been suggested that platelet aggregation inhibitors such as ticlopidine, clopidogrel, and prasugrel 
should be discontinued 7 to 10 days before an interventional technique is performed. While some studies indicate that 3 days is effective, the American Society of Regional Anesthesia and Pain Medicine (ASRA) consensus is at least 7 days is needed before a central nervous system related injection $(8,335,336,341)$.

Warfarin is more complicated in regards to discontinuation, as much of the clinical decision-making depends on a patient's international normalized ratio (INR) achieved during therapy and trends associated with INR over the past few months. For high-risk interventional techniques such as interlaminar epidural injections, warfarin may need to be discontinued until an INR of 1.4 or less is achieved. For lower risk procedures, an INR of 2 is an appropriate level to achieve before undergoing these techniques $(8,335,336,341)$. There is limited evidence to suggest that unfractionated or low molecular weight heparins should be discontinued prior to interventional techniques, but the current suggestion is 12 hours of discontinuation before central nervous system-related injections.

Similar to INR values in Warfarin, renal function values significantly alter clinical decision-making in relation to dabigatran (Pradaxa). In procedures with a high risk of bleeding, creatinine clearance greater than $50 \mathrm{~mL}$ per minute in patients allows a 2- to 4-day period of discontinuation. However, in those with 50 $\mathrm{mL}$ per minute or less, a period of 4 to 5 days is currently suggested before central nervous system-related interventional techniques.

\subsubsection{Effects of Antithrombotic Therapy on PRP and Stem Cell Efficacy}

The biochemical pathways of the coagulation cascade are key in that the disruption of platelet surfaces or prematurely activated platelets may cause the limited efficacy of the clinical procedure (342). Furthermore, with the recent advent of MSC technology in regenerative medicine, it is important to consider the viability of these cells in the context of antithrombotic therapy. To that end, the effects of heparin on ex vivo MSCs recovered from bone marrow showed that supplementation of even low doses of heparin could adversely impact the growth and differentiation potential of this pleiotropic cell type (343). Therefore, it is important to evaluate bone marrow tissue in patients receiving heparin treatment particularly if ex vivo expansion hMSCs is to occur.

The use of PRP is increasing due to its ligament and tendon healing potential. It is also considered to be a natural alternative to surgery. However, anticoagulants and antiplatelet drugs are commonly used in patients who are candidates for receipt of PRP. Alternatively, the use of an anticoagulant, while not taken systemically, is required to process PRP to prevent automatic activation. Since antithrombotic agents influence the stability of platelets, they are, therefore, likely to exert an effect on PRP efficacy as well and should be ceased at a suitable timeframe preceding injection therapy (344). PRP has been shown to significantly improve the proliferation of differentiated cells, enhance synthesis of collagen, and prompt angiogenesis and revascularization, all of which aid regeneration. The study by Sutherland and colleagues (344) in 2005 eloquently demonstrated the utility of autologous MSCs in regenerative medicine using sheep through reconstruction of stem cell tissueengineered heart valves.

The healing influence of the dispensation of PRP depends on the bioactive amalgams such as cytokines and growth factors that are being released (via activation and aggregation) precisely to the location of the injury. The characteristic of the platelets confined in autologous PRP (mainly exhibited by the potential of activation and aggregation of platelets) may be essential (345).

NSAIDs are depicted to have negative influences on platelets such as inhibition of activation, a decrease in storage of alpha granules, and aggregation of platelets. The negative impact of these medications on platelet activation and aggregation may be significant since a substandard quality of autologous PRP is emitted post-NSAID therapy. The coherent substantial inhibition of platelet function such as aggregation acquired post stimulation using arachidonic acid within the NSAID designated study group was found, regardless of NSAID duration, type of ingestion, and the blood compendium technique used for PRP formulation (345). Without NSAIDs intake, such effects could not be observed in the healthy control group. NSAID's impede cyclo-oxygenase-mediated oxygen utilization and therefore prevent platelet activation and aggregation (345). Moreover, bioactive compounds such as TGF- $\alpha$, growth factors, and platelet factor 4 stored in the alpha granules, cannot be released adequately if NSAIDs bar this pathway, and platelet function is drastically compromised. Thus, such stipulations validate the hypothesis that autologous PRP generated after NSAID intake is of inferior attribute, and therefore, may negatively influence the healing outcomes.

NSAIDs are essential to control pain in the posttraumatic setting. While NSAIDs can interfere with bone 
healing, some contradict these findings (346). Although NSAID analgesic potency is well documented, clinicians continue to questions the associated safety issues. A 2012 study of the effects of NSAIDs on bone healing in animals reveal very mixed results (346). However, the authors' conclusion correctly notes that the "lack of evidence does not constitute the absence of an effect" and further cautions that the clinician should [continue to] treat NSAIDs as a risk factor for bone healing impairment and should be avoided in high-risk patients" (346).

Ramsook and Danesh (342) described issues related to PRP injections and antithrombotic therapy. They discussed the importance of understanding the intrinsic and extensive pathways of the coagulation cascade and that any disruption of this mechanism may result in prematurely activated platelets and therefore limited efficacy. They also made clear that antithrombotic agents affect platelet stability and will have an effect on PRP efficacy and must be discontinued at an appropriate time frame prior to injection therapy. Overall, the general rules appear to be the same for antithrombotic and anticoagulant agents similar to utilization in interventional techniques as described above.

However, there is a significant paucity of literature in regards to the safety, efficacy, and timing of PRP injections in patients with concomitant antithrombotic therapy. The importance of an intact platelet surface membrane allows for the appropriate release of the healing bioproteins and growth factors granting PRP therapy its efficacy. Antithrombotic agents that affect the stability of platelets will have an effect on PRP efficacy and must be discontinued at an appropriate time frame prior to injection therapy. With future research, appropriate guidelines may be established not only for PRP, but also for stem cell therapy.

\subsubsection{Safe and Efficient Administration of Regenerative Medicine}

If it is deemed advisable that antithrombotic therapy should be halted (even temporarily), then thromboembolic risk determines if bridging is necessary. "Heparin bridging" involves discontinuing warfarin 4-5 days prior to a procedure while using subcutaneous low molecular weight heparin (LMWH) to maintain anticoagulation until the day prior to the procedure. This mitigates thromboembolic risk during the time the patient is off warfarin by effectively shortening the amount of time the patient is not anticoagulated. LMWH has a shorter half-life than warfarin and can be discontinued the day prior to the procedure.
Bridging with subcutaneous LMWH is appropriate and reliable. For patients who have chronic kidney disease, the LMWH should be decreased in dose or substituted by intravenous unfractionated heparin. For atrial fibrillation patients, the American Heart Association (AHA) advocates a once-daily therapeutic dose of LMWH, with half the dose to be taken at dawn of the day before the procedure (347). Moreover, therapeutic LMWH should be taken up again 24 to 72 hours post procedure, dependent on the bleeding risk of the technique. Warfarin therapy ought to be resumed when viable. It is vital to consider that bridging could lead to unexpected post-op bleeding after anticoagulants are resumed.

International guidelines reflect the differing views on the safe interval between cessation of antithrombotic therapies and implementation of neuraxial and peripheral procedures, and for the re-introduction of the therapeutic drug regimen.

While 2 to 3 half-life intervals might be adequate in patients who are at excessive threat of venous thromboembolism (VTE) or stroke, an interval of 4 to 6 half-lives amid the cessation of the drug and neuraxial injection is reliable in the majority of patients at a lowlevel risk of thrombosis (348). However, in patients with kidney disease, the interval should be calculated on creatinine clearance. In particular instances, laboratory monitoring of the antithrombotic effect is applicable, and reversal agents may be suitable when a hemostatic function requires rapid restoration.

\subsection{Adverse Reactions and Complications}

Health care consumers must be informed of all aspects of potential therapies, risks, benefits, and indications. Risks may include, but are not limited to, infection, tissue rejection and changes in the characteristics of the cells in the product that may alter how they respond. PRP therapies derive their benefit from localized inflammation, and can thus cause worsening pain and sensations of pressure before healing demonstrates increased functionality. Generalized rest and restraining from the use of NSAID medications are important to optimize therapy.

A final concern for the use of biologic therapies is the induction of neoplasms from undifferentiated cells in high volume. A multicenter analysis of over 2,300 patients treated with MSCs (bone marrow and adipose included) for musculoskeletal conditions demonstrated that after nine years, only seven patients developed a neoplasm. This is lower than the rate of neoplasm development in the general population, MSC therapy is therefore not 
considered causative (349). The review also noted that the majority of postoperative complications were very few, but included pain post-procedure (3.9\%), and pain due to continued degeneration of the joint (3.8\%) (349).

\subsection{Guidance for Responsible, Safe, ANd Effective Use of Biologics}

The current body of evidence on the use of biologics for the spine is limited. Previous systematic literature reviews, such as the 2015 review by Nourissat et al (350) reiterate the lack of many well-designed RCTs regarding PRP use in the most common tendinopathies' and suggest that while PRP treatment for acute or chronic tendinopathy is more beneficial than standard nonintervention techniques of NSAIDs and rest, it should be considered after failure of ultrasound-guided corticosteroid injection into the specific tendon.

The variation of follow-up for the studies has ranged from 6 weeks to 3 years before conclusions were drawn. Of the studies reviewed, there has been a demonstration of benefit with the initial injection/injection series that can last from 6 months to 24 months. Studies requiring a repeat of the injection series after 24 months should be conducted to determine the maximum duration of time that can remain between series.

The lack of standardization of methodology and analysis is a handicap to the ability to reproduce the same models or make declarative recommendations. Since the factors at play in healing and regeneration are still unknown, clinicians continue to test new combinations, contributing to the heterogeneity in composition, techniques and outcomes (350-353).

In regard to cost, corticosteroid injections are cheaper than PRP and are the current standard of care for chronic conditions of joint degeneration. For this reason and in consistency with current guidelines from musculoskeletal interventional pain management, and national guidelines as listed in Table 19 (351), PRP is considered in patients after corticosteroids fail, or are deemed no longer appropriate for corticosteroid use. This may however, change depending on availability of more robust data on safety and long-term effectiveness of biologics when compared to corticosteroids.

\subsection{Conclusion}

Both PRP and MSCs are used autogenously to supplement the healing process. Their natural properties are being discovered, including functional strengths and limitations. The guidelines presented have reviewed studies that both confirm and refute current uses of these biologics. In general, PRP is a concentration of inflammatory mediators and growth factors that complement healing in injured tissues. Biologics are considered by many to be a more economic and expedited healing approach and are becoming a reasonable alternative to patients that fail standard of care treatments. Based on the available literature, treatments for lumbar discs, facet and sacroiliac joints are performed in conjunction with a definitive diagnosis, and after the patient has tried and failed conservative therapy. The published studies have reported the results of single injection biologic use on chronic pathology which has provided short-term relief. PRP has been the most commonly utilized biologic within the lumbar spine.

The survival of the clinical use of biologics depends on the standardization of their use, the consistency of outcomes, and on the documentation of an overall decrease in healthcare costs. This can be achieved by the publication of high-quality studies which will increase the predictability in the use of biologic therapy. These efforts, on behalf of our patients and to ensure the future of Regenerative Medicine, will require dedication on the part of all stakeholders to move the science and technology of biologic therapy forward.

\section{Acknowledgments}

The authors wish to thank Tonie M. Hatton and Diane E. Neihoff, transcriptionists, for their assistance in preparation of this manuscript. We would like to thank the editorial board of Pain Physician for review and criticism in improving the manuscript.

\section{Disclosures}

Funding: There was no external funding in the preparation of this manuscript.

\section{Author Affiliations}

'Dr. Navani is Medical Director, Comprehensive Spine \& Sports Center, Campbell, CA, and Adjunct Clinical Associate Professor, Stanford University School of Medicine, Stanford, CA.

${ }^{2}$ Dr. Manchikanti is Medical Director of the Pain Management Center of Paducah, Paducah, KY, and Clinical Professor, Anesthesiology and Perioperative Medicine, University of Louisville, Louisville, KY.

${ }^{3}$ Dr. Albers is Director of Research, Radiology Research and Consultation, Sacramento, CA.

${ }^{4}$ Dr. Latchaw is a Professor of Radiology, Department of Radiology, UC-Davis Medical Center, Sacramento, 
CA.

${ }^{5}$ Dr. Sanapati, Pre-Intern, University Pain Medicine and Rehabilitation Center, Department of Physical Medicine and Rehabilitation, Rutgers New Jersey Medical School

${ }^{6}$ Dr. Kaye is Professor, Program Director, and Chairman, Department of Anesthesiology, Louisiana State University Health Science Center, New Orleans, LA.

${ }^{7}$ Dr. Atluri is Medical Director, Tri-State Spine Care Institute, Cincinnati, $\mathrm{OH}$

${ }^{8}$ Dr. Jordan is a neurologist at Neurological Associates of West Los Angeles, Santa Monica, CA

${ }^{9} \mathrm{Dr}$. Gupta is Associate Director of Research at Millennium Pain Center, Bloomington, IL; Chief Science Officer at South Texas Orthopaedic Research Institute, Laredo, TX; and Adjunct Researcher at Illinois Wesleyan University, Bloomington, IL

${ }^{10}$ Dr. Cedeno, Millennium Pain Center, Department of Psychology, Illinois Wesleyan University, and Stimgenics LLC, Bloomington, IL

${ }^{11} \mathrm{Mr}$. Vallejo, Millennium Pain Center, Bloomington, IL

${ }^{12}$ Bert Fellows is Director Emeritus of Psychological Services at the Pain Management Center of Paducah, Paducah, KY.

${ }^{13} \mathrm{Dr}$. Knezevic is Vice Chair for Research and Education, Advocate Illinois Masonic Medical Center, and Clinical Associate Professor of Anesthesiology and Surgery, University of Illinois, Chicago, IL.

${ }^{14} \mathrm{Dr}$. Pappolla is Medical Director, St. Michael's Pain and Spine Clinics, Houston, TX, and Professor of Neurology, Univeristy of Texas Medical Branch, Galveston, TX.

${ }^{15}$ Dr. Diwan is President, Park Avenue Spine and Pain, New York, NY

${ }^{16} \mathrm{Dr}$. Trescot is the Director, The Pain \& Headache Center, Eagle River, AK.

${ }^{17} \mathrm{Dr}$. Soin is Medical Director, Ohio Pain Clinic, Centerville, $\mathrm{OH}$ and Clinical Assistant Professor of Surgery at Wright State University, Dayton, $\mathrm{OH}$.

${ }^{18}$ Dr. A. M. Kaye is Clinical Professor of Pharmacy, Thomas J. Long School of Pharmacy and Health Sciences, University of the Pacific, Stockton, CA.

${ }^{19} \mathrm{Dr}$. Aydin is Chief of PMR \& Interventional Pain Management, Kayal Orthopaedic Center, PC, Franklin Lakes, $\mathrm{NJ}$, and Clinical Assistant Professor of PMR, Northwell Health-Hofstra School of Medicine, New York, NY.

${ }^{20} \mathrm{Dr}$. Calodney is Director of Clinical Research, Precision Spine Care, Baylor Scott and White Texas Spine and Joint Hospital, Tyler, TX.

${ }^{21} \mathrm{Dr}$. Candido is Chairman, Department of Anesthesiology, Advocate Illinois Masonic Medical Center, Professor of Clinical Anesthesiology, and Clinical Professor of Surgery, University of Illinois College of Medicine, Chicago, IL.

${ }^{22} \mathrm{Dr}$. Bakshi is an interventional pain physician at Lenox Hill Hospital, New York, NY.

${ }^{23} \mathrm{Dr}$. Benyamin is Medical Director, Millennium Pain Center, Bloomington, IL, Clinical Assistant Professor of Surgery, College of Medicine, University of Illinois, Urbana-Champaign, IL, Department of Psychology, Illinois Wesleyan University, and Stimgenics LLC, Bloomington IL

${ }^{24} \mathrm{Dr}$. Vallejo is Director of Research, Millennium Pain Center, Adjunct Research Professor, Illinois Wesleyan University, Bloomington, IL, and Stimgenics LLC, Bloomington, IL

${ }^{25} \mathrm{Dr}$. Watanabe is an Interventional Pain Physician, Mt. Baker Pain Center, Bellingham, WA.

${ }^{26} \mathrm{Dr}$. Beall is Chief of Radiology Services, Clinical Radiology of Oklahoma, Oklahoma City, OK

${ }^{27} \mathrm{Dr}$. Stitik is Director, Musculoskeletal/Occupational Medicine, Associate Professor, Department of Physical Medicine \& Rehabilitation, Rutgers-New Jersey Medical School, Newark, NJ

${ }^{28} \mathrm{Dr}$. Foye is Professor Clinical Chair, Department of Physical Medicine \& Rehabilitation, Co-Director, Musculoskeletal Medicine, PM\&R, Director, Coccyx Pain Center (Tailbone Pain Center), PM\&R, Newark, NJ

${ }^{29} \mathrm{Dr}$. Helander, Assistant Professor, Department of Anesthesiology, Louisiana State University Health Sciences Center, New Orleans, LA

${ }^{30} \mathrm{Dr}$. Hirsch is Vice Chief of Interventional Care, Quality and Safety; Service Line Chief of Interventional Radiology; Division Chief: Interventional Neuroradiology Chief: Neurolnterventional Spine Service, Massachusetts General Hospital; Harvard Medical School, Boston, MA.

\section{Conflicts of Interest}

Dr. Manchikanti has provided limited consulting services to Semnur Pharmaceuticals, Incorporated, which is developing nonparticulate steroids.

Dr. Kaye is a speaker for Depomed and Merck, Inc.

Dr. Gupta is a Scientific Advisory Board Member for Dunamis Medical and KLSMC Stem Cells Inc.

Dr. Calodney is a consultant for Medtronic, SI-Bone, Stryker, Nevro, and APEX Biologix.

Dr. Benyamin is a consultant for Medtronic Inc., Vertiflex Inc., Vertos Medical Inc.

Dr. Vallejo is a consultant for Medtronic Inc. and Avanos Medical Inc.

Dr. Hirsch is a consultant for Medtronic. 


\title{
Appendix
}

\author{
Appendix Figure 1 \\ Appendix Table 1 \\ Appendix Table 2 \\ Appendix Table 3 \\ Appendix Table 4 \\ Appendix Table 5 \\ Appendix Table 6 \\ Appendix Table 7
}

To view pdf with Appendix links active, visit

Pain Physician journal website

to access manuscript pdf. 


\section{References}

1. Dieleman JL, Baral R, Birger M, Bui AL, Bulchis A, Chapin A, Hamavid H, Horst C, Johnson EK, Joseph J, Lavado R, Lomsadze L, Reynolds A, Squires E, Campbell $M$, DeCenso $B$, Dicker D, Flaxman AD, Gabert R, Highfill T, Naghavi M, Nightingale N, Templin T, Tobias MI, Vos T, Murray CJ. US spending on personal health care and public health, 1996-2013. JAMA 2016; 316:2627-2646.

2. Dieleman JL, Squires E, Bui AL, Campbell $M$, Chapin A, Hamavid H, Horst C, Li Z, Matyasz T, Reynolds A, Sadat $\mathrm{N}$, Schneider MT, Murray CJL. Factors associated with increase in US health care spending, 1996-2013. JAMA 2017; 318:1668-1678.

3. Conway PH. Editorial: Factors associated with increased US health care spending. Implications for controlling health care costs. JAMA 2017; 318:1657-1658.

4. Manchikanti L, Soin A, Mann DP, Bakshi S, Pampati V, Hirsch JA. Reversal of growth of utilization of interventional techniques in managing chronic pain in Medicare population post Affordable Care Act. Pain Physician 2017; 20:551-567.

5. Rajaee SS, Bae HW, Kanim LE, Delamarter RB. Spinal fusion in the United States: Analysis of trends from 1998 to 2008. Spine (Phila Pa 1976) 2012; 37:67-76

6. Bae HW, Rajaee SS, Kanim LE. Nationwide trends in the surgical management of lumbar spinal stenosis. Spine (Phila Pa 1976). 2013;38:916-926.

7. Kim CH, Chung CK, Park CS, Choi B, Kim MJ, Park BJ. Reoperation rate after surgery for lumbar herniated intervertebral disc disease: nationwide cohort study. Spine (Phila Pa 1976) 2013; 38:581-590.

8. Manchikanti L, Abdi S, Atluri S, Benyamin RM, Boswell MV, Buenaventura RM, Bryce DA, Burks PA, Caraway DL, Calodney AK, Cash KA, Christo PJ, Cohen SP, Colson J, Conn A, Cordner HJ Coubarous S, Datta S, Deer TR, Diwan SA, Falco FJE, Fellows B, Geffert SC, Grider JS, Gupta S, Hameed H, Hameed $M$, Hansen $H$, Helm II S, Janata JW, Justiz R, Kaye $A D$, Lee $M$, Manchikanti KN, McManus CD, Onyewu O, Parr AT, Patel VB, Racz GB, Sehgal N, Sharma $M$, Simopoulos TT, Singh V, Smith HS, Snook LT, Swicegood J, Vallejo R, Ward SP, Wargo BW, Zhu J, Hirsch JA. An update of comprehensive evidence-based guidelines for interventional techniques of chronic spinal pain: Part II: Guidance and recommendations. Pain Physician
2013; 16:S49-S283.

9. Manchikanti L, Kaye AM, Knezevic NN, McAnally $\mathrm{H}$, Trescot AM, Blank S, Pampati V, Abdi S, Grider JS, Kaye AD, Manchikanti KN, Cordner HJ, Gharibo CG, Harned ME, Albers SL, Atluri S, Aydin SM, Bakshi S, Barkin R, Benyamin RM, Boswell MV, Buenaventura RM, Calodney AK, Cedeno DL, Datta S, Deer TR, Fellows B, Galan V, Grami V, Hansen $\mathrm{H}$, Helm S 2nd, Justiz R, Koyyalagunta D, Malla Y, Navani A, Nouri K, Pasupuleti R, Sehgal N, Silverman SM, Simopoulos TT, Singh V, Slavin KV, Solanki DR, Staats PS, Vallejo R, Wargo BW, Watanabe A, Hirsch JA. Responsible, safe, and effective prescription of opioids for chronic non-cancer pain: American Society of Interventional Pain Physicians (ASIPP) guidelines. Pain Physician 2017: 20:2S:S3-S92.

10. U.S. Burden of Disease Collaborators. The state of US health, $1990-2010$ : Burden of diseases, injuries, and risk factors. JAMA 2013; 310:591-608.

11. US Burden of Disease Collaborators, Mokdad AH, Ballestros K, Echko M, Glenn S, Olsen HE, Mullany E, Lee A, Khan AR, Ahmadi A, Ferrari AJ, Kasaeian A, Werdecker A, Carter A, Zipkin B, Sartorius B, Serdar B, Sykes BL, Troeger C Fitzmaurice $C$, Rehm CD, Santomauro D, Kim D, Colombara D, Schwebel DC Tsoi D, Kolte D, Nsoesie E, Nichols E, Oren E, Charlson FJ, Patton GC, Roth GA, Hosgood HD, Whiteford HA, Kyu $H$, Erskine $H E$, Huang $H$, Martopullo I, Singh JA, Nachega JB, Sanabria JR, Abbas K, Ong K, Tabb K, Krohn KJ, Cornaby L, Degenhardt L, Moses M, Farvid M, Griswold $M$, Criqui $M$, Bell $M$, Nguyen $M$, Wallin $M$, Mirarefin $M$, Qorbani $M$, Younis $M$, Fullman N, Liu P, Briant $P$, Gona P, Havmoller R, Leung R, Kimokoti R, Bazargan-Hejazi S, Hay SI, Yadgir S, Biryukov S, Vollset SE, Alam T, Frank $\mathrm{T}$, Farid T, Miller T, Vos T, Bärnighausen T, Gebrehiwot TT, Yano Y, Al-Aly Z, Mehari A, Handal A, Kandel A, Anderson B, Biroscak B, Mozaffarian D, Dorsey ER, Ding EL, Park EK, Wagner G, Hu G, Chen H, Sunshine JE, Khubchandani J, Leasher J, Leung J, Salomon J, Unutzer J, Cahill L, Cooper L, Horino M, Brauer M, Breitborde N, Hotez P, Topor-Madry $R$, Soneji $S$, Stranges $S$, James $S$, Amrock $S$, Jayaraman $S$, Patel T, Akinyemiju T, Skirbekk V, Kinfu Y, Bhutta Z, Jonas JB, Murray CJL. The State of US Health, 1990-2016: Burden of Diseases, Injuries, and Risk Factors Among US States. JAMA
2018; 319:1444-1472.

12. Manchikanti L, Helm $S$ 2nd, Benyamin RM, Hirsch JA. A critical analysis of Obamacare: Affordable care or insurance for many and coverage for few? Pain Physician 2017; 20:111-138.

13. Manchikanti L, Hirsch JA. Repeal and replace of affordable care: A complex, but not an impossible task. Pain Physician 2016; 19:E1109-E1113.

14. Hirsch JA, Rosenkrantz AB, Nicola GN, Harvey HB, Duszak R Jr, Silva E zrd, Barr RM, Klucznik RP, Brook AL, Manchikanti L. Contextualizing the first-round failure of the AHCA: Down but not out. J Neurointerv Surg 2017; 9:595-600.

15. Hirsch JA, Leslie-Mazwi TM, Barr RM, McGinty G, Nicola GN, Patel AB, Manchikanti L. The Burwell roadmap. J Neurointerv Surg 2016; 8:544-546.

16. Cannon MF. Is Obamacare harming quality? (Part 1). Health Affairs, January 4, 2018.

https://www.healthaffairs.org/ do/10.1377/hblog20180103.261091/full/

17. Manchikanti L, Navani A. Evolution of regenerative medicine in managing chronic pain. In: Manchikanti L, Navani A, Atluri S (eds). Essentials of Regenerative Medicine in Interventional Pain Management. ASIPP Publishing, Paducah, KY 2019, IN PRESS.

18. Manchikanti L, Navani A, Singh V, Falco FJE, Hirsch JA. Intradiscal injection of biologics. In: Manchikanti L, Navani A, Atluri S (eds). Essentials of Regenerative Medicine in Interventional Pain Management. ASIPP Publishing, Paducah, KY 2019, IN PRESS.

19. Manchikanti L, Navani A. Lumbar epidural administration of PRP and stem cells. In: Manchikanti L, Navani A, Atluri $S$ (eds). Essentials of Regenerative Medicine in Interventional Pain Management. ASIPP Publishing, Paducah, KY 2019, IN PRESS.

20. Navani A, Manchikanti L. Lumbar facet joints and regenerative medicine. In: Manchikanti L, Navani A, Atluri S (eds). Essentials of Regenerative Medicine in Interventional Pain Management. ASIPP Publishing, Paducah, KY 2019, IN PRESS.

21. Cabaret J, Manchikanti L, Calodney AK. Regenerative medicine for sacroiliac joint dysfunction. In: Manchikanti L, Navani A, Atluri S (eds). Essentials of Regenerative Medicine in Interventional Pain Management. ASIPP Publishing, 
Paducah, KY 2019, IN PRESS.

22. Rodeback DG, Navani A. Sacroiliac ligaments. In: Manchikanti L, Navani A, Atluri S (eds). Essentials of Regenerative Medicine in Interventional Pain Management. ASIPP Publishing, Paducah, KY 2019, IN PRESS.

23. Bodor M, Dregalla R, Uribe Y. Platelet rich plasma. In: Manchikanti L, Navani A, Atluri S (eds). Essentials of Regenerative Medicine in Interventional Pain Management. ASIPP Publishing, Paducah, KY 2019, IN PRESS.

24. Valeri CR, Zaroulis CG. Rejuvenation and freezing of outdated stored human red cells. N Engl J Med 1972; 287:1307-1313.

25. Khan S, Mafi P, Mafi R, Khan W. A systematic review of mesenchymal stem cells in spinal cord injury, intervertebral disc repair and spinal fusion. Curr Stem Cell Res Ther 2018; 13:316-323.

26. Basso M, Cavagnaro L, Zanirato A, Divano $S$, Formica $C$, Formica $M$, Felli $L$. What is the clinical evidence on regenerative medicine in intervertebral disc degeneration? Musculoskelet Surg 2017; 101:93-104.

27. Wang Z, Perez-Terzic CM, Smith J, Mauck WD, Shelerud RA, Maus TP, Yang TH, Murad MH, Gou S, Terry MJ, Dauffenbach JP, Pingree MJ, Eldrige JS, Mohammed K, Benkhadra K, van Wijnen AJ, Qu W. Efficacy of intervertebral disc regeneration with stem cells-A systematic review and meta-analysis of animal controlled trials. Gene 2015; 564:1-8.

28. Wu T, Song HX, Dong Y, Li J. Cell-based therapies for lumbar discogenic low back pain: Systematic review and singlearm meta-analysis. Spine (Phila Pa 1976) 2018; 43:49-57.

29. Sanapati J, Manchikanti L, Atluri S, Jordan S, Albers SL, Pappolla MA, Kaye AD, Candido KD, Pampati V, Hirsch JA. Do regenerative medicine therapies provide long-term relief in chronic low back pain: A systematic review and metaanalysis. Pain Physician 2018; 21:515-540.

30. Lana JF, Purita J, Silva Rava CA, Nicholls MA, Parada CA, Forti AP, Ventura Vierira IF, Madureira Junior JL, Fortis Gusmão PD, de Camargo LS, CaliariOliveira C. Bone marrow concentrate. In: Manchikanti L, Navani A, Atluri S (eds). Essentials of Regenerative Medicine in Interventional Pain Management. ASIPP Publishing, Paducah, KY 2019, IN PRESS.

31. Riazi AM, Kwon SY, Stanford WL. Stem cell sources for regenerative medicine. Methods Mol Biol 2009; 482:55-90.

32. Muneoka $\mathrm{K}$, Allan $\mathrm{CH}$, Yang $\mathrm{X}$, Lee J; Han M. Mammalian regeneration and regenerative medicine. Birth Defects Res C Embryo Today 2008; 84:265-280.

33. Marks PW, Witten CM, Califf CM. Clarifying stem-cell therapy's benefits and risks. N Engl J Med 2016; 376:1007-1009.

34. Knoepfler PS. From bench to FDA to bedside: US regulatory trends for new stem cell therapies. Adv Drug Deliv Rev 2015; 82-83:192-196.

35. FDA News Release. FDA acts to remove unproven, potentially harmful treatment used in 'stem cell' centers targeting vulnerable patients. Vaccinia Virus Vaccine (Live) seized after being used inappropriately in vulnerable cancer patients. August 28, 2017.

www.fda.gov/NewsEvents/Newsroom/ PressAnnouncements/ucm573427.htm

36. Turner LG. Federal regulatory oversight of US clinics marketing adipose-derived autologous stem cell interventions: Insights from 3 new FDA draft guidance documents. Mayo Clin Proc 2015; 90:567-571.

37. Turner L. US stem cell clinics, patient safety, and the FDA. Trends Mol Med 2015; 21:271-273.

38. Charo A, Sipp D. Rejuvenating regenerative medicine regulation. $N$ Engl J Med 2018; 378:504-505

39. U.S. Food and Drug Administration. FDA New Release: FDA announces comprehensive regenerative medicine policy framework. November 16, 2017.

www.fda.gov/NewsEvents/Newsroom/ PressAnnouncements/ucm 585345.htm

40. U.S. Food and Drug Administration. Regulation Considerations for Human Cells, Tissues, and Cellular and TissueBased Products: Minimal manipulation and Homologous Use. Guidance for Industry and Food and Drug Administration Staff.

www.fda.gov/downloads/BiologicsBloodVaccines/GuidanceComplianceRegulatorylnformation/Guidances/CellularandGeneTherapy/UCM585403.pdf

41. Draft report of the FSMB Workgroup to study regenerative and stem cell therapy practices, December 2017.

42. Manchikanti L, Boswell MV, Hirsch JA. Innovations in interventional pain management of chronic spinal pain. Expert Rev Neurother 2016; 16:1033-1042.

43. Knezevic NN, Candido KD, Desai R, Kaye AD. Is platelet-rich plasma a future therapy in pain management? Med Clin North Am 2016; 100:199-217.

44. The National Uniform Claims Committee. Specialty Designation for Interventional Pain Management- 09.

www.cms.hhs.gov/transmittals/Downloads/r1779b3.pdf

45. Medicare Payment Advisory Commission. Report to the Congress: Paying for interventional pain services in ambulatory settings. Washington, DC: MedPAC. December. 2001.

http://www.medpac.gov/documents/reports/december-2001-report-to-thecongress-paying-for-interventionalpain-services-in-ambulatory-settings. pdf?sfursn=o

46. Graham R, Mancher M, Wolman DM, Greenfield S, Steinberg E (eds); Committee on Standards for Developing Trustworthy Clinical Practice Guidelines; Institute of Medicine. Clinical Practice Guidelines We Can Trust. The National Academies Press, Washington, DC, 2011.

47. National Guideline Clearinghouse Extent Adherence to Trustworthy Standards (NEATS) instrument.

www.ncbi.nlm.nih.gov/pubmedhealth/ PMHoo79458/.

48. Harris RP, Helfand M, Woolf SH, Lohr KN, Mulrow CD, Teutsch SM, Atkins D; Methods Work Group, Third US Preventive Services Task Force. Current methods of the US Preventive Services Task Force. Am J Prevent Med 2001; 20:21-35.

49. Manchikanti L, Falco FJE, Benyamin R $M$, Kaye AD, Boswell MV, Hirsch JA. A modified approach to grading of evidence. Pain Physician 2014; 17:E319-E325.

50. Institute of Medicine (IOM). Relieving Pain in America: A Blueprint for Transforming Prevention, Care, Education, and Research. The National Academies Press, Washington, DC, June 29, 2011.

www.iom.edu/ /media/Files/Report\%2oFiles/2011/Relieving-Pain-inAmerica-A-Blueprint-for-TransformingPrevention-Care-Education-Research/ Pain\%20Research\%202011\%20Report\%2oBrief.pdf

51. Gaskin DJ, Richard P. The economic costs of pain in the United States. J Pain 2012; 13:715-724.

52. Manchikanti L, Atluri S, Candido KD, Boswell MV, Simopoulos TT, Grider JS, Falco FJE, Hirsch JA. Zohydro ${ }^{\text {TM }}$ approval by Food and Drug Administration: Controversial or frightening? Pain Physician 2014; 17:E437-E450. 
53. Martin BI, Turner JA, Mirza SK, Lee MJ, Comstock BA, Deyo RA. Trends in health care expenditures, utilization, and health status among US adults with spine problems, 1997-2006. Spine (Phila Pa 1976) 2009; 34:2077-2084.

54. Freburger JK, Holmes GM, Agans RP, Jackman AM, Darter JD, Wallace AS, Castel LD, Kalsbeek WD, Carey TS. The rising prevalence of chronic low back pain. Arch Intern Med 2009; 169:251-258.

55. Manchikanti L, Singh V, Falco FJE, Benyamin RM, Hirsch JA. Epidemiology of low back pain in adults. Neuromodulation 2014; 17:3-10.

56. Hoy DG, Bain C, Williams G, March L, Brooks P, Blyth F, Woolf A, Vos T, Buchbinder R. A systematic review of the global prevalence of low back pain. Arthritis Rheum 2012; 64:2028-2037.

57. Hoy D, March L, Brooks P, Blyth F, Woolf A, Bain C, Williams G, Smith E, Vos T, Barendregt J, Murray C, Burstein $\mathrm{R}$, Buchbinder R. The global burden of low back pain: Estimates from the Global Burden of Disease 2010 study. Ann Rheum Dis 2014; 73:968-974.

58. Labusca L, Zugun-Eloae F, Mashayekhi $K$. Stem cells for the treatment of musculoskeletal pain. World J Stem Cells 2015; 7:96-105.

59. Sjøgren P, Ekholm O, Peuckmann V, Grønbæk M. Epidemiology of chronic pain in Denmark: An update. Eur ] Pain 2009; 13:287-292.

60. Blyth FM, Rochat S, Cumming RG, Creasey $\mathrm{H}$, Handelsman DJ, Le Couteur DG, Naganathan V, Sambrook PN, Seibel MJ, Waite LM. Pain, frailty and comorbidity on older men: The CHAMP study. Pain 2008; 140:224-230.

61. Cassidy JD, Carroll LJ, Côté P. The Saskatchewan Health and Back Pain Survey. The prevalence of low back pain and related disability in Saskatchewan adults. Spine (Phila Pa 1976) 1998; 23:1860-1867.

62. Côté $P$, Cassidy JD, Carroll L. The Saskatchewan Health and Back Pain Survey. The prevalence of neck pain and related disability in Saskatchewan adults. Spine (Phila Pa 1976) 1998; 23:1689-1698.

63. Leboeuf-Yde C, Nielsen J, Kyvik KO, Fejer R, Hartvigsen J. Pain in the lumbar, thoracic or cervical regions: Do age or gender matter? A population-based study of 34,902 Danish twins 20-71 years of age. BMC Musculoskelet Disord 2009; 10:39.

64. Waterman RS, Morgenweck J, Nossaman BD, Scandurro AE, Scandurro SA, Betancourt AM. Anti-inflammatory mesenchymal stem cells (MSC2) attenuate symptoms of painful diabetic peripheral neuropathy. Stem Cells Transl Med 2012; 1:557-565.

65. Merskey H, Bogduk N. Task Force on Taxonomy of the International Association for the Study of Pain. Classification of Chronic Pain: Descriptions of Chronic Pain Syndromes and Definition of Pain Terms. 2nd ed. IASP Press, Seattle, WA, 1994.

66. Jarvik JG, Gold LS, Tan K, Friedly JL, Nedeljkovic SS, Comstock BA, Deyo RA, Turner JA, Bresnahan BW, Rundell SD, James KT, Nerenz DR, Avins AL, Bauer Z, Kessler L, Heagerty PJ. Long-term outcomes of a large, prospective observational cohort of older adults with back pain. Spine J 2018; 18:1540-1551.

67. Best MJ, Buller LT, Eismont FJ. National trends in ambulatory surgery for intervertebral disc disorders and spinal stenosis: A 12-year analysis of the national surveys of ambulatory surgery. Spine (Phila Pa 1976) 2015; 40:1703-1711.

68. Deyo RA, Mirza SK, Turner JA, Martin BI. Overtreating chronic back pain: Time to back off? J Am Board Fam Med 2009; 22:62-68.

69. Ragab A, Deshazo RD. Management of back pain in patients with previous back surgery. Am J Med 2008; 121:272-278.

70. Lad SP, Babu R, Ugiliweneza B, Patil CG, Boakye M. Surgery for spinal stenosis: Long-term reoperation rates, health care cost, and impact of instrumentation. Spine (Phila Pa 1976) 2014; 39:978-987.

71. Singh K, Nandyala SV, Marquez-Lara A, Fineberg SJ. Epidemiological trends in the utilization of bone morphogenetic protein in spinal fusions from 2002 to 2011. Spine (Phila Pa 1976) 2014; 39:491-496.

72. Rajaee SS, Kanim LE, Bae HW. National trends in revision spinal fusion in the USA: Patient characteristics and complications. Bone Joint J 2014; 96-B:807-816.

73. O'Gara T, Kemper KJ, Birkedal J, Curl W, Miller N, Abadie B. Survey of conventional and complementary and alternative therapy in patients with low back pain. J Surg Orthop Adv 2016; 25:27-33.

74. Karvelas DA, Rundell SD, Friedly JL, Gellhorn AC, Gold LS, Comstock BA, Heagerty PJ, Bresnahan BW, Nerenz DR, Jarvik JG. Subsequent health-care utilization associated with early physical therapy for new episodes of low back pain in older adults. Spine J 2017; 17:380-389.
75. Sclafani JA, Constantin A, Ho PS, Akuthota V, Chan L. Descriptive analysis of spinal neuroaxial injections, surgical interventions, and physical therapy utilization for degenerative lumbar spondylolisthesis within Medicare beneficiaries from 2000 to 2011. Spine (Phila Pa 1976) 2017; 42:240-246.

76. Amirdelfan K, Webster L, Poree L, Sukul V, McRoberts P. Treatment options for failed back surgery syndrome patients with refractory chronic pain: An evidence based approach. Spine (Phila Pa 1976) 2017; 42:S41-S52.

77. Dagenais S, Caro J, Haldeman S. A systematic review of low back pain cost of illness studies in the United States and internationally. Spine ] 2008; 8:8-20.

78. Becker A, Held H, Redaelli M, Strauch K, Chenot JF, Leonhardt C, Keller S, Baum E, Pfingsten M, Hildebrandt J, Basler HD, Kochen MM, Donner-Banzhoff N. Low back pain in primary care: Costs of care and prediction of future health care utilization. Spine (Phila Pa 1976) 2010; 35:1714-1720.

79. Bressler HB, Keyes WJ, Rochon PA, Badley $E$. The prevalence of low back pain in the elderly. A systematic review of the literature. Spine (Phila Pa 1976) 1999; 24:1813-1819.

8o. Ritzwoller DP, Crounse L, Shetterly S, Rublee $D$. The association of comorbidities, utilization and costs for patients identified with low back pain. BMC Musculoskelet Disord 2006; 7:72.

81. Leavitt SB. NSAID dangers may limit pain-relief options. Pain-Topics News/ Research UPDATES, March 14, 2010.

http://updates.pain-topics.org/2010/03/ nsaid-dangers-may-limit-pain-relief. html.

82. Moore A, Wiffen P, Kalso E. Antiepileptic drugs for neuropathic pain and fibromyalgia. JAMA 2014; 312:182-183.

83. Pannell WC, Savin DD, Scott TP, Wang JC, Daubs MD. Trends in the surgical treatment of lumbar spine disease in the United States. Spine J 2015; 15:1719-1727.

84. Gaudin D, Krafcik BM, Mansour TR, Alnemari A. Considerations in spinal fusion surgery for chronic lumbar pain: psychosocial factors, rating scales, and perioperative patient education-a review of the literature. World Neurosurg 2017; 98:21-27.

85. Yoshihara $\mathrm{H}$, Yoneoka D. National trends in the surgical treatment for lumbar degenerative disc disease: United States, 2000 to 2009. Spine J 2015; 15:265-271.

86. Manchikanti L, Pampati V, Benyamin 
RM, Hirsch JA. Declining utilization of percutaneous epidural adhesiolysis in Medicare population: Evidence-based or over-regulated? IPM Reports 2018; 2:9-18.

87. Manchikanti L, Pampati V, Hirsch JA. Utilization of interventional techniques in managing chronic pain in Medicare population from 2000 to 2014: An analysis of patterns of utilization. Pain Physician 2016; 19:E531-E546.

88. Manchikanti L, Hirsch JA, Pampati V, Boswell MV. Utilization of facet joint and sacroiliac joint interventions in Medicare population from 2000 to 2014 : Explosive growth continues! Curr Pain Headache Rep 2016; 20:58.

89. Manchikanti L, Pampati V, Hirsch JA. Retrospective cohort study of usage patterns of epidural injections for spinal pain in the US fee-for-service Medicare population from 2000 to 2014 . BM] Open 2016; 6:e013042.

90. Manchikanti L, Soin A, Mann DP, Bakshi S, Pampati V, Hirsch JA. Comparative analysis of utilization of epidural procedures in managing chronic pain in the Medicare population: Pre and the Post Affordable Care Act. Spine (Phila Pa 1976) 2018; Jul 12. [Epub ahead of print].

91. Manchikanti L, Soin A, Mann DP, Bakshi S, Pampati V, Hirsch JA. Utilization patterns of facet joint interventions in managing spinal pain: A retrospective cohort study in the U.S. fee-for-service Medicare population. BMJ Open 2018; in press.

92. Manchikanti MV, Manchikanti L, Kaye AD, Pampati V, Hirsch JA. Usage patterns of sacroiliac joint injections - a comparative evaluation of pre and post Affordable Care Act in Medicare population. IPM Reports 2018; 2:157-166.

93. Hirsch JA, Chandra RV, Pampati V, Barr JD, Brook AL, Manchikanti L. Analysis of vertebral augmentation practice patterns: A 2016 update. J Neurointer Surg 2016; 8:1299-1304.

94. Graves JM, Fulton-Kehoe D, Jarvik JG, Franklin GM. Health care utilization and costs associated with adherence to clinical practice guidelines for early magnetic resonance imaging among workers with acute occupational low back pain. Health Serv Res 2014; 49:645-665.

95. Chou R, Hashimoto R, Friedly J, Fu R, Dana T, Sullivan S, Bougatsos C, Jarvik J. Pain Management Injection Therapies for Low Back Pain. Technology Assessment Report ESIBo813. (Prepared by the Pacific Northwest Evidence-based Prac- tice Center under Contract No. HHSA 290-2012-00014-I.) Rockville, MD: Agency for Healthcare Research and Quality; July 10, 2015.

96. Chou R, Hashimoto R, Friedly J, Fu R, Bougatsos C, Dana T, Sullivan SD, Jarvik J. Epidural corticosteroid injections for radiculopathy and spinal stenosis: A systematic review and meta-analysis. Ann Intern Med 2015; 163:373-381.

97. Manchikanti L, Knezevic NN, Boswell MV, Kaye AD, Hirsch JA. Epidural injections for lumbar radiculopathy and spinal stenosis: A comparative systematic review and meta-analysis. Pain Physician 2016; E365-E410.

98. Boswell MV, Manchikanti L. Appropriate design and methodologic quality assessment, clinically relevant outcomes are essential to determine the role of epidural corticosteroid injections. Commentary RE: Chou R, Hashimoto R, Friedly J, Fu R, Bougatsos C, Dana T, Sullivan SD, Jarvik J. Epidural corticosteroid injections for radiculopathy and spinal stenosis: A systematic review and meta-analysis. Ann Intern Med 2015; 163:373-381. Evid Based Med 2016; 21:89.

99. Friedly JL, Comstock BA, Turner JA, Heagerty PJ, Deyo RA, Sullivan SD, Bauer Z, Bresnahan BW, Avins AL, Nedeljkovic SS, Nerenz DR, Standaert C, Kessler L, Akuthota V, Annaswamy T, Chen A, Diehn F, Firtch W, Gerges FJ, Gilligan C, Goldberg H, Kennedy DJ, Mandel S, Tyburski M, Sanders W, Sibell D, Smuck M, Wasan A, Won L, Jarvik JG. A randomized trial of epidural glucocorticoid injections for spinal stenosis. $N$ Engl J Med 2014; 371:11-21.

10o. Manchikanti L, Candido KD, Kaye AD, Boswell MV, Benyamin RM, Falco FJE, Gharibo CG, Hirsch JA. Randomized trial of epidural injections for spinal stenosis published in the New England Journal of Medicine: Further confusion without clarification. Pain Physician 2014; 17:E475-E488.

101. Boswell MV, Manchikanti L, Kaye AD, Bakshi S, Gharibo CG, Gupta S, Jha S, Nampiaparampil DE, Simopoulos TT, Hirsch JA. A best-evidence systematic appraisal of the diagnostic accuracy and utility of facet (zygapophysial) joint injections in chronic spinal pain. Pain Phy-

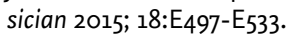

102. Manchikanti L, Kaye AD, Boswell MV, Bakshi S, Gharibo CG, Grami V, Grider JS, Gupta S, Jha S, Mann DP, Nampiaparampil DE, Sharma ML, Shroyer LN, Singh V, Soin A, Vallejo R, Wargo BW,
Hirsch JA. A systematic review and best evidence synthesis of the effectiveness of therapeutic facet joint interventions in managing chronic spinal pain. Pain Physician 2015; 18: E535-E582.

103. Simopoulos TT, Manchikanti L, Gupta S, Aydin SM, Kim CH, Solanki D, Nampiaparampil DE, Singh V, Staats PS, Hirsch JA. Systematic review of the diagnostic accuracy and therapeutic effectiveness of sacroiliac joint interventions. Pain Physician 2015; 18:E713-E756.

104. Manchikanti L, Hirsch JA, Falco FJ, Boswell MV. Management of lumbar zygapophysial (facet) joint pain. World J Orthop 2016; 7:315-337.

105. Manchikanti L, Hirsch JA, Kaye AD, Boswell MV. Cervical zygapophysial (facet) joint pain: Effectiveness of interventional management strategies. Postgrad Med 2016; 128:54-68.

106. Kaye AD, Manchikanti L, Abdi S, Atluri $\mathrm{S}$, Bakshi S, Benyamin R, Boswell MV, Buenaventura R, Candido KD, Cordner HJ, Datta S, Doulatram G, Gharibo CG, Grami V, Gupta S, Jha S, Kaplan ED, Malla Y, Mann DP, Nampiaparampil DE, Racz G, Raj P, Rana MV, Sharma $M L$, Singh V, Soin A, Staats PS, Vallejo R, Wargo BW, Hirsch JA. Efficacy of epidural injections in managing chronic spinal pain: A best evidence synthesis. Pain Physician 2015; 18:E939-E1004.

107. Manchikanti L, Kaye AD, Manchikanti KN, Boswell MV, Pampati V, Hirsch JA. Efficacy of epidural injections in the treatment of lumbar central spinal stenosis: A systematic review. Anesth Pain Med 2015; 5:e23139.

108. Manchikanti L, Singh V, Cash KA, Pampati V, Datta S. A comparative effectiveness evaluation of percutaneous adhesiolysis and epidural steroid injections in managing lumbar post surgery syndrome: A randomized, equivalence controlled trial. Pain Physician 2009; 12: $\mathrm{E}_{355}-\mathrm{E}_{3} 68$.

109. Helm II S, Racz GB, Gerdesmeyer L, Justiz L, Hayek SM, Kaplan ED, El Terany MA, Knezevic NN. Percutaneous and endoscopic adhesiolysis in managing low back and lower extremity pain: A systematic review and meta-analysis. Pain Physician 2016; 19:E245-E282.

110. Grider JS, Manchikanti L, Carayannopoulos A, Sharma ML, Balog CC, Harned ME, Grami V, Justiz R, Nouri KH, Hayek SM, Vallejo R, Christo PJ. Effectiveness of spinal cord stimulation in chronic spinal pain: A systematic review. Pain Physician 2016; 19:E33-E54. 
111. Manchikanti L, Staats PS, Nampiaparampil DE, Hirsch JA. What is the role of epidural injections in the treatment of lumbar discogenic pain: A systematic review of comparative analysis with fusion and disc arthroplasty. Korean J Pain 2015; 28:75-87.

112. Meng H, Fei Q, Wang B, Yang Y, Li D, Li J, Su N. Epidural injections with or without steroids in managing chronic low back pain secondary to lumbar spinal stenosis: a meta-analysis of 13 randomized controlled trials. Drug Des Devel Ther 2015; 9:4657-67.

113. Lee JH, Shin KS, Park SJ, Lee GJ, Lee CH, Kim DH, Kim DH, Yang HS. Comparison of clinical efficacy between transforaminal and interlaminar epidural injections in lumbosacral disc herniation: A systematic review and meta-analysis. Pain Physician 2018; 21:433-448.

114. Lee JH, Kim DH, Kim, DH, Shin KS, Park SJ, Lee GJ, Lee CH, Yang HS. Comparison of clinical efficacy of epidural injection with or without steroid in lumbosacral disc herniation: A systematic review and meta-analysis. Pain Physician 2018; 449-468.

115. Manchikanti L, Benyamin RM, Falco FJ, Kaye AD, Hirsch JA. Do epidural injections provide short- and long-term relief for lumbar disc herniation? A systematic review. Clin Orthop Relat Res 2015; 473:1940-1956.

116. Liu K, Liu P, Wu X, Cai M. Steroid for epidural injection in spinal stenosis: $A$ systematic review and meta-analysis. Drug Des Devel Ther 2015; 9:707-716.

117. Zhai J, Zhang L, Li M, Tian Y, Zheng W, Chen J, Huang T, Li X, Tian Z. Epidural injection with or without steroid in managing chronic low back and lower extremity pain: A meta-analysis of ten randomized controlled trials. Int J Clin Exp Med 2015; 8:8304-8316.

118. Manchikanti L, Nampiaparampil DE, Manchikanti KN, Falco FJE, Singh V, Benyamin RM, Kaye AD, Sehgal N, Soin A, Simopoulos TT, Bakshi S, Gharibo CG, Gilligan CJ, Hirsch JA. Comparison of the efficacy of saline, local anesthetics, and steroids in epidural and facet joint injections for the management of spinal pain: A systematic review of randomized controlled trials. Surg Neurol Int 2015; 6:S194-S235.

119. Hunter CW, Stovall B, Chen G, Carlson J, Levy R. Anatomy, pathophysiology and interventional therapies for chronic pelvic pain: A review. Pain Physician 2018; 21:147-167.
120. Shen J, Xu S, Xu S, Ye S, Hao J. Fusion or not for degenerative lumbar spinal stenosis: A meta-analysis and systematic review. Pain Physician 2018; 21:1-8.

121. Wu JJ, Chen HZ, Zheng C. Transforaminal percutaneous endoscopic discectomy and foraminoplasty after lumbar spinal fusion surgery. Pain Physician 2017; 20:E647-E651.

122. Kumar K, Rizvi S. Cost-effectiveness of spinal cord stimulation therapy in management of chronic pain. Pain Med 2013; 14:1631-1649.

123. Taylor RS, Ryan J, O'Donnell R, Eldabe S, Kumar K, North RB. The cost-effectiveness of spinal cord stimulation in the treatment of failed back surgery syndrome. Clin J Pain 2010; 26:463-469.

124. Manchikanti L, Pampati V, Kaye AD, Hirsch JA. Therapeutic lumbar facet joint nerve blocks in the treatment of chronic low back pain: Cost utility analysis based on a randomized controlled trial. Korean J Pain 2018; 31:27-38.

125. Manchikanti L, Pampati V, Kaye AD, Hirsch JA. Cost utility analysis of cervical therapeutic medial branch blocks in managing chronic neck pain. Int J Med Sci 2017; 14:1307-1316.

126. Manchikanti L, Falco FJE, Pampati V, Cash KA, Benyamin RM, Hirsch JA. Cost utility analysis of caudal epidural injections in the treatment of lumbar disc herniation, axial or discogenic low back pain, central spinal stenosis, and post lumbar surgery syndrome. Pain Physician 2013; 16:E129-E143.

127. Manchikanti L, Pampati V, Benyamin RM, Hirsch JA. Cost utility analysis of lumbar interlaminar epidural injections in the treatment of lumbar disc herniation, central spinal stenosis, and axial or discogenic low back pain. Pain Physician 2017; 20:219-228.

128. Atluri S, Sudarshan G, Manchikanti L. Assessment of the trends in medical use and misuse of opioid analgesics from 2004 to 2011. Pain Physician 2014; 17:E119-E128.

129. Manchikanti L, Cash KA, Malla Y, Pampati $V$, Fellows B. A prospective evaluation of psychotherapeutic and illicit drug use in patients presenting with chronic pain at the time of initial evaluation. Pain Physician 2013; 16:E1-E13.

130. Manchikanti L, Sanapati J, Benyamin RM, Atluri S, Kaye AD, Hirsch JA. Reframing the prevention strategies of the opioid crisis: Focusing on prescription opioids, fentanyl, and heroin epidemic. Pain Physician 2018; 21:309-326.
131. Guy Jr GP, Zhang K, Bohm MK, Losby J, Lewis B, Young R, Murphy LB, Dowell D. Vital Signs: Changes in opioid prescribing in the United States, 2006-2015. MMWR Morb Mortal Wkly Rep 2017; 66:697-704.

132. Dowell D, Noonan RK, Houry D. Underlying factors in drug overdose deaths. JAMA 2017; 318:2295-2296.

133. US Centers for Disease Control and Prevention. Provisional counts of drug overdose deaths as of August 6, 2017.

https://www.cdc.gov/nchs/data/health_policy/ monthly-drug-overdose-death-estimates.pdf

134. Singer JA. Stop calling it an opioid crisis - it's a heroin and fentanyl crisis. Cato Institute, January 9, 2018.

https://www.cato.org/blog/stop-calling-itopioid-crisis-its-heroin-fentanyl-crisis

135. National Institute on Drug Abuse. Overdose death rates. August 2018

https://www.drugabuse.gov/related-topics/ trends-statistics/overdose-death-rates

136. United States Drug Enforcement Administration. DEA proposes reduction to amount of controlled substances to be manufactured in 2018. August 4, 2017.

https://www.dea.gov/divisions/hq/2017/ hqo80417.shtml

137. Schuchat A, Houry D, Guy GP Jr. New data on opioid use and prescribing in the United States. JAMA 2017; 318:425-426.

138. Centers for Disease Control and Prevention. Annual Surveillance Report of Drug-Related Risks and Outcomes -United States, 2017. Surveillance Special Report 1. Centers for Disease Control and Prevention, U.S. Department of Health and Human Services. August 31, 2017.

https://www.cdc.gov/drugoverdose/pdf/ pubs/2017-cdc-drug-surveillance-report.pdf

139. Seth P, Rudd RA, Noonan RK, Haegerich TM. Quantifying the epidemic of prescription opioid overdose deaths. Am J Public Health 2018; 108:500-502.

140. IQVIA Institute for Human Data Science Study. Medicine use and spending in the U.S. A review of 2017 and outlook for 2022. April 2018.

https://www.iqvia.com/-/media/iqvia/ pdfs/institute-reports/medicineuse-and-spending-in-the-us-a-review-of-2017-and-outlook-to-2022. pdf?_=1527706762033

141. Nwachukwu BU, Schairer WW, Shifflett 
GD, Kellner DB, Sama AA. Cost-utility analyses in spine care: a qualitative and systematic review. Spine (Phila Pa 1976) 2015; 40:31-40.

142. Al-Khouja LT, Baron EM, Johnson JP, Kim TT, Drazin D. Cost-effectiveness analysis in minimally invasive spine surgery. Neurosurg Focus 2014; 36:E4.

143. Tosteson AN, Skinner JS, Tosteson TD, Lurie JD, Andersson GB, Berven S, Grove MR, Hanscom B, Blood EA, Weinstein JN. The cost effectiveness of surgical versus nonoperative treatment for lumbar disc herniation over two years: Evidence from the Spine Patient Outcomes Research Trial (SPORT). Spine (Phila Pa 1976) 2008; 33:2108-2115.

144. Tosteson AN, Lurie JD, Tosteson TD, Skinner JS, Herkowitz $\mathrm{H}$, Albert T, Boden $\mathrm{SD}$, Bridwell K, Longley $\mathrm{M}$, Andersson GB, Blood EA, Grove MR, Weinstein JN; SPORT Investigators. Surgical treatment of spinal stenosis with and without degenerative spondylolisthesis: Cost-effectiveness after 2 years. Ann Intern Med 2008; 149:845-853.

145. Tosteson AN, Tosteson TD, Lurie JD, Abdu W, Herkowitz H, Andersson G, Albert T, Bridwell K, Zhao W, Grove MR, Weinstein MC, Weinstein JN. Comparative effectiveness evidence from the spine patient outcomes research trial: Surgical versus nonoperative care for spinal stenosis, degenerative spondylolisthesis, and intervertebral disc herniation. Spine (Phila Pa 1976) 2011; 36:2061-2068.

146. Kepler CK, Wilkinson SM, Radcliff KE, Vaccaro AR, Anderson DG, Hilibrand AS, Albert TJ, Rihn JA. Cost-utility analysis in spine care: A systematic review. Spine J 2012; 12:676-69o.

147. Indrakanti SS, Weber MH, Takemoto SK, Hu SS, Polly D, Berven SH. Value-based care in the management of spinal disorders: A systematic review of cost-utility analysis. Clin Orthop Relat Res 2012; 470:1106-1023.

148. Johnson RE, Jones GT, Wiles NJ, Chaddock C, Potter RG, Roberts C, Symmons DP, Watson PJ, Torgerson DJ, Macfarlane GJ. Active exercise, education, and cognitive behavioral therapy for persistent disabling low back pain: A randomized controlled trial. Spine (Phila Pa 1976) 2007; 32:1578-1585.

149. Fritz JM, Kim M, Magel JS, Asche CV. Cost-effectiveness of primary care management with or without early physical therapy for acute low back pain: Economic evaluation of a randomized clinical trial. Spine (Phila Pa 1976) 2017;
42:285-290.

150. National Institute for Health and Clinical Excellence. Guide to the Methods of Technology Appraisal. NICE, London, 2008.

151. Manchikanti L, Soin A, Benyamin RM, Singh V, Falco FJE, Calodney AK, Grami V, Hirsch JA. An update of the systematic appraisal of the accuracy and utility of discography in chronic spinal pain. Pain Physician 2018; 21:91-110.

152. Manchikanti L, Navani A. Lumbar facet joints and regenerative medicine. In: Manchikanti L, Navani A, Atluri S (eds). Essentials of Regenerative Medicine in Interventional Pain Management. ASIPP Publishing, Paducah, KY 2018, pp 459-472.

153. Fardon DF, Milette PC. Nomenclature and classification of lumbar disc pathology: Recommendations of the Combined Task Forces of the North American Spine Society, American Society of Spine Radiology, and American Society of Neuroradiology. Spine (Phila Pa 1976) 2001; 26:E93-E113.

154. Manchikanti L, Hirsch JA, Datta S, Falco FJE. Low back and lumbar radicular pain. In: Manchikanti L, Christo PJ, Trescot AM, Falco FJE (eds). Clinical Aspects of Pain Medicine and Interventional Pain Management: A Comprehensive Review. ASIPP Publishing, Paducah, KY, 2011, pp 87-114.

155. Mixter WJ, Barr JS. Rupture of the intervertebral disc with involvement of the spinal canal. N Eng J Med 1934; 211:210-215.

156. Manchikanti L, Albers SL, Hirsh JA, Boswell, MV. Lumbar Disk Herniation. In: Kaye AD, ed. Scientific American Pain Management. Hamilton: Decker; September 2017. DOI: 10.2310/7900.15047. www.DeckerIP.com

157. Postacchini F, Cinotti G. Etiopathogenesis. In: Postacchini F (ed). Lumbar Disc Herniation. Spring-Verlag, New York, 1999, pp 151-164.

158. Savettieri G, Salemi G, Rocca WA, Meneghini F, D'Arpa A, Morgante L, Coraci MA, Reggio A, Grigoletto $F$, Di Perri R. Prevalence of lumbosacral radiculopathy in two Sicilian municipalities. Sicilian Neuro-Epidemiologic Study (SNES) Group. Acta Neurol Scand 1996; 93:464-469.

159. Hahne AJ, Ford JJ, McMeeken JM. Conservative management of lumbar disc herniation with associated radiculopathy: A systematic review. Spine (Phila Pa 1976) 2010; 35: E488-E504.

160. Peng B, Fu X, Pang X, Li D, Liu W, Gao $\mathrm{C}$, Yang $\mathrm{H}$. Prospective clinical study on natural history of discogenic low back pain at 4 years of follow-up. Pain Physician 2012; 15:523-532.

161. Pang WW, Mok MS, Lin ML, Chang DP, Hwang $\mathrm{MH}$. Application of spinal pain mapping in the diagnosis of low back pain-analysis of 104 cases. Acta Anaesthesiol Sin 1998; 36:71-74.

162. Manchikanti L, Singh V, Pampati V, Damron K, Barnhill R, Beyer C, Cash K. Evaluation of the relative contributions of various structures in chronic low back pain. Pain Physician 2001; 4:308-316.

163. Wolfer L, Derby R, Lee JE, Lee SH. Systematic review of lumbar provocation discography in asymptomatic subjects with a meta-analysis of false-positive rates. Pain Physician 2008; 11:513-538.

164. Schwarzer AC, Aprill CN, Derby R, Fortin J, Kine G, Bogduk N. The prevalence and clinical features of internal disc disruption in patients with chronic low back pain. Spine (Phila Pa 1976) 1995; 20:1878-1883.

165. DePalma MJ, Ketchum JM, Saullo T. What is the source of chronic low back pain and does age play a role? Pain Med 2011; 12:224-233.

166. Manchikanti L, Albers SL, Latchaw R. Lumbar Spinal Stenosis and Neurogenic Claudication. In: Kaye AD, ed. Scientific American Pain Management. Hamilton: Decker; August 2017. DOI: 10.2310/7900.15048. www.DeckerIP.com

167. Haig AJ, Tomkins CC. Diagnosis and management of lumbar spinal stenosis. JAMA 2010; 303:71-72.

168. Kalichman L, Cole R, Kim DH, Li L, Suri P, Guermazi A, Hunter DJ. Spinal stenosis prevalence and association with symptoms: The Framingham Study. Spine J 2009; 9:545-550.

169. Zeckser J, Wolff M, Tucker J, Goodwin J. Multipotent mesenchymal stem cell treatment for discogenic low back pain and disc degeneration. Stem Cells Int 2016; 2016:3908389.

170. Dong L, Odeleye AO, Jordan-Sciutto KL, Winkelstein BA. Painful facet joint injury induces neuronal stress activation in the DRG: Implications for cellular mechanisms of pain. Neurosci Lett 2008; 443:90-94.

171. Lee KE, Davis MB, Winkelstein BA. Capsular ligament involvement in the development of mechanical hyperalgesia after facet joint loading: Behavioral and inflammatory outcomes in a rodent model of pain. J Neurotrauma 2008; 25:1383-1393.

172. Tachihara H, Kikuchi S, Konno S, Seki- 
guchi M. Does facet joint inflammation induce radiculopathy?: An investigation using a rat model of lumbar facet joint inflammation. Spine (Phila Pa 1976) 2007; 32:406-412.

173. Vasquez E, Bär K, Ebersberger A, Klein B, Vanegas $H$, Schaible HG. Spinal prostaglandins are involved in the development but not the maintenance of inflammation-induced spinal hyperexcitability. J Neurosci 2001; 21:9001-9008.

174. Graziani F, Ivanovski S, Cei S, Ducci F, Tonetti $M$, Gabriele $M$. The in vitro effect of different PRP concentrations on osteoblasts and fibroblasts. Clin Oral Implants Res 2006; 17:212-219.

175. Yoshida R, Cheng M, Murray MM. Increasing platelet concentration in platelet-rich plasma inhibits anterior cruciate ligament cell function in threedimensional culture. J Orthop Res 2014; 32:291-295.

176. Wasterlain AS, Braun HJ, Harris AH, Kim HJ, Dragoo JL. The systemic effects of platelet-rich plasma injection. Am J Sports Med 2013; 41:186-193.

177. Karli DC. PRP, BMC, and adipose mesenchymal stem cells: Hemo-analysis and quality control: What does it all mean? In: Manchikanti L, Navani A, Atluri $S$ (eds). Essentials of Regenerative Medicine in Interventional Pain Management. ASIPP Publishing, Paducah, KY 2019, IN PRESS.

178. Wu PI, Diaz R, Borg-Stein J. Plateletrich plasma. Phys Med Rehabil Clin N Am 2016; 27:825-853.

179. Lansdown DA, Fortier LA. Platelet-rich plasma: Formulations, preparations, constituents, and their effects. Oper Tech Sports Med 2017; 25:7-12.

180. Beitzel K, Allen D, Apostolakos J, Russell RP, McCarthy MB, Gallo GJ, Cote MP, Mazzocca AD. US Definitions, current use, and FDA stance on use of plateletrich plasma in sports medicine. J Knee Surg 2015; 28:29-34.

181. Malanga GA, Goldin M. PRP: Review of the current evidence for musculoskeletal conditions. Curr Phys Med Rehabil Rep 2014; 2:1-5.

182. Davis VL, Abukabda $A B$, Radio NM, Witt-Enderby PA, Clafshenkel WP, Cairone JV, Rutkowski JL. Platelet-rich preparations to improve healing. Part I: Workable options for every size practice. J Oral Implantol 2014; 40:500-510.

183. Boswell SG, Cole BJ, Sundman EA, Karas $\mathrm{V}$, Fortier LA. Platelet-rich plasma: A milieu of bioactive factors. Arthroscopy 2012; 28:429-439.
184. Blair P, Flaumenhaft R. Platelet alphagranules: Basic biology and clinical correlates. Blood Rev 2009; 23:177-189.

185. Sheth U, Simunovic N, Klein G, Fu F, Einhorn TA, Schemitsch E, Ayeni OR, Bhandari M. Efficacy of autologous platelet-rich plasma use for orthopaedic indications: A meta-analysis. J Bone Joint Surg 2012; 94:298-307.

186. Dohan Ehrenfest DM, Rasmusson L, Albrektsson T. Classification of platelet concentrates: From pure platelet-rich plasma (P-PRP) to leucocyte- and platelet-rich fibrin (L-PRF). Trends Biotechnol 2009; 27:158-167.

187. DeLong JM, Russell RP, Mazzocca AD. Platelet-rich plasma: ThePAW classification system. Arthroscopy 2012; 28:998-1009.

188. LaPrade RF, Dragoo JL, Koh JL, Murray IR, Geeslin AG, Chu CR. AAOS Research Symposium Updates and Consensus: Biologic Treatment of Orthopaedic Injuries. J Am Acad Orthop Surg 2016; 24:e62-e78.

189. Caplan Al. Adult mesenchymal stem cells for tissue engineering versus regenerative medicine. J Cell Physiol 2007; 213:341-347.

190. Caplan Al. Cell delivery and tissue regeneration. J Control Release 1989; 11:157-165.

191. Caplan Al. Mesenchymal stem cells. J Orthop Res 1991; 9:641-650.

192. Caplan Al. Review: Mesenchymal stem cells: Cell-based reconstructive therapy in orthopedics. Tissue Eng 2005; 11:1198-1211.

193. Caplan Al. Mesenchymal stem cells: Time to change the name! Stem Cells Transl Med 2017; 6:1445-1451.

194. Sell S. Stem Cells Handbook. Springer Science \& Business Media, New York, NY, 2013.

195. Kobolak J, Dinnyes A, Memic A, Khademhosseini A, Mobasheri A.. Mesenchymal stem cells: Identification, phenotypic characterization, biological properties and potential for regenerative medicine through biomaterial micro-engineering of their niche. Methods 2016; 99:62-68.

196. Rigotti G, Marchi A, Sbarbati A. Adiposederived mesenchymal stem cells: Past, present, and future. Aesthetic Plast Surg 2009; 33:271-273.

197. Watson L, Elliman SJ, Coleman CM. From isolation to implantation: A concise review of mesenchymal stem cell therapy in bone fracture repair. Stem Cell Res Ther 2014; 5:51.
198. Murray IR, West CC, Hardy WR, James AW, Park TS, Nguyen A, Tawonsawatruk T, Lazzari L, Soo C, Péault B. Natural history of mesenchymal stem cells, from vessel walls to culture vessels. Cell Mol Life Sci 2014; 71:1353-1374.

199. Katz AJ, Tholpady A, Tholpady SS, Shang $\mathrm{H}$, Ogle RC. Cell surface and transcriptional characterization of human adipose-derived adherent stromal (hADAS) cells. Stem Cells 2005; 23:412-423.

200. Mitchell JB, Mclntosh K, Zvonic S, Garrett S, Floyd ZE, Kloster A, Di Halvorsen Y, Storms RW, Goh B, Kilroy G, Wu X, Gimble JM. Immunophenotype of human adipose derived cells: Temporal changes in stromal-associated and stem cell associated markers. Stem Cells 2006; 24:376-385.

201. Kilroy GE, Foster SJ, Wu X, , Ruiz J, Sherwood S, Heifetz A, Ludlow JW, Stricker DM, Potiny S, Green P, Halvorsen YD, Cheatham B, Storms RW, Gimble JM. Cytokine profile of human adipose derived stem cells: Expression of angiogenic, hematopoietic, and proinflammatory factors. J Cell Physiol 2007; 212:702-709.

202. Day TF, Guo X, Garrett-Beal L, Yang Y. Wnt/beta-catenin signaling in mesenchymal progenitors controls osteoblast and chondrocyte differentiation during vertebrate skeletogenesis. Dev Cell 2005; 8:739-750.

203. Cawthorn WP, Bree AJ, Yao Y, Du B, Hemati N, Martinez-Santibañez G, MacDougald OA. Wnt6, Wntioa and Wntiob inhibit adipogenesis and stimulate osteoblastogenesis through a b-catenindependent mechanism. Bone 2012; 50:477-489.

204. Li Y, Foster W, Deasy BM, Chan Y, Prisk $V$, Tang $Y$, Cummins J, Huard J. Transforming growth factor-betal induces the differentiation of myogenic cells into fibrotic cells in injured skeletal muscle: A key event in muscle fibrogenesis. Am J Pathol 2004; 164:1007-1019.

205. Serra $R$, Johnson M, Filvaroff $E H$, LaBorde J, Sheehan DM, Derynck R, Moses HL. Expression of a truncated, kinase defective TGF-beta type II receptor in mouse skeletal tissue promotes terminal chondrocyte differentiation and osteoarthritis. J Cell Biol 1997; 139:541-552.

206. Murphy MB, Moncivais K, Caplan Al. Mesenchymal stem cells: Environmentally responsive therapeutics for regenerative medicine. Exp Mol Med 2013; 45:e54. 
207. Center for Biologic Evaluation and Research. List of Licensed Biological Products with (1) Reference Product Exclusivity and (2) Biosimilarity or Interchangeability Evaluations to Date.

www.fda.gov/downloads/Drugs/DevelopmentApprovalProcess/HowDrugsareDevelopedandApproved/ApprovalApplications/TherapeuticBiologicApplications/Biosimilars/UCM412398.pdf

208. Spiel D. The role of exosomes in regenerative medicine. In: Manchikanti L, Navani A, Atluri S (eds). Essentials of Regenerative Medicine in Interventional Pain Management. ASIPP Publishing, Paducah, KY 2019, IN PRESS.

209. Kirkaldy-Willis $\mathrm{WH}$, Wedge $\mathrm{JH}$, YongHing K, Tchang S, de Korompay $V$, Shannon R. Lumbar spinal nerve lateral entrapment. Clin Orthop Relat Res 1982; 169:171-178.

210. Dowdell J, Erwin M, Choma T, Vaccaro A, latridis J, Cho SK. Intervertebral disk degeneration and repair. Neurosurgery 2017; 80:S46-S54.

211. Mascarinas A, Harrison J, Boachie-Adjei K, Lutz G. Regenerative treatments for spinal conditions. Phys Med Rehabil Clin N Am 2016; 27:1003-1017.

212. Kim KD. Stem cells and discogenic low back pain. Spine (Phila Pa 1976) 2016; 41:S11-S12.

213. Zhang J, Lu VM, van Wijnen AJ, Kerezoudis P, Yeap I, Cong L, Larson N, Qu W, Nassr A, Bydon M. Molecular factors in intervertebral disc degeneration. J $A m$ Acad Reg Med 2017; 1:7203.

214. Bertolo A, Thiede T, Aebli N, Baur M, Ferguson SJ, Stoyanov JV. Human mesenchymal stem cell co-culture modulates the immunological properties of human intervertebral disc tissue fragments in vitro. Eur Spine J 2011; 20:592-603.

215. Priyadarshani P, Li Y, Yao L. Advances in biological therapy for nucleus pulposus regeneration. Osteoarthritis Cartilage 2016; 24:206-212.

216. Willems N, Tellegen AR, Bergknut N, Creemers LB, Wolfswinkel J, Freudigmann C, Benz K, Grinwis GC, Tryfonidou MA, Meij BP. Inflammatory profiles in canine intervertebral disc degeneration. BMC Vet Res 2016; 12:10.

217. Elabd C, Centeno CJ, Schultz JR, Lutz G, Ichim T, Silva FJ. Intra-discal injection of autologous, hypoxic cultured bone marrow-derived mesenchymal stem cells in five patients with chronic lower back pain: a long-term safety and feasibility study. J Transl Med 2016; 14:253.
218. Hunt CL, Her YF, Law LA, Bydon M, Nassr A, Smith J, Mauck WD, Eldrige JS< Malanga GA, Qu W. Five generations of cell preparation: A translational framework for categorizing regenerative stem cell therapies. J Am Acad Regen Med 2017; 1:7239.

219. Depalma M. Biologic treatments for discogenic low back pain. SpineLine 2012; 13:19-23.

220. Wei A, Shen B, Williams L, Diwan A. Mesenchymal stem cells: Potential application in intervertebral disc regeneration. Transl Pediatr 2014; 3:71-90.

221. Comella K, Silbert R, Parlo M. Effects of the intradiscal implantation of stromal vascular fraction plus platelet rich plas$\mathrm{ma}$ in patients with degenerative disc disease. J Transl Med 2017; 15:12.

222. Buchanan RM, Blashki D, Murphy MB. Stem cell therapy for regenerative medicine. Chem Eng Prog 2014; 110:55-58.

223. Bogduk N. Clinical and Radiological Anatomy of the Lumbar Spine. 5 th ed. Elsevier Churchill Livingstone, 2012.

224. latridis JC, Nicoll SB, Michalek AJ, Walter BA, Gupta MS. Role of biomechanics in intervertebral disc degeneration and regenerative therapies: what needs repairing in the disc and what are promising biomaterials for its repair? Spine ] 2013; 13:243-262.

225. Bogduk N, Aprill C, Derby R. Lumbar discogenic pain: State-of-the-art review. Pain Med 2013; 14:813-836.

226. Hegewald AA, Endres M, Abbushi A, Cabraja M, Woiciechowsky C, Schmieder K, Kaps C, Thomé C.. Adequacy of herniated disc tissue as a cell source for nucleus pulposus regeneration.] Neurosurg Spine 2011; 14:273-280.

227. Risbud MV, Guttapalli A, Tsai TT, Lee JY, Danielson KG, Vaccaro AR, Albert TJ, Gazit Z, Gazit D, Shapiro IM. Evidence for skeletal progenitor cells in the degenerate intervertebral disc. Spine (Phila Pa 1976) 2007; 32:2537-2544.

228. Brisby $\mathrm{H}$, Papadimitriou $\mathrm{N}$, Brantsing $\mathrm{C}$, Bergh P, Lindahl A, Barreto Henriksson $H$.. The presence of local mesenchymal progenitor cells in human degenerated intervertebral discs and possibilities to influence these in vitro: A descriptive study in humans. Stem Cells Dev 2013; 22:804-814.

229. Kim KW, Ha KY, Lee JS, Nam SW, Woo YK, Lim TH, An HS. Notochordal cells stimulate migration of cartilage end plate chondrocytes of the intervertebral disc in in vitro cell migration assays. Spine J 2009; 9:323-329.
230. Helm S 2nd, Simopoulos TT, Stojanovic MP, Abdi S, El Terany MA. Effectiveness of thermal annular procedures in treating discogenic low back pain. Pain Physician 2017; 20:447-470.

231. Lurie JD, Tosteson TD, Tosteson AN, Zhao W, Morgan TS, Abdu WA, Herkowitz $H$, Weinstein JN. Surgical versus nonoperative treatment for lumbar disc herniation: eight-year results for the spine patient outcomes research trial. Spine (Phila Pa 1976) 2014; 39:3-16.

232. Lurie JD, Tosteson TD, Tosteson A, Abdu WA, Zhao W, Morgan TS, Weinstein JN. Long-term outcomes of lumbar spinal stenosis: eight-year results of the Spine Patient Outcomes Research Trial (SPORT). Spine (Phila Pa 1976) 2015; 40:63-76.

233. Peng B, Wu W, Hou S, Li P, Zhang C, Yang $Y$. The pathogenesis of discogenic low back pain. J Bone Joint Surg Br 2005; 87:62-67.

234. Hiyama A, Mochida J, Iwashina T, Omi $H$, Watanabe T, Serigano K, Tamura F, Sakai D. Transplantation of mesenchymal stem cells in a canine disc degeneration model. J Orthop Res 2008; 26:589-600.

235. Zhang YG, Guo X, Xu P, Kang LL, Li J. Bone mesenchymal stem cells transplanted into rabbit intervertebral discs can increase proteoglycans. Clin Orthop Relat Res 2005; 430:219-226.

236. Yang $\mathrm{H}, \mathrm{Wu}$ J, Liu J, Ebraheim M, Castillo S, Liu X, Tang T, Ebraheim NA. Transplanted mesenchymal stem cells with pure fibrinous gelatin-transforming growth factor-betal decrease rabbit intervertebral disc degeneration. Spine ] 2010; 10:802-810.

237. Ghosh P, Moore R, Vernon-Roberts B, Goldschlager T, Pascoe D, Zannettino A, Gronthos S, Itescu S. Immunoselected STRO-3+ mesenchymal precursor cells and restoration of the extracellular matrix of degenerate intervertebral discs. J Neurosurg Spine 2012; 16:479-488.

238. Shim EK, Lee JS, Kim DE, Kim SK, Jung BJ, Choi EY, Kim CS. Autogenous mesenchymal stem cells from the vertebral body enhance intervertebral disc regeneration via paracrine interaction: An in vitro pilot study. Cell Transplant 2016; 25:1819-1832.

239. Teixeira GQ, Pereira CL, Ferreira JR, Maia AF, Gomez-Lazaro M, Barbosa MA, Neidlinger-Wilke C, Goncalves RM. Immunomodulation of human mesenchymal stem/stromal cells in intervertebral disc degeneration: Insights 
from a proinflammatory/degenerative ex vivo model. Spine (Phila Pa 1976) 2017; 43:E673-E682.

240. Le Maitre CL, Baird P, Freemont AJ, Hoyland JA. An in vitro study investigating the survival and phenotype of mesenchymal stem cells following injection into nucleus pulposus tissue. Arthritis Res Ther 2009; 11:R20.

241. Pereira CL, Teixeira GQ, Ribeiro-Machado C, Caldeira J, Costa M, Figueiredo F, Fernandes R, Aguiar P, Grad S, Barbosa MA, Gonçalves RM. mesenchymal stem/stromal cells seeded on cartilaginous endplates promote intervertebral disc regeneration through extracellular matrix remodeling. Sci Rep 2016; 6:33836.

242. Jezierska-Wozniak K, Barczewska $M$, Habich A, Wojtacha P, Badowska W, Maksymowicz W, Wojtkiewicz J. The feasibility of the CD271+ and CD271- mesenchymal stromal cell enrichment toward nucleus pulposus-like cells. Folia Histochem Cytobiol 2017; 55:114-123.

243. Jeong JH, Jin ES, Min JK, Jeon SR, Park $\mathrm{CS}$, Kim HS, Choi KH. Human mesenchymal stem cells implantation into the degenerated coccygeal disc of the rat. Cytotechnology 2009; 59:55-64.

244. Yang F, Leung VY, Luk KD, Chan D, Cheung KM. Mesenchymal stem cells arrest intervertebral disc degeneration through chondrocytic differentiation and stimulation of endogenous cells. Mol Ther 2009; 17:1959-1966.

245. Fairbank JC, Pynsent PB. The Oswestry Disability Index. Spine (Phila Pa 1976) 2000; 25:2940-2952

246. Feng $\mathrm{G}$, Zhao X, Liu H, Zhang $\mathrm{H}$, Chen $X$, Shi R, Liu X, Zhao X, Zhang W, Wang B. Transplantation of mesenchymal stem cells and nucleus pulposus cells in a degenerative disc model in rabbits: a comparison of 2 cell types as potential candidates for disc regeneration. J Neurosurg Spine 2011; 14:322-329.

247. Mochida J, Sakai D, Nakamura Y, Watanabe T, Yamamoto $Y$, Kato $S$. Intervertebral disc repair with activated nucleus pulposus cell transplantation: a threeyear, prospective clinical study of its safety. Eur Cell Mater 2015; 29:202-212.

248. Wang YH, Yang B, Li WL, Li JM. Effect of the mixture of bone marrow mesenchymal stromal cells and annulus fibrosus cells in repairing the degenerative discs of rabbits. Genet Mol Res 2015; 14:2365-2373.

249. Sakai D, Mochida J, Iwashina T, Hiyama A, Omi H, Imai M, Nakai T, Ando K,
Hotta T. Regenerative effects of transplanting mesenchymal stem cells embedded in atelocollagen to the degenerated intervertebral disc. Biomaterials 2006; 27:335-345.

250. Wang H, Zhou Y, Chu TW, Li CQ, Wang J, Zhang ZF, Huang B. Distinguishing characteristics of stem cells derived from different anatomical regions of human degenerated intervertebral discs. Eur Spine ] 2016; 25:2691-2704.

251. Vadalà G, Russo F, Ambrosio L, Loppini $M$, Denaro V. Stem cells sources for intervertebral disc regeneration. World J Stem Cells 2016; 8:185-201.

252. Miguélez-Rivera L, Pérez-Castrillo S, González-Fernández ML, PrietoFernández JG, López-González ME, García-Cosamalón J, Villar-Suárez V. Immunomodulation of mesenchymal stem cells in discogenic pain. Spine J 2018; 18:330-342.

253. Pettine K, Suzuki R, Sand T, Murphy M. Treatment of discogenic back pain with autologous bone marrow concentrate injection with minimum two year follow-up. Int Orthop 2016; 40:135-140.

254. Foster TE, Puskas BL, Mandelbaum BR, Gerhardt MB, Rodeo SA. Platelet-rich plasma: from basic science to clinical applications. Am J Sports Med 2009; 37:2259-2272.

255. Chen $\mathrm{WH}$, Lo WC, Lee JJ, Su CH, Lin CT, Liu HY, Lin TW, Lin WC, Huang TY, Deng WP. Tissue-engineered intervertebral disc and chondrogenesis using human nucleus pulposus regulated through TGF-betar in platelet-rich plasma. J Cell Physiol 2006; 209:744-754.

256. Gullung GB, Woodall JW, Tucci MA, James J, Black DA, McGuire RA. Plateletrich plasma effects on degenerative disc disease: analysis of histology and imaging in an animal model. Evid Based Spine Care J 2011; 2:13-18.

257. Obata S, Akeda K, Imanishi T, Masuda K, Bae W, Morimoto R, Asanuma Y, Kasai Y, Uchida A, Sudo A. Effect of autologous platelet-rich plasma-releasate on intervertebral disc degeneration in the rabbit anular puncture model: a preclinical study. Arthritis Res Ther 2012; 14:R241.

258. Kim HJ, Yeom JS, Koh YG, Yeo JE, Kang KT, Kang YM, Chang BS, Lee CK. Anti-inflammatory effect of platelet-rich plasma on nucleus pulposus cells with response of TNF-a and IL-1. J Orthop Res 2014; 32:551-556.

259. Sawamura K, Ikeda T, Nagae M, Okamoto S, Mikami Y, Hase H, Ikoma K, Yamada T, Sakamoto H, Matsuda K, Tabata
Y, Kawata M, Kubo T. Characterization of in vivo effects of platelet-rich plasma and biodegradable gelatin hydrogel microspheres on degenerated intervertebral discs. Tissue Eng Part A 2009; 15:3719-3727.

260. Kristjánsson B, Limthongkul W, Yingsakmongkol W, Thantiworasit $\mathrm{P}$, Jirathanathornnukul $\mathrm{N}$, Honsawek $\mathrm{S}$. Isolation and characterization of human mesenchymal stem cells from facet joints and interspinous ligaments. Spine (Phila Pa 1976) 2016; 41:E1-E7.

261. Richardson SM, Kalamegam G, Pushparaj PN, Matta C, Memic A, Khademhosseini A, Mobasheri R, Poletti FL, Hoyland JA, Mobasheri A. Mesenchymal stem cells in regenerative medicine: Focus on articular cartilage and intervertebral disc regeneration. Methods 2016; 99:69-80.

262. Eden J, Levit L, Berg A, Morton S (eds); Committee on Standards for Systematic Reviews of Comparative Effectiveness Research; Institute of Medicine. Finding What Works in Health Care. Standards for Systematic Reviews. The National Academies Press, Washington, DC, 2011.

www.nap.edu/catalog/13059/findingwhat-works-in-health-carestandardsfor-systematic-reviews

263. Agency for Healthcare Research and Quality. Methods guide for effectiveness and comparative effectiveness reviews. AHRQ publication no. 10(13)-EHCo63EF. Rockville MD; 2014.

www.effectivehealthcare.ahrq.gov/ ehc/products/60/318/CER-MethodsGuide-140109.pdf

264. Moher D, Liberati A, Tetzlaff J, Altman DG; PRISMA Group. Preferred reporting items for systematic reviews and metaanalyses: The PRISMA statement. PLoS Med 2009; 6:e1000097.

265. Shea BJ, Reeves BC, Wells G, Thuku M, Hamel C, Moran J, Moher D, Tugwell P, Welch V, Kristjansson E, Henry DA. AMSTAR 2: A critical appraisal tool for systematic reviews that include randomised or non-randomised studies of healthcare interventions, or both. BMJ 2017; 358:j4008.

266. Furlan AD, Malmivaara $A$, Chou R, Maher CG, Deyo RA, Schoene M, Bronfort G, van Tulder MW; Editorial Board of the Cochrane Back, Neck Group. 2015 Updated Method Guideline for Systematic Reviews in the Cochrane Back and Neck Group. Spine (Phila Pa 1976) 2015; 40:1660-1673. 
267. Manchikanti L, Hirsch JA, Cohen SP, Heavner JE, Falco FJE, Diwan S, Boswell MV, Candido KD, Onyewu CO, Zhu J, Sehgal N, Kaye AD, Benyamin RM, Helm $S$ 2nd, Singh V, Datta S, Abdi S, Christo PJ, Hameed H, Hameed M, Vallejo R, Pampati V, Racz GB, Raj PP. Assessment of methodologic quality of randomized trials of interventional techniques: Development of an interventional pain management specific instrument. Pain Physician 2014; 17:E263-E290.

268. Manchikanti L, Hirsch JA, Heavner JE, Cohen SP, Benyamin RM, Sehgal N, Falco FJE, Vallejo R, Onyewu O, Zhu J, Kaye AD, Boswell MV, Helm II S, Candido KD, Diwan S, Simopoulos TT, Singh V, Pampati V, Racz GB, Raj PP. Development of an interventional pain management specific instrument for methodologic quality assessment of nonrandomized studies of interventional techniques. Pain Physician 2014; 17:E291-E317.

269. Huedo-Medina TB, Sánchez-Meca J, Marín-Martínez F, Botella J. Assessing heterogeneity in meta-analysis: $\mathrm{Q}$ statistic or 12 index? Psychol Methods 2006; 11:193-206.

270. Pang $X$, Yang H, Peng B. Human umbilical cord mesenchymal stem cell transplantation for the treatment of chronic discogenic low back pain. Pain Physician 2014; 17:E525-E530.

271. Orozco L, Soler R, Morera C, Alberca M, Sánchez A, García-Sancho J. Intervertebral disc repair by autologous mesenchymal bone marrow cells: A pilot study. Transplantation 2011; 92:822-828.

272. Coric D, Pettine K, Sumich A, Boltes MO. Prospective study of disc repair with allogeneic chondrocytes presented at the 2012 Joint Spine Section Meeting. J Neurosurg Spine 2013; 18:85-95.

273. Meisel HJ, Ganey T, Hutton WC, Libera J, Minkus Y, Alasevic O. Clinical experience in cell based therapeutics: Intervention and outcome. Eur Spine J 2006; 15:S397-S405.

274. Navani A, Ambach MA, Navani R, Wei J. Biologics and lumbar discogenic pain: 18 month follow-up for safety and efficacy. IPM Reports 2018;IPM Reports 2018; 2:111-118.

275. Levi D, Horn S, Tyszko S, Levin J, HechtLeavitt C, Walko E. Intradiscal plateletrich plasma injection for chronic discogenic low back pain: Preliminary results from a prospective trial. Pain Med2o16 17:1010-1022.

276. Monfett M, Harrison J, Boachie-Adjei K, Lutz G. Intradiscal platelet-rich plas- ma (PRP) injections for discogenic low back pain: an update. Int Orthop 2016; 40:1321-1328.

277. Tuakli-Wosornu YA, TerryA, Boachie-Adjei K, Harrison JR, Gribbin CK, LaSalle EE, Nguyen JT, Solomon JL, Lutz GE. Lumbar intradiskal platelet-rich plasma (PRP) injections: A prospective, doubleblind, randomized controlled study. PM R 2016; 8:1-10.

278. Kirchner F, Anitua E. Intradiscal and intra-articular facet infiltrations with plasma rich in growth factors reduce pain in patients with chronic low back pain. J Craniovertebr Junction Spine 2016; 7:250-256.

279. Akeda K, Ohishi K, Masuda K, Bae WC, Takegami N, Yamada J, Nakamura T, Sakakibara T, Kasai Y, Sudo A. Intradiscal injection of autologous platelet-rich plasma releasate to treat discogenic low back pain: A preliminary clinical trial. Asian Spine J 2017; 11:380-389.

28o. Pettine KA, Suzuki RK, Sand TT, Murphy MB. Autologous bone marrow concentrate intradiscal injection for the treatment of degenerative disc disease with three-year follow-up. Int Orthop 2017; 41:2097-2103

281. Pettine KA, Murphy MB, Suzuki RK, Sand TT. Percutaneous injection of autologous bone marrow concentrate cells significantly reduces lumbar discogenic pain through 12 months. Stem Cells 2015; 33:146-156.

282. Yoshikawa T, Ueda Y, Miyazaki K, Koizumi M, Takakura Y. Disc regeneration therapy using marrow mesenchymal cell transplantation: A report of two case studies. Spine (Phila Pa 1976) 2010; 35:E475-E480.

283. Noriega DC, Adura F, HernándezRamajo R, Martín-Ferrero MA, SánchezLite I, Toribio B, Alberca M, García V Moraleda JM, Sánchez A, Garcia-Sancho J. Intervertebral disc repair by allogeneic mesenchymal bone marrow cells: A randomized controlled trial. Transplantation 2017; 10:1945-1951.

284. Kumar H, Ha DH, Lee EJ, Park JH, Shim JH, Ahn TK, Kim KT, Ropper AE, Sohn $\mathrm{S}$, Kim CH, Thakor DK, Lee SH, Han IB. Safety and tolerability of intradiscal implantation of combined autologous adipose-derived mesenchymal stem cells and hyaluronic acid in patients with chronic discogenic low back pain: 1-year follow-up of a phase I study. Stem Cell Res Ther 2017; 8:262.

285. Wu J, Du Z, Lv Y, Zhang J, Xiong W, Wang R, Liu R, Zhang G, Liu Q. A new technique for the treatment of lumbar facet joint syndrome using intra-articular injection with autologous platelet rich plasma. Pain Physician 2016; 19:617-625

286. Wu J, Zhou J, Liu C, Zhang J, Xiong W, Lv Y, Liu R, Wang R, Du Z, Zhang G, Liu Q. A prospective study comparing plateletrich plasma and local anesthetic (LA)/ corticosteroid in intra-articular injection for the treatment of lumbar facet joint syndrome. Pain Pract 2017; 17:914-924.

287. Singla V, Batra YK, Bharti N, Goni VG, Marwaha N. Steroid vs. platelet-rich plasma in ultrasound-guided sacroiliac joint injection for chronic low back pain. Pain Pract 2017; 17:782-791.

288. Navani A, Gupta D. Role of intra-articular platelet-rich plasma in sacroiliac joint pain. Reg Anesth Pain Med2015; 19:54-59.

289. Ko GD, Mindra S, Lawson GE, Whitmore S, Arseneau L. Case series of ultrasound-guided platelet-rich plasma injections for sacroiliac joint dysfunction. J Back Musculoskelet Rehabil 2017; 30:363-370.

290. Bhatia R, Chopra G. Efficacy of platelet rich plasma via lumbar epidural route in chronic prolapsed intervertebral disc patients-A pilot study. J Clin Diagn Res 2016; 10:UCo5-UCo7.

291. Centeno C, Markle J, Dodson E, Stemper I, Hyzy M, Williams C, Freeman M. The use of lumbar epidural injection of platelet lysate for treatment of radicular pain. J Exp Orthop 2017; 4:38.

292. Kumar R, Goni VG, Batra YK. Autologous conditioned serum as a novel alternative option in the treatment of unilateral lumbar radiculopathy: A prospective study. Asian Spine J 2015; 9:916-922.

293. Becker C, Heidersdorf S, Drewlo S, de Rodriguez SZ, Krämer J, Willburger RE. Efficacy of epidural perineural injections with autologous conditioned serum for lumbar radicular compression: an investigator-initiated, prospective, double-blind, reference-controlled study. Spine (Phila Pa 1976) 2007; 32:1803-1808.

294. World Health Organization. Transplantation: Transplantation of human cells, tissues, and organs. www.who.int/ transplantation/en/

295. World Health Organization. Transplantation: Human Cell and tissue transplantation.

www.who.int/transplantation/ cell_tissue/en/

296. CMC and GMP Guidelines. US Drug Administration, FDA. Accessed online 12 Dec 2016: 
http://www.fda.gov/BiologicsBloodVaccines/ GuidanceComplianceRegulatorylnformation/Guidances/General/ucm217665. htm

297. Marks P, Gottlieb S. Balancing safety and innovation for cell-based regenerative medicine. $N$ Engl J Med 2018 378:954-959.

298. Trounson A. Potential pitfall of pluripotent stem cells. N Engl J Med 2017; 377:490-491.

299. Taylor-Weiner H, Graff Zivin J. Medicine's Wild West--unlicensed stem-cell clinics in the United States. N Engl J Med 2015; 373:985-987.

300. Halme DG, Kessler DA. FDA regulation of stem-cell-based therapies. $N$ Engl J Med 2006; 355:1730-1735.

301. Okie S. Stem-cell politics. N Engl J Med 2006; 355:1633-1637.

302. Daley GQ. Polar extremes in the clinical use of stem cells. N Engl J Med 2017; 376:1075-1077.

303. Regulatory Considerations for Human Cell, Tissues, and Cellular and TissueBased Products: Minimal Manipulation and Homologous Use. Guidance for Industry and Food and Drug Administration Staff, November 2017.

www.fda.gov/downloads/BiologicsBloodVaccines/GuidanceComplianceRegulatoryInformation/Guidances/CellularandGeneTherapy/UCM585403.pdf

304. U.S. Department of Health and Human Services. Same Surgical Procedure Exception under 21 CFR 1271.15(b): Questions and Answers Regarding the Scope of the Exception. Guidance for Industry. November 2017.

www.fda.gov/downloads/BiologicsBloodVaccines/GuidanceComplianceRegulatorylnformation/Guidances/Tissue/UCM419926.pdf

305. U.S. Food and Drug Administration. Regenerative medicine advanced therapy designation. March 13, 2017.

www.fda.gov/BiologicsBloodVaccines/CellularGeneTherapyProducts/ ucm53767o.htm

306. Shook JR, Giordano J. Ethical and policy issues in practices of regenerative medicine for the treatment of chronic pain. In: Manchikanti L, Navani A, Atluri $S$ (eds). Essentials of Regenerative Medicine in Interventional Pain Management. ASIPP Publishing, Paducah, KY 2019, IN PRESS.

307. Rosenthal RM, Murphy M. Regulatory aspects of regenerative therapy and stem cell therapy: Current perspectives. In: Manchikanti L, Navani A, Atluri S (eds). Essentials of Regenerative Medicine in Interventional Pain Management. ASIPP Publishing, Paducah, KY2019, IN PRESS.

308. Draft Guidance for Industry: Same Surgical Procedure Exception Under 21 CFR 1271.15(b): Questions and Answers Regarding the Scope of the Exception. www.fda.gov/BiologicsBloodVaccines/ GuidanceComplianceRegulatoryInformation/Guidances/Tissue/ucm419911. htm

309. Aicher $\mathrm{RH}$. Is the FDA regulating the practice of medicine? Aesthet Surg J 2013; 33:452-455.

310. Berman $M$, Lander $E$. Regulatory issues with human cells: An alternate view. In: Manchikanti L, Navani A, Atluri $S$ (eds). Essentials of Regenerative Medicine in Interventional Pain Management. ASIPP Publishing, Paducah, KY 2019, IN PRESS.

311. Malarkey MA. Warning letter to Dr. Steven Victor, Chief Executive Officer, IntelliCell Biosciences Inc. Rockville, MD: Public Health Service, Food and Drug Administration; March 13, 2012.

www.fda.gov/ICECI/EnforcementActions/WarningLetters/2012/ucm297245. htm.

312. Mescher AL. Adipose Tissue. In: Junqueira's Basic Histology: Text \& Atlas. 13th ed. McGraw-Hill, New York, 2013, pp 124-129.

313. Malarkey MA. Warning letter to Thomas E. Young, MD, Owner and Medical Director, Young Medical Spa. Rockville, MD: Public Health Service, Food and Drug Administration; April 20, 2012. www.fda.gov/ICECI/EnforcementActions/WarningLetters/2012/ucm301620. $\mathrm{htm}$

314. Warning Letter to John S. Arnone, American CryoStem Corporation from Elizabeth Waltrip, Acting Program Division Director, Office of Biological Products Operations - Division 1, U.S. Food and Drug Administration.

www.fda.gov/ICECI/EnforcementActions/WarningLetters/ucm591225.htm

315. Associated Press. North Dakota stem cell clinic investigated after complaints. The Seattle Times, November 16, 2017.

www.seattletimes.com/nation-world/ bismarck-stem-cell-clinic-investigatedafter-complaints/

316. Kuriyan AE, Albini TA, Townsend JH, Rodriguez $\mathrm{M}$, Pandya HK, Leonard RE 2nd, Parrott MB, Rosenfeld PJ, Flynn HW Jr, Goldberg JL. Vision loss after intravitreal injection of autologous "stem cells" for
AMD. N Engl] Med 2017; 376:1047-1053.

317. Malarkey MA. Warning letter to David G. Eller, Chief Executive Officer and President, Celltex Therapeutics Corporation. Rockville, MD: Public Health Service, Food and Drug Administration; September 24, 2012.

www.fda.gov/ICECI/EnforcementActions/WarningLetters/2012/ucm323853. htm

318. Brown SA, Levi, B, Lequeux C, Wong VW, Mojallal A, Longaker MT. Basic science review on adipose tissue for clinicians. Plast Reconstr Surg 2010; 126:1936-1946.

319. Department of Health and Human Services, Food and Drug Administration. 21 CFR Parts 207, 807, and 1271. Establishment Registration and Listing for Manufacturers of Human Cellular and Tissue-Based Products. Proposed Rule, May 14, 1998.

320. Human Cells, Tissues, and Cellular and Tissue-Based Products (HCT/Ps) From Adipose Tissue: Regulatory Considerations; Draft Guidance for Industry. Rockville, MD: Food and Drug Administration; December 2014.

www.fda.gov/BiologicsBloodVaccines/ GuidanceComplianceRegulatorylnformation/Guidances/Tissue/ucm427795. htm

321. Department of Health and Human Services, Food and Drug Administration. 21 CFR Parts 207, 807, and 1271. Human Cells, Tissues, and Cellular and TissueBased Products; Establishment Registration and Listing. Final Rule, January 19, 2001.

322. Sherman RE, Li J, Shapley S, Robb M, Woodcock J. Expediting drug development - the FDA's new "breakthrough therapy" designation. N Engl] Med 2013; 369:1877-1880.

323. H.R. 34 - 21st Century Cures Act. P.L. 114-255, December 13, 2016.

324. Jarow JP, LaVange L, Woodcock J. Multidimensional evidence generation and FDA regulatory decision making: Defining and using "real-world" data. JAMA 2017; 318:703-704.

325. Sherman RE, Anderson SA, Dal Pan GJ, Gray GW, Gross T, Hunter NL, LaVange L, Marinac-Dabic D, Marks PW, Robb MA, Shuren J, Temple R, Woodcock J, Yue LQ, Califf RM. Real-world evidence - What is it and what can it tell us? N Engl J Med 2016; 375:2293-2297.

326. Letter to Gregory B. Snyder, MD, Federation of State Medical Boards from Senator Lamar Alexander RE: Stem cell 
therapy, April 21, 2017.

327. Berger I, Ahmad A, Bansal A, Kapoor T, Sipp D, Rasko JEJ. Global distribution of businesses marketing stem cell based interventions. Cell Stem Cell 2016; 19:158-162.

328. Sipp D, Caulfield T, Kaye J, Barfoot J, Blackburn C, Chan S, De Luca M, Kent A, McCabe C, Munsie M, SleeboomFaulkner M, Sugarman J, van Zimmeren E, Zarzeczny A, Rasko JEJ. Marketing of unproven stem cell based interventions: A call to action. Sci Transl Med 2017; 9(397).

329. FDA's warning letters: www.fda.gov/ICECI/EnforcementActions/WarningLetters/default.htm

330. Federation of State Medical Boards. Model Policy for the Appropriate Use of Telemedicine Technologies in the Practice of Medicine, 2014.

331. White BD, Gelinas LC. Balancing the surgeon's responsibility to individuals and society. In: Stain SC et al (eds). The SAGES Manual Ethics of Surgical Innovation. Springer International Publishing, Switzerland, 2016, pp 191-211.

332. Barry MJ, Edgman-Levitan S. Shared decision making--pinnacle of patientcentered care. N Engl J Med 2012; 366:780-781.

333. National Research Council. Crossing the quality chasm: a new health system for the 21st century. Washington, DC: National Academies Press, 2001.

334. Stacey $D$, Légaré $F$, Lewis $K$, Barry $M J$, Bennett $\mathrm{CL}$, Eden KB, Holmes-Rovner $M$, Llewellyn-Thomas $H$, Lyddiatt $A$, Thomson R, Trevena L. Decision aids for people facing health treatment or screening decisions. Cochrane Database Syst Rev 2011; 4:CDool431.

335. Narouze $S$, Benzon HT, Provenzano $D$, Buvanendran A, De Andres J, Deer T, Rauck R, Huntoon MA. Interventional spine and pain procedures in patients on antiplatelet and anticoagulant medications (Second Edition): Guidelines from the American Society of Regional Anesthesia and Pain Medicine, the European Society of Regional Anaesthesia and Pain Therapy, the American Academy of Pain Medicine, the Internationa Neuromodulation Society, the North
American Neuromodulation Society, and the World Institute of Pain. Reg Anesth Pain Med 2018; 43:225-262.

336. Manchikanti L, Falco FJE, Benyamin RM, Caraway DL, Kaye AD, Helm II S, Wargo BW, Hansen H, Parr AT, Singh V, Swicegood JR, Smith HS, Schultz DM, Malla Y, Hirsch JA. Assessment of bleeding risk of interventional techniques: $A$ best evidence synthesis of practice patterns and perioperative management of anticoagulant and antithrombotic therapy. Pain Physician 2013; 16:SE261-SE318.

337. Garvican ER, Cree S, Bull L, Smith RK, Dudhia J. Viability of equine mesenchymal stem cells during transport and implantation. Stem Cell Res Ther 2014; 5:94.

338. Breivik H, Bang $U$, Jalonen J, Vigfússon G, Alahuhta S, Lagerkranser M. Nordic guidelines for neuraxial blocks in disturbed haemostasis from the Scandinavian Society of Anaesthesiology and Intensive Care Medicine. Acta Anaesthesiol Scand 2010; 54:16-41.

339. Gogarten W, Vandermeulen E, Van Aken H, Kozek S, Llau JV, Samama CM; European Society of Anaesthesiology. Regional anaesthesia and antithrombotic agents: Recommendations of the European Society of Anaesthesiology. Eur J Anaesthesiol 2010; 27:999-1015.

340. Vandermeulen E. Regional anaesthesia and anticoagulation. Best Pract Res Clin Anaesthesiol 2010; 24:121-131.

341. Horlocker TT, Wedel DJ, Rowlingson JC, Enneking FK, Kopp SL, Benzon HT, Brown DL, Heit JA, Mulroy MF, Rosenquist RW, Tryba M, Yuan CS. Regional anesthesia in the patient receiving antithrombotic or thrombolytic therapy: American Society of Regional Anesthesia and Pain Medicine Evidence-Based Guidelines (Third Edition). Reg Anesth Pain Med 2010; 35:64-101.

342. Ramsook RR, Danesh H. Timing of platelet rich plasma injections during antithrombotic therapy. Pain Physician 2016; 19:E1055-E1061.

343. Ling L, Camilleri ET, Helledie T, Samsonraj RM, Titmarsh DM, Chua RJ, Dreesen O, Dombrowski C, Rider DA, Galindo M, Lee I, Hong W, Hui JH, Nurcombe V, van Wijnen AJ, Cool SM. Effect of heparin on the biological proper- ties and molecular signature of human mesenchymal stem cells. Gene 2016; 576:292-303.

344. Sutherland FW, Perry TE, Yu Y, Sherwood MC, Rabkin E, Masuda Y, Garcia GA, McLellan DL, Engelmayr GC Jr, Sacks MS, Schoen FJ, Mayer JE Jr. From stem cells to viable autologous semilunar heart valve. Circulation 2005; 111:2783-2791.

345. Schippinger $G$, Prüller $F$, Divjak $M$, Mahla E, Fankhauser F, Rackemann S, Raggam RB. Autologous platelet-rich plasma preparations. Orthop] Sport Med 2015; 3:232596711558889.

346. Pountos I, Georgouli T, Calori GM, Giannoudis PV. Do nonsteroidal antiinflammatory drugs affect bone healing? A critical analysis. Sci World J 2012; 2012:1-14.

347. Ortel TL. Perioperative management of patients on chronic antithrombotic therapy. Hematol Am Soc Hematol Educ Progr 2012; 2012:529-535.

348. Benzon HT, Avram MJ, Green D, Bonow RO. New oral anticoagulants and regional anaesthesia. Br J Anaesth 2013; 111:ig6-i113.

349. Centeno CJ, Al-Sayegh H, Freeman MD, Smith J, Murrell WD, Bubnov R. A multicenter analysis of adverse events among two thousand, three hundred and seventy two adult patients undergoing adult autologous stem cell therapy for orthopaedic conditions. Int Orthop 2016; 40:1755-1765.

350. Nourissat G, Ornetti $P$, Berenbaum F, Sellam J, Richette P, Chevalier X. Does platelet-rich plasma deserve a role in the treatment of tendinopathy? Joint Bone Spine 2015; 82:230-234.

351. Slabiak T. Stem cell-based therapies and FDA regulations. Regulatory Focus, November 2012.

352. Navani A, Li G, Chrystal J. Platelet-rich plasma in musculoskeletal pathology: A necessary rescue it a lost cause? Pain Physician 2017; 20:E345-E356.

353. Hakimi O, Murphy R, Stachewicz U, Hislop S, Carr AJ. An electrospun polydioxanone patch for the localisation of biological therapies during tendon repair. Eur Cell Mater 2012; 24:344-357. 


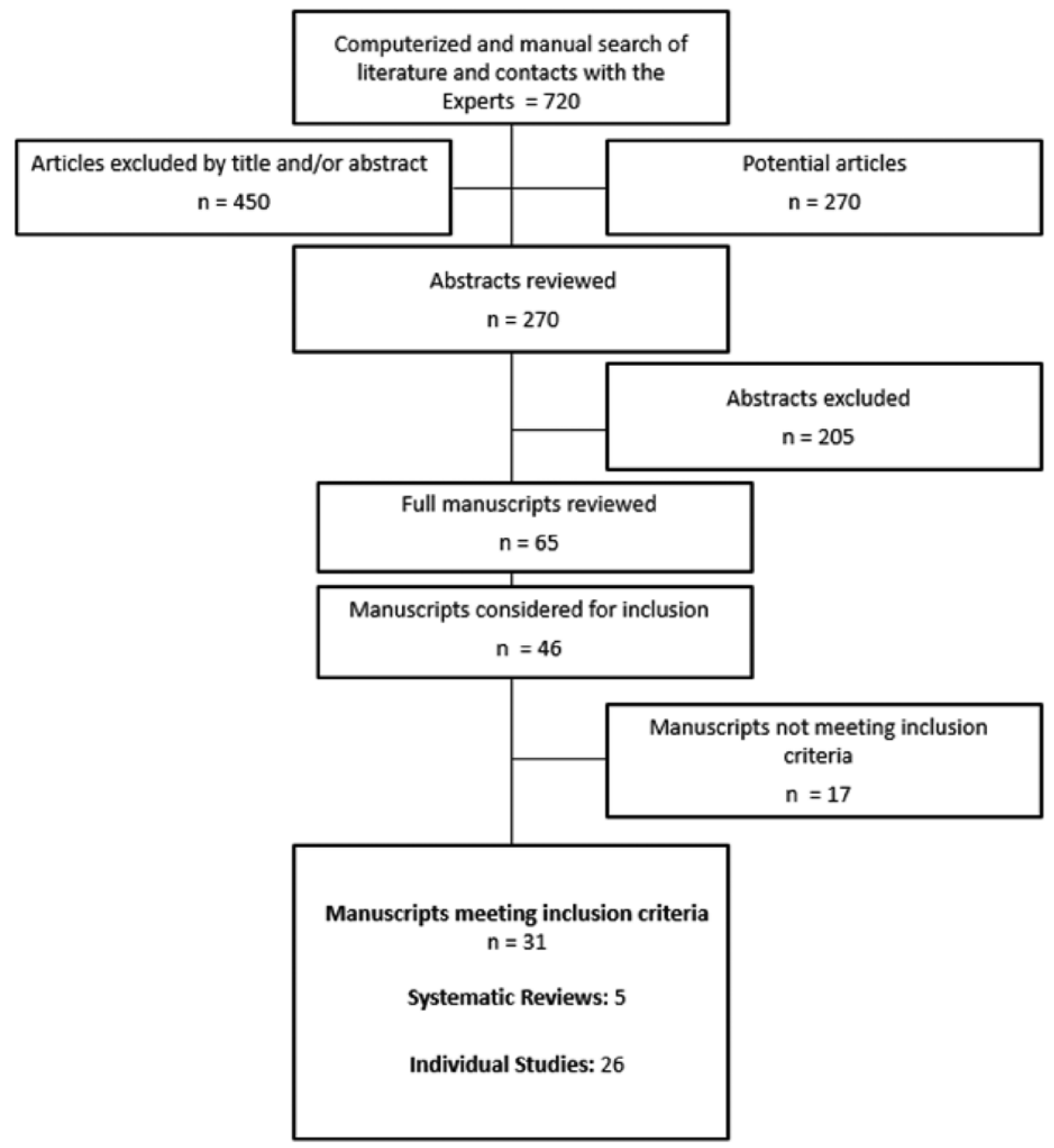

Appendix Fig. 1. Flow diagram illustrating published literature evaluating regenerative therapies. 
Appendix Table 1. PRISMA 2009 checklist for quality assessment.

\begin{tabular}{|c|c|c|c|c|}
\hline & & YES & NO & NA \\
\hline 1. Protocol and registration & $\begin{array}{l}\text { Indicate if a review protocol exists, if and where it can be } \\
\text { accessed (e.g., Web address), and, if available, provide registration } \\
\text { information including registration number. }\end{array}$ & & & \\
\hline 2. Eligibility criteria & $\begin{array}{l}\text { Specify study characteristics (e.g., PICOS, length of follow-up) and } \\
\text { report characteristics (e.g., years considered, language, publication } \\
\text { status) used as criteria for eligibility, giving rationale. }\end{array}$ & & & \\
\hline 3. Information sources & $\begin{array}{l}\text { Describe all information sources (e.g., databases with dates of } \\
\text { coverage, contact with study authors to identify additional studies) } \\
\text { in the search and date last searched. }\end{array}$ & & & \\
\hline 4. Search & $\begin{array}{l}\text { Present full electronic search strategy for at least one database, } \\
\text { including any limits used, such that it could be repeated. }\end{array}$ & & & \\
\hline 5. Study selection & $\begin{array}{l}\text { State the process for selecting studies (i.e., screening, eligibility, } \\
\text { included in systematic review, and, if applicable, included in the } \\
\text { meta-analysis). }\end{array}$ & & & \\
\hline 6. Data collection process & $\begin{array}{l}\text { Describe method of data extraction from reports (e.g., piloted } \\
\text { forms, independently, in duplicate) and any processes for obtaining } \\
\text { and confirming data from investigators. }\end{array}$ & & & \\
\hline 7. Data items & $\begin{array}{l}\text { List and define all variables for which data were sought (e.g., } \\
\text { PICOS, funding sources) and any assumptions and simplifications } \\
\text { made. }\end{array}$ & & & \\
\hline $\begin{array}{l}\text { 8. Risk of bias in individual } \\
\text { studies }\end{array}$ & $\begin{array}{l}\text { Describe methods used for assessing risk of bias of individual } \\
\text { studies (including specification of whether this was done at the } \\
\text { study or outcome level), and how this information is to be used in } \\
\text { any data synthesis. }\end{array}$ & & & \\
\hline 9. Summary measures & $\begin{array}{l}\text { State the principal summary measures (e.g., risk ratio, difference in } \\
\text { means). }\end{array}$ & & & \\
\hline 10. Synthesis of results & $\begin{array}{l}\text { Describe the methods of handling data and combining results of } \\
\text { studies, if done, including measures of consistency (e.g., I2) for } \\
\text { each meta-analysis. }\end{array}$ & & & \\
\hline 11. Risk of bias across studies & $\begin{array}{l}\text { Specify any assessment of risk of bias that may affect the cumulative } \\
\text { evidence (e.g., publication bias, selective reporting within studies). }\end{array}$ & & & \\
\hline 12. Additional analyses & $\begin{array}{l}\text { Describe methods of additional analyses (e.g., sensitivity or } \\
\text { subgroup analyses, meta-regression), if done, indicating which } \\
\text { were pre-specified. }\end{array}$ & & & \\
\hline 13. Summary of evidence & $\begin{array}{l}\text { Summarize the main findings including the strength of evidence } \\
\text { for each main outcome; consider their relevance to key groups (e.g., } \\
\text { healthcare providers, users, and policy makers). }\end{array}$ & & & \\
\hline 14. Limitations & $\begin{array}{l}\text { Discuss limitations at study and outcome level (e.g., risk of bias), } \\
\text { and at review-level (e.g., incomplete retrieval of identified research, } \\
\text { reporting bias). }\end{array}$ & & & \\
\hline 15. Funding & $\begin{array}{l}\text { Describe sources of funding for the systematic review and other } \\
\text { support (e.g., supply of data); role of funders for the systematic } \\
\text { review. }\end{array}$ & & & \\
\hline
\end{tabular}

Source: Moher D, Liberati A, Tetzlaff J, Altman DG, The PRISMA Group (2009). Preferred Reporting Items for Systematic Reviews and MetaAnalyses: The PRISMA Statement. PLoS Med 6(7): e1000097 (264). 
Appendix Table 2. Compliance with individual AMSTAR checklist items.

\begin{tabular}{|c|c|c|c|}
\hline & YES & NO & NA \\
\hline 1. Was a priori design provided (protocol established before the conduct of review)? & & & \\
\hline 2. Was there duplicate study selection and data extraction? & & & \\
\hline 3. Was a comprehensive literature search performed? & & & \\
\hline 4. Was the status of publication (ie, gray literature) used as an inclusion criterion? & & & \\
\hline 5. Was a list of studies (included and excluded) provided? & & & \\
\hline 6. Were the characteristics of the included studies provided? & & & \\
\hline 7. Was the scientific quality of the included studies assessed and documented? & & & \\
\hline 8. Was the scientific quality of the included studies used appropriately in formulating conclusions? & & & \\
\hline 9. Were the methods used to combine the findings of studies appropriate? & & & \\
\hline 10. Was the likelihood of publication bias assessed? & & & \\
\hline $\begin{array}{l}\text { 11. Was the conflict of interest included, both for the systematic review authors and included studies' } \\
\text { authors? }\end{array}$ & & & \\
\hline
\end{tabular}

Source: Shea BJ, Reeves BC, Wells G, Thuku M, Hamel C, Moran J, Moher D, Tugwell P, Welch V, Kristjansson E, Henry DA. AMSTAR 2: A critical appraisal tool for systematic reviews that include randomised or non-randomised studies of healthcare interventions, or both. BMJ 2017; $358: j 4008$ (265). 
Appendix Table 3. Sources of risk of bias and Cochrane Review rating system.

\begin{tabular}{|c|c|c|c|}
\hline & \multicolumn{2}{|l|}{ Source of Bias } & Possible \\
\hline \multirow[t]{2}{*}{ Selection } & \multirow[t]{2}{*}{$\begin{array}{l}\text { (1) Was the method of } \\
\text { randomization adequate? }\end{array}$} & $\begin{array}{l}\text { A random (unpredictable) assignment sequence. Examples of adequate } \\
\text { methods are coin toss (for studies with } 2 \text { groups), rolling a dice (for studies } \\
\text { with } 2 \text { or more groups), drawing of balls of different colors, drawing of } \\
\text { ballots with the study group labels from a dark bag, computer-generated } \\
\text { random sequence, preordered sealed envelopes, sequentially-ordered } \\
\text { vials, telephone call to a central office, and preordered list of treatment } \\
\text { assignments. }\end{array}$ & \multirow[t]{2}{*}{ Yes/No/Unsure } \\
\hline & & $\begin{array}{l}\text { Examples of inadequate methods are: alternation, birth date, social } \\
\text { insurance/security number, date in which they are invited to participate in } \\
\text { the study, and hospital registration number. }\end{array}$ & \\
\hline Selection & $\begin{array}{l}\text { (2) Was the treatment } \\
\text { allocation concealed? }\end{array}$ & $\begin{array}{l}\text { Assignment generated by an independent person not responsible for } \\
\text { determining the eligibility of the patients. This person has no information } \\
\text { about the persons included in the trial and has no influence on the } \\
\text { assignment sequence or on the decision about eligibility of the patient. }\end{array}$ & Yes/No/Unsure \\
\hline Performance & $\begin{array}{l}\text { (3) Was the patient blinded to } \\
\text { the intervention? }\end{array}$ & $\begin{array}{l}\text { Index and control groups are indistinguishable for the patients or if the } \\
\text { success of blinding was tested among the patients and it was successful. }\end{array}$ & Yes/No/Unsure \\
\hline Performance & $\begin{array}{l}\text { (4) Was the care provider } \\
\text { blinded to the intervention? }\end{array}$ & $\begin{array}{l}\text { Index and control groups are indistinguishable for the care providers or } \\
\text { if the success of blinding was tested among the care providers and it was } \\
\text { successful. }\end{array}$ & Yes/No/Unsure \\
\hline \multirow[t]{6}{*}{ Detection } & \multirow[t]{6}{*}{$\begin{array}{l}\text { (5) Was the outcome assessor } \\
\text { blinded to the intervention? }\end{array}$} & $\begin{array}{l}\text { Adequacy of blinding should be assessed for each primary outcome } \\
\text { separately. This item should be scored "yes" if the success of blinding was } \\
\text { tested among the outcome assessors and it was successful or: }\end{array}$ & \multirow[t]{6}{*}{ Yes/No/Unsure } \\
\hline & & $\begin{array}{l}\text { - for patient-reported outcomes in which the patient is the outcome } \\
\text { assessor (e.g., pain, disability): the blinding procedure is adequate for } \\
\text { outcome assessors if participant blinding is scored "yes" }\end{array}$ & \\
\hline & & $\begin{array}{l}\text { - for outcome criteria assessed during scheduled visit and that supposes } \\
\text { a contact between participants and outcome assessors (e.g., clinical } \\
\text { examination): the blinding procedure is adequate if patients are blinded, and } \\
\text { the treatment or adverse effects of the treatment cannot be noticed during } \\
\text { clinical examination }\end{array}$ & \\
\hline & & $\begin{array}{l}\text { - for outcome criteria that do not suppose a contact with participants } \\
\text { (e.g., radiography, magnetic resonance imaging): the blinding procedure } \\
\text { is adequate if the treatment or adverse effects of the treatment cannot be } \\
\text { noticed when assessing the main outcome }\end{array}$ & \\
\hline & & $\begin{array}{l}\text { - for outcome criteria that are clinical or therapeutic events that will be } \\
\text { determined by the interaction between patients and care providers (e.g., } \\
\text { cointerventions, hospitalization length, treatment failure), in which the care } \\
\text { provider is the outcome assessor: the blinding procedure is adequate for } \\
\text { outcome assessors if item " } 4 \text { " (caregivers) is scored "yes" }\end{array}$ & \\
\hline & & $\begin{array}{l}\text { - for outcome criteria that are assessed from data of the medical forms: } \\
\text { the blinding procedure is adequate if the treatment or adverse effects of the } \\
\text { treatment cannot be noticed on the extracted data }\end{array}$ & \\
\hline Attrition & $\begin{array}{l}\text { (6) Was the drop-out rate } \\
\text { described and acceptable? }\end{array}$ & $\begin{array}{l}\text { The number of participants who were included in the study but did not } \\
\text { complete the observation period or were not included in the analysis must } \\
\text { be described and reasons given. If the percentage of withdrawals and drop- } \\
\text { outs does not exceed } 20 \% \text { for short-term follow-up and } 30 \% \text { for long-term } \\
\text { follow-up and does not lead to substantial bias a "yes" is scored (N.B. these } \\
\text { percentages are arbitrary, not supported by literature). }\end{array}$ & Yes/No/Unsure \\
\hline Attrition & $\begin{array}{l}\text { (7) Were all randomized } \\
\text { participants analyzed in the } \\
\text { group to which they were } \\
\text { allocated? }\end{array}$ & $\begin{array}{l}\text { All randomized patients are reported/analyzed in the group they were } \\
\text { allocated to by randomization for the most important moments of effect } \\
\text { measurement (minus missing values) irrespective of noncompliance and } \\
\text { cointerventions. }\end{array}$ & Yes/No/Unsure \\
\hline Reporting & $\begin{array}{l}\text { (8) Are reports of the study } \\
\text { free of suggestion of selective } \\
\text { outcome reporting? }\end{array}$ & $\begin{array}{l}\text { All the results from all prespecified outcomes have been adequately reported } \\
\text { in the published report of the trial. This information is either obtained by } \\
\text { comparing the protocol and the report, or in the absence of the protocol, } \\
\text { assessing that the published report includes enough information to make } \\
\text { this iudgment. }\end{array}$ & Yes/No/Unsure \\
\hline
\end{tabular}


Appendix Table 3 con't. Sources of risk of bias and Cochrane Review rating system.

\begin{tabular}{|c|c|c|c|}
\hline & \multicolumn{2}{|l|}{ Source of Bias } & \multirow{2}{*}{$\begin{array}{l}\text { Possible } \\
\text { Answers } \\
\text { Yes/No/Unsure }\end{array}$} \\
\hline Selection & $\begin{array}{l}\text { (9) Were the groups similar } \\
\text { at baseline regarding the } \\
\text { most important prognostic } \\
\text { indicators? }\end{array}$ & $\begin{array}{l}\text { Groups have to be similar at baseline regarding demographic factors, } \\
\text { duration and severity of complaints, percentage of patients with neurological } \\
\text { symptoms, and value of main outcome measure(s). }\end{array}$ & \\
\hline Performance & $\begin{array}{l}\text { (10) Were cointerventions } \\
\text { avoided or similar? }\end{array}$ & $\begin{array}{l}\text { If there were no cointerventions or they were similar between the index and } \\
\text { control groups. }\end{array}$ & Yes/No/Unsure \\
\hline Performance & $\begin{array}{l}\text { (11) Was the compliance } \\
\text { acceptable in all groups? }\end{array}$ & $\begin{array}{l}\text { The reviewer determines if the compliance with the interventions is } \\
\text { acceptable, based on the reported intensity, duration, number and frequency } \\
\text { of sessions for both the index intervention and control intervention(s). } \\
\text { For example, physiotherapy treatment is usually administered for several } \\
\text { sessions; therefore it is necessary to assess how many sessions each patient } \\
\text { attended. For single-session interventions (e.g., surgery), this item is } \\
\text { irrelevant. }\end{array}$ & Yes/No/Unsure \\
\hline Detection & $\begin{array}{l}\text { (12) Was the timing of the } \\
\text { outcome assessment similar } \\
\text { in all groups? }\end{array}$ & $\begin{array}{l}\text { Timing of outcome assessment should be identical for all intervention } \\
\text { groups and for all primary outcome measures. }\end{array}$ & Yes/No/Unsure \\
\hline \multirow[t]{2}{*}{ Other } & \multirow{2}{*}{$\begin{array}{l}\text { (13) Are other sources of } \\
\text { potential bias unlikely? }\end{array}$} & Other types of biases. For example: & \multirow[t]{2}{*}{ Yes/No/Unsure } \\
\hline & & $\begin{array}{l}\text { When the outcome measures were not valid. There should be evidence } \\
\text { from a previous or present scientific study that the primary outcome can be } \\
\text { considered valid in the context of the present. } \\
\text { - Industry-sponsored trials. The conflict of interest (COI) statement } \\
\text { should explicitly state that the researchers have had full possession of the } \\
\text { trial process from planning to reporting without funders with potential } \\
\text { COI having any possibility to interfere in the process. If, for example, the } \\
\text { statistical analyses have been done by a funder with a potential COI, usually } \\
\text { "unsure" is scored. }\end{array}$ & \\
\hline
\end{tabular}

Source: Furlan AD, Malmivaara A, Chou R, Maher CG, Deyo RA, Schoene M, Bronfort G, van Tulder MW; Editorial Board of the Cochrane Back, Neck Group. 2015 Updated Method Guideline for Systematic Reviews in the Cochrane Back and Neck Group. Spine (Phila Pa 1976) 2015; 40:1660$1673(266)$. 
Appendix Table 4. Item checklist for assessment of randomized controlled trials of IPM techniques utilizing IPM-QRB.

\begin{tabular}{|c|c|c|}
\hline & & Scoring \\
\hline I. & TRIAL DESIGN AND GUIDANCE REPORTING & \\
\hline \multirow[t]{5}{*}{1.} & CONSORT or SPIRIT & \\
\hline & Trial designed and reported without any guidance & 0 \\
\hline & $\begin{array}{l}\text { Trial designed and reported utilizing minimum criteria other than CONSORT or SPIRIT criteria or trial was conducted } \\
\text { prior to } 2005\end{array}$ & 1 \\
\hline & $\begin{array}{l}\text { Trial implies it was based on CONSORT or SPIRIT without clear description with moderately significant criteria for } \\
\text { randomized trials or the trial was conducted before } 2005\end{array}$ & 2 \\
\hline & $\begin{array}{l}\text { Explicit use of CONSORT or SPIRIT with identification of criteria or trial conducted with high level reporting and } \\
\text { criteria or conducted before } 2005\end{array}$ & 3 \\
\hline II. & DESIGN FACTORS & \\
\hline \multirow[t]{4}{*}{2.} & Type and Design of Trial & \\
\hline & Poorly designed control group (quasi selection, convenient sampling) & 0 \\
\hline & Proper active-control or sham procedure with injection of active agent & 2 \\
\hline & Proper placebo control (no active solutions into active structures) & 3 \\
\hline \multirow[t]{4}{*}{3.} & Setting/Physician & \\
\hline & General setting with no specialty affiliation and general physician & 0 \\
\hline & Specialty of anesthesia/PMR/neurology/radiology/ortho, etc. & 1 \\
\hline & Interventional pain management with interventional pain management physician & 2 \\
\hline \multirow[t]{5}{*}{4.} & Imaging & \\
\hline & Blind procedures & 0 \\
\hline & Ultrasound & 1 \\
\hline & CT & 2 \\
\hline & Fluoro & 3 \\
\hline \multirow[t]{5}{*}{5.} & Sample Size & \\
\hline & Less than 50 participants in the study without appropriate sample size determination & 0 \\
\hline & Sample size calculation with less than 25 patients in each group & 1 \\
\hline & Appropriate sample size calculation with at least 25 patients in each group & 2 \\
\hline & Appropriate sample size calculation with 50 patients in each group & 3 \\
\hline \multirow[t]{3}{*}{6.} & Statistical Methodology & \\
\hline & None or inappropriate & 0 \\
\hline & Appropriate & 1 \\
\hline III. & PATIENT FACTORS & \\
\hline 7. & Inclusiveness of Population & \\
\hline \multirow[t]{4}{*}{ 7a. } & For epidural procedures: & \\
\hline & Poorly identified mixed population & 0 \\
\hline & Clearly identified mixed population & 1 \\
\hline & $\begin{array}{l}\text { Disorders specific trials (i.e. well defined spinal stenosis and disc herniation, disorder specific, disc herniation or spinal } \\
\text { stenosis or post surgery syndrome) }\end{array}$ & 2 \\
\hline \multirow[t]{4}{*}{$7 \mathrm{~b}}$. & For facet or sacroiliac joint interventions: & \\
\hline & No diagnostic blocks & 0 \\
\hline & Selection with single diagnostic blocks & 1 \\
\hline & Selection with placebo or dual diagnostic blocks & 2 \\
\hline \multirow[t]{4}{*}{8.} & Duration of Pain & \\
\hline & Less than 3 months & 0 \\
\hline & 3 to 6 months & 1 \\
\hline & $>6$ months & 2 \\
\hline
\end{tabular}


Appendix Table 4 con't. Item checklist for assessment of randomized controlled trials of IPM techniques utilizing IPM-QRB.

\begin{tabular}{|c|c|c|}
\hline & & Scoring \\
\hline \multirow[t]{5}{*}{9.} & Previous Treatments & \\
\hline & Conservative management including drug therapy, exercise therapy, physical therapy, etc. & \\
\hline & Were not utilized & 0 \\
\hline & Were utilized sporadically in some patients & 1 \\
\hline & Were utilized in all patients & 2 \\
\hline \multirow[t]{5}{*}{10.} & Duration of Follow-up with Appropriate Interventions & \\
\hline & $\begin{array}{l}\text { Less than } 3 \text { months or } 12 \text { weeks for epidural or facet joint procedures, etc. and } 6 \text { months for intradiscal procedures and } \\
\text { implantables }\end{array}$ & 0 \\
\hline & 3 to 6 months for epidural or facet joint procedures, etc., or 1 year for intradiscal procedures or implantables & 1 \\
\hline & $\begin{array}{l}6 \text { months to } 17 \text { months for epidurals or facet joint procedures, etc., and } 2 \text { years or longer for discal procedures and } \\
\text { implantables }\end{array}$ & 2 \\
\hline & $\begin{array}{l}18 \text { months or longer for epidurals and facet joint procedures, etc., or } 5 \text { years or longer for discal procedures and } \\
\text { implantables }\end{array}$ & 3 \\
\hline IV. & OUTCOMES & \\
\hline \multirow[t]{6}{*}{11.} & Outcomes Assessment Criteria for Significant Improvement & \\
\hline & $\begin{array}{l}\text { No descriptions of outcomes } \\
\text { OR } \\
<20 \% \text { change in pain rating or functional status }\end{array}$ & 0 \\
\hline & $\begin{array}{l}\text { Pain rating with a decrease of } 2 \text { or more points or more than } 20 \% \text { reduction } \\
\text { OR } \\
\text { functional status improvement of more than } 20 \%\end{array}$ & 1 \\
\hline & $\begin{array}{l}\text { Pain rating with decrease of } \geq 2 \text { points } \\
\text { AND } \\
\geq 20 \% \text { change or functional status improvement of } \geq 20 \%\end{array}$ & 2 \\
\hline & $\begin{array}{l}\text { Pain rating with a decrease of } 3 \text { or more points or more than } 50 \% \text { reduction } \\
\text { OR } \\
\text { functional status improvement with a } 50 \% \text { or } 40 \% \text { reduction in disability score }\end{array}$ & 2 \\
\hline & Significant improvement with pain and function $\geq 50 \%$ or 3 points and $40 \%$ reduction in disability scores & 4 \\
\hline \multirow[t]{4}{*}{12.} & Analysis of all Randomized Participants in the Groups & \\
\hline & Not performed & 0 \\
\hline & Performed without intent-to-treat analysis without inclusion of all randomized participants & 1 \\
\hline & All participants included with or without intent-to-treat analysis & 2 \\
\hline \multirow[t]{4}{*}{13.} & Description of Drop Out Rate & \\
\hline & No description of dropouts, despite reporting of incomplete data or $\geq 20 \%$ withdrawal & 0 \\
\hline & Less than $20 \%$ withdrawal in one year in any group & 1 \\
\hline & Less than $30 \%$ withdrawal at 2 years in any group & 2 \\
\hline \multirow[t]{4}{*}{14.} & Similarity of Groups at Baseline for Important Prognostic Indicators & \\
\hline & Groups dissimilar with significant influence on outcomes with or without appropriate randomization and allocation & 0 \\
\hline & Groups dissimilar without influence on outcomes despite appropriate randomization and allocation & 1 \\
\hline & Groups similar with appropriate randomization and allocation & 2 \\
\hline \multirow[t]{3}{*}{15.} & Role of Co-Interventions & \\
\hline & Co-interventions were provided but were not similar in the majority of participants & 0 \\
\hline & No co-interventions or similar co-interventions were provided in the majority of the participants & 1 \\
\hline V. & RANDOMIZATION & \\
\hline \multirow[t]{3}{*}{16.} & Method of Randomization & \\
\hline & Quasi randomized or poorly randomized or not described & 0 \\
\hline & Adequate randomization (coin toss, drawing of balls of different colors, drawing of ballots) & 1 \\
\hline
\end{tabular}


Appendix Table 4 con't. Item checklist for assessment of randomized controlled trials of IPM techniques utilizing IPM - QRB.

\begin{tabular}{|c|c|c|}
\hline & & Scoring \\
\hline & $\begin{array}{l}\text { High quality randomization (Computer generated random sequence, pre-ordered sealed envelopes, sequentially ordered } \\
\text { vials, telephone call, pre-ordered list of treatment assignments, etc.) }\end{array}$ & 2 \\
\hline VI. & ALLOCATION CONCEALMENT & \\
\hline \multirow[t]{4}{*}{17.} & Concealed Treatment Allocation & \\
\hline & Poor concealment of allocation (open enrollment) or inadequate description of concealment & 0 \\
\hline & Concealment of allocation with borderline or good description of the process with probability of failure of concealment & 1 \\
\hline & High quality concealment with strict controls (independent assignment without influence on the assignment sequence) & 2 \\
\hline VII. & BLINDING & \\
\hline \multirow[t]{3}{*}{18.} & Patient Blinding & \\
\hline & Patients not blinded & 0 \\
\hline & Patients blinded adequately & 1 \\
\hline \multirow[t]{3}{*}{19.} & Care Provider Blinding & \\
\hline & Care provider not blinded & 0 \\
\hline & Care provider blinded adequately & 1 \\
\hline \multirow[t]{3}{*}{20.} & Outcome Assessor Blinding & \\
\hline & Outcome assessor not blinded or was able to identify the groups & 0 \\
\hline & $\begin{array}{l}\text { Performed by a blinded independent assessor with inability to identify the assignment-based provider intervention (i.e., } \\
\text { subcutaneous injection, intramuscular distant injection, difference in preparation or equipment use, numbness and } \\
\text { weakness, etc.) }\end{array}$ & 1 \\
\hline VIII. & CONFLICTS OF INTEREST & \\
\hline \multirow[t]{7}{*}{21.} & Funding and Sponsorship & \\
\hline & Trial included industry employees & -3 \\
\hline & $\begin{array}{l}\text { Industry employees involved; high levels of funding with remunerations by industry or an organization funded with } \\
\text { conflicts }\end{array}$ & -3 \\
\hline & Industry or organizational funding with reimbursement of expenses with some involvement & 0 \\
\hline & Industry or organization funding of expenses without involvement & 1 \\
\hline & Funding by internal resources only with supporting entity unrelated to industry & 2 \\
\hline & Governmental funding without conflict such as NIH, NHS, AHRQ & 3 \\
\hline \multirow[t]{8}{*}{22.} & Conflicts of Interest & \\
\hline & None disclosed with potential implied conflict & 0 \\
\hline & Marginally disclosed with potential conflict & 1 \\
\hline & Well disclosed with minor conflicts & 2 \\
\hline & Well disclosed with no conflicts & 3 \\
\hline & Hidden conflicts with poor disclosure & -1 \\
\hline & Misleading disclosure with conflicts & -2 \\
\hline & Major impact related to conflicts & -3 \\
\hline \multicolumn{2}{|c|}{ TOTAL } & 48 \\
\hline
\end{tabular}

Source: Manchikanti L, et al. Assessment of methodologic quality of randomized trials of interventional techniques: Development of an interventional pain management specific instrument. Pain Physician 2014; 17:E263-E290 (267). 
Appendix Table 5. IPM checklist for assessment of nonrandomized or observational studies of IPM techniques utilizing IPM$Q R B N R$.

\begin{tabular}{|c|c|c|}
\hline & & Scoring \\
\hline I. & STUDY DESIGN AND GUIDANCE REPORTING & \\
\hline \multirow[t]{6}{*}{1.} & STROBE or TREND Guidance & \\
\hline & Case Report/Case Series & 0 \\
\hline & Study designed without any guidance & 1 \\
\hline & Study designed with minimal criteria and reporting with or without guidance & 2 \\
\hline & $\begin{array}{l}\text { Study designed with moderately significant criteria or implies it was based on STROBE or TREND without clear description } \\
\text { or the study was conducted before } 2011 \text { or similar criteria utilized with study conducted before } 2011\end{array}$ & 3 \\
\hline & $\begin{array}{l}\text { Designed with high level criteria or explicitly uses STROBE or TREND with identification of criteria or conducted prior to } \\
2011\end{array}$ & 4 \\
\hline II. & DESIGN FACTORS & \\
\hline \multirow[t]{6}{*}{2.} & Study Design and Type & \\
\hline & Case report or series (uncontrolled - longitudinal) & 0 \\
\hline & Retrospective cohort or cross-sectional study & 1 \\
\hline & Prospective cohort case-control study & 2 \\
\hline & Prospective case control study & 3 \\
\hline & Prospective, controlled, nonrandomized & 4 \\
\hline \multirow[t]{4}{*}{3.} & Setting/Physician & \\
\hline & General setting with no specialty affiliation and general physician & 0 \\
\hline & Specialty of anesthesia/PMR/neurology, etc. & 1 \\
\hline & Interventional pain management with interventional pain management physician & 2 \\
\hline \multirow[t]{5}{*}{4.} & Imaging & \\
\hline & Blind procedures & 0 \\
\hline & Ultrasound & 1 \\
\hline & $\mathrm{CT}$ & 2 \\
\hline & Fluoro & 3 \\
\hline \multirow[t]{6}{*}{5.} & Sample Size & \\
\hline & Less than 100 participants without appropriate sample size determination & 0 \\
\hline & At least 100 participants in the study without appropriate sample size determination & 1 \\
\hline & Sample size calculation with less than 50 patients in each group & 2 \\
\hline & Appropriate sample size calculation with at least 50 patients in each group & 3 \\
\hline & Appropriate sample size calculation with 100 patients in each group & 4 \\
\hline \multirow[t]{4}{*}{6.} & Statistical Methodology & \\
\hline & None & 0 \\
\hline & Some statistics & 1 \\
\hline & Appropriate & 2 \\
\hline III. & PATIENT FACTORS & \\
\hline 7. & Inclusiveness of Population & \\
\hline \multirow[t]{5}{*}{$7 \mathrm{a}}$. & For epidural procedures: & \\
\hline & Poorly identified mixed population & 1 \\
\hline & Poorly identified mixed population with large sample $(\geq 200)$ & 2 \\
\hline & Clearly identified mixed population & 3 \\
\hline & $\begin{array}{l}\text { Disorders specific trials (i.e. well defined spinal stenosis and disc herniation, disorder specific, disc herniation or spinal } \\
\text { stenosis or post surgery syndrome) }\end{array}$ & 4 \\
\hline \multirow[t]{2}{*}{$7 \mathrm{~b}}$. & For facet or sacroiliac joint interventions: & \\
\hline & No specific selection criteria & 1 \\
\hline
\end{tabular}


Appendix Table 5 con't. IPM checklist for assessment of nonrandomized or observational studies of IPM techniques utilizing IPMQRBNR.

\begin{tabular}{|c|c|c|}
\hline & & Scoring \\
\hline & No diagnostic blocks based on clinical symptomatology & 2 \\
\hline & Selection with single diagnostic blocks & 3 \\
\hline & Selection with placebo or dual diagnostic blocks & 4 \\
\hline \multirow[t]{4}{*}{8.} & Duration of Pain & \\
\hline & Less than 3 months & 0 \\
\hline & 3 to 6 months & 1 \\
\hline & $>6$ months & 2 \\
\hline \multirow[t]{5}{*}{9.} & Previous Treatments & \\
\hline & Conservative management including drug therapy, exercise therapy, physical therapy, etc. & \\
\hline & Were not utilized & 0 \\
\hline & Were utilized sporadically in some patients & 1 \\
\hline & Were utilized in all patients & 2 \\
\hline \multirow[t]{5}{*}{10.} & Duration of Follow-up with Appropriate Interventions & \\
\hline & $\begin{array}{l}\text { Less than } 3 \text { months or less for epidural or facet joint procedures, etc., and } 6 \text { months for intradiscal procedures and } \\
\text { implantables }\end{array}$ & 1 \\
\hline & 3-6 months for epidural or facet joint procedures, etc., or one year for intradiscal procedures or implantables & 2 \\
\hline & 6-12 months for epidurals or facet joint procedures, etc., and 2 years or longer for discal procedures and implantables & 3 \\
\hline & 18 months or longer for epidurals and facet joint procedures, etc., or 5 years or longer for discal procedures and implantables & 4 \\
\hline IV. & OUTCOMES & \\
\hline \multirow[t]{6}{*}{11.} & Outcomes Assessment Criteria for Significant Improvement & \\
\hline & $\begin{array}{l}\text { No descriptions of outcomes } \\
\text { OR } \\
<20 \% \text { change in pain rating or functional status }\end{array}$ & 0 \\
\hline & $\begin{array}{l}\text { Pain rating with a decrease of } 2 \text { or more points or more than } 20 \% \text { reduction } \\
\text { OR } \\
\text { functional status improvement of more than } 20 \%\end{array}$ & 1 \\
\hline & $\begin{array}{l}\text { Pain rating with decrease of } \geq 2 \text { points } \\
\text { AND } \\
\geq 20 \% \text { change or functional status improvement of } \geq 20 \%\end{array}$ & 2 \\
\hline & $\begin{array}{l}\text { Pain rating with a decrease of } 3 \text { or more points or more than } 50 \% \text { reduction } \\
\text { OR } \\
\text { functional status improvement with a } 50 \% \text { or } 40 \% \text { reduction in disability score }\end{array}$ & 2 \\
\hline & Significant improvement with pain and function $\geq 50 \%$ or 3 points and $40 \%$ reduction in disability scores & 4 \\
\hline \multirow[t]{4}{*}{12.} & Description of Drop Out Rate & \\
\hline & No description despite reporting of incomplete data or more than $30 \%$ withdrawal & 0 \\
\hline & Less than $30 \%$ withdrawal in one year in any group & 1 \\
\hline & Less than $40 \%$ withdrawal at 2 years in any group & 2 \\
\hline \multirow[t]{4}{*}{13.} & Similarity of Groups at Baseline for Important Prognostic Indicators & \\
\hline & No groups or groups dissimilar with significant influence on outcomes & 0 \\
\hline & Groups dissimilar without significant influence on outcomes & 1 \\
\hline & Groups similar & 2 \\
\hline \multirow[t]{3}{*}{14.} & Role of Co-Interventions & \\
\hline & Dissimilar co-interventions or similar co-interventions in some of the participants & 1 \\
\hline & No co-interventions or similar co-interventions in majority of the participants & 2 \\
\hline V. & ASSIGNMENT & \\
\hline 15. & Method of Assignment of Participants & \\
\hline
\end{tabular}


Appendix Table 5 con't. IPM checklist for assessment of nonrandomized or observational studies of IPM techniques utilizing IPM$Q R B N R$.

\begin{tabular}{|l|l|l||}
\hline & \multicolumn{1}{|c||}{ Scoring } \\
\hline & Case report/case series or selective assignment based on outcomes or retrospective evaluation based on clinical criteria & 1 \\
\hline & Prospective study with inclusion without specific criteria & 2 \\
\hline & Retrospective method with inclusion of all participants or random selection of retrospective data & 3 \\
\hline & $\begin{array}{l}\text { Prospective, well-defined assignment of methodology and inclusion criteria (quasi randomization, matching, stratification, } \\
\text { etc.) }\end{array}$ & 4 \\
\hline VI. & CONFLICTS OF INTEREST & \\
\hline 16. & Funding and Sponsorship & -3 \\
\hline & Trial included industry employees with or without proper disclosure & -3 \\
\hline & Industry employees involved; high levels of funding with remunerations by industry or an organization funded with conflicts & -3 \\
\hline & Industry or organizational funding with reimbursement of expenses with some involvement or no information available & 0 \\
\hline & Industry or organization funding of expenses without involvement & 1 \\
\hline & Funding by internal resources only & 2 \\
\hline & Governmental funding without conflict such as NIH, NHS, AHRQ & 3 \\
\hline TOTAL MAXIMUM & 48 \\
\hline
\end{tabular}

Source: Manchikanti L, et al. Development of an interventional pain management specific instrument for methodologic quality assessment of nonrandomized studies of interventional techniques. Pain Physician 2014; 17:E291-E317 (268). 
Appendix Table 6. PRISMA 2009 checklist for quality assessment of systematic reviews.

\begin{tabular}{|l|l|l|l|}
\hline & $\begin{array}{l}\text { Basso et al } \\
(\mathbf{2 6})\end{array}$ & $\begin{array}{l}\text { Wu et al } \\
(\mathbf{2 8})\end{array}$ & $\begin{array}{l}\text { Sanapati } \\
\text { et al (29) }\end{array}$ \\
\hline $\begin{array}{l}\text { 1. Protocol and } \\
\text { registration }\end{array}$ & $\mathrm{N}$ & $\mathrm{N}$ & $\mathrm{N}$ \\
\hline 2. Eligibility criteria & $\mathrm{N}$ & $\mathrm{N}$ & $\mathrm{Y}$ \\
\hline 3. Information sources & $\mathrm{Y}$ & $\mathrm{Y}$ & $\mathrm{Y}$ \\
\hline 4. Search & $\mathrm{Y}$ & $\mathrm{Y}$ & $\mathrm{Y}$ \\
\hline 5. Study selection & $\mathrm{N}$ & $\mathrm{Y}$ & $\mathrm{Y}$ \\
\hline 6. Data collection process & $\mathrm{N}$ & $\mathrm{Y}$ & $\mathrm{Y}$ \\
\hline 7. Data items & $\mathrm{Y}$ & $\mathrm{Y}$ & $\mathrm{Y}$ \\
\hline $\begin{array}{l}\text { 8. Risk of bias in } \\
\text { individual studies }\end{array}$ & $\mathrm{N}$ & $\mathrm{Y}$ & $\mathrm{Y}$ \\
\hline 9. Summary measures & $\mathrm{N}$ & $\mathrm{Y}$ & $\mathrm{Y}$ \\
\hline 10. Synthesis of results & $\mathrm{Y}$ & $\mathrm{Y}$ & $\mathrm{Y}$ \\
\hline $\begin{array}{l}\text { 11. Risk of bias across } \\
\text { studies }\end{array}$ & $\mathrm{N}$ & $\mathrm{Y}$ & $\mathrm{Y}$ \\
\hline 12. Additional analyses & $\mathrm{N}$ & $\mathrm{Y}$ & $\mathrm{Y}$ \\
\hline 13. Summary of evidence & $\mathrm{Y}$ & $\mathrm{Y}$ & $\mathrm{Y}$ \\
\hline 14. Limitations & $\mathrm{Y}$ & $\mathrm{Y}$ & $\mathrm{Y}$ \\
\hline 15. Funding & $\mathrm{Y}$ & $\mathrm{Y}$ & $\mathrm{Y}$ \\
\hline TOTAL & $7 / 15$ & $13 / 15$ & $14 / 15$ \\
\hline \hline
\end{tabular}

$\mathrm{Y}=$ Yes; $\mathrm{N}=\mathrm{No} ; \mathrm{NA}=$ Not applicable

Source: Moher D, Liberati A, Tetzlaff J, Altman DG, The PRISMA Group (2009). Preferred Reporting Items for Systematic Reviews and Meta-Analyses: The PRISMA Statement. PLoS Med 6(7): e1000097 (264). 
Appendix Table 7. Compliance with individual AMSTAR checklist items of systematic reviews.

\begin{tabular}{|c|c|c|c|}
\hline & $\begin{array}{l}\text { Basso et al } \\
\text { (26) }\end{array}$ & $\begin{array}{l}\text { Wu et al } \\
(28)\end{array}$ & $\begin{array}{l}\text { Sanapati et } \\
\text { al (29) }\end{array}$ \\
\hline 1. Was a priori design provided (protocol established before the conduct of review)? & $\mathrm{N}$ & $\mathrm{N}$ & $\mathrm{N}$ \\
\hline 2. Was there duplicate study selection and data extraction? & $\mathrm{N}$ & $\mathrm{Y}$ & $\mathrm{Y}$ \\
\hline 3. Was a comprehensive literature search performed? & $\mathrm{Y}$ & $\mathrm{Y}$ & $\mathrm{Y}$ \\
\hline 4. Was the status of publication (ie, gray literature) used as an inclusion criterion? & $\mathrm{N}$ & $\mathrm{N}$ & $\mathrm{N}$ \\
\hline 5. Was a list of studies (included and excluded) provided? & $\mathrm{N}$ & $\mathrm{Y}$ & $\mathrm{Y}$ \\
\hline 6. Were the characteristics of the included studies provided? & $\mathrm{N}$ & $\mathrm{Y}$ & $\mathrm{Y}$ \\
\hline 7. Was the scientific quality of the included studies assessed and documented? & $\mathrm{N}$ & $\mathrm{Y}$ & $\mathrm{Y}$ \\
\hline $\begin{array}{l}\text { 8. Was the scientific quality of the included studies used appropriately in formulating } \\
\text { conclusions? }\end{array}$ & $\mathrm{N}$ & Y & $\mathrm{Y}$ \\
\hline 9. Were the methods used to combine the findings of studies appropriate? & $\mathrm{N}$ & $\mathrm{Y}$ & $\mathrm{Y}$ \\
\hline 10. Was the likelihood of publication bias assessed? & $\mathrm{N}$ & Y & $\mathrm{Y}$ \\
\hline $\begin{array}{l}\text { 11. Was the conflict of interest included, both for the systematic review authors and } \\
\text { included studies' authors? }\end{array}$ & Y & Y & Y \\
\hline TOTAL & $2 / 11$ & $9 / 11$ & $9 / 11$ \\
\hline
\end{tabular}

$\mathrm{Y}=$ Yes; N=No; NA=Not applicable

Source: Shea BJ, Reeves BC, Wells G, Thuku M, Hamel C, Moran J, Moher D, Tugwell P, Welch V, Kristjansson E, Henry DA. AMSTAR 2: A critical appraisal tool for systematic reviews that include randomised or non-randomised studies of healthcare interventions, or both. BMJ 2017; $358: j 4008$ (265). 